US Army Corps

of Engineers ${ }_{\circledast}$

Engineer Research and

Development Center

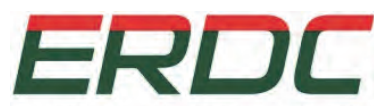

INNOVATIVE SOLUTIONS for a safer, better world

\title{
Laboratory and Field Evaluation of In-Place Asphalt Recycling Technologies for Small Airfield Repair
}

Mariely Mejías-Santiago, William D. Carruth,

Jeffrey C. Petermann, and Dean H. Hitzelberger

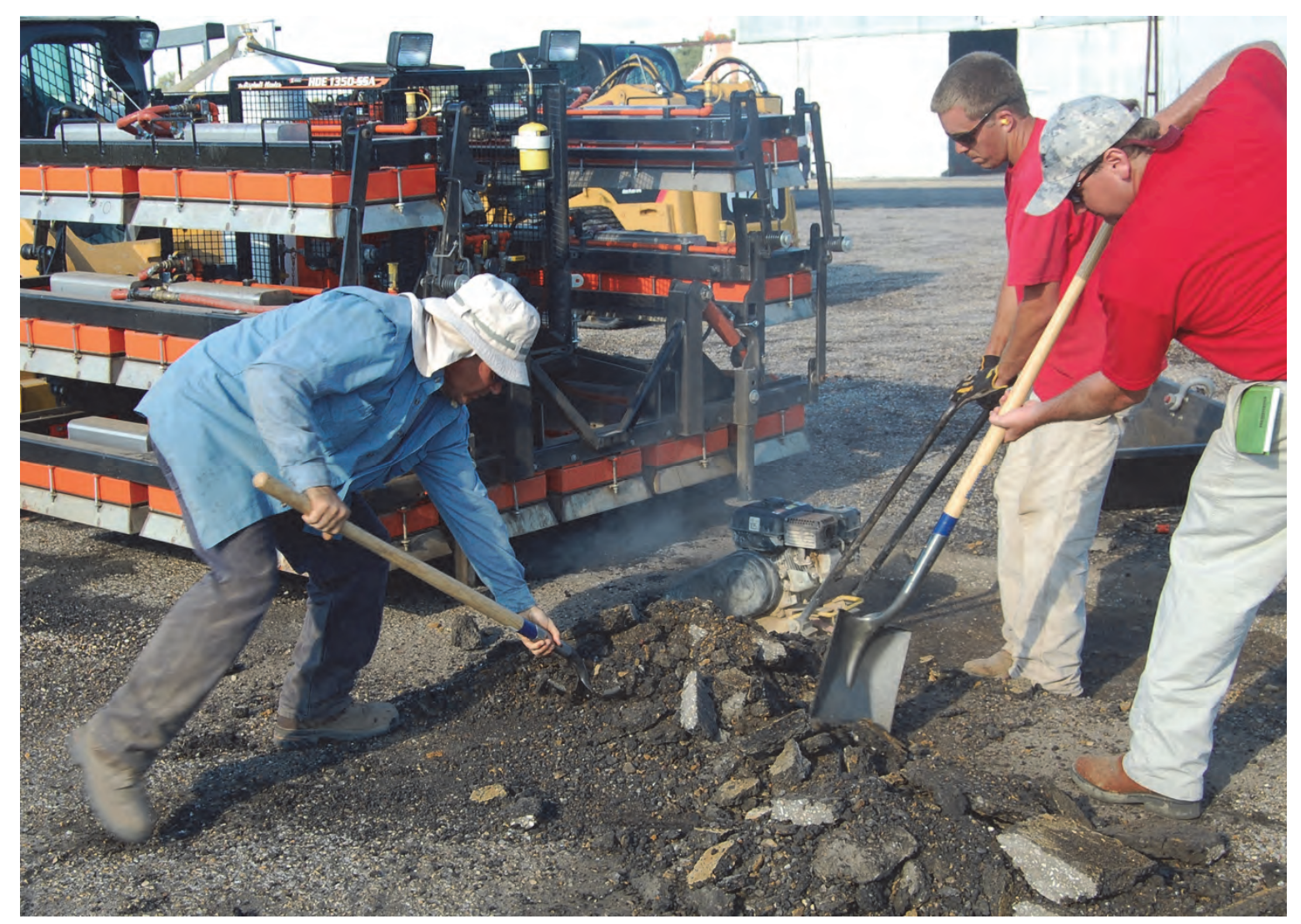


The US Army Engineer Research and Development Center (ERDC) solves the nation's toughest engineering and environmental challenges. ERDC develops innovative solutions in civil and military engineering, geospatial sciences, water resources, and environmental sciences for the Army, the Department of Defense, civilian agencies, and our nation's public good. Find out more at www.erdc.usace.army.mil.

To search for other technical reports published by ERDC, visit the ERDC online library at http://acwc.sdp.sirsi.net/client/default. 


\title{
Laboratory and Field Evaluation of In-Place Asphalt Recycling Technologies for Small Airfield Repair
}

\author{
Mariely Mejías-Santiago and William D. Carruth \\ Geotechnical and Structures Laboratory \\ US Army Engineer Research and Development Center \\ 3909 Halls Ferry Rd. \\ Vicksburg, MS 39180 \\ Jeffery C. Petermann and Dean H. Hitzelberger \\ Applied Research Associates, Inc. \\ 421 Oak Avenue \\ Panama City, FL 32401
}

Final report

Approved for public release; distribution is unlimited.

Prepared for Headquarters, US Army Corps of Engineers

Washington, DC 20314-1000 


\section{Abstract}

This report describes development of an augmentation kit that will give users of the sustainment pavement repair (SuPR) kit the capability for inplace asphalt recycling. This type of repair has the potential for reducing not only logistics associated with airfield pavement repair, but also the airfield downtime during the repairs. The specific technologies evaluated were infrared heaters, rejuvenator products, and cement stabilization. Different variations of these technologies were combined and evaluated in the laboratory to study the best combination that would produce quality sustainment repairs in asphalt concrete pavement yielding good performance with limited construction periods. The researchers also performed a series of pavement repairs to evaluate the equipment, materials and procedures required for in-place asphalt recycling in terms of the efficiency of the components to reduce repair logistics, equipment footprint, and airfield downtime during repairs. The performance of the repairs was evaluated under simulated F-15 aircraft traffic. Data collected from this study were used to develop guidance for the use of in-place asphalt recycling for sustainment repairs on military airfield pavements.

DISCLAIMER: The contents of this report are not to be used for advertising, publication, or promotional purposes. Citation of trade names does not constitute an official endorsement or approval of the use of such commercial products. All product names and trademarks cited are the property of their respective owners. The findings of this report are not to be construed as an official Department of the Army position unless so designated by other authorized documents. 


\section{Contents}

Abstract....................................................................................................................................... if

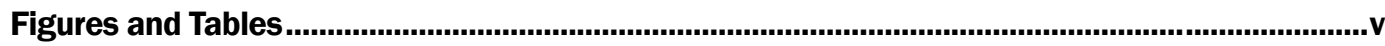

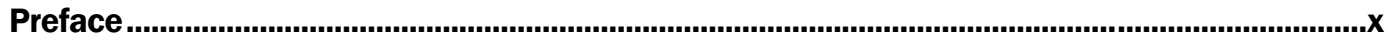

Unit Conversion Factors........................................................................................................xi

1 Introduction................................................................................................................... 1

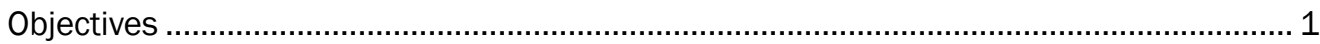

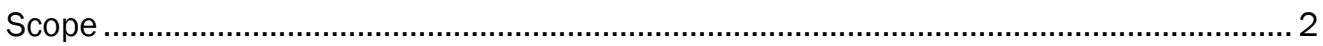

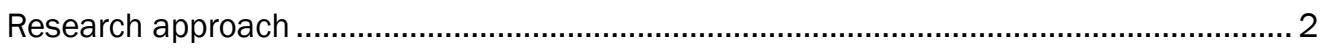

Report organization............................................................................................... 4

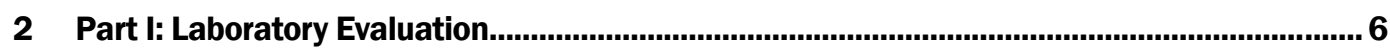

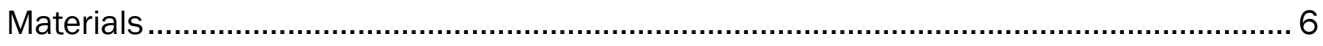

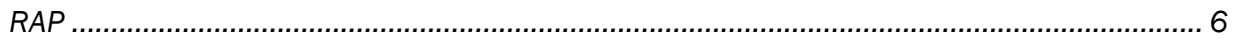

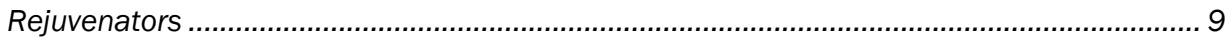

Type I Portland cement ............................................................................................... 10

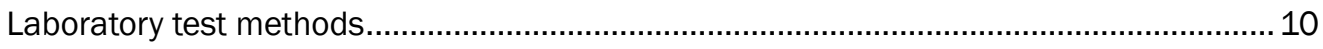

Specimen preparation and compaction ...................................................................... 10

Asphalt pavement analyzer (APA) testing .................................................................... 11

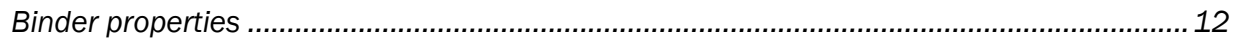

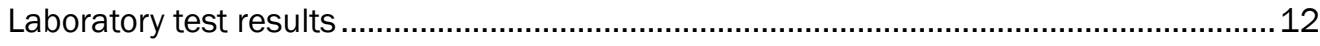

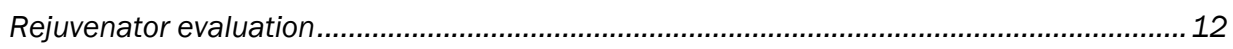

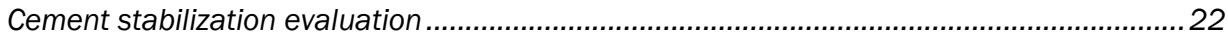

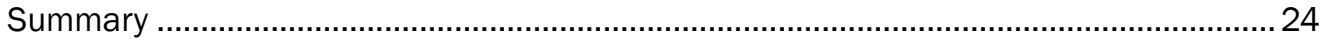

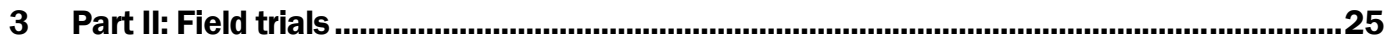

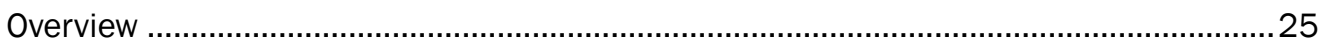

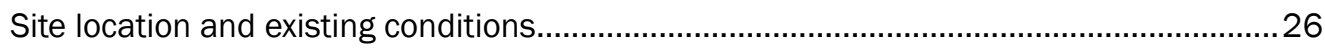

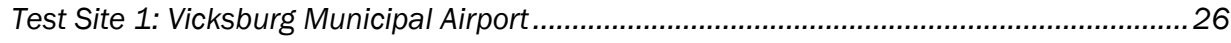

Test Site 2: Poorhouse Property, ERDC station .................................................................... 29

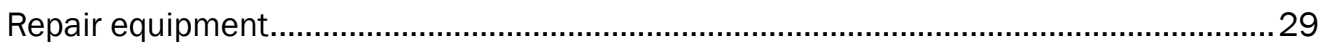

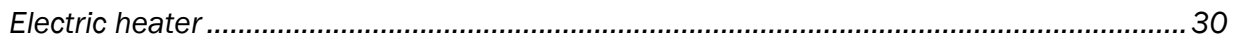

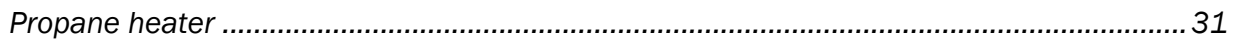

Skid steer mounted asphalt processor / Screed attachment .............................................. 31

Impact compactor ......................................................................................................... 33

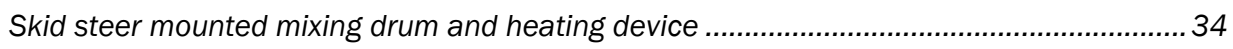

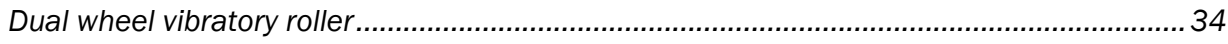

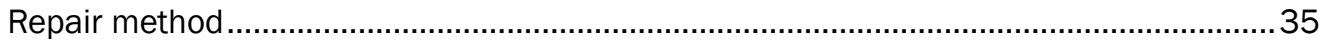

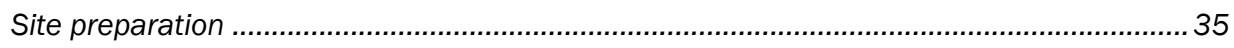

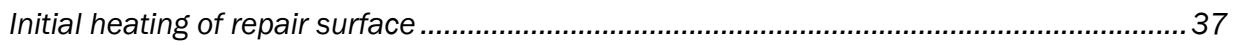




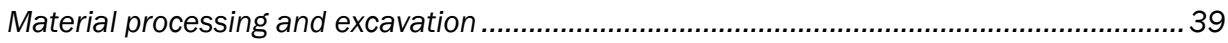

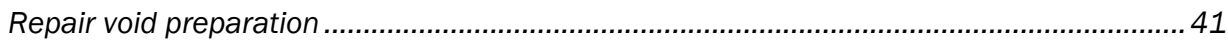

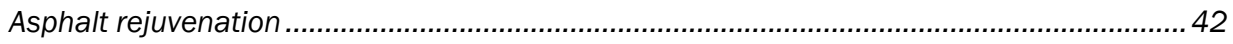

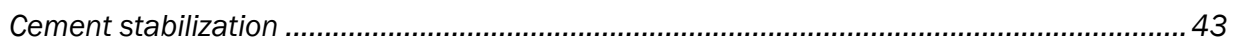

Rejuvenated stockpile and temperature maintenance ......................................................43

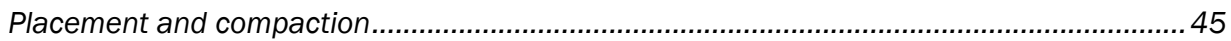

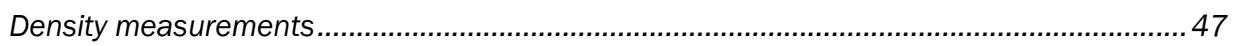

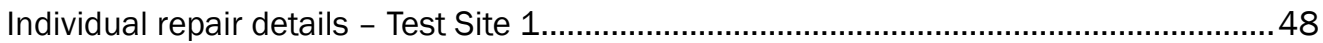

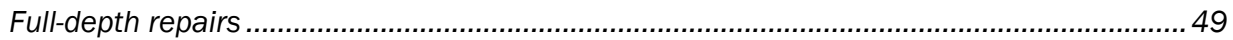

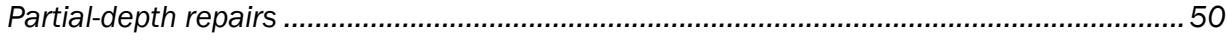

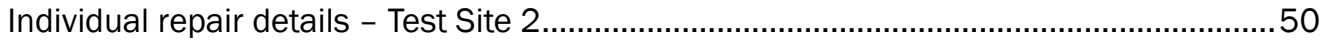

4 Repair Performance Evaluation .......................................................................................58

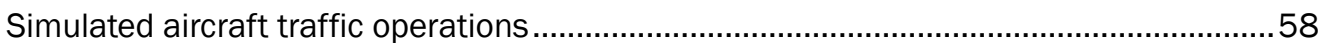

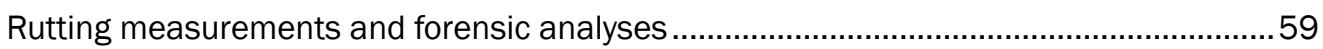

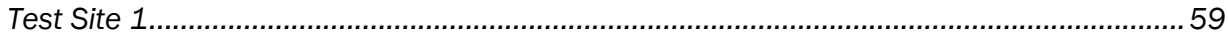

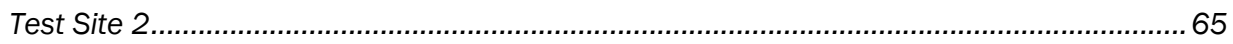

5 Recycling Effects on Asphalt Properties .............................................................................. 71

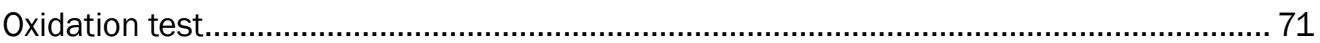

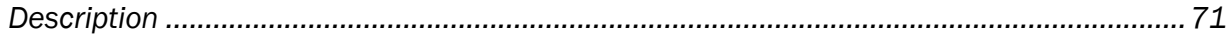

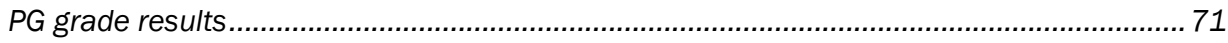

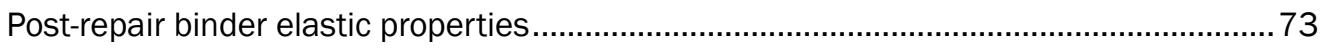

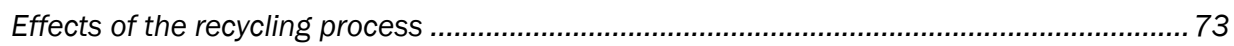

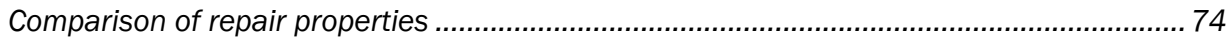

6 Conclusions and Recommendations .................................................................................. 76

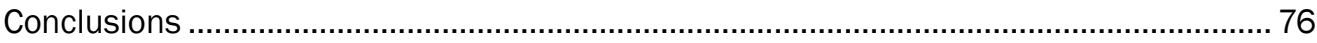

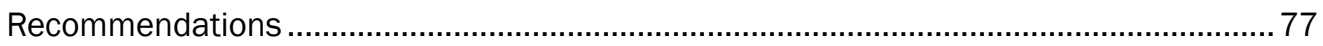

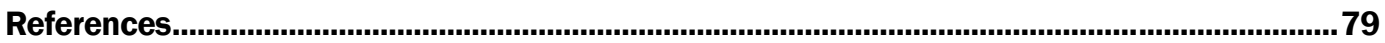

Appendix A: Recommended Equipment, Materials, and Process for Repair of Airfield Asphalt Pavements Using In-Place Asphalt Recycling Technology........................................80

Appendix B: Material Fact Sheets ...................................................................................................92

Appendix C: Field Raw Data .......................................................................................................98

\section{Report Documentation Page}




\section{Figures and Tables}

\section{Figures}

Figure 1. Some of the components of the SuPR kit...................................................................... 1

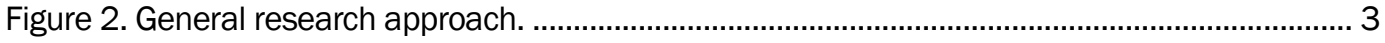

Figure 3. General approach for the rejuvenator evaluation. .............................................................. 7

Figure 4. Samples collected for laboratory testing......................................................................... 7

Figure 5. RAP aggregates gradation curves............................................................................. 8

Figure 6. Vicksburg Airport RAP material broken down to granulated material................................. 9

Figure 7. Gyratory compactor. ................................................................................................... 11

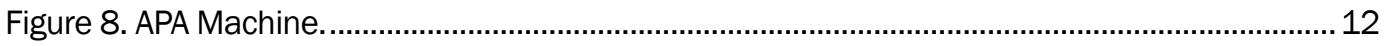

Figure 9. Compaction data.......................................................................................................... 14

Figure 10. Maximum rut depth for all mixes tested................................................................... 15

Figure 11. Binder failure temperatures - CRF and Cyclogen............................................................ 17

Figure 12. Binder failure temperatures - Viplex and Rejuvaseal. .................................................. 17

Figure 13. APA and compaction data for the Rejuvaseal recycled mix.......................................... 18

Figure 14. APA and compaction data for the Viplex 50 recycled mix.............................................. 18

Figure 15. APA and compaction data for the Cyclogen recycled mix................................................ 19

Figure 16. APA and compaction data for the CRF recycled mix...................................................... 19

Figure 17. APA and DSR data for the Rejuvaseal recycled mix.................................................... 20

Figure 18. APA and DSR data for the Viplex 50 recycled mix. ........................................................2

Figure 19. APA and DSR data for the Cyclogen recycled mix....................................................... 21

Figure 20. APA and DSR data for the CRF recycled mix. ............................................................... 21

Figure 21. APA average rut depth of rejuvenated RAP (with 0.5 percent RejuvaSeal) and different dosages of Type I Portland cement.................................................................................... 23

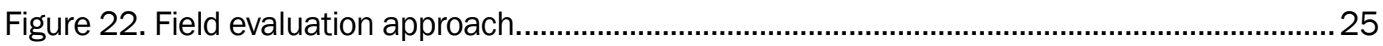

Figure 23. Existing surface conditions at Test Site 1.................................................................. 27

Figure 24. Pavement structure at Test Site 1........................................................................ 28

Figure 25. Pavement structure at ERDC test site. ........................................................................30

Figure 26. Heatwurx HWX-30 electric heater. ........................................................................ 31

Figure 27. Heat Design Equipment (HDE-1350) propane heater......................................................32

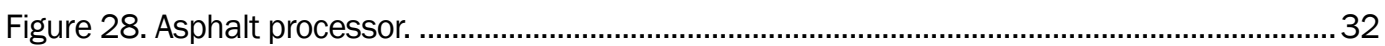

Figure 29. Asphalt processor tine configuration. .........................................................................3

Figure 30. Base material being compacted. ............................................................................. 33

Figure 31. Skid steer mounted mixer with heating device.............................................................. 34

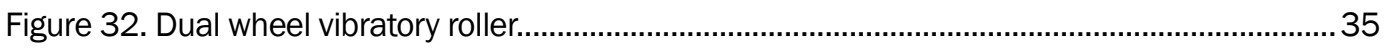

Figure 33. Skid steer mounted broom attachment. .....................................................................36

Figure 34. Spoil pile from site sweeping. ……………................................................................... 36 


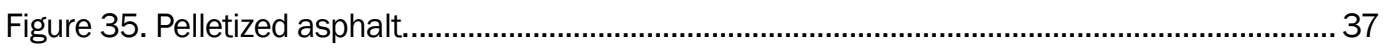

Figure 36. Electric heater being placed on repair area. .............................................................38

Figure 37. Propane heater during initial heat sequence. ............................................................. 39

Figure 38. Skid steer-mounted bucket attachment................................................................. 40

Figure 39. Skid steer-mounted asphalt processor..................................................................... 40

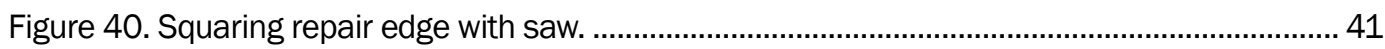

Figure 41. Squared edges and large chunks from saw cutting. ................................................... 41

Figure 42. Final repair void preparation (partial-depth). .............................................................. 41

Figure 43. Base compaction (full-depth)................................................................................... 41

Figure 44. Rejuvenator applied to repair void. ............................................................................ 42

Figure 45. Repair prior to asphalt placement ............................................................................. 42

Figure 46. Cement being added to rejuvenated batch mixture........................................................ 44

Figure 47. Propane heater keeping rejuvenated stockpile hot. ........................................................ 44

Figure 48. Rejuvenated asphalt being stockpiled near repair.......................................................... 45

Figure 49. Rejuvenated stockpile being placed into repair void....................................................... 46

Figure 50. Rejuvenated material being prepared for compaction. ................................................... 46

Figure 51. Dual-drum compactor pinching edges of repair........................................................... 47

Figure 52. Final compaction effort. ..................................................................................... 47

Figure 53. Nuclear density gauge taking measurement............................................................ 48

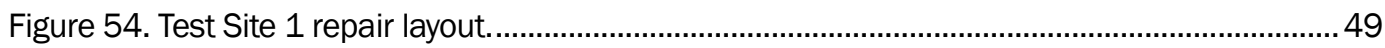

Figure 55. Post-compaction surface cracks (FD-2)................................................................ 50

Figure 56. Typical rejuvenator application to mitigate surface cracking. ........................................50

Figure 57. Disturbed base material mixed with excavated RAP....................................................... 51

Figure 58. Post-compaction repair surface (PD-2).......................................................................53

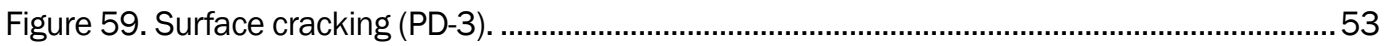

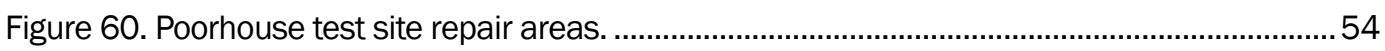

Figure 61. Cement addition to PHP-4.................................................................................... 56

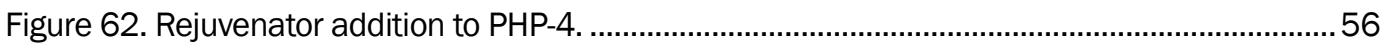

Figure 63. Post-compaction surface cracking (PHP-4) ................................................................. 56

Figure 64. F15-E load cart................................................................................................ 58

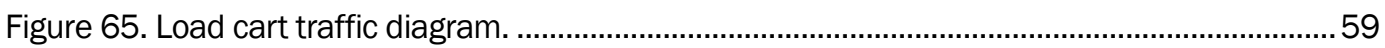

Figure 66. Full-depth repairs lane after traffic ............................................................................... 60

Figure 67. Partial-depth repairs lane after traffic........................................................................ 60

Figure 68. Rut depth measurements on full-depth repairs. ............................................................ 61

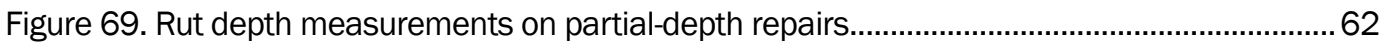

Figure 70. Repair PD-2 after traffic. .............................................................................................. 63

Figure 71. Cracking on repair FD-1 caused by surrounding material failure....................................63

Figure 72. Repair FD-2 trenched cross-section view after failure. .................................................64

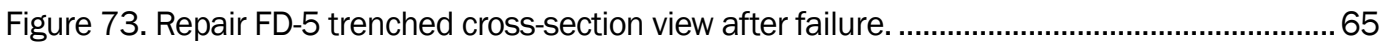

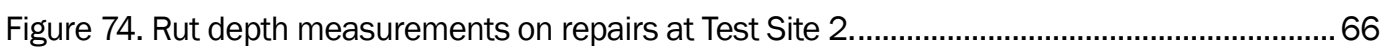


Figure 75. Repair PHP-1 trenched cross-section view post traffic. ……........................................ 67

Figure 76. Repair PHP-2 trenched cross-section view post traffic. …….........................................67

Figure 77. Repair PHP-3 trenched cross-section view post traffic....................................................68

Figure 78. Repair PHP-4 trenched cross-section view post traffic. ……..........................................68

Figure 79. Trenched cross-section view of original asphalt pavement between repairs

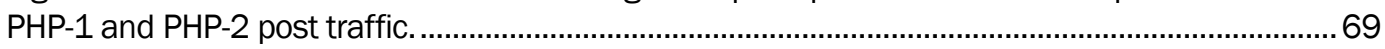

Figure 80. Loose recycled asphalt material after repair PHP-4 was trenched................................... 70

Figure 81. Asphalt material from oxidation test. ............................................................................ 72

Figure 82. Oxidation test binder failure temperatures. ……………............................................ 72

Figure 83. Repair binder failure temperatures............................................................................74

Figure A1. In-place asphalt recycling repair process.................................................................. 81

Figure A2. Heater being placed over repair area. ................................................................... 83

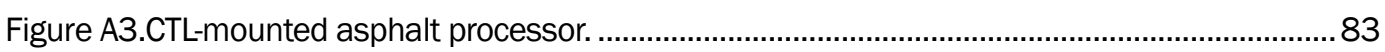

Figure A4. Manually adjusting processor cut depth....................................................................... 83

Figure A5. CTL-mounted bucket attachment............................................................................ 84

Figure A6. Pelletized asphalt..................................................................................................... 85

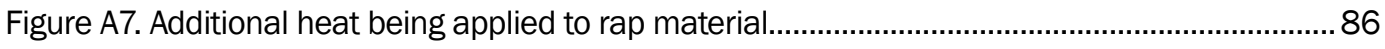

Figure A8. Rejuvenated asphalt being stockpiled near repair. ..................................................... 87

Figure A9. Heater placed over the rejuvenated stockpile............................................................... 87

Figure A10. Final repair void preparation for partial-depth repair...................................................... 89

Figure A11. Base compaction for full-depth repair. ..................................................................... 89

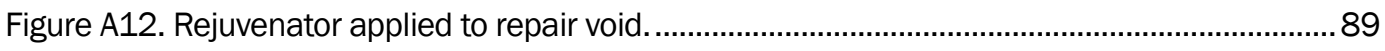

Figure A13. CTL placing rejuvenated material into repair void........................................................ 89

Figure A14. Preparing final lift for compaction.............................................................................90

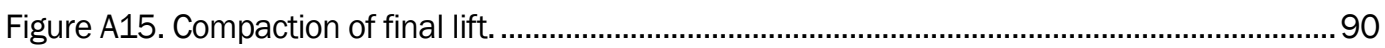

Figure A16. Final repair........................................................................................................... 91

Figure C1. Layout of rut depth measurements on each repair......................................................98

Figure C2. Rut depth measurements on north cross-section of FD-1 ..........................................99

Figure C3. Rut depth measurements on center cross-section of FD-1 ............................................99

Figure C4. Rut depth measurements on south cross-section of FD-1 ........................................100

Figure C5. Rut depth measurements on cross-section at midpoint between repairs FD-1

and FD-2 .

Figure C6. Rut depth measurements on north cross-section of FD-2 ........................................ 101

Figure C7. Rut depth measurements on center cross-section of FD-2 ......................................... 101

Figure C8. Rut depth measurements on south cross-section of FD-2 . .........................................102

Figure C9. Rut depth measurements on cross-section at midpoint between repairs FD-2

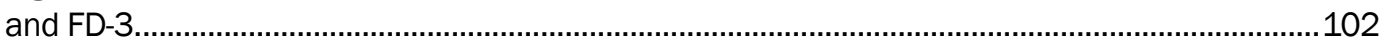

Figure C10. Rut depth measurements on north cross-section of FD-3.......................................103

Figure C11. Rut depth measurements on center cross-section of FD-3. ......................................103

Figure C12. Rut depth measurements on south cross-section of FD-3. ......................................104 
Figure C13. Rut depth measurements on cross-section at midpoint between repairs FD-3

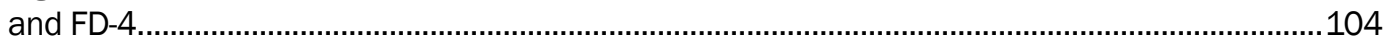

Figure C14. Rut depth measurements on north cross-section of FD-4 ......................................105

Figure C15. Rut depth measurements on center cross-section of FD-4 .....................................105

Figure C16. Rut depth measurements on south cross-section of FD-4 .......................................106

Figure C17. Rut depth measurements on cross-section at midpoint between repairs FD-4

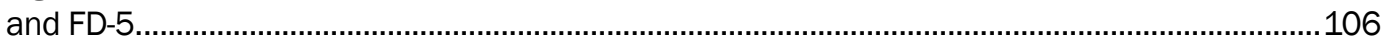

Figure C18. Rut depth measurements on north cross-section of FD-5 ......................................... 107

Figure C19. Rut depth measurements on center cross-section of FD-5 ..................................... 107

Figure C20. Rut depth measurements on south cross-section of FD-5....................................108

Figure C21. Rut depth measurements on cross-section $2 \mathrm{ft}$ after repair FD-5.............................108

Figure C22. Rut depth measurements on north cross-section of FD-1a.....................................109

Figure C23. Rut depth measurements on center cross-section of FD-1a.....................................109

Figure C24. Rut depth measurements on south cross-section of FD-1a. ...................................110

Figure C25. Rut depth measurements on cross-section at mid-point between repairs FD-

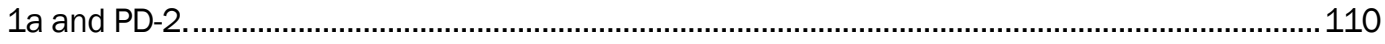

Figure C26. Rut depth measurements on north cross-section of PD-2 …...................................111

Figure C27. Rut depth measurements on center cross-section of PD-2 2......................................111

Figure C28. Rut depth measurements on south cross-section of PD-2 .......................................112

Figure C29. Rut depth measurements on cross-section at midpoint between repairs PD-2 and PD-3.

Figure C30. Rut depth measurements on north cross-section of PD-3......................................113

Figure C31. Rut depth measurements on center cross-section of PD-3. ....................................113

Figure C32. Rut depth measurements on south cross-section of PD-3. ......................................114

Figure C33. Rut depth measurements on cross-section at midpoint between repairs PD-3

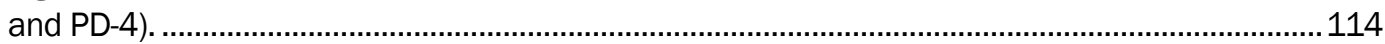

Figure C34. Rut depth measurements on north cross-section of PD-4.......................................115

Figure C35. Rut depth measurements on center cross-section of PD-4 .....................................115

Figure C36. Rut depth measurements on south cross-section of PD-4 .....................................116

Figure C37. Rut depth measurements on cross-section at midpoint between repairs PD-4

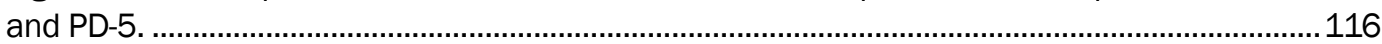

Figure C38. Rut depth measurements on north cross-section of PHP-1. .....................................117

Figure C39. Rut depth measurements on center cross-section of PHP-1....................................117

Figure C40. Rut depth measurements on south cross-section of PHP-1.....................................118

Figure C41. Rut depth measurements on cross-section at midpoint between repairs PHP-

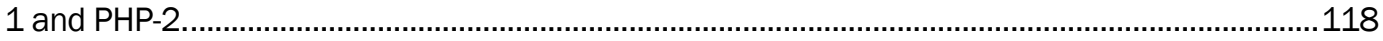

Figure C42. Rut depth measurements on north cross-section of PHP-2 ....................................119

Figure C43. Rut depth measurements on center cross-section of PHP-2 ....................................119

Figure C44. Rut depth measurements on south cross-section of PHP-2 …................................120

Figure C45. Rut depth measurements on cross-section at midpoint between repairs PHP-

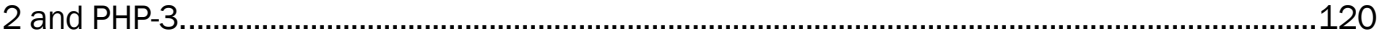

Figure C46. Rut depth measurements on north cross-section of PHP-3. ....................................121 
Figure C47. Rut depth measurements on center cross-section of PHP-3.....................................121

Figure C48. Rut depth measurements on south cross-section of PHP-3. 122

Figure C49. Rut depth measurements on cross-section at midpoint between repairs PHP-

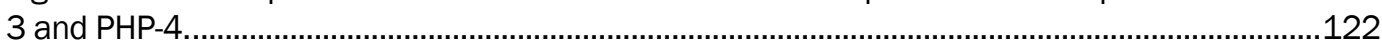

Figure C50. Rut depth measurements on north cross-section of PHP-4 ...................................123

Figure C51. Rut depth measurements on center cross-section of PHP-4 .....................................123

Figure C52. Rut depth measurements on south cross-section of PHP-4....................................124

Figure C53. Rut depth measurements on cross-section $2 \mathrm{ft}$ after repair PHP-4 ............................124

\section{Tables}

Table 1. Asphalt binder and aggregate tests............................................................................ 7

Table 2. Performance grade of recovered asphalt........................................................................ 8

Table 3. Rejuvenators selected for laboratory testing. ………...................................................... 10

Table 4. Cement stabilization evaluation matrix. ........................................................................... 10

Table 5. Compaction data. ................................................................................................ 13

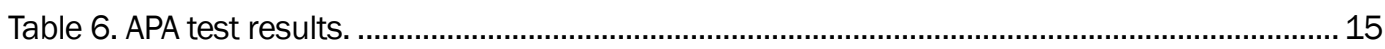

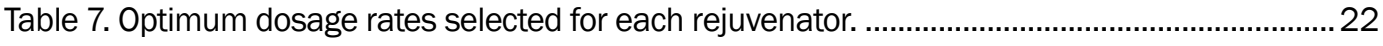

Table 8. APA rut data for cement-rejuvenator combinations ............................................................ 23

Table 9. Results from pavement failure prediction analyses for the Vicksburg Municipal

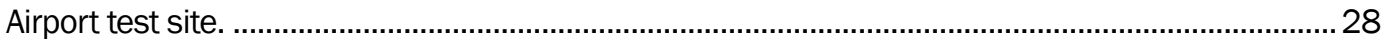

Table 10. Results from pavement failure prediction analyses for ERDC test site..............................30

Table 11. Repair nomenclature used for Test Site 1................................................................. 48

Table 12. Full-depth repairs description................................................................................... 51

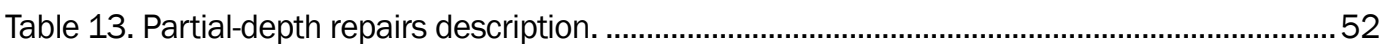

Table 14. Repair nomenclature used for ERDC test site. ............................................................. 54

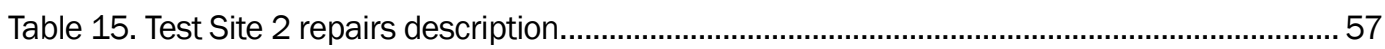

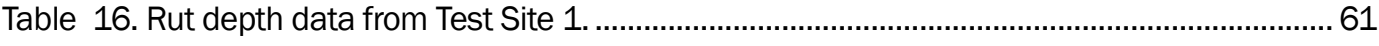

Table 17. Rut depth data from ERDC test site. ……...................................................................... 65 


\section{Preface}

This report was prepared by the US Army Engineer Research and Development Center (ERDC) in collaboration with Applied Research Associates (ARA). J eb S. Tingle, ERDC, Geotechnical and Structures Laboratory (GSL), was the manager of the US Air Force Asphalt Recycling Technology project.

This publication was prepared by personnel of ERDC GSL, Vicksburg, MS, and personnel of ARA, Panama City, FL. The principal investigator for this study was Mariely Mejías-Santiago. William D. Carruth assisted in the research effort and preparation of this report. Both Mejías-Santiago and Carruth are from the Airfields and Pavements Branch (APB), Engineering Systems and Materials Division (ESMD) at ERDC. J effrey C. Petermann and Dean $\mathrm{H}$. Hitzelberger of ARA also participated in the research effort and report preparation. Other ERDC personnel who assisted in this research effort include J ames (J ay) Rowland of APB, Timothy J McCaffrey, Lance C. Warnock, and Kevin Taylor of the ESMD Concrete Materials Branch (CMB) and Kevin Rodriguez of the University of Puerto Rico at Mayagüez. Technical oversight was provided by J eb S. Tingle, Engineering Systems and Materials Division (ESMD). This document was prepared under the supervision of Dr. Gary L. Anderton, Chief, APB; Christopher M. Moore, Chief, CMB; Dr. Larry N. Lynch, Chief, ESMD; Dr. William P. Grogan, Deputy Director, GSL; and Dr. David W. Pittman, Director, GSL.

COL Kevin J . Wilson was the Commander of ERDC. Dr. J effery P. Holland was the Director.

Recommended changes for improving this publication in content and/ or format should be submitted on DA Form 2028 (Recommended Changes to Publications and Blank Forms) and forwarded to Headquarters, US Army Corps of Engineers, ATTN: CECW-EWS, Kingman Building, Room 321, 7701 Telegraph Road, Alexandria, VA 22315. 


\section{Unit Conversion Factors}

\begin{tabular}{|l|l|l|}
\hline Multiply & By & To Obtain \\
\hline cubic feet & 0.02831685 & cubic meters \\
\hline degrees (angle) & 0.01745329 & radians \\
\hline degrees Fahrenheit & $(\mathrm{F}-32) / 1.8$ & degrees Celsius \\
\hline feet & 0.3048 & meters \\
\hline gallons (U.S. liquid) & $3.785412 \mathrm{E}-03$ & cubic meters \\
\hline horsepower (550 foot-pounds force per second) & 745.6999 & watts \\
\hline inches & 0.0254 & meters \\
\hline pounds (force) & 4.448222 & newtons \\
\hline pounds (force) per square foot & 47.88026 & pascals \\
\hline pounds (force) per square inch & 6.894757 & kilopascals \\
\hline pounds (mass) & 0.45359237 & kilograms \\
\hline pounds (mass) per cubic foot & 16.01846 & kilograms per cubic meter \\
\hline square feet & 0.09290304 & square meters \\
\hline tons (2,000 pounds, mass) & 907.1847 & kilograms \\
\hline
\end{tabular}




\section{Introduction}

The need for rapid and effective contingency asphalt pavement repair methods on airfields using in-house capabilities led to the research and the development of a sustainment pavement repair (SuPR) kit (Figure 1). This kit provides its users the capability to perform small to medium sized repairs on existing Portland cement concrete (PCC) and asphalt concrete (AC) pavements with non-structural problems, and with a minimal amount of equipment, manpower, and time.

Figure 1. Some of the components of the SuPR kit (utility vehicles, attachments, etc.).
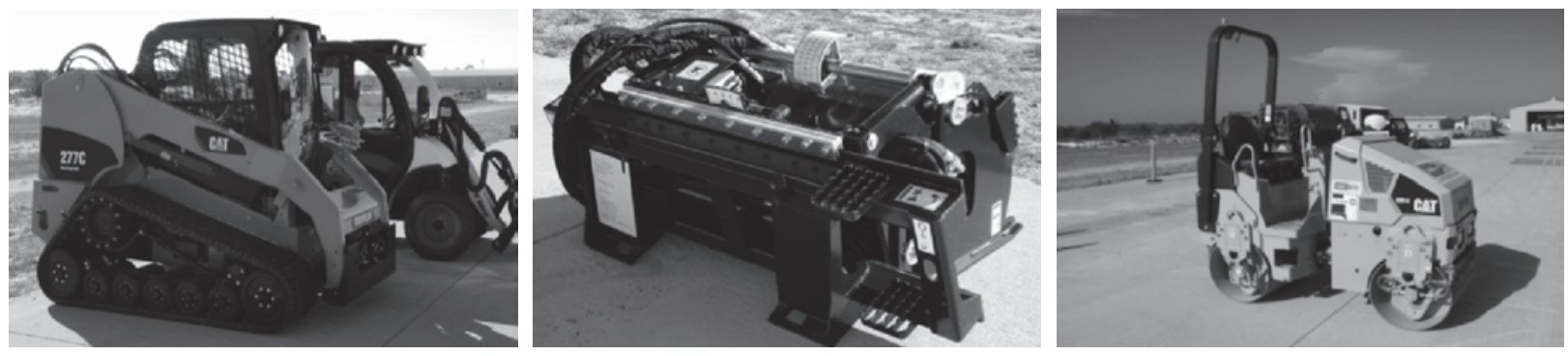

Situations occur when the availability of acceptable materials is limited. Therefore, the SuPR kit needs to be augmented to add the capability of reusing in-place materials. One alternative available for repairing AC pavements is using in-place recycling techniques. In-place asphalt recycling through the use of infrared heating units and chemical rejuvenators is an inexpensive and efficient method of making small-scale asphalt repairs. The US Army Engineer Research and Development Center (ERDC) was tasked to collaborate with the Applied Research Associates (ARA) to develop an augmentation kit that will give users of the SuPR kit the capability to perform AC repairs using in-place asphalt recycling. This type of repair has the potential for reducing the logistics associated with airfield pavement repair and the airfield downtime during the repairs.

\section{Objectives}

The main purpose of this research project was to determine the most expedient methods, materials, and equipment for small-to-medium repairs in damaged airfield asphalt concrete (AC) pavements using inplace asphalt recycling technologies. Specific objectives of this research were to: 
- identify commercially available technologies for heated asphalt pavement removal using an infrared heating process and tracked skid steer equipment.

- identify and evaluate commercially available products in the laboratory for asphalt rejuvenation and cement stabilization in order to downselect materials for field trials.

- conduct asphalt pavement repairs to evaluate the proposed in-place asphalt recycling processes, including asphalt heaters, additives, mixing equipment, and compaction equipment.

- evaluate the repair performance under F-15 load cart trafficking.

- determine a final protocol for in-place asphalt recycling yielding the highest quality repair in the shortest time.

\section{Scope}

This research effort consisted of evaluating commercially available infrared heating technologies and asphalt rejuvenators to supplement the current SuPR kit with the ability to conduct in-place asphalt recycling. The evaluation consisted of two parts: I) a laboratory evaluation of rejuvenator products and Type I Portland cement, and II) a field evaluation of different materials, equipment, and procedures used for in-place asphalt recycling. In Part I, laboratory tests were conducted to evaluate rejuvenated asphalt mixes using four different rejuvenators to determine the top performing rejuvenator and its optimum dosage rate. The use of Type I Portland cement for early strength improvement was also investigated. The properties evaluated in the laboratory included: mix compactability, rutting potential, and binder viscoelastic properties. Part II consisted of conducting field repairs to evaluate the efficiency of two different asphalt heaters, to study different repair processes, and to evaluate the effectiveness of the repairs for in-place asphalt recycling. The repairs were trafficked with simulated F-15 aircraft loading to determine the suitability of in-place asphalt recycling for sustainment repair operations on airfields.

\section{Research approach}

The general research approach of this project is presented in Figure 2 and described in the following paragraphs.

The Air Force Civil Engineer Center (AFCEC) was consulted to develop requirements needed for selection of materials and equipment for this study, including transportation and handling of materials and equipment. 
Figure 2. General research approach.

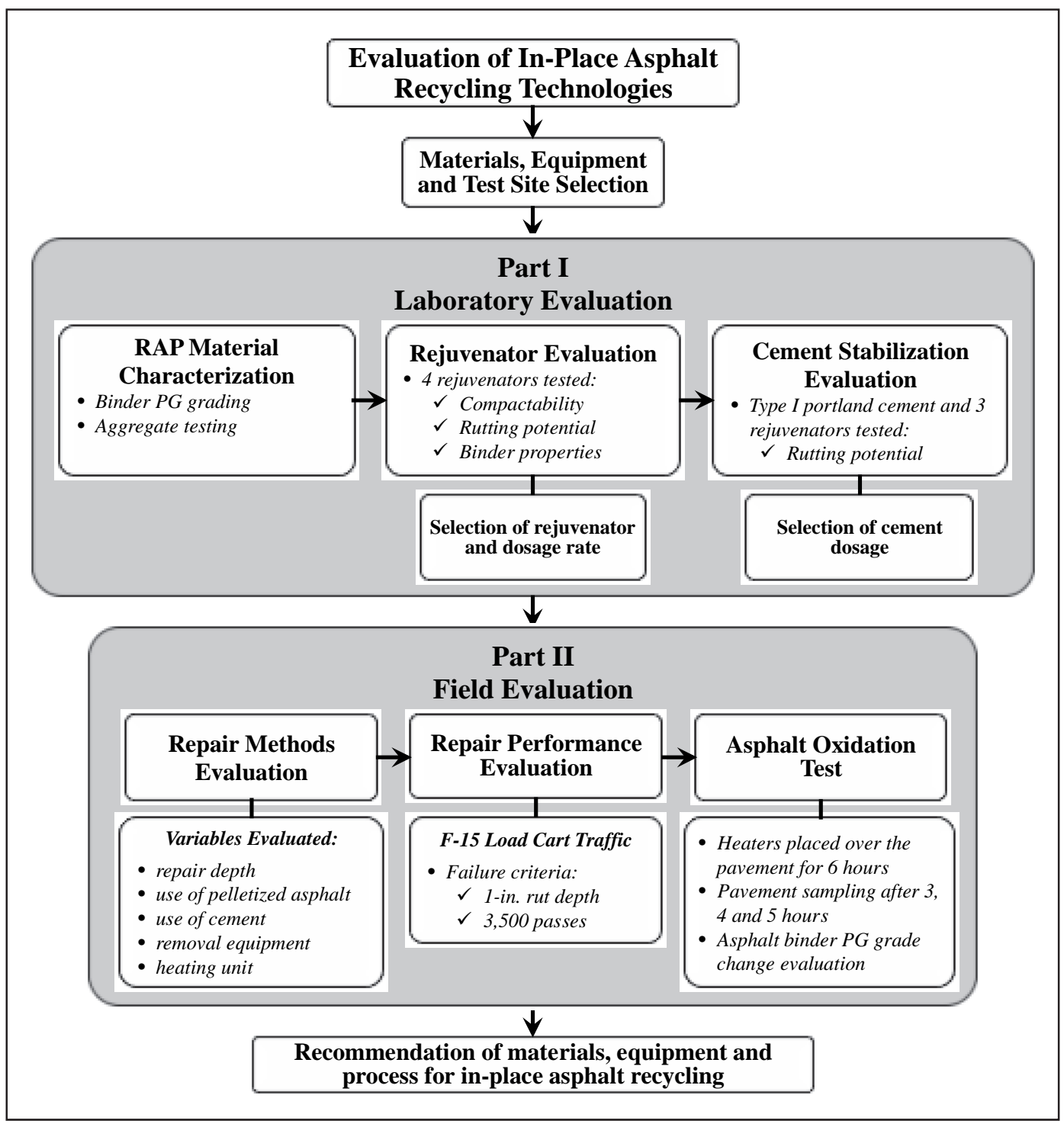

Two test sites were selected for this study based on their availabilities and pavement conditions. Test Site 1 was located at the Vicksburg Municipal Airport and represented a pavement with poor surface conditions. This test site was used to conduct the evaluation of the repair methods. The pavement structure in Test Site 1 was not designed for heavy aircraft loading. Therefore, a second test site located at ERDC, which consisted of a pavement structure capable of withstanding heavy military aircraft loading, was selected to conduct the repair performance evaluation. Repairs at both test sites were trafficked with simulated F-15 aircraft loading to evaluate performance, failure being defined as 1-in. rut depth before 3,500 passes. 
Various rejuvenators were investigated, and four types were down-selected for extensive laboratory testing based upon their chemical properties and costs. Reclaimed asphalt pavement (RAP) material was obtained from both test sites for characterization testing in the laboratory. The RAP was then mixed with four different rejuvenator products at varying dosages, and the resulting rejuvenated mixes were tested to down-select the top performing rejuvenator and its optimum dosage rate for the field testing. The properties evaluated in the rejuvenated mixes were compactability, rutting potential, and binder properties. The possibility of adding Type I Portland cement to stiffen the asphalt while still allowing for rejuvenation was also explored, and an optimum cement dosage rate was selected with a rejuvenator based on rutting potential results.

Researchers evaluated the repair methods at Test Site 1 using two types of infrared heaters: one fueled by liquid propane and one electric unit operated by a diesel generator producing $43 \mathrm{Btu} / \mathrm{s}$. These two heaters were down-selected earlier in the project based on specifications, costs, and transportation and hauling requirements. The purpose of the initial field test was to evaluate the equipment, materials, and procedures for in-place asphalt recycling in terms of the efficiency of the components to reduce not only the repair logistics and equipment footprint, but also airfield downtime during repairs. The variables evaluated were repair depth, use of pelletized asphalt, use of cement, removal equipment, and the overall efficiency of each heater unit, including the ability to maintain stockpile temperatures over time and asphalt oxidation potential. Repair times were also monitored to determine the different repair durations. An asphalt oxidation test was conducted at Test Site 2 to determine the feasibility of prematurely oxidizing a newer pavement using an infrared heater in order to increase the initial stiffness.

All of the data collected during both parts of this study were used to recommend materials, equipment, and procedures to augment the airfield SuPR kit to include in-place asphalt recycling.

\section{Report organization}

This report consists of six chapters beginning with an introduction in Chapter 1. Chapter 2 outlines the laboratory evaluation of rejuvenators and cement stabilization. Chapter 3 describes all the repair procedures evaluated during the field trials. Chapter 4 presents the repair performance evaluation. The oxidation tests and an analysis of the effects of the recycling 
process on the asphalt properties are presented in Chapter 5. Chapter 6 presents conclusions and recommendations from the study with references immediately following. Appendix A presents the rut depth data from the field trials. 


\section{Part l: Laboratory Evaluation}

The objective of Part I of this study was to conduct laboratory testing to:

- characterize the reclaimed asphalt pavement (RAP) from the test sites,

- evaluate how different types of rejuvenators affect the rutting potential and the binder properties of one of the RAP materials to down-select the top performing rejuvenator product and its optimum dosage to be used for field testing, and

- evaluate the use of Type I Portland cement in addition to a rejuvenator to stiffen the asphalt mixture while still allowing for rejuvenation, and to select the optimum cement dosage to be used for field testing.

The general approach of Part I of this project is shown in Figure 3. The RAP material obtained from two test sites was tested to determine binder PG grade and aggregate properties. Then, different combinations of rejuvenator types and percentages were mixed with the RAP material obtained from Test Site 1. The resulting recycled mixes were tested to determine mix compactability, rutting potential, and binder failure temperature. These data were analyzed to determine the optimum rejuvenator and dosage rate to be used for the field evaluation of in-place asphalt recycling technology. Additionally, the RAP was mixed with each rejuvenator (at their optimum dosages) and Type I cement to determine the optimum cement dosage that would possibly stiffen the asphalt mix while still allowing for rejuvenation.

\section{Materials}

\section{RAP}

Samples of RAP material were collected from two test sites (Test Site 1 was at the Vicksburg Municipal Airport, and Test Site 2 was at ERDC Vicksburg) for characterization. The test sites are described in Chapter 4 of this report. Core samples (Figure 4a) were collected from both test sites for mix characterization through asphalt binder and aggregate testing. Slab samples (Figure 4b) were collected from Test Site 1 to evaluate the effect of the rejuvenators and cement. Core samples were also obtained from Test Site 1 for baseline testing using the Asphalt Pavement Analyzer (APA), and the results are discussed later on in this chapter. 
Figure 3. General approach for the rejuvenator evaluation.

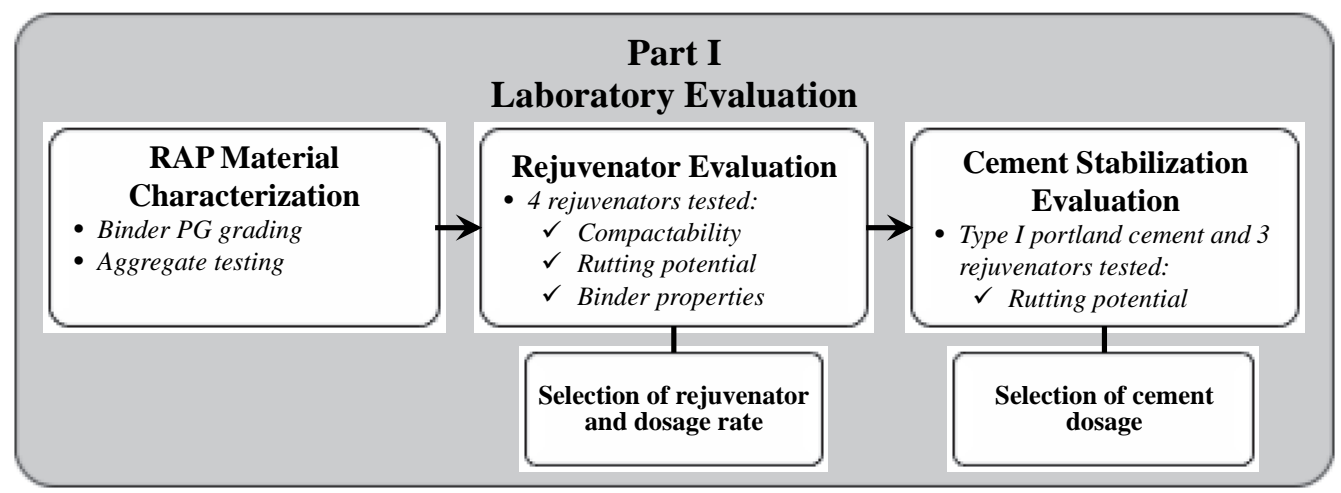

Figure 4. Samples collected for laboratory testing.

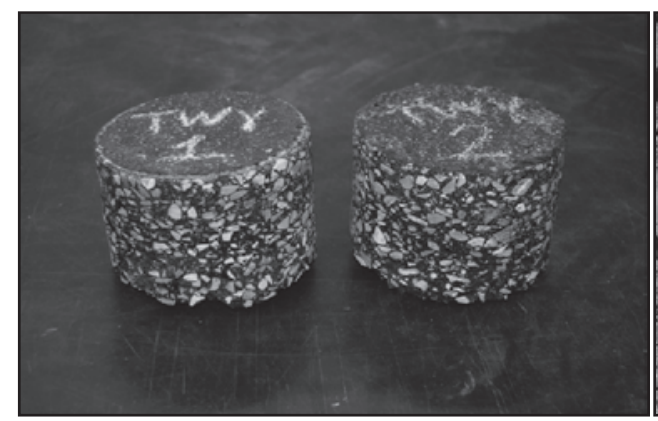

a) Cores

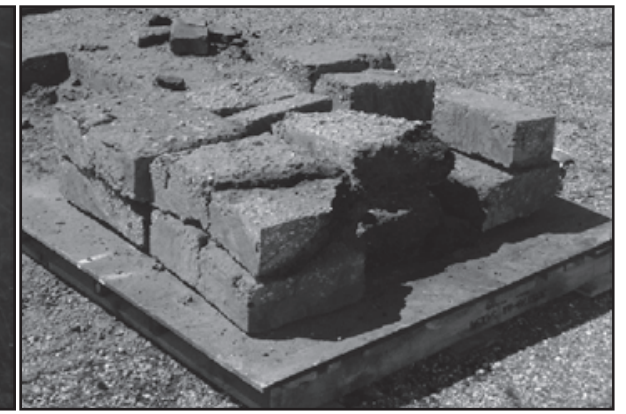

b) Slabs

The asphalt binder was extracted and recovered from the core samples for performance grading in accordance with the standard binder tests listed in Table 1 . The aggregate material was tested to determine specific gravity and gradation in accordance with the standard aggregate tests also listed in Table 1.

Table 1. Asphalt binder and aggregate tests.

\begin{tabular}{|l|l|}
\hline Test & Standard Test Method \\
\hline Extraction of Asphalt Cement & AASHTO T 164 \\
\hline Recovery of Asphalt Cement & AASHTO T 319 \\
\hline Asphalt Cement Performance Grade (PG) Verification & AASHTO M 320 \\
\hline Aggregate Gradation & AASHTO T 30 \\
\hline Fine Aggregate Specific Gravity & AASHTO T 84 \\
\hline Coarse Aggregate Specific Gravity & AASHTO T 85 \\
\hline
\end{tabular}

Table 2 shows the results from the performance grading of the recovered binder. The high temperatures show that the asphalt binder at both test sites had aged (oxidized) and had gained stiffness, assuming that the 
original asphalt binder PG was 67-22. A visual inspection of Test Site 1 revealed an oxidized and brittle pavement, with serious raveling and weathering issues. This condition made this test site a prime candidate for an asphalt recycling evaluation. Test Site 2 consisted of a newer pavement without critical distresses. Figure 5 shows the average aggregate gradation curve obtained for both RAP materials and the properties measured. Both gradations generally met the airfield specification gradation limits.

Table 2. Performance grade of recovered asphalt.

\begin{tabular}{|l|l|l|l|l|}
\hline \multirow{2}{*}{ RAP Material } & \multirow{2}{*}{$\begin{array}{l}\text { Total Asphalt } \\
\text { Content (percent) }\end{array}$} & \multicolumn{4}{|c|}{ Pass/Fail Temperature $\left({ }^{\circ} \mathrm{C}\right)$} \\
\cline { 3 - 6 } & High & Intermediate & Low $^{\mathrm{a}}$ \\
\hline Vicksburg Airport RAP & 4.7 & 88 & 27 & -10 \\
\hline ERDC Vicksburg RAP & 4.3 & 83 & 34 & -10 \\
\hline
\end{tabular}

a The low temperatures were extrapolated from the Bending Beam Rheometer (BBR) test data since BBR tests were conducted at only one temperature, $0^{\circ} \mathrm{C}$.

Figure 5. RAP aggregates gradation curves.

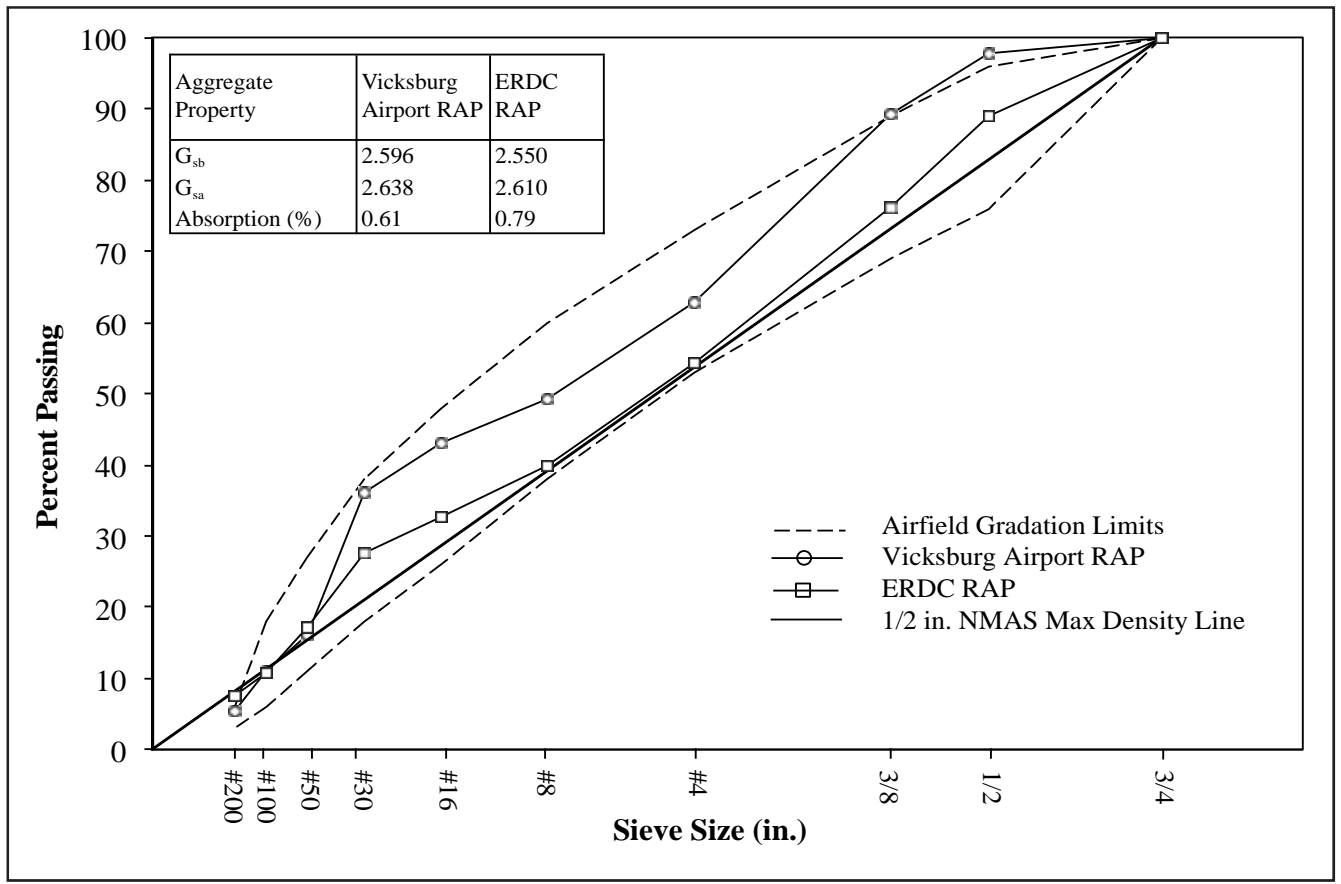

The Vicksburg Municipal Airport RAP material that was used for the rejuvenator and cement stabilization evaluations was processed as follows. The slab samples were washed to remove the base course material to keep it from impacting the original mix gradation. The samples were then allowed to dry to their original states and placed in large pans. The samples were then placed into a large batching oven and heated at $300^{\circ} \mathrm{F}$ for $4 \mathrm{hr}$. The 
pavement samples consisted of two layers, and the upper layer seemed to be very oxidized and stiff compared to the lower layer. Due to its heavy oxidation, the top 1 to $1.5 \mathrm{in}$. of material was separated from the remaining materials and placed back into the oven for an additional hour. The lower section was easily crumbled into a workable size for separation and testing. After the additional hour in the oven, the upper layer was broken down into the smallest size possible and cooled. The total sample was recombined and run through a large sample shaker to separate any material larger than $1 \mathrm{in}$. Any material greater than $1 \mathrm{in}$. was reheated to $300{ }^{\circ} \mathrm{F}$ for duration of $2 \mathrm{hr}$ and further reduced to the desired size of less than $1 \mathrm{in}$. The complete sample was then split using an asphalt sample splitter and reduced to 70- to 80 -lb lots. This process was repeated until a total of approximately $800 \mathrm{lb}$ of material was reduced and separated. Figure 6 shows some of the RAP material after it was broken down from slab samples to granulated material.

Figure 6. Vicksburg Airport RAP material broken down to granulated material.

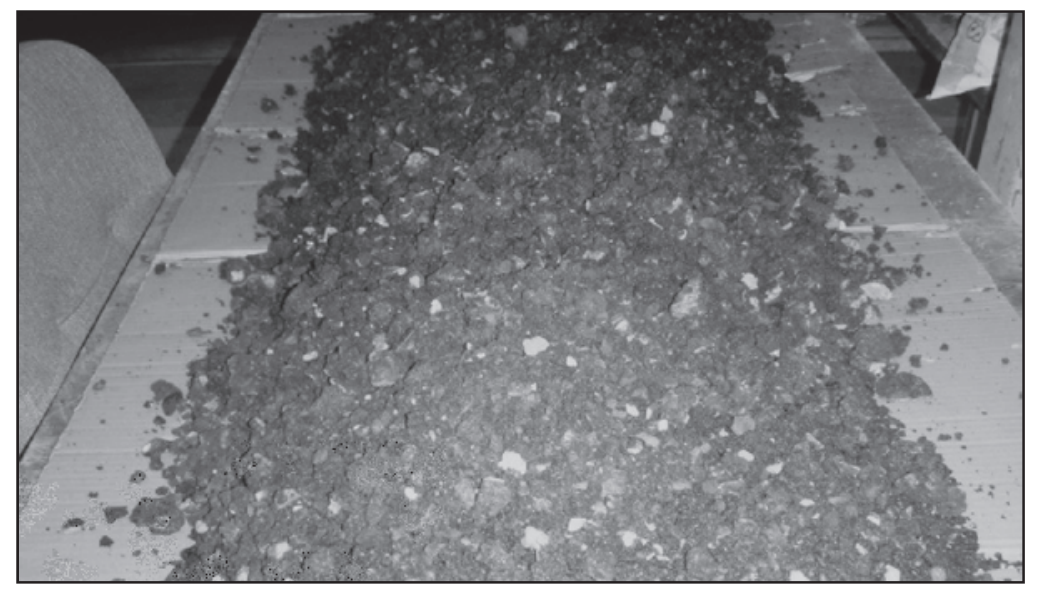

\section{Rejuvenators}

Four different rejuvenator products were selected based on their commercial availabilities and applications to this project. These products are listed in Table 3. The three emulsion products (CRF, Cyclogen LE, and Rejuvaseal) were diluted 1:1 (one part product to one part water) and were cured for $1 \mathrm{hr}$ at room temperature. Viplex 50 was used neat and required a cure time of $1 \mathrm{hr}$.

All four products are typically applied to aged pavement using a spray-on application. This method of application was not used for these experiments. The rejuvenators were directly mixed into heated RAP material to simulate the same process that would be used in the field. 
Table 3. Rejuvenators selected for laboratory testing.

\begin{tabular}{|l|l|l|l|}
\hline Rejuvenator & Type & Manufacturer & $\begin{array}{l}\text { Dosage Rates } \\
\text { Evaluateda }\end{array}$ \\
\hline Rejuvaseal & Coal Tar Based Emulsion & Pavement Rejuvenation Intl., LP & $0.25,0.5,1.0,1.5$ \\
\hline Cyclogen LE & Petroleum Based Oil & Tricor Refining, LLC & $1.0,1.5,2.0,2.5$ \\
\hline CRF & Petroleum Based Emulsion & Tricor Refining, LLC & $1.5,2.0,2.5,3.0$ \\
\hline Viplex 50 & Petroleum Based Oil & Crowley Chemical & $0.5,0.7,1.0,1.25$ \\
\hline
\end{tabular}

a Percent by weight of total mix

\section{Type I Portland cement}

Type I Portland cement has been widely used as a soil stabilizer for base and subbase layers. It has also been used in the full-depth reclamation (FDR) process, where existing asphalt pavements are pulverized and used as a high quality base layer for asphalt construction. In this project, the use of Type I Portland cement alongside a rejuvenator was evaluated for its ability to stiffen an asphalt mixture while still obtaining the desired viscoelastic properties of the asphalt mixture. An ordinary commercial off-theshelf (COTS) Type I Portland cement was used. Table 4 lists the cement dosage rates that were used with the different rejuvenators.

Table 4. Cement stabilization evaluation matrix.

\begin{tabular}{|l|l|}
\hline Rejuvenator & Cement Dosage Ratesa \\
\hline Rejuvaseal & $1.0,1.5,2.0$, and 2.5 \\
\hline Cyclogen LE & 1.5, and 2.5 \\
\hline CRF & 1.5, and 2.5 \\
\hline
\end{tabular}

a Percent by weight of total RAP

\section{Laboratory test methods}

\section{Specimen preparation and compaction}

Samples of approximately $7.3 \mathrm{lb}$ of the RAP material were heated to $140{ }^{\circ} \mathrm{F}$ and then placed in a mixer for $1 \mathrm{~min}$. If cement was being tested, it was added by total weight of RAP and mixed for 1 additional minute. Then the rejuvenator was added, and mixing continued for $2 \mathrm{~min}$. Once mixing was completed, the batch was returned to the oven for $30 \mathrm{~min}$ to re-establish the compaction temperature $\left(140^{\circ} \mathrm{F}\right)$. For compaction, $6.6 \mathrm{lb}$ of material was poured into a 5.9-in-diam mold for compaction. The specimens were compacted to $7.0 \pm 0.5$ percent voids and a specific height of $3.0 \pm 0.1 \mathrm{in}$. 
using a Rainhart gyratory compactor (Figure 7). Two specimens were compacted at each rejuvenator dosage rate for replication. In addition, two samples were set aside from each lot for maximum theoretical specific gravity testing (ASTM 2011b). The compacted specimens were allowed to cool over night, and bulk specific gravity testing (ASTM 2011c) was performed the following day. The target air void content was determined to be 7 percent and calculated in accordance with ASTM 2011d.

Figure 7. Gyratory compactor.

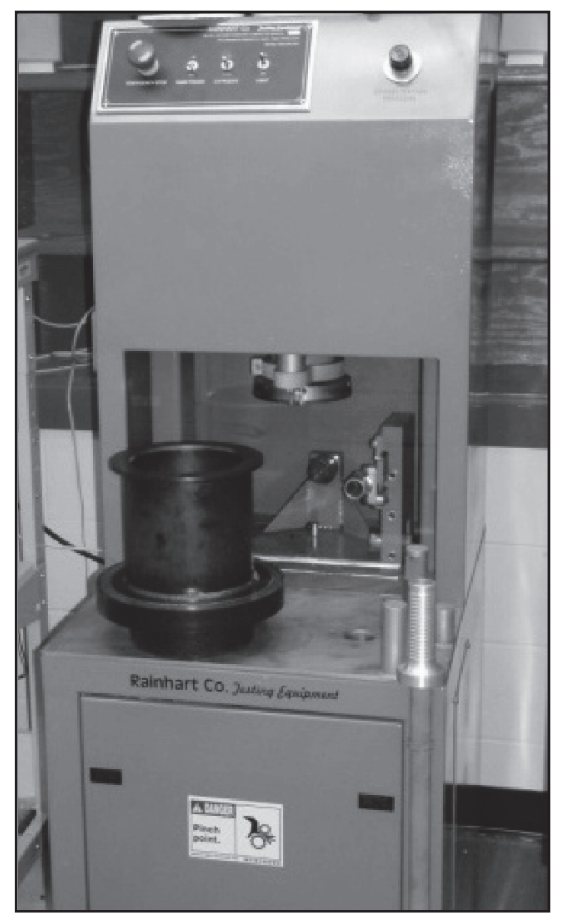

\section{Asphalt pavement analyzer (APA) testing}

Rutting potential was evaluated using the APA test in accordance with AASHTO 2009a. The APA simulates single-wheel vehicle traffic using pneumatic rubber hoses and steel-wheel loading. The APA is used to compare relative rutting performance between specimens and cannot be used for direct comparison to actual field results. All data gathered during the testing were collected and tabulated for indexing purposes only. A photo of the APA used for this testing is shown in Figure 8.

The molds were pre-heated to the test temperature $\left(147^{\circ} \mathrm{F}\right)$ for $6 \mathrm{hr}$ prior to the test. Paired specimens of the same rejuvenator dosage were placed into the APA. The maximum vertical wheel depth and load were calibrated prior to testing. The hose pressure was initially varied to determine an 
Figure 8. APA Machine.

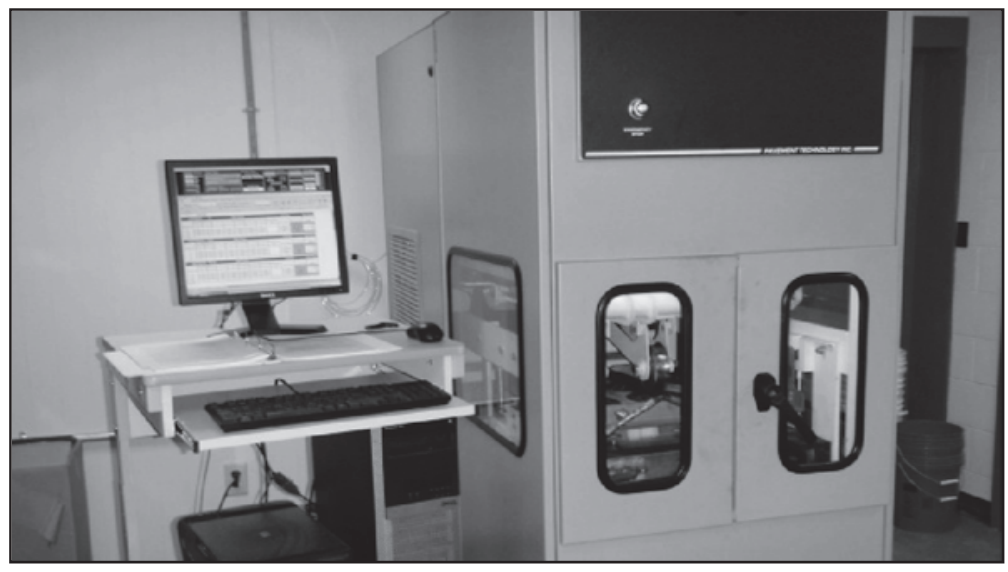

optimum pressure that would prevent premature specimen failure. It was imperative that the optimum pressure was set to provide useful data points based on rejuvenator type and dosage rates. The test hose pressure for this experiment was set to $150 \mathrm{psi}$, and the load level was standardized at $100 \mathrm{lb}$. Specimens were placed in the APA, and the test length was set to 8,000 maximum cycles and $0.5 \mathrm{in}$. (14 mm) maximum rutting.

\section{Binder properties}

Viscoelastic properties of the asphalt binders were evaluated using the Dynamic Shear Rheometer (DSR) test in accordance with AASHTO 2009h. The DSR test is used to characterize the viscous and elastic behavior of asphalt binders at medium to high temperatures. This characterization is used in the Superpave PG asphalt binder specification.

For this project, the DSR test was conducted to evaluate the effect of the rejuvenators on the viscoelastic properties of the asphalt binder. The test was conducted on samples of asphalt binder that were extracted and recovered from the APA specimens. The binder specimens were aged at $325^{\circ} \mathrm{F}$ in the Rolling Thin-Film Oven (RTFO) (AASHTO 2009g) prior to testing.

\section{Laboratory test results}

\section{Rejuvenator evaluation}

Compaction

The number of gyrations required to compact to 7 percent voids was recorded for each specimen, and the data are summarized in Table 5. 
Table 5. Compaction data.

\begin{tabular}{|l|l|l|l|}
\hline \multirow{4}{*}{ Rejuvenator } & Dosage & $\begin{array}{l}\text { Avg. Air Voids } \\
\text { (percent) }\end{array}$ & $\begin{array}{l}\text { Avg. No. } \\
\text { Gyrations }\end{array}$ \\
\hline \multirow{4}{*}{ Rejuvaseal } & 0.25 & 7.1 & 90 \\
\cline { 2 - 4 } & 0.50 & 7.4 & 67 \\
\cline { 2 - 4 } & 1.00 & 7.0 & 24 \\
\cline { 2 - 4 } & 1.50 & 6.7 & 15 \\
\hline \multirow{5}{*}{ Viplex 50 } & 0.50 & 6.9 & 105 \\
\cline { 2 - 4 } & 0.70 & 6.7 & 112 \\
\cline { 2 - 4 } & 1.00 & 6.7 & 66 \\
\cline { 2 - 4 } & 1.25 & 6.8 & 50 \\
\hline \multirow{5}{*}{ Crclogen LE } & 1.00 & 7.0 & 111 \\
\cline { 2 - 4 } & 1.50 & 7.0 & 73 \\
\cline { 2 - 4 } & 2.00 & 7.0 & 70 \\
\cline { 2 - 4 } & 2.50 & 6.9 & 42 \\
\hline \multirow{5}{*}{} & 1.50 & 6.9 & 168 \\
\cline { 2 - 4 } & 2.00 & 7.1 & 68 \\
\cline { 2 - 4 } & 2.50 & 7.0 & 66 \\
\cline { 2 - 4 } & 3.00 & 7.0 & 39 \\
\hline
\end{tabular}

a Percent by weight of total mix

These data were plotted to compare the required number of gyrations to compact to 7 percent air voids at each rejuvenator dosage rate for all recycled mixes. The plot is presented in Figure 9. Trend lines were used to model the compaction behavior of each mix.

All of the curves show that higher rejuvenator dosages required fewer gyrations to achieve 7 percent air voids. This shows the ability of all tested rejuvenators to aid in compaction by softening the binder and flowing with it during compaction. However, not all rejuvenators exhibited the same behavior; certain types reacted more dramatically to slight dosage changes than others. Higher percentages of Cyclogen LE and CRF were required to achieve compaction at a reasonable number of gyrations compared to Rejuvaseal and Viplex 50. This could be due to the fact that Cyclogen LE and $\mathrm{CRF}$ are water-based emulsions (typically designed for cold recycling), and they were mixed with water (1:1), while the other two rejuvenators were added without dilution. The amount of water added was reflected in 
the percentage of rejuvenator added by total weight of mix. Therefore, the presence of actual rejuvenator in the mix was reduced by 50 percent, and higher percentages of $\mathrm{CRF}$ and Cyclogen were required to achieve the same amount of compaction achieved using the pure RejuvaSeal.

Figure 9. Compaction data.

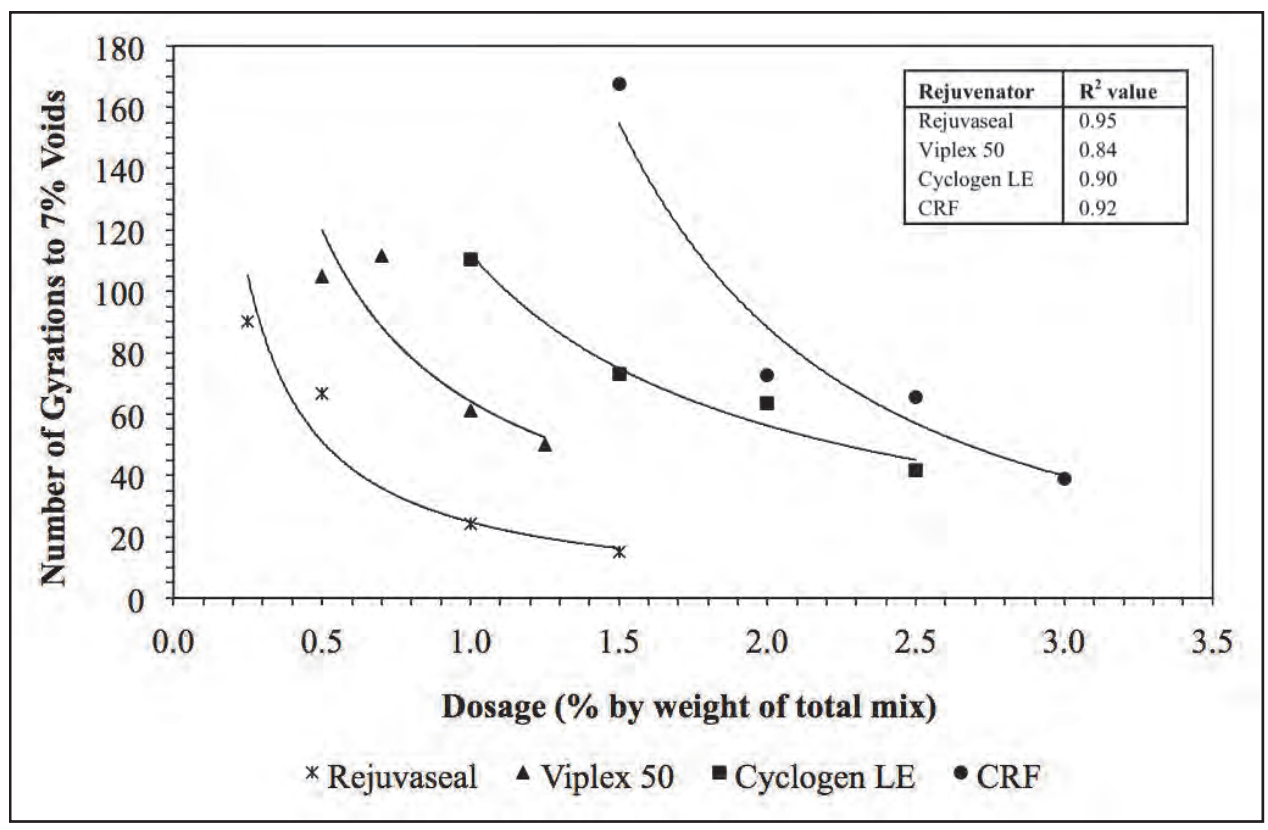

Rutting potential

Test data from the APA are listed in Table 6. The average maximum rut depth for each of the recycled mixes was determined and is presented in Figure 10. Six-in.-diam by 4- to 6-in.-thick core samples were obtained from the Vicksburg Municipal Airport test site. These core samples were trimmed down to a height of 3 in., and APA testing was conducted on the uncut face of the cores. The test results were used to represent the rutting behavior of the existing asphalt pavement material without rejuvenator. These results are presented in Figure 10 as "RAP".

For the Viplex 50 and Rejuvaseal mixes, the rut depth data from the APA test were extrapolated. During the test, one of the depth measurements in some of the specimens exceeded the termination rut depth. Therefore, data collection was stopped in that measurement point while testing continued. These tests could not be repeated due to a lack of RAP material. However, the data were extrapolated using trend lines with good R-squared values, and the maximum rut depth for those mixes was estimated. 
Table 6. APA test results.

\begin{tabular}{|c|c|c|c|}
\hline Rejuvenator & Dosage & $\begin{array}{l}\text { Average } \\
\text { Air Voids (percent) }\end{array}$ & $\begin{array}{l}\text { Average Maximum } \\
\text { Rut Depth at } 8,000 \text { cycles (in.) }\end{array}$ \\
\hline RAP & 0.00 & 5.4 & 0.05 \\
\hline \multirow{4}{*}{ Rejuvaseal } & 0.25 & 7.1 & 0.20 \\
\hline & 0.50 & 7.4 & 0.33 \\
\hline & 1.00 & 7.0 & 0.67 \\
\hline & 1.50 & 6.7 & 1.40 \\
\hline \multirow{4}{*}{ Viplex 50} & 0.50 & 6.9 & 0.27 \\
\hline & 0.70 & 6.7 & 0.36 \\
\hline & 1.00 & 6.8 & 0.61 \\
\hline & 1.25 & 6.8 & 0.70 \\
\hline \multirow{4}{*}{ Cyclogen LE } & 1.00 & 7.0 & 0.21 \\
\hline & 1.50 & 7.0 & 0.23 \\
\hline & 2.00 & 7.0 & 0.33 \\
\hline & 2.50 & 6.9 & 0.39 \\
\hline \multirow{4}{*}{ CRF } & 1.50 & 6.9 & 0.17 \\
\hline & 2.00 & 7.1 & 0.22 \\
\hline & 2.50 & 7.0 & 0.21 \\
\hline & 3.00 & 7.0 & 0.29 \\
\hline
\end{tabular}

a Percent by weight of total mix

Figure 10. Maximum rut depth for all mixes tested.

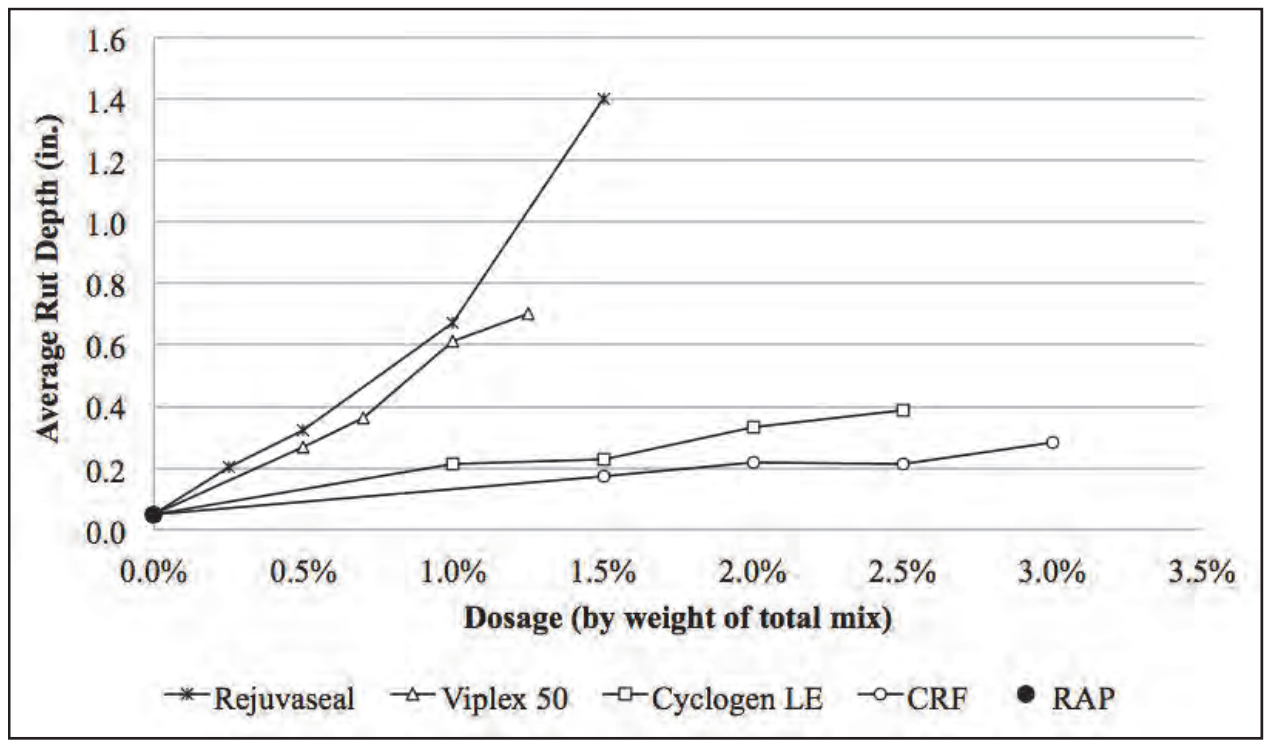


Rut depth results showed an increase in rutting as the rejuvenator dosage was increased for all four rejuvenators. A small change in dosage of the oil base and coal tar-based products tended to rejuvenate the RAP mix to a point where it rutted excessively compared to the two water-based products. Based on their consistent lower rut depths at different rejuvenator dosages compared to the other products, the top performing rejuvenators among those tested were Cyclogen LE and CRF.

\section{Binder properties}

Results from the DSR testing are summarized in Figures 11 and 12 . The failure temperatures are displayed for $\mathrm{CRF}$ and Cyclogen $\mathrm{LE}$ (LE) specimens in Figure 11 and for Rejuvaseal (R) and Viplex 50 (V) specimens in Figure 12. "Original" refers to binder extracted from pavement at the test location. The Superpave binder specification for original binder $(1.0 \mathrm{kPa}$ minimum) was used to calculate the failure temperatures. Higher failure temperatures indicate stiffer binder. As shown, the failure temperatures generally decreased slightly as the rejuvenator content increased for CRF and Cyclogen. The Viplex specimens appeared to soften the binder more so than $\mathrm{CRF}$ and Cyclogen as the dosage rate increased. Insufficient binder was available to continue testing Rejuvaseal at temperatures above $88^{\circ} \mathrm{F}$. However, complex modulus values at $88^{\circ} \mathrm{F}$ were $5.99,3.09,1.70$, and $1.05 \mathrm{kPa}$ for $0.25,0.50,1.0$, and 1.25 percent Rejuvaseal content, respectively. These results indicate a softening of the rejuvenated binder as the Rejuvaseal content increased. As discussed in the previous section, rutting potential appeared to increase as the rejuvenator dosage rate increased. Therefore, an optimum dosage rate should be selected so that the recycled material is rejuvenated just enough to soften the binder, but without increasing the rutting potential.

These results were used during the down selection process of the top performing rejuvenator and its optimum dosage rate to be used in the field tests. A more complete analysis of the effects of the whole recycling process on the PG grade of the asphalt cement is discussed in Chapter 5.

Selection of rejuvenator optimum dosage rate

The laboratory data were combined and analyzed to compare the performance of the recycled mixes in different types of tests in order to select the optimum dosage rate to be used for the cement trials and the field tests. 
Figure 11. Binder failure temperatures - CRF and Cyclogen.

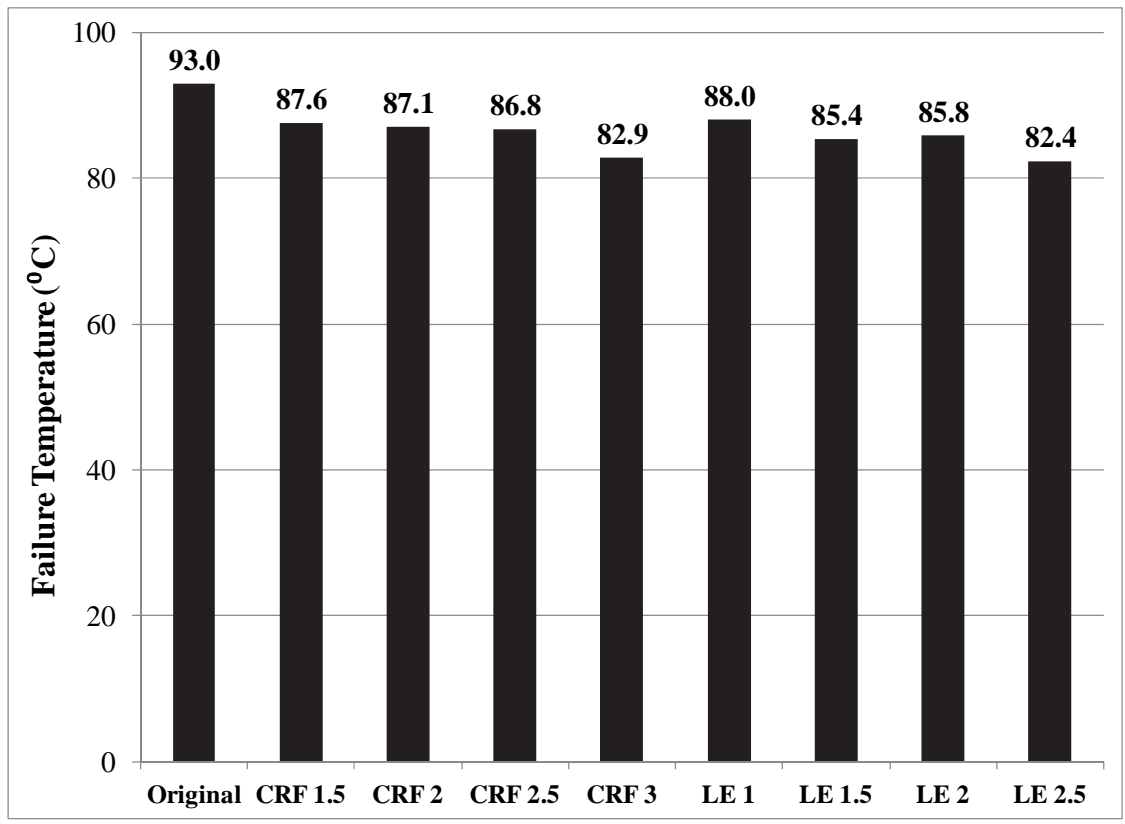

Figure 12. Binder failure temperatures - Viplex and Rejuvaseal.

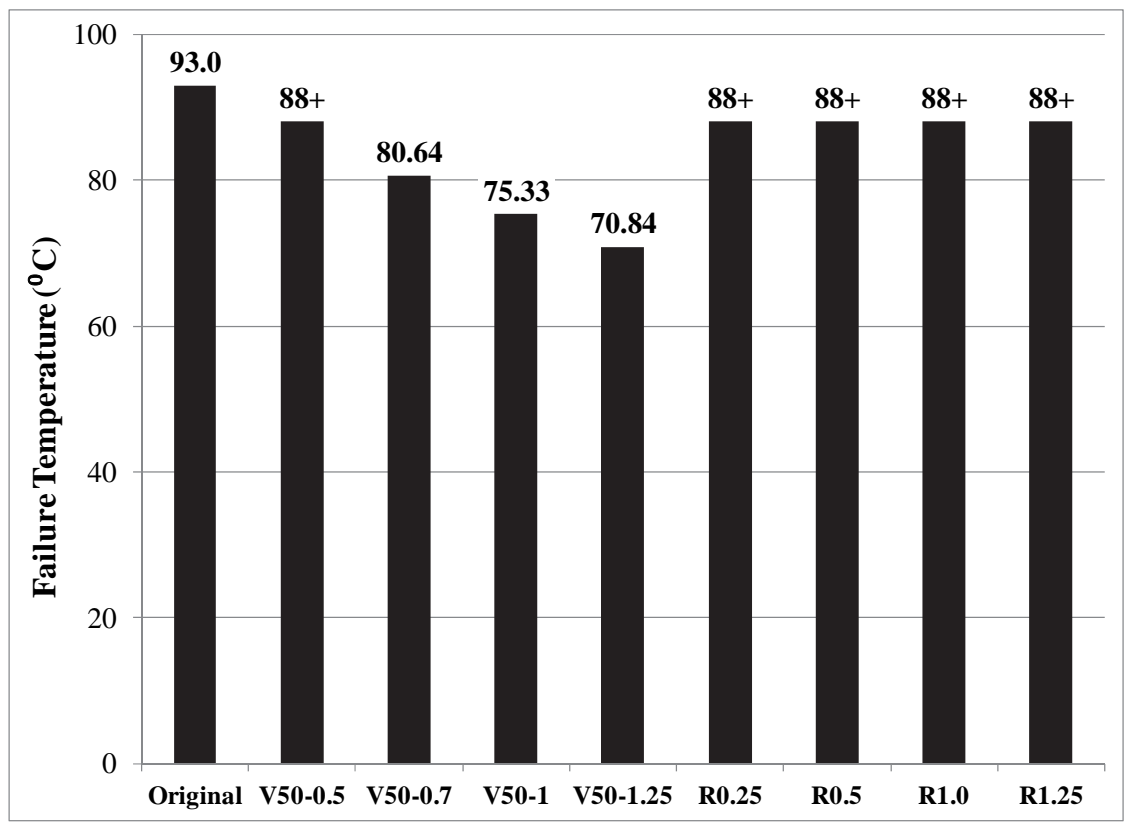

Compaction and rutting data were first combined in the plots shown in Figures 13 through 15. The compaction and rutting behaviors of the mixes were linear with opposite slopes. The lines intersected at a point where mix compaction was easy, but rutting was not excessive. The DSR and APA data were combined in the plots shown in Figures 16 through 20. Again, both behaviors were linear with opposite slopes, which intersected at a point where the mixes were rejuvenated enough so that they did not show 
excessive rutting potential. The optimum dosage rates were selected by averaging the two data points obtained from these plots for each product and rounding down to the next half percent.

Table 7 lists the optimum dosage rates selected for each product based on this analysis.

Figure 13. APA and compaction data for the Rejuvaseal recycled mix.

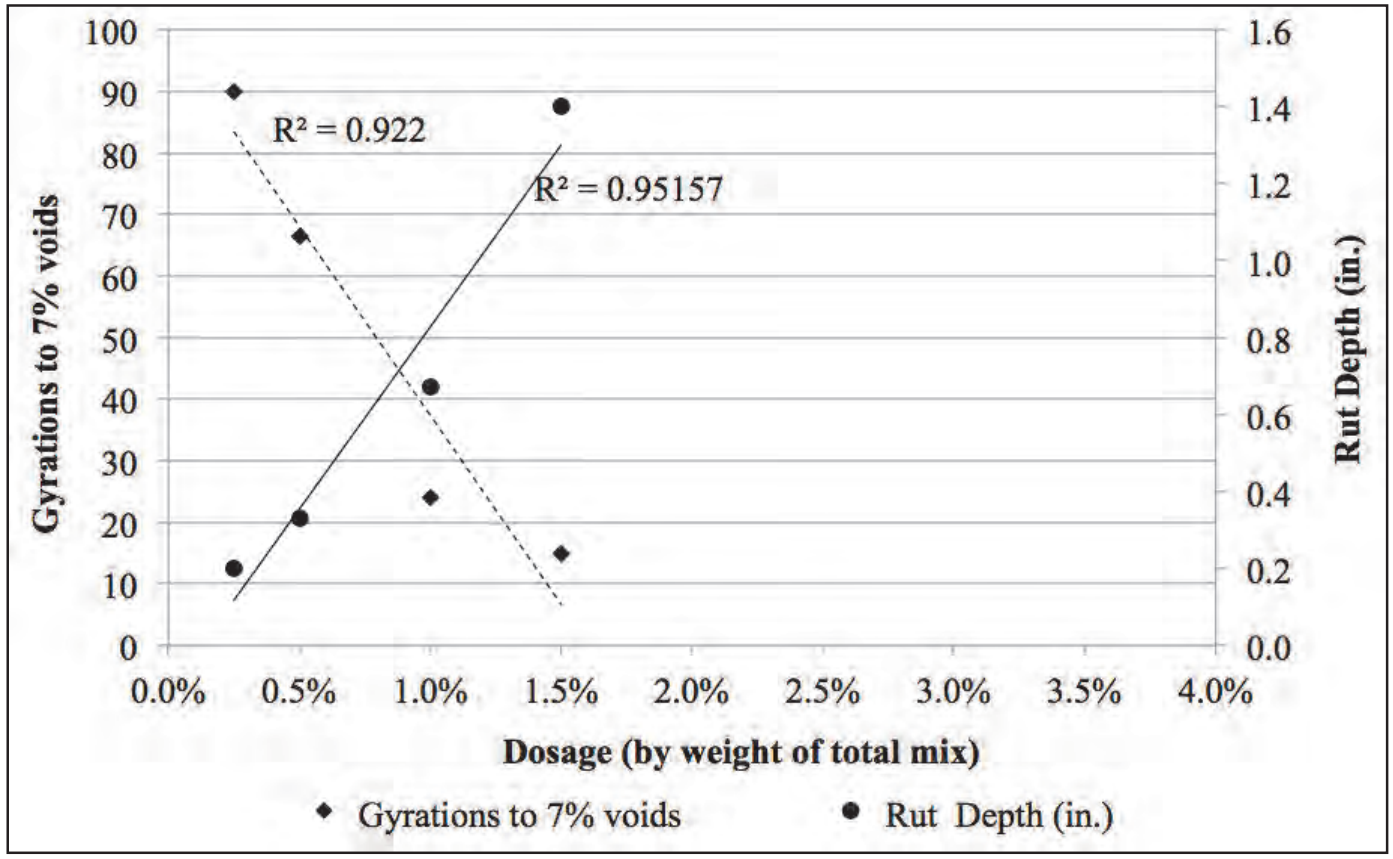

Figure 14. APA and compaction data for the Viplex 50 recycled mix.

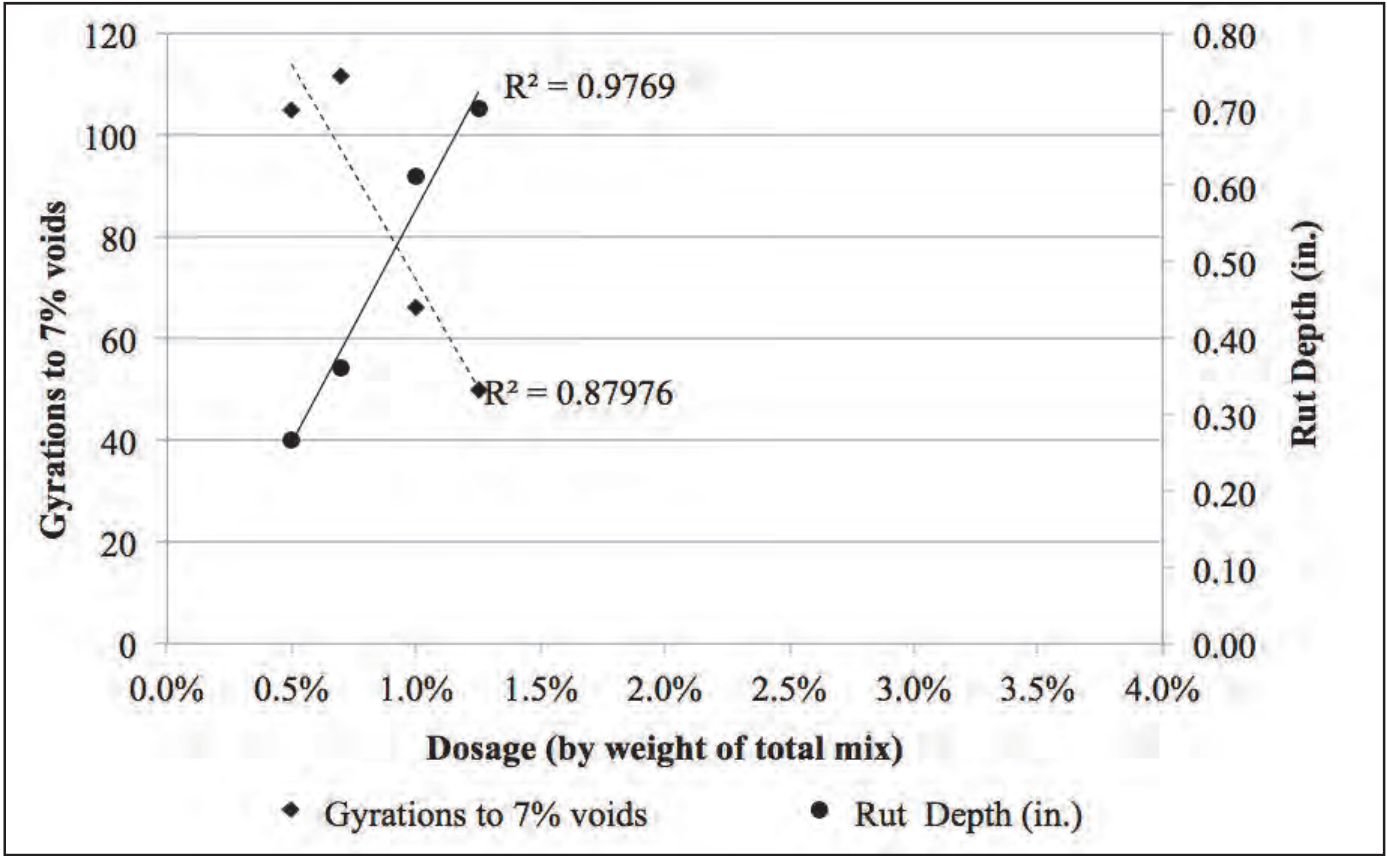


Figure 15. APA and compaction data for the Cyclogen recycled mix.

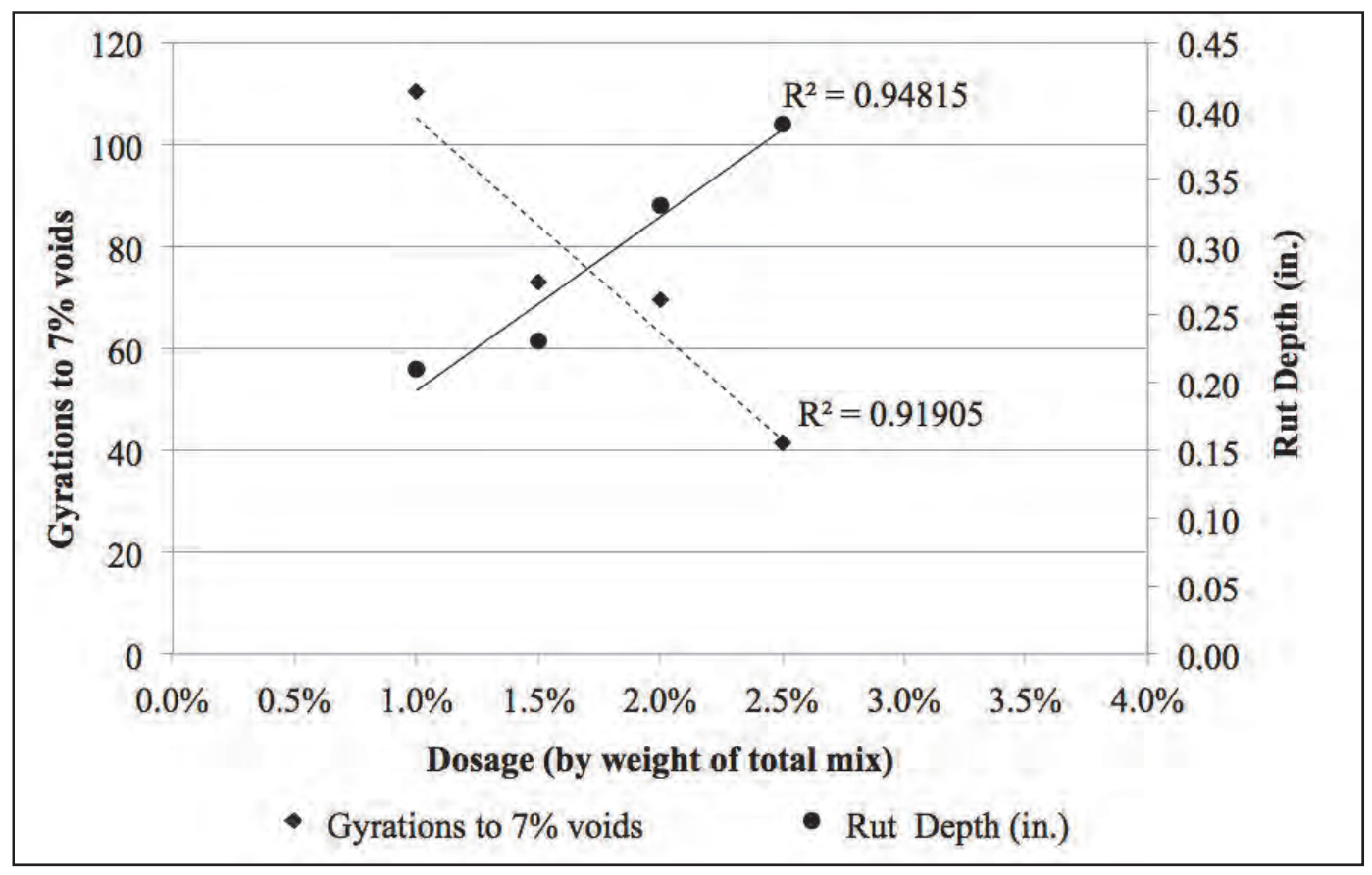

Figure 16. APA and compaction data for the CRF recycled mix.

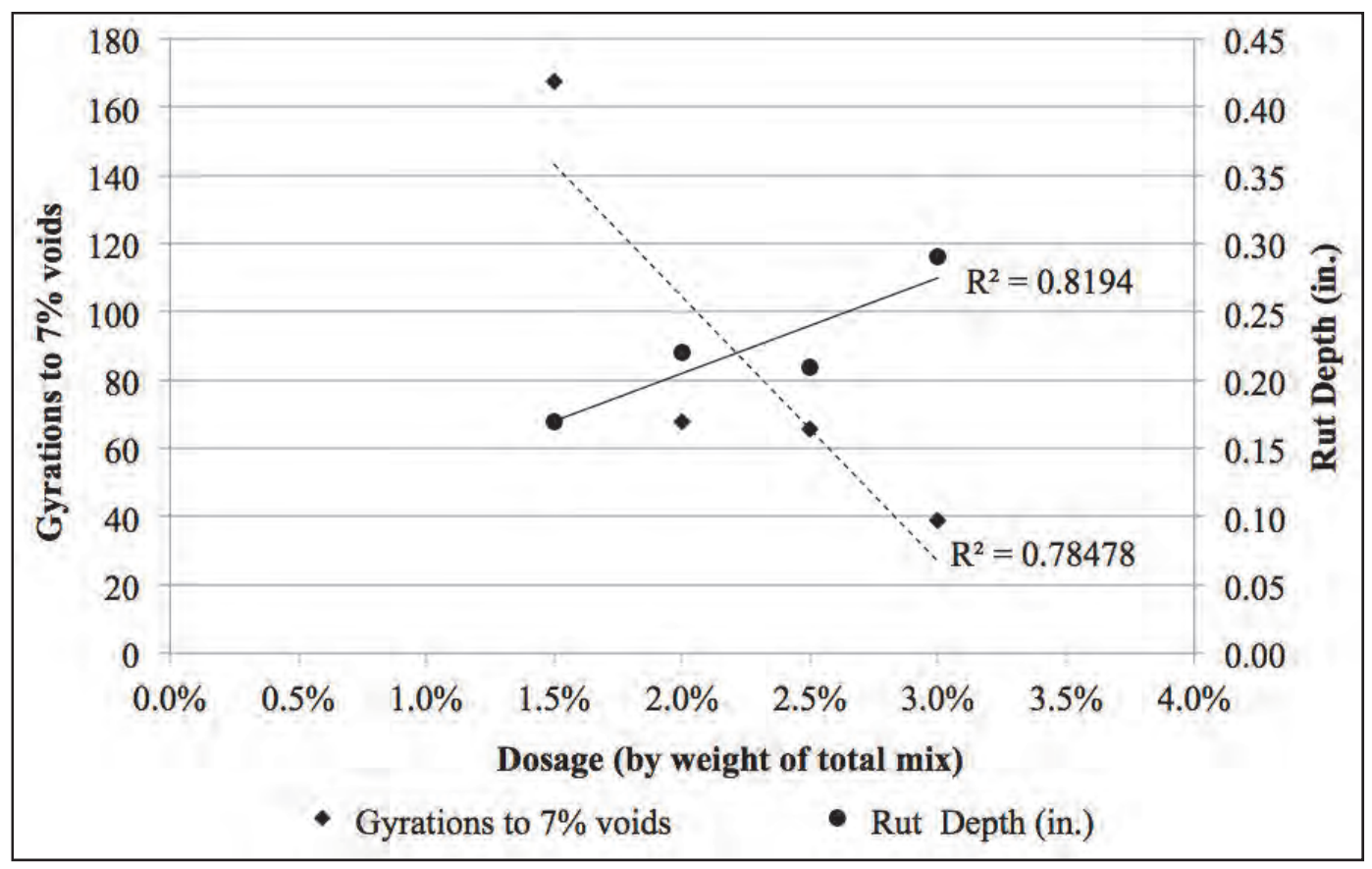


Figure 17. APA and DSR data for the Rejuvaseal recycled mix.

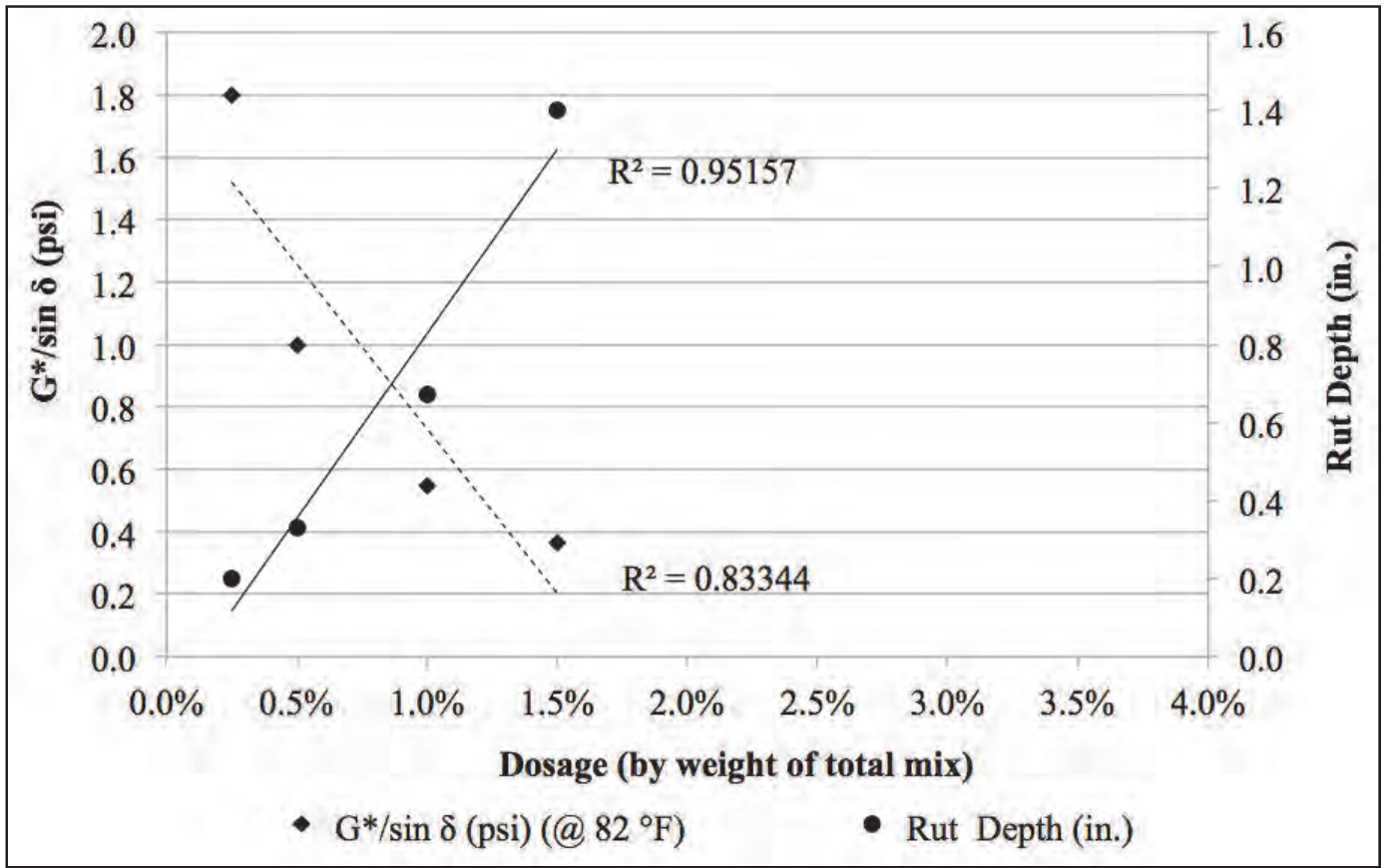

Figure 18. APA and DSR data for the Viplex 50 recycled mix.

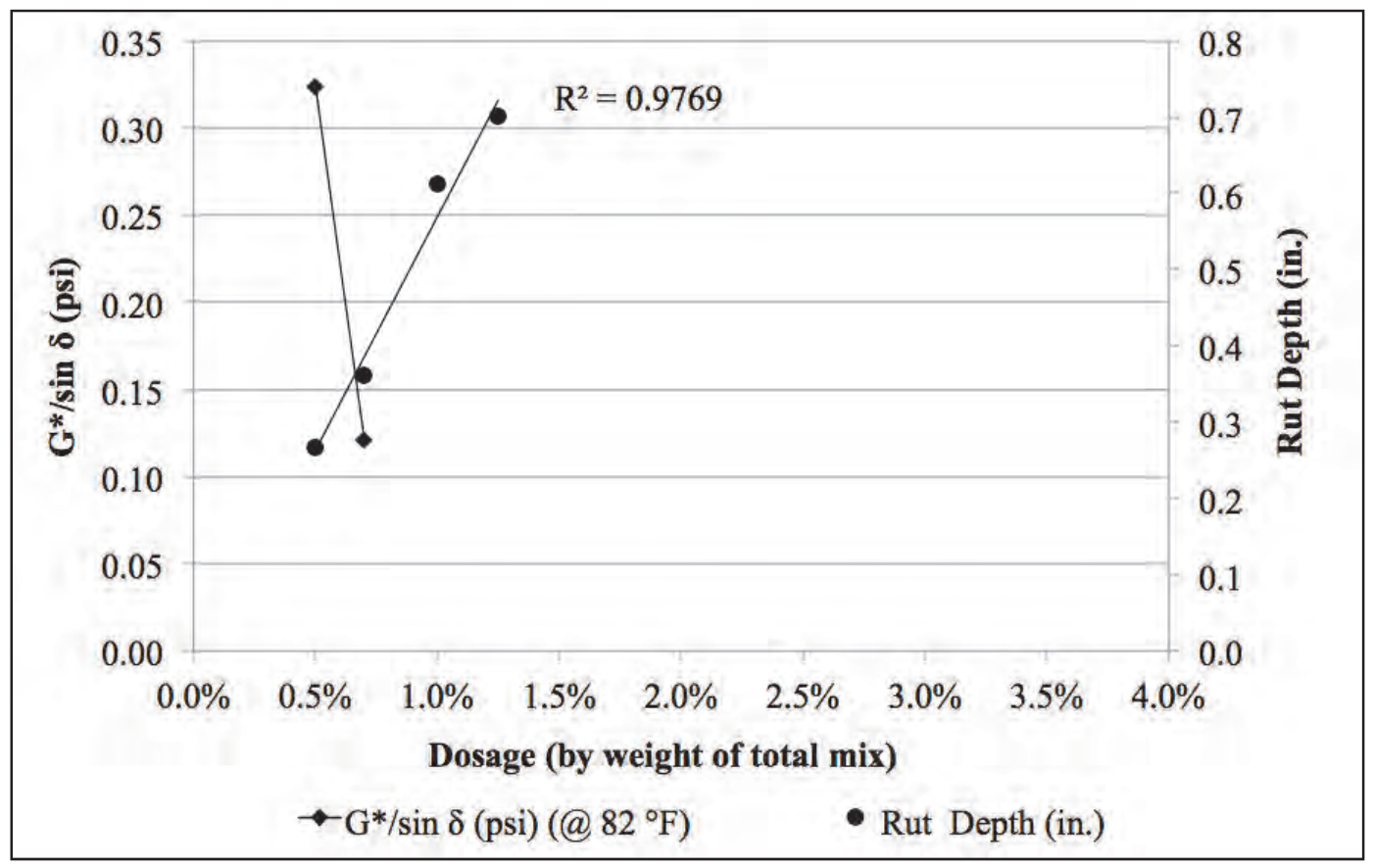


Figure 19. APA and DSR data for the Cyclogen recycled mix.

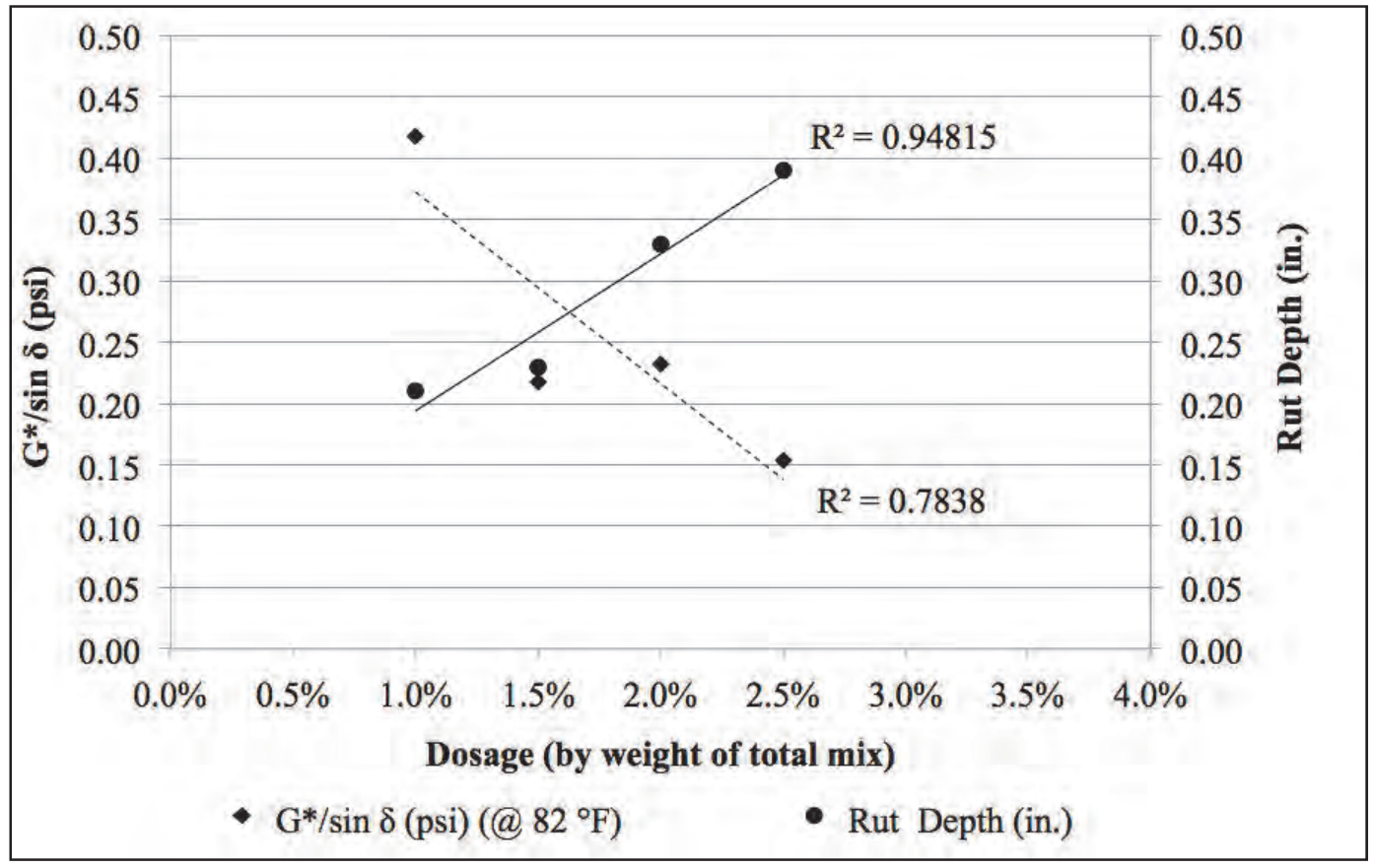

Figure 20. APA and DSR data for the CRF recycled mix.

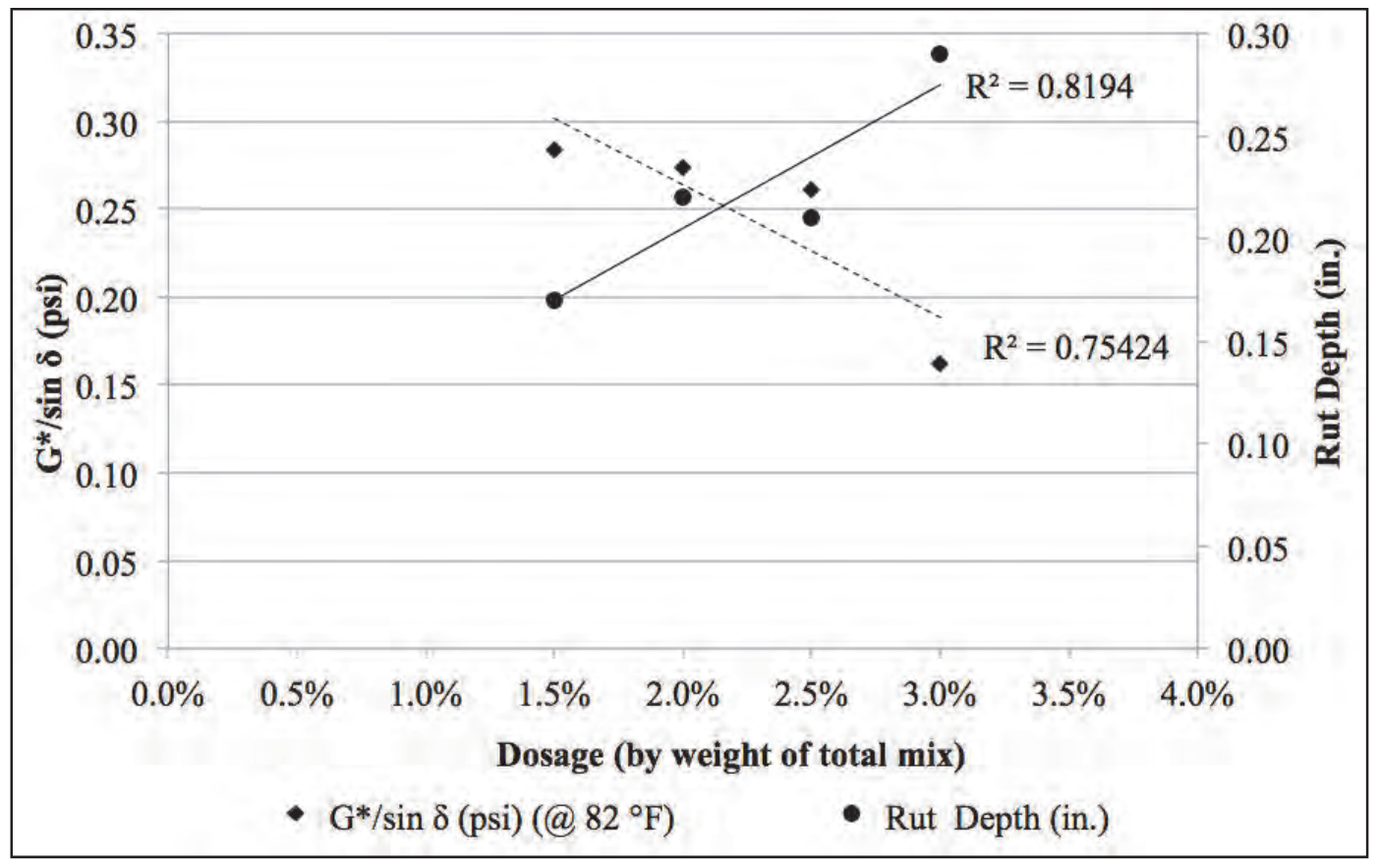


Table 7. Optimum dosage rates selected for each rejuvenator.

\begin{tabular}{|l|l|}
\hline Rejuvenator & Dosage $^{a}$ \\
\hline Rejuvaseal & 0.5 \\
\hline Viplex 50 & 0.5 \\
\hline Cyclogen LE & 1.5 \\
\hline CRF & 2.0 \\
\hline
\end{tabular}

a percent by weight of total mix

\section{Cement stabilization evaluation}

The concept of adding Type I Portland cement in combination with a rejuvenator to stiffen the asphalt mixture while still allowing for rejuvenation was explored in the laboratory before field trials. The APA was used to test three of the rejuvenators (Rejuvaseal, Cyclogen, and CRF) at a cement content of 1.5 percent by total weight of the RAP mixture to determine if the addition of cement was able to decrease rutting potential for any of the three rejuvenators. The rejuvenator dosage rate used was the optimum dosage rate as previously determined. After preliminary testing using both cement and a rejuvenator together, it was observed that the specimens required much less compactive effort to reach the APA target of 7.0 percent air voids. In order to more adequately represent a field scenario, the average number of gyrations used to compact specimens with rejuvenator only was used to compact specimens with both rejuvenator and cement. For example, all specimens dosed with Rejuvaseal and cement were compacted with 67 gyrations, which is the average number of gyrations used to compact specimens dosed with 0.5 percent Rejuvaseal only.

Table 8 displays the APA maximum rut depths and the average air voids obtained. Cyclogen and CRF exhibited an increase in rutting potential due to the addition of cement. In contrast, Rejuvaseal, a coal tar based product, appeared to benefit from cement addition. Based on these results, further testing at additional cement contents was performed only with Rejuvaseal, as shown in Table 8 and in Figure 21. At cement contents above 1 percent, rutting potential appeared to be similar to the results observed at 1 percent. Since there appeared to be no considerable advantage to be gained by adding additional cement, a cement content of 1 percent with 0.5 percent Rejuvaseal was selected to use for field testing. 
Table 8. APA rut data for cement-rejuvenator combinations

\begin{tabular}{|l|l|l|l|}
\hline \multirow{2}{*}{ Rejuvenator } & Cement Dosage $^{\mathrm{a}}$ & $\begin{array}{l}\text { Average Air Voids } \\
\text { (percent) }\end{array}$ & $\begin{array}{l}\text { Max. Rut Depth } \\
\text { (in) }\end{array}$ \\
\hline \multirow{2}{*}{ Cyclogen (1.5 percent) } & 0 & 7.0 & 0.23 \\
\cline { 2 - 4 } & 1.5 & 6.3 & 0.44 \\
\hline \multirow{3}{*}{ CRF (2.0 percent) } & 0 & 7.1 & 0.22 \\
\hline \multirow{5}{*}{ Rejuvaseal (0.5 percent) } & 1.5 & 6.4 & 0.34 \\
\cline { 2 - 4 } & 0 & 7.4 & 0.33 \\
\cline { 2 - 4 } & 1.5 & 6.0 & 0.22 \\
\cline { 2 - 4 } & 1.0 & 7.0 & 0.23 \\
\cline { 2 - 4 } & 2.0 & 6.7 & 0.24 \\
\cline { 2 - 4 } & & 6.5 & 0.25 \\
\cline { 2 - 4 } & 2.5 & 5.8 & 0.25 \\
\hline
\end{tabular}

a Percent by weight of total RAP

Figure 21. APA average rut depth of rejuvenated RAP (with 0.5 percent RejuvaSeal) and different dosages of Type I Portland cement.

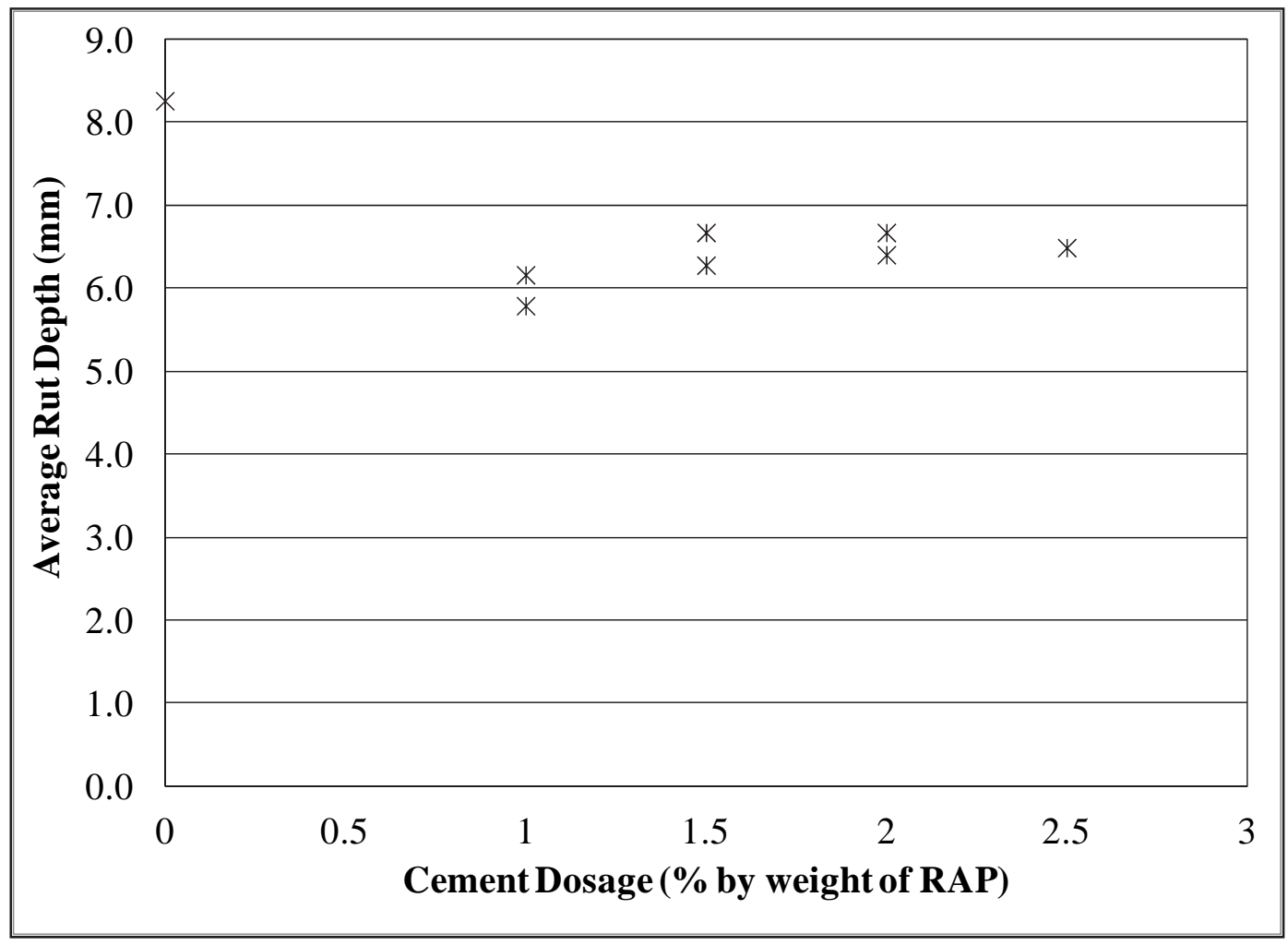




\section{Summary}

The main purpose of the laboratory component of this study was to evaluate different rejuvenators at different dosage rates and cement stabilization to determine the best combination to be used in the field tests. From this part of the evaluation, one rejuvenator was selected at an optimal dosage to be used as the control mix during field trials. A different rejuvenator and dosage were selected for the cement-based field trials. Based on the APA and DSR results, CRF at a dosage of 2.0 percent was selected for field tests, because it successfully rejuvenated the RAP while minimizing rutting potential. The laboratory tests with cement added resulted in the selection of a combination of Rejuvaseal at 0.5 percent and Type I Portland cement at 1.0 percent by weight, respectively, for field tests. 


\section{Part II: Field trials}

\section{Overview}

In Part II of this study, a series of field trials were performed to determine the most effective overall method for asphalt rejuvenation with respect to the following requirements:

- minimal equipment footprint for military air transportability,

- minimal airfield downtime during repairs, and

- minimal rutting under repeated F-15E aircraft loading.

The approach used for Part II of this study is presented in Figure 22.

Figure 22. Field evaluation approach.

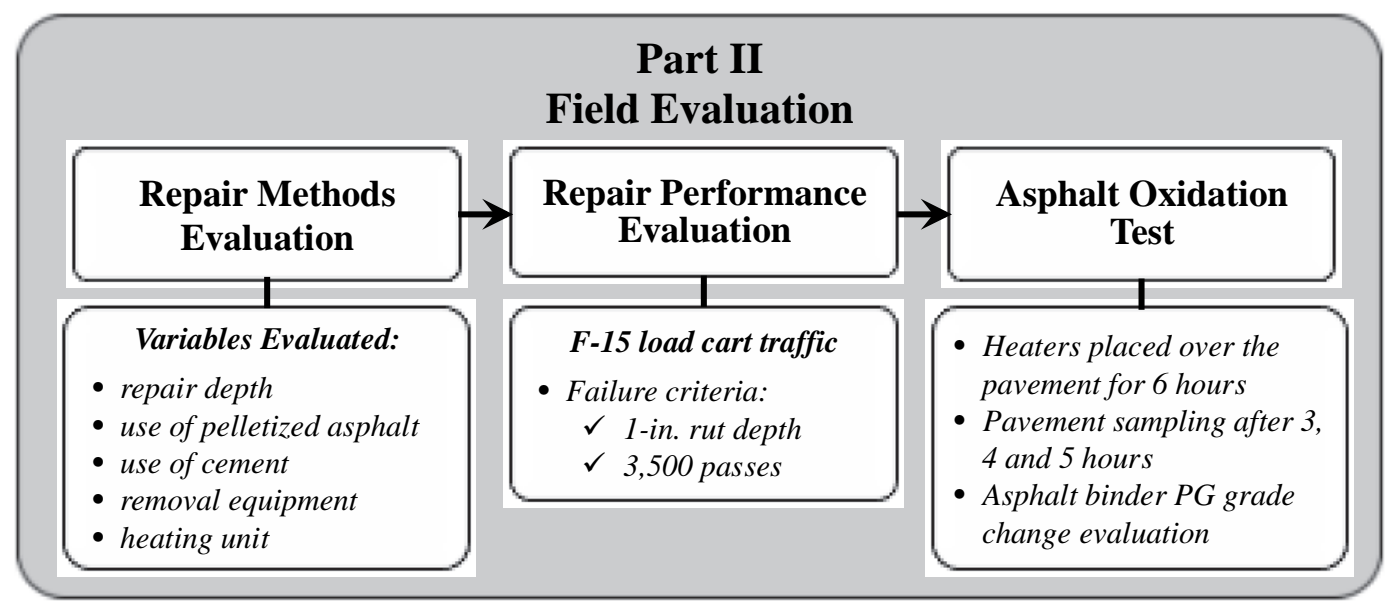

The variables investigated during the evaluation of repair methods were: repair depth, use of pelletized asphalt versus RAP, use of cement, removal equipment, the overall efficiency of each heater unit including the ability to maintain stockpile temperatures over time, and asphalt oxidation potential. The additives and optimum dosage rates were those selected in Part I. Repairs were heated using one of two tested heating systems: a $43 \mathrm{Btu} / \mathrm{s}$ electric unit and a liquid propane-based unit. Repair times were monitored to determine the different repair durations.

Repair test areas for all field trials were nominally 4-ft-wide by 6-ft-long. Both full and partial-depth repairs were performed; partial-depth repairs 
were excavated to a depth of 2 to $2.5 \mathrm{in}$. and full-depth repairs were excavated to depths of 4 to $5.5 \mathrm{in}$.

During the repair performance evaluation, the repairs were trafficked with an F-15E load cart until failure (1-in. rut depth) was reached. The repair success was evaluated using the US Air Force (USAF) requirement for sustainment repairs on airfields of 3,500 passes of simulated F-15E aircraft load.

The asphalt oxidation test was conducted to determine the feasibility of prematurely oxidizing a newer pavement using an infrared heater in order to gain additional stiffness. The testing procedures used for the oxidation tests as well as the test results are discussed in Chapter 5 of this report.

\section{Site location and existing conditions}

Various test sites were visited to evaluate their feasibility for conducting this study. The criteria used were proximity to ERDC for easy mobilization of testing equipment and degraded pavement surface condition requiring maintenance and repair. The two locations selected for testing were:

- Test Site 1: Vicksburg Municipal Airport, Vicksburg, MS

- Test Site 2: Poorhouse Property, ERDC Vicksburg, MS

Test Site 1 represented a pavement with poor surface conditions. This test site was used to evaluate the equipment, materials, and procedures for inplace asphalt recycling in terms of the efficiency of all these components to reduce not only the repair logistics and equipment footprint, but also airfield downtime during repairs. The pavement structure in Test Site 1 was not designed for heavy aircraft loading. Therefore, a second test site with a pavement structure capable of withstanding heavy military aircraft loading was selected to conduct the repair performance evaluation under F-15 load cart trafficking.

\section{Test Site 1: Vicksburg Municipal Airport}

Test Site 1 was located at an abandoned asphalt apron at the Vicksburg Municipal Airport, in Vicksburg, MS. The apron was approximately 40 years old at the time of this study. This test site was used to evaluate the process for in-place asphalt recycling in terms of the efficiency. 
The existing surface was extremely raveled and loose aggregate was abundant as shown in Figure 23. Dynamic cone penetrometer (DCP) tests revealed a weak subgrade layer of material with a California Bearing Ratio (CBR) of 11 (Figure 24). An initial core investigation of the site identified varying pavement thicknesses from 4 to 6 in., but later the original pavement was determined to be 4 -in. thick, later covered with a 2-in. overlay that was now partially de-bonded. The base course consisted of a compacted, unstabilized layer of clay gravel with a CBR of 35, and the subgrade consisted of a silt with a CBR of 11.

The strength of the subgrade was evaluated using a falling-weight deflectometer (FWD). The data from this test were used to back-calculate the subgrade modulus. The back-calculation produced a subgrade modulus ( $\left.E_{\text {subgrade }}\right)$ value of $11,000 \mathrm{psi}$. This value was used in an $\mathrm{E}_{n+1}$ analysis (UFC 3-260-03) to calculate the modulus of the base. A modulus ( $E_{\text {base }}$ ) of 20,000 psi was obtained from this analysis. These two modulus values and an assumed asphalt modulus ( $\mathrm{E}_{\mathrm{AC}}$ ) of 400,000 psi were used to predict the passes to failure using the Layered Elastic Evaluation Procedure (LEEP). The results from this analysis are listed in Table 9.

Figure 23. Existing surface conditions at Test Site 1.

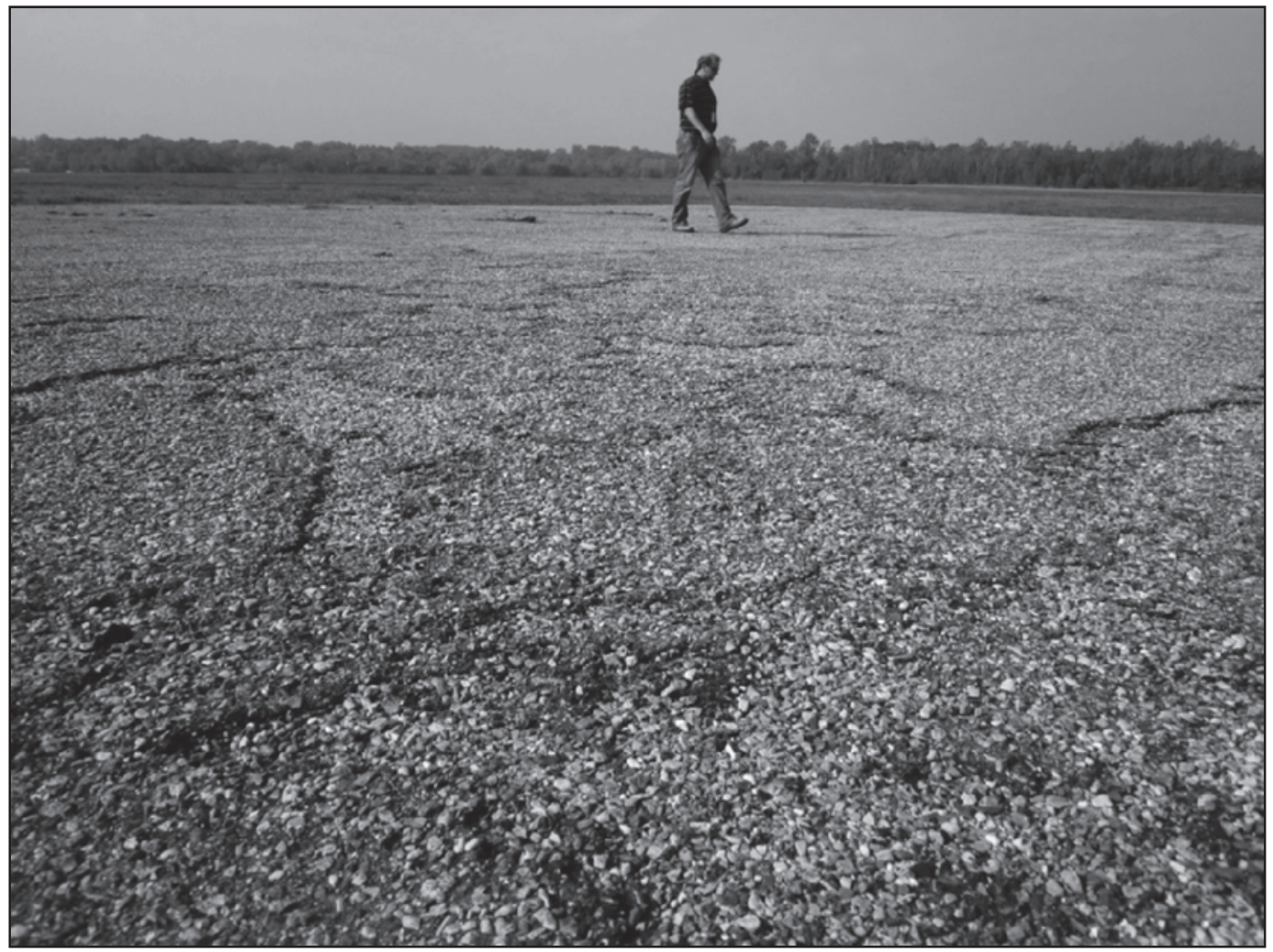


Figure 24. Pavement structure at Test Site 1.

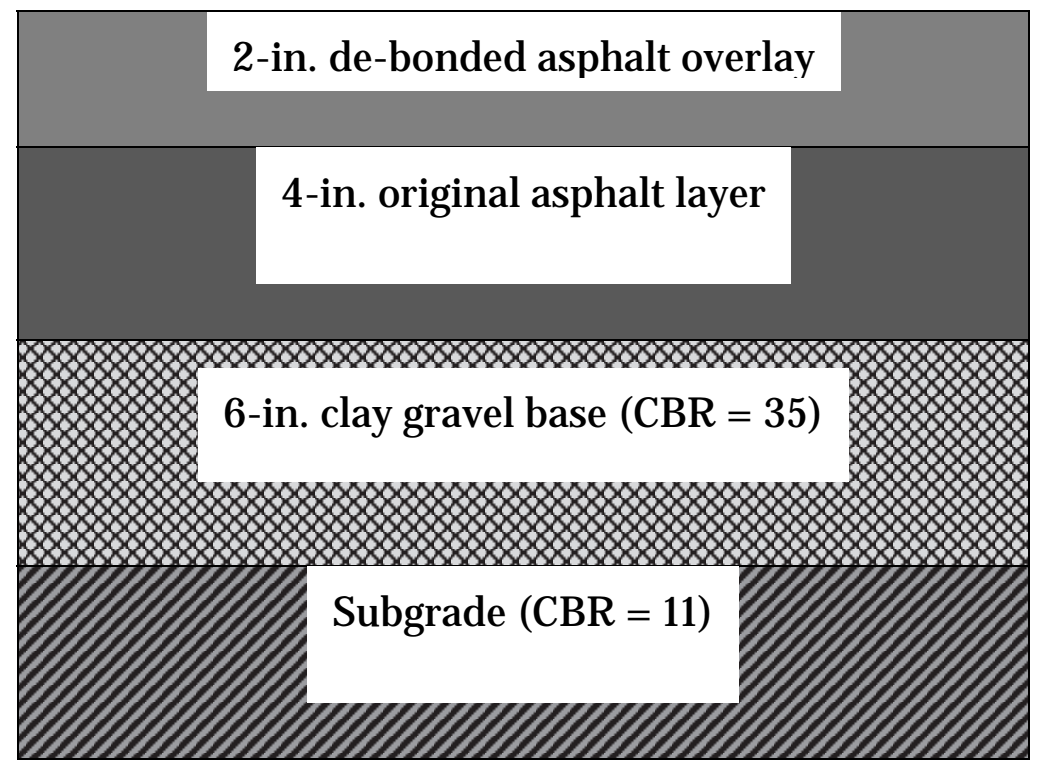

Table 9. Results from pavement failure prediction analyses for the Vicksburg Municipal Airport test site.

\begin{tabular}{|l|l|l|}
\hline Analysis & Parameter Used & $\begin{array}{l}\text { Predicted } \\
\text { Passes to Failure }\end{array}$ \\
\hline Layer Elastic Procedure & $\begin{array}{l}\text { 6-in. AC, EAC }=400,000 \mathrm{psi} \\
\text { 6-in. Base, Ebase }=20,000 \mathrm{psi} \\
\text { Subgrade, Esubgrade }=11,000 \mathrm{psi}\end{array}$ & 26 \\
\hline $\begin{array}{l}\text { CBR Beta Procedure } \\
\text { Pseudo Pavement } \\
\text { (subgrade data from FWD) }\end{array}$ & $\begin{array}{l}\text { 3-in. AC } \\
\text { 3.45-in. Base } \\
\text { 6-in. Subbase } \\
\text { Subgrade, CBR }=\text { Esubgrade } / 1500=7\end{array}$ & 24 \\
\hline $\begin{array}{l}\text { CBR Beta Procedure } \\
\text { Pseudo Pavement } \\
\text { (subgrade data from DCP) }\end{array}$ & $\begin{array}{l}\text { 3-in. AC } \\
\text { 3.45-in. Base } \\
\text { 6-in. Subbase } \\
\text { Subgrade, CBR }=11\end{array}$ \\
\hline
\end{tabular}

Failure was also predicted using the CBR-Beta Procedure (UFC 3-260-03), by converting the back-calculated subgrade modulus to CBR and using the Pseudo Pavement method, which converts the existing pavement structure to a typical pavement design that includes base, subbase, and subgrade. Results from this analysis are listed in Table 9. This analysis was also conducted using the CBR values calculated from the DCP data for comparison. The results are also listed in Table 9.

All the analyses were conducted using the F-15E aircraft loading with a gross weight of 35,235 lb and tire pressure of $325 \mathrm{psi}$. Results indicated that the layer that would control failure is the subgrade, due to its low 
strength and that the pavement structure was not originally designed for heavy traffic loads.

\section{Test Site 2: Poorhouse Property, ERDC station}

The Poorhouse Property test site is an area located within ERDC that contains an asphalt test site meeting airfield asphalt mix requirements. The asphalt test pad considered for this study was constructed approximately 4 years prior to this test. It was designed and constructed to support repeated loading by a C-17 Globemaster aircraft. This test site was chosen to evaluate the rutting performance under F-15 load cart traffic of repairs using the repair methods evaluated in Test Site 1 but using two different RAP materials: a RAP material with known properties and rejuvenation response (Vicksburg Airport RAP) and another RAP material of unknown properties (ERDCRAP). The ERDCRAP was used to simulate a situation where no prior laboratory testing had been performed. This scenario would likely be the case in a military theater environment, and it was necessary to determine repair effectiveness and integrity using an unknown, random RAP material. Because all equipment and method evaluations were performed at Test Site 1, it was deemed redundant to repeat this portion of the research. Therefore, only the rejuvenation and cement stabilization methods were evaluated at Test Site 2 .

The existing pavement was excavated from the repair area to a depth of 6 in. All the excavated material was discarded as the RAP materials to be used for the evaluation were brought from another area within ERDC and from Test Site 1. Excavation was performed without heat and using a saw to cut the repair perimeter in advance. Dynamic Cone Penetrometer (DCP) testing was conducted in-situ to evaluate the strength of the pavement foundation layers. The results are shown in Figure 25. Failure was predicted using the CBR-Beta Procedure (UFC 3-260-03), and the base layer controlled it with only 912 passes of the F-15E aircraft with a gross weight of 35,235 lb and tire pressure of 325 psi. Results from this analysis are listed in Table 10.

\section{Repair equipment}

The most common method for the removal of existing asphalt material is through the use of a heating device and/ or a milling head system. Since this experiment was focused on the repair of smaller areas of oxidized asphalt and the preservation of existing aggregate integrity, a milling head was not employed. Rather, the repair area was brought to temperature using one of two evaluated heater systems, and the softened material removed using one of two evaluated excavation methods. 
Figure 25. Pavement structure at ERDC test site.

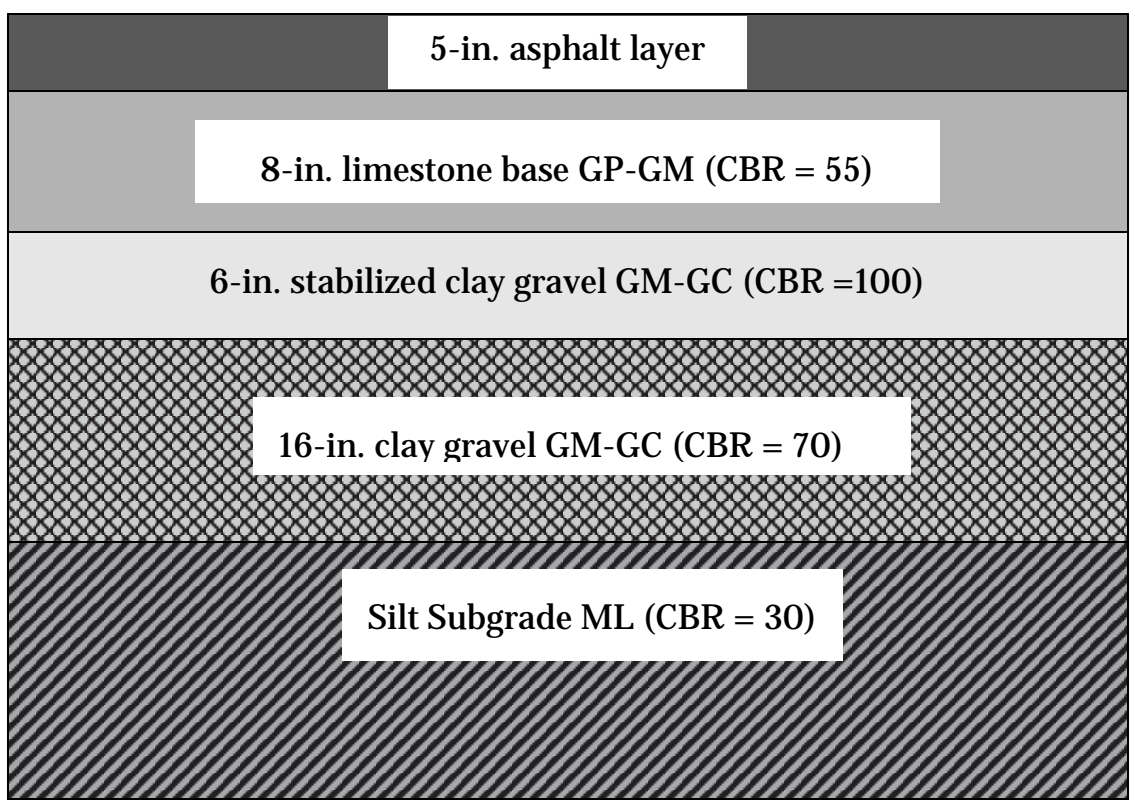

Table 10. Results from pavement failure prediction analyses for ERDC test site.

\begin{tabular}{|l|l|}
\hline Pavement Layer & $\begin{array}{l}\text { Predicted Passes to Failure under } \\
\text { F-15E Aircraft Loading }\end{array}$ \\
\hline Base & 912 \\
\hline Stabilized Subbase & $100,000,000$ \\
\hline Subbase & $100,000,000$ \\
\hline Subgrade & $100,000,000$ \\
\hline
\end{tabular}

The two heaters were selected based on their independent methods for heat production: 1) generator-based electric and 2) liquid propane (LP) based. It must be noted that the USAF mandates that liquid propane shall not be transported on a military aircraft. The liquid propane system was included because of an available technology, which can convert common diesel fuel into synthetic gas or, by using a specific catalyst, into liquid propane. This technology could be applied to the LP heater to prevent the need for LP air transport.

\section{Electric heater}

The electric heater unit used (HWX-30), as shown in Figure 26, is manufactured by Heatwurx, Inc. out of Park City, UT and is driven by an aftermarket $43 \mathrm{Btu} / \mathrm{s}$ diesel generator. The heater is designed as a skid steer loader attachment and weighs approximately 2,200 lb. 
Figure 26. Heatwurx HWX-30 electric heater.

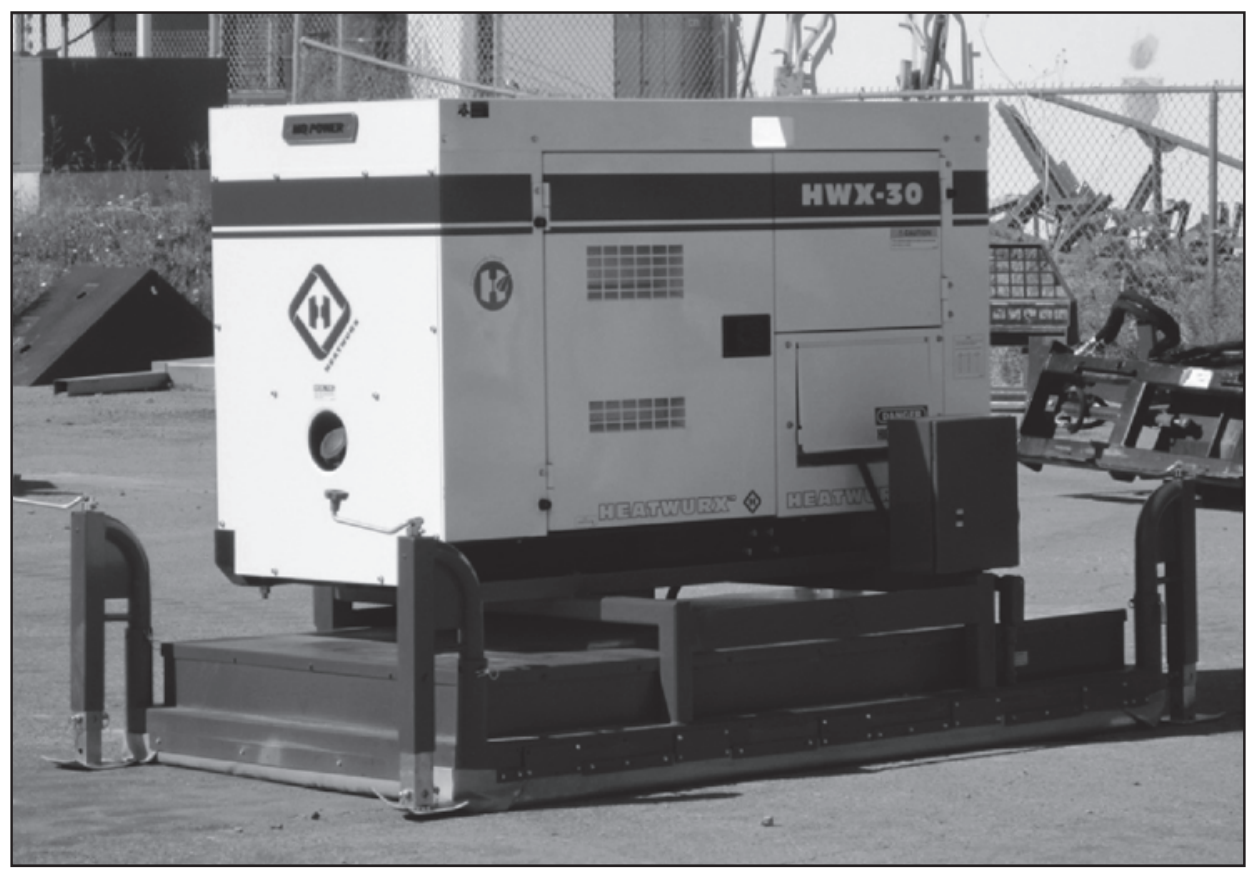

\section{Propane heater}

The propane-based infrared heater unit used was the HDE-1350 (Figure 27), which is manufactured by Heat Design Equipment out of Kitchener, Canada. The heater is skid steer mountable, weighs approximately 2,000 lb, and has approximate overall (folded out) dimensions of $15 \mathrm{ft}$ wide by $6 \mathrm{ft}$ deep by $6 \mathrm{ft}$ high. The standard burner footprint width is expandable from its collapsed configuration of $8 \mathrm{ft}$ to a maximum of $15 \mathrm{ft}$. The additional burner cartridges fold up and out of the way when not in use and can be hydraulically operated by controls within the skid steer. The ceramic fiber burner cartridges are powered by vaporized propane gas.

\section{Skid steer mounted asphalt processor / Screed attachment}

Two excavation methods were evaluated. The first method used a skid steer mounted bucket for heated asphalt removal. This method was cumbersome and slow. It was difficult to maintain a constant depth across the repair, and the material removed was left in large chunks, which caused problems during rejuvenation. The second method evaluated used a skid steer operated asphalt processor unit, which mechanically tills the heated asphalt and reduces it to a gradation that is useable in the rejuvenation process. After several practice repairs using both methods for excavation, the processor was selected for use in the majority of official test repairs. The skid steer-mounted bucket was used for the excavation of only two repairs. 
Figure 27. Heat Design Equipment (HDE-1350) propane heater.

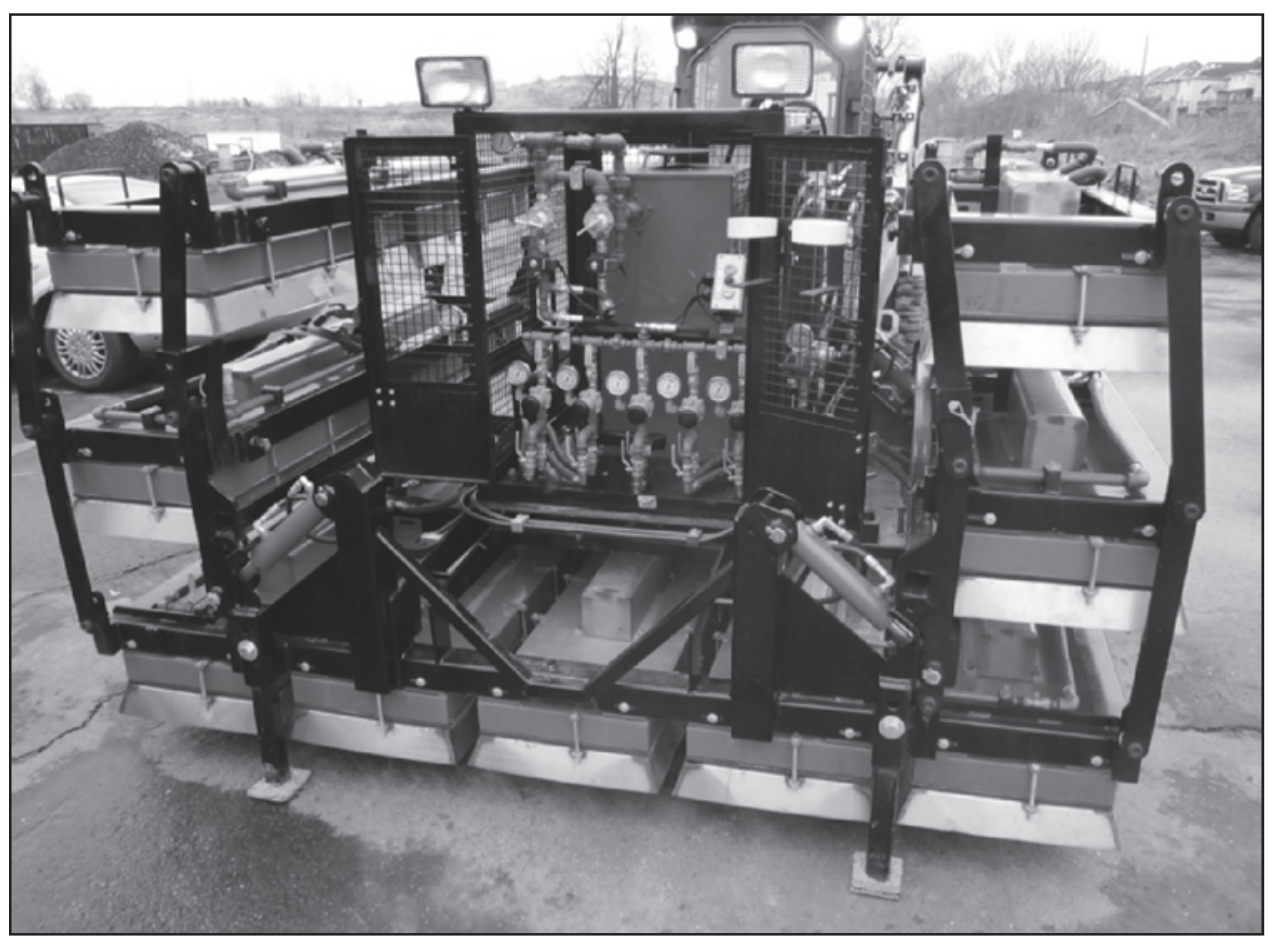

The heated repair area was mechanically tilled to a pre-set depth using the skid steer-mounted asphalt processor as shown in Figure 28a. The asphalt processor was manufactured and provided by Heatwurx, Inc. (model HWXAP40). It doubles as both an asphalt processor mechanism and adjustable asphalt screed. The attachment is powered by the auxiliary hydraulic system on the skid steer unit. The screed option is used by rotating the asphalt processor forward 90 deg as displayed in Figure 28b. Steel shim plates are added or removed to adjust screed distance from the pavement surface.

Figure 28. Asphalt processor.

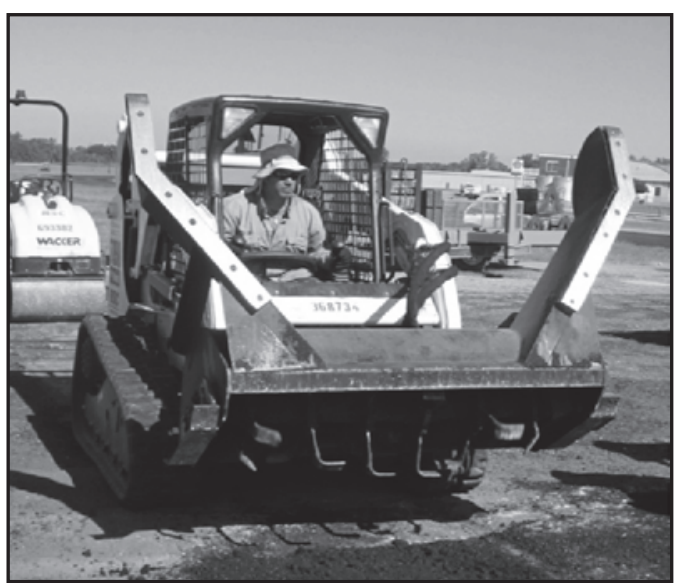

a) Asphalt processor option

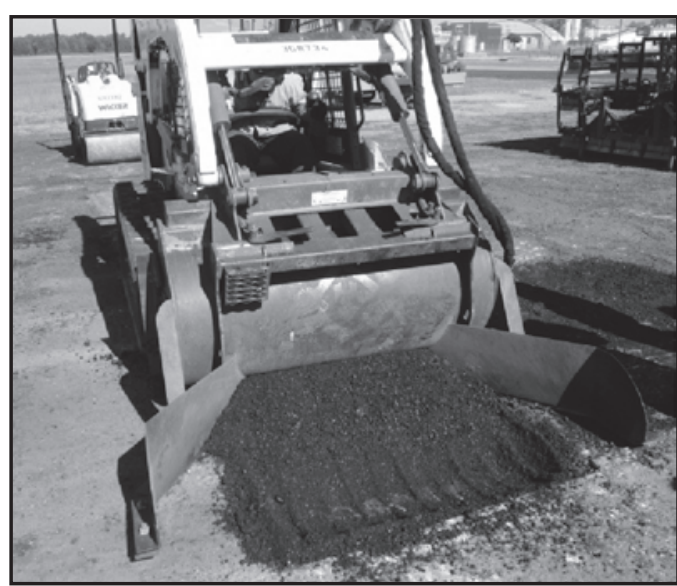

b) Screed option 
The asphalt processor function was used to loosen and mix the heated repair area. The asphalt processor had a cut width of $40 \mathrm{in}$. and could be adjusted vertically to compensate for depth requirements to a maximum of $4.0 \mathrm{in}$. The exterior tines were designed to cut at $45 \mathrm{deg}$ to the vertical, and the interior tines were all configured at 90 deg as shown in Figure 29.

Figure 29. Asphalt processor tine configuration.

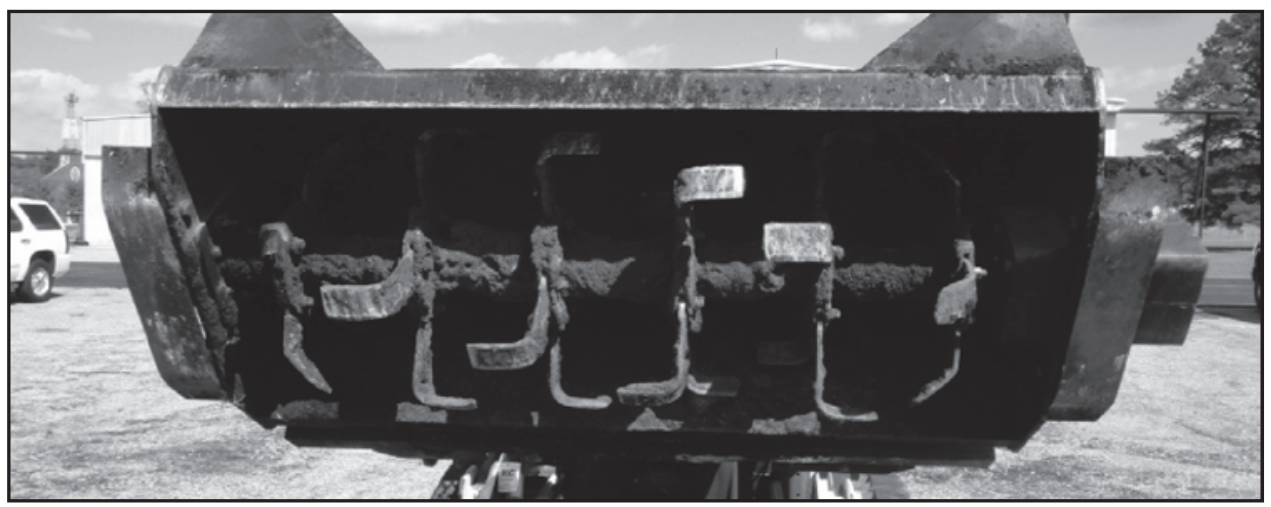

\section{Impact compactor}

The base material below each excavated repair area was recompacted using a "jumpingjack" style impact compactor as shown in Figure 30. This compactor was found to produce the most impact energy and be the most effective at providing maximum density of the underlying base layer compared to the plate compactor. The purpose of base compaction was to set loosened aggregates and stabilize the foundation under the rejuvenated repair material. Water was not added and density measurements were not performed once compaction was completed; it was simply an added measure to ensure final adequate final repair performance.

Figure 30. Base material being compacted.

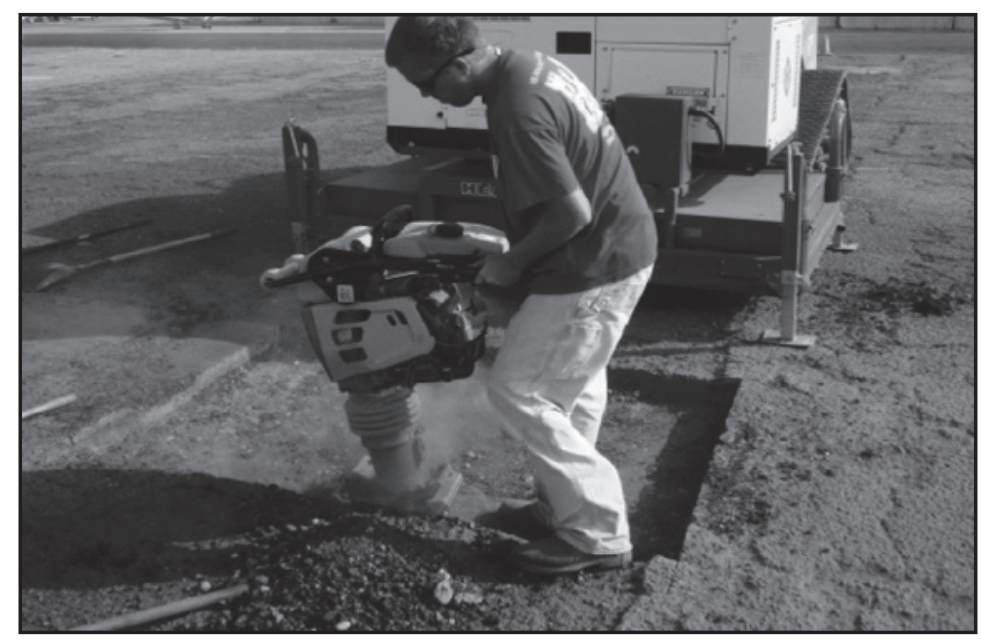




\section{Skid steer mounted mixing drum and heating device}

Rejuvenating agents were used to renew the heated and reclaimed asphalt material. A skid steer mounted mixing drum was used to complete this task. The drum was outfitted with a customized fuel-based heating system designed to operate with diesel directly from the skid steer fuel tank. An armature system allowed the heater to be pivoted out of the way during loading and unloading maneuvers. While the mixer was in operation, the heating device was locked into place and used as necessary to maintain temperature within the drum. The mixing drum assembly is shown in Figure 31. Due to the repair size and limited mixer capacity, multiple batches were mixed and stockpiled prior to placement.

Figure 31. Skid steer mounted mixer with heating device.

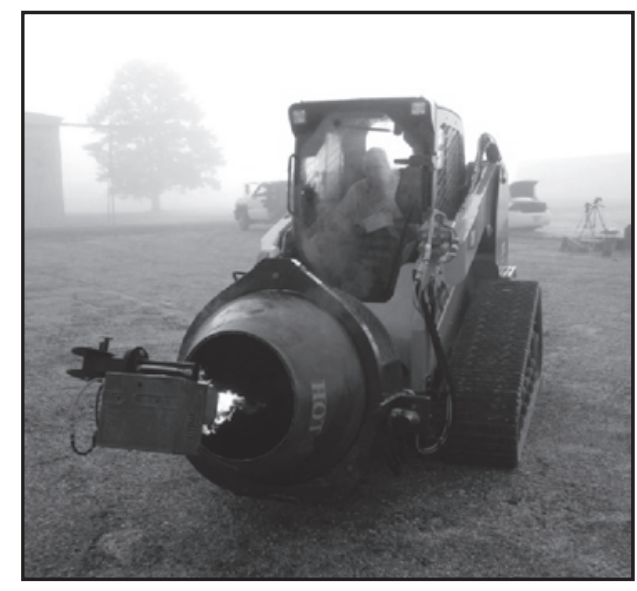

a) Mixer

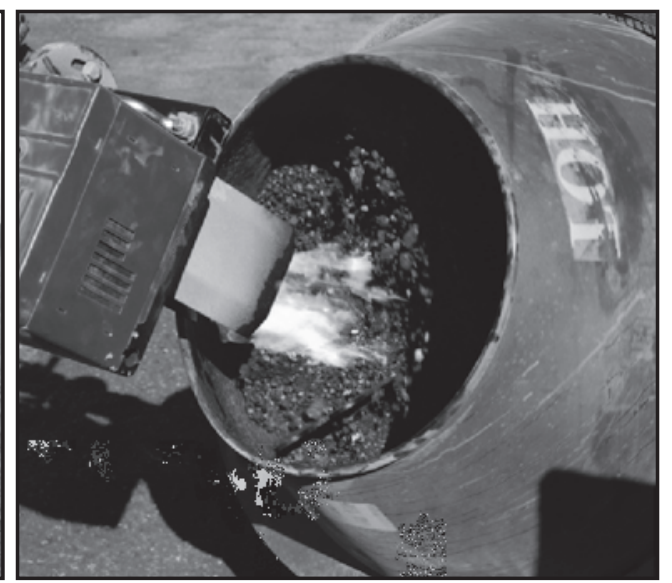

b) Heating device

\section{Dual wheel vibratory roller}

After the rejuvenated mix was placed in the repair, the loose mix was spread to an even thickness using hand rakes, and the surface was compacted using a dual-drum vibratory compactor equivalent to a Caterpillar CB14 as shown in Figure 32. The roller was first used to pinch all repair edges and begin compacting inwards without vibration. Once the material had been initially set, the vibrating drum was activated to finish compaction. A few passes of the roller without vibration was used to smooth the finish surface. An initial effort to compact in two equal lifts was performed, but it was learned that density could be achieved in one lift should material temperatures not fall below $225^{\circ} \mathrm{F}$ when placement occurred. 
Figure 32. Dual wheel vibratory roller.

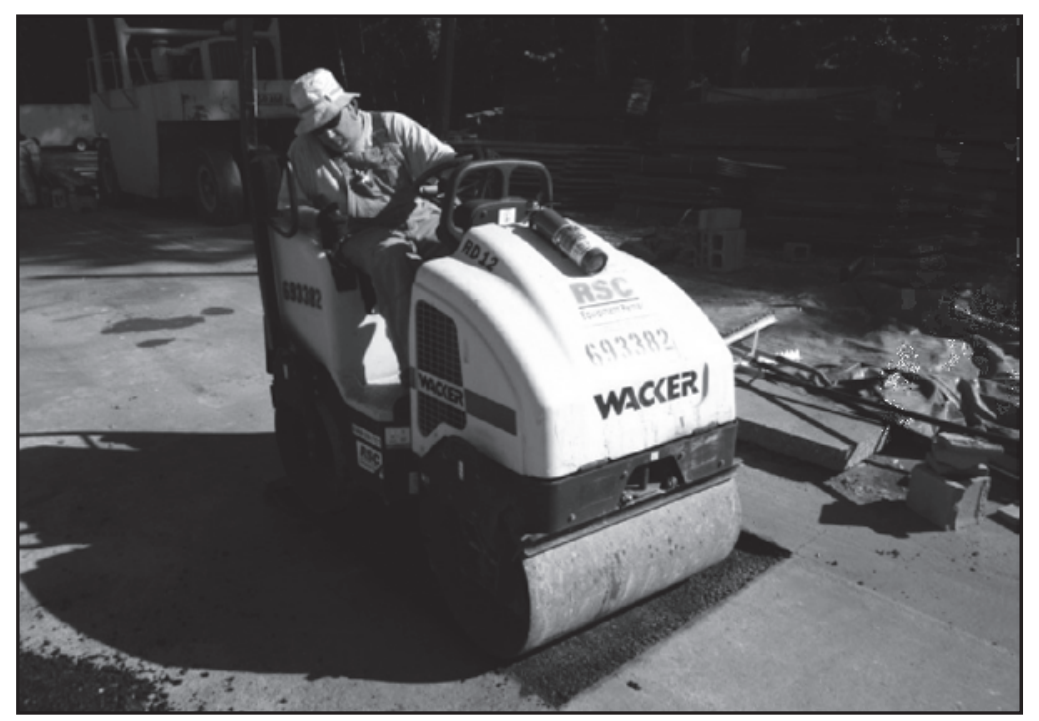

\section{Repair method}

This section describes all the methods evaluated in this study as they were applied, observations on the performance of the equipment and materials during the repair process, and problems encountered during the evaluation. A step-by-step description of the method recommended for in-place asphalt recycling based on the findings of this study is presented in Appendix A.

\section{Site preparation}

\section{Pavement surface sweeping}

Due to the extensive raveling and loose aggregate on the apron surface, the entire site was swept using a skid steer-mounted broom attachment (Figure 33). The sweeping effort collected most of the loose material for offsite disposal. Removing debris from the pavement surface was important to prevent aggregate with little or no bonded asphalt from being included in the rejuvenation process. Uncoated aggregates in the final asphalt mix reduced the net asphalt content and ultimately decrease final performance of the repair. The removal of this debris also allowed the infrared heat to permeate directly into the existing asphalt layer, rather than being absorbed into the surface area of the loose aggregates. This increased overall heating efficiency and decreased time needed for sufficient heating. A photo of the loose material recovered from the repair site (Figure 34) illustrates the magnitude of site deterioration as well as the severity of overlay erosion and wear. 
Figure 33. Skid steer mounted broom attachment.

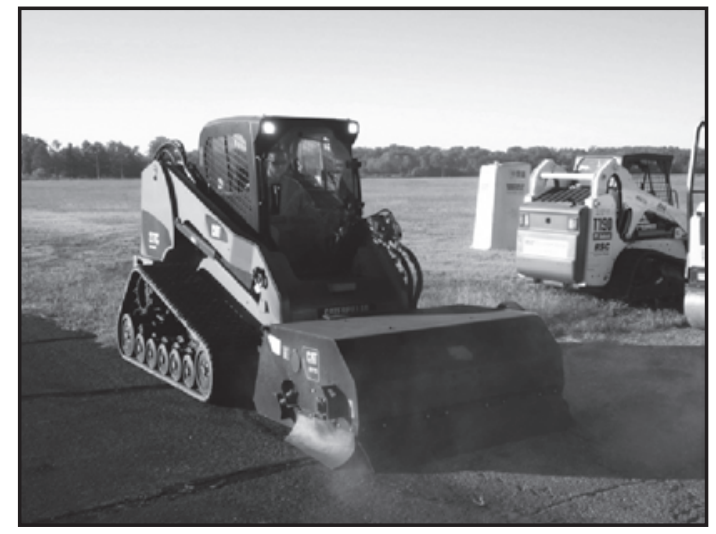

Figure 34. Spoil pile from site sweeping.

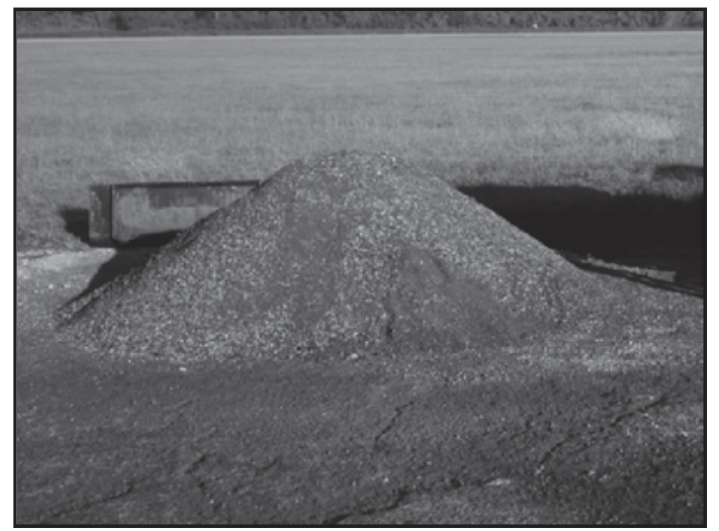

RAP stockpile harvesting for mix weight and volume compensation

The asphalt heater and processor equipment were used to excavate a section of the apron adjacent to the repair areas. To harvest and stage this material near the repair site for immediate availability during the rejuvenation process was important. To ensure that only the asphalt material was processed and that base material was not included was also vital. For this reason, the processor was set to obtain a partial-depth excavation for the stockpile.

During material excavation, breakdown of the entire repair volume into a homogenous coarse mixture was difficult. The repair edges remained intact, and removing these larger chunks of asphalt manually using shovels, pry bars and other hand tools was necessary. These chunks could not be broken down during mixing and rejuvenation, so they were weighed and material from the RAP stockpile was used to compensate for the loss.

Additionally, the removal, rejuvenation, and compaction of the existing asphalt caused consolidation and an overall loss of volume. The RAP stockpile material provided the material necessary to replace the lost volume and ensure a flush repair.

Pelletized asphalt was another method used to compensate for the lost volume in some of the repairs. Pelletized asphalt is a pre-manufactured product that can be shipped at ambient temperature to remote locations in 50-lb plastic bags, and is a dense-graded mix consisting of asphalt cement, fine aggregate, fiber, and polymer. Applied Research Associates has tested this material in full-scale airfield pavement test sections and results have 
shown that it meets airfield pavement requirements. Figure 35 shows a typical load of pelletized asphalt. When pelletized asphalt was used in a repair, it was added to the mix after all the RAP material was rejuvenated, since it did not require rejuvenation. The bags were placed in the drum mixer, and the heating device was locked in place to provide enough heat to melt the plastic bags, while the mix was broken down into a homogenous granular mixture.

Figure 35. Pelletized asphalt.

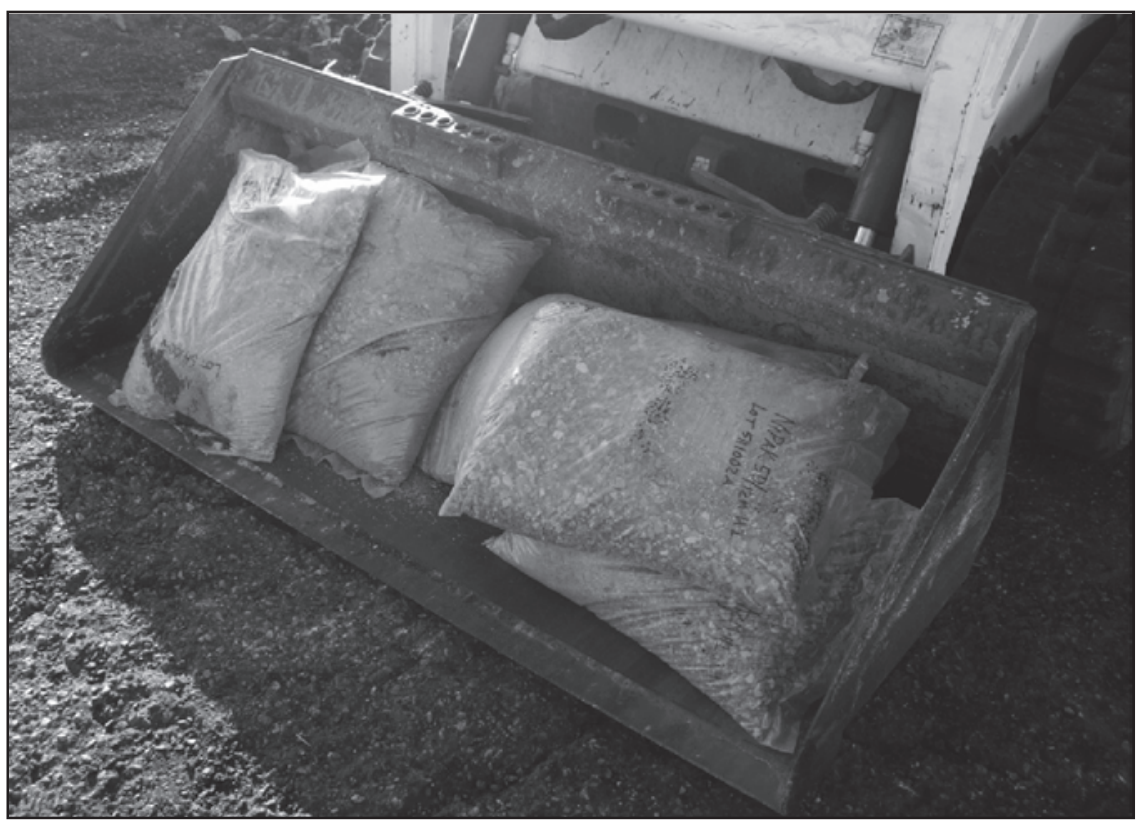

\section{Initial heating of repair surface}

All areas to be repaired were brought to temperature using one of the two available heater units. The time required for initial heating varied and was dependent upon heater type, ambient temperature and depth to be heated. The heater was placed directly over the marked repair area and lowered into place as shown in Figure 36.

Each unit was equipped with adjustable stands, allowing vertical height adjustment from the pavement surface during stand-alone operations. The electric Heatwurx unit produced a fixed thermal output of approximately $400^{\circ} \mathrm{F}$ and was placed directly onto its fabric perimeter gasket with stands fully retracted. This produced maximum unit efficiency and prevented heat from escaping. 
Figure 36. Electric heater being placed on repair area.

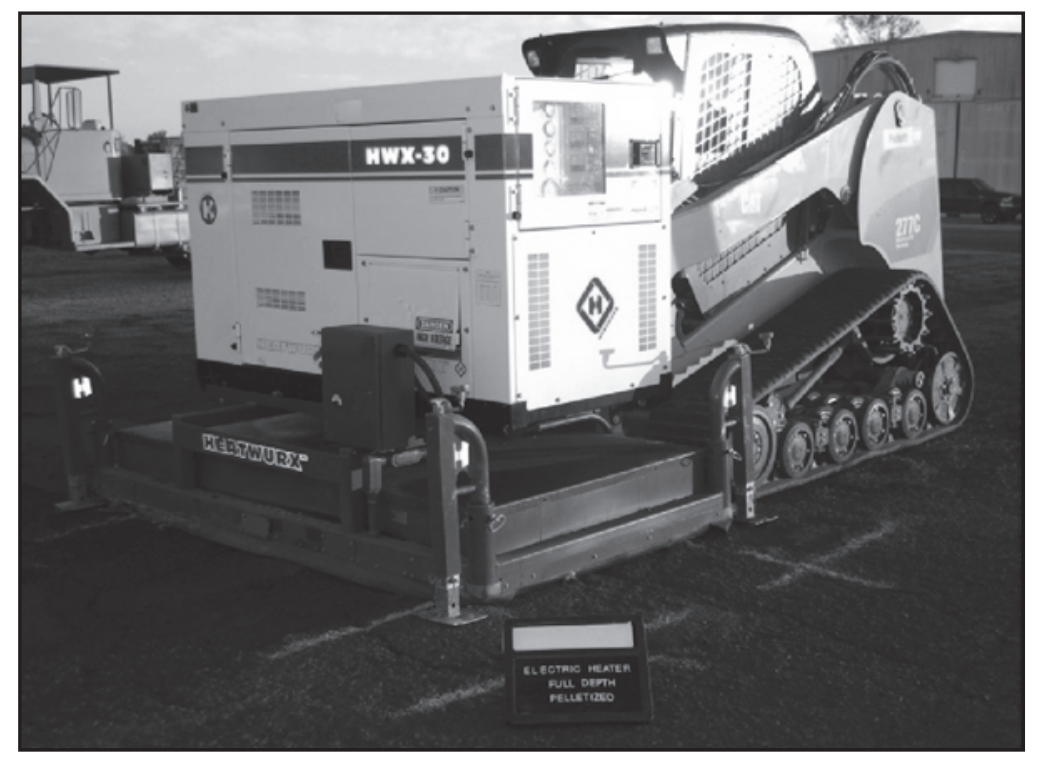

Conversely, the propane-based HDE heater unit could produce temperatures to $1,450^{\circ} \mathrm{F}$ at maximum fuel pressures, so care was taken to adjust element height from the repair surface depending upon ambient wind, temperatures, and operating pressure. During this experiment, operating pressures were set to $35 \mathrm{psi}$ for initial repair heating and as low as $5 \mathrm{psi}$ during stockpile warming, based upon recommended manufacturer guidelines.

The propane heater was designed to sit approximately 6 in. to $1 \mathrm{ft}$ above the pavement surface during operation without a sealing gasket or wind drape. The open-air distance between the elements and the pavement surface made operating in the 35-psi range necessary. While this pressure generated element temperatures approaching $800^{\circ} \mathrm{F}$, the open air and side wind condition reduced surface temperatures to $450^{\circ} \mathrm{F}$ nominally. Figure 37 shows the propane heater configuration during the initial heating sequence.

Initial heating durations varied from $30 \mathrm{~min}$ to $1 \mathrm{hr}$, depending upon target depth and ambient conditions. All partial-depth repairs required no more than $30 \mathrm{~min}$ to effectively reach temperatures at depth. Full-depth repairs on cooler days required a longer duration. After $30 \mathrm{~min}$ on each repair, the heater was removed and a short piece of rebar (or other slender, rigid tool) was used to determine asphalt softness. If the probe could easily penetrate to depth, the heater was removed from the skid steer, and the processor attached for excavation. A hand shovel was used to remove the softened material to depth so that a hand-held non-contact thermometer could be 
Figure 37. Propane heater during initial heat sequence.

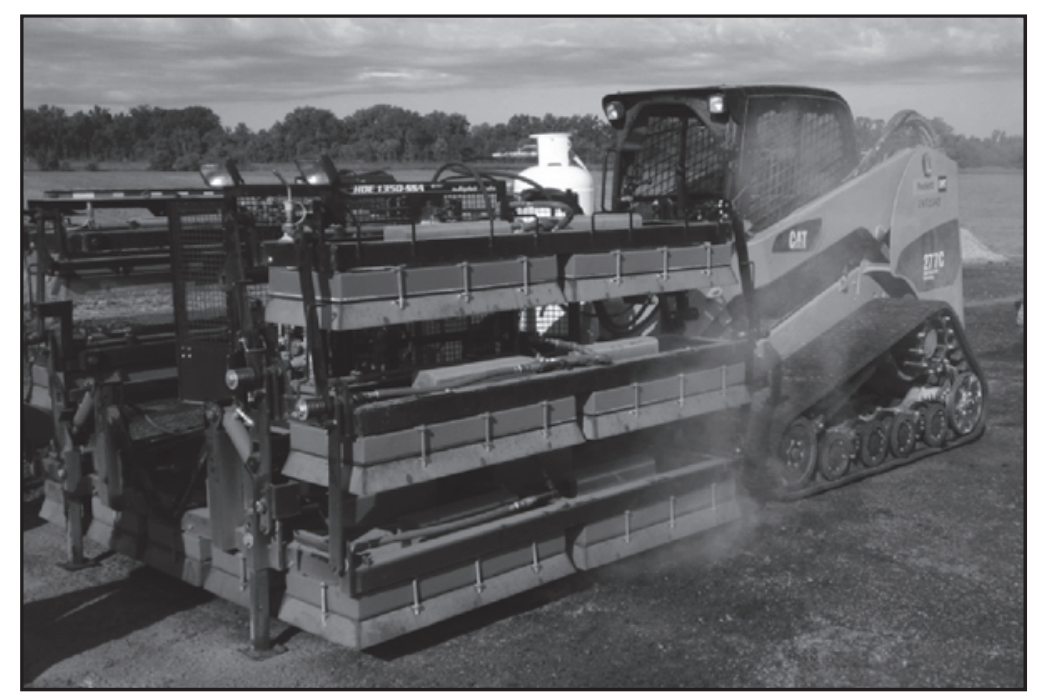

used to measure the temperature at the bottom of the asphalt layer. If probe penetration was difficult and the asphalt still stiff, the heater was replaced and additional heating time was given to reach a workable temperature.

\section{Material processing and excavation}

Two separate methods for excavation of the existing asphalt material were tested. The initial method used a skid steer mounted general-purpose bucket to cut into the heated asphalt layer and remove the oxidized material. This method proved ineffective because it was difficult to maintain a constant depth across the repair area. It also produced large chunks of reclaimed asphalt, which were hard to break down in the drum mixer. Figure 38 shows the bucket being used to reclaim heated material from a repair area. 
Figure 38. Skid steer-mounted bucket attachment.

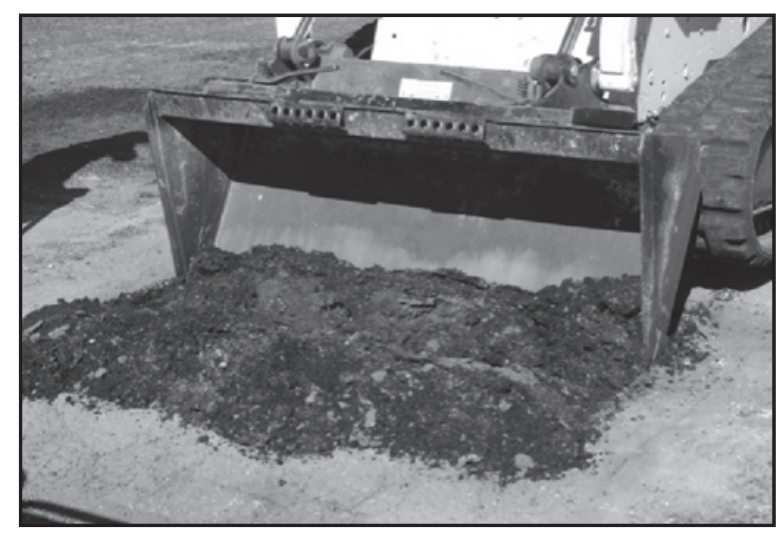

Figure 39. Skid steer-mounted asphalt processor.

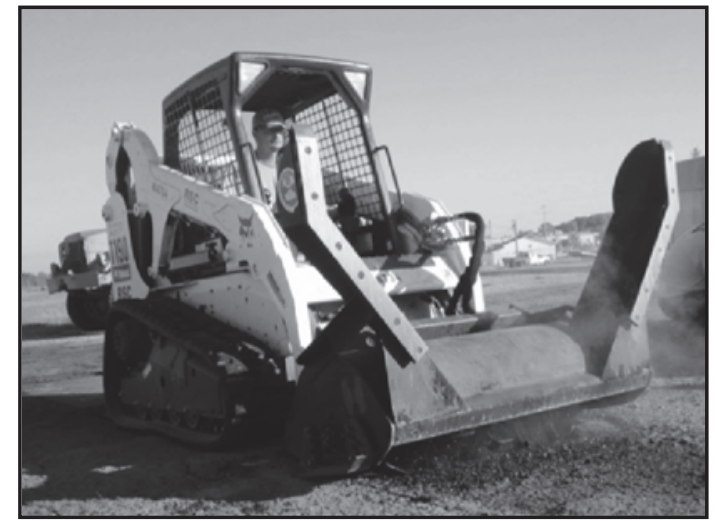

The alternative to a bucket excavation was to use the Heatwurx AP-30 asphalt processor as shown in Figure 39. It is a skid steer mounted attachment which doubles as a depth adjustable tiller and asphalt screed. The screed function of the processor was not used during these tests; finishing was performed using hand tools only.

The tiller function did not remove the material, instead it provided an efficient method in which to break down the heated asphalt mass into a finer and evenly distributed gradation. This allowed for easy mix batching and rejuvenation within the drum. This meant that very little replacement material had to be brought in to substitute for large, unmanageable chunks of excavated material.

An adjustable elevation system was used to manage tine cut depth during operation. It consisted of metal skids which would ride along the outside edge of the repair area and maintain consistent tiller elevation. This ensured a uniform depth across the repair area bottom. Once the processor mechanically broke down the loosened material volume into a sufficiently fine gradation, hand shovels were used to transfer the processed material to a series of 5-gal buckets for weighing.

Because the outer tines on the processor were designed using $45^{\circ}$ cut angles, beveled edges were created along the repair length. Likewise, the spinning motion of the tiller tines also produced a radius at both ends. These effects can be identified in the repair cavity shown in Figure 40. A hand-held concrete saw was used around the repair perimeter to produce $90^{\circ}$ vertical edges as visible in Figure 41. 
Figure 40. Squaring repair edge with saw.

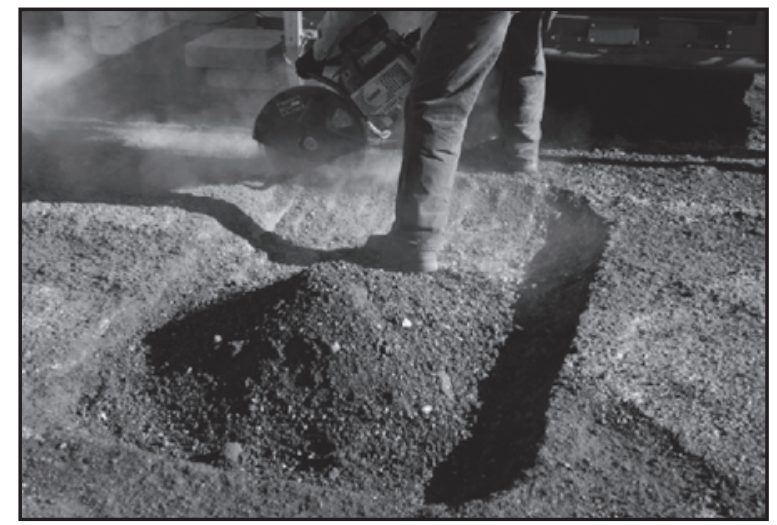

Figure 41. Squared edges and large chunks from saw cutting.

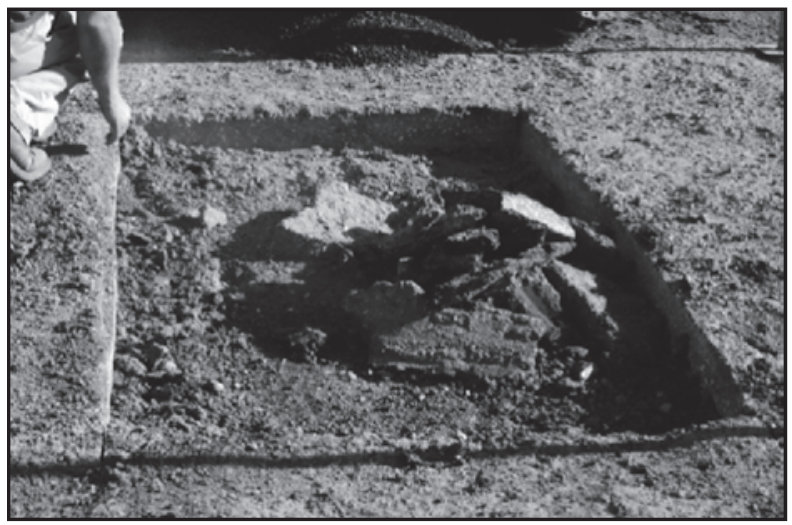

The saw cutting produced larger pieces of asphalt that could not be broken down effectively within the mixer during the rejuvenation process. Therefore, these large pieces were collected by hand in 5-gal buckets and weighed before being discarded. RAP material from the harvest stockpile or pelletized asphalt was then used in the rejuvenated batch (depending on individual repair protocol) to replace this lost volume.

\section{Repair void preparation}

Hand shovels and brooms were used to sweep away and remove any remaining fines and debris from the repair cavity as seen in Figure 42. If the repair was full-depth, the underlying base material was compacted using an impact-style compactor as shown in Figure 43.

Figure 42. Final repair void preparation (partial-depth).

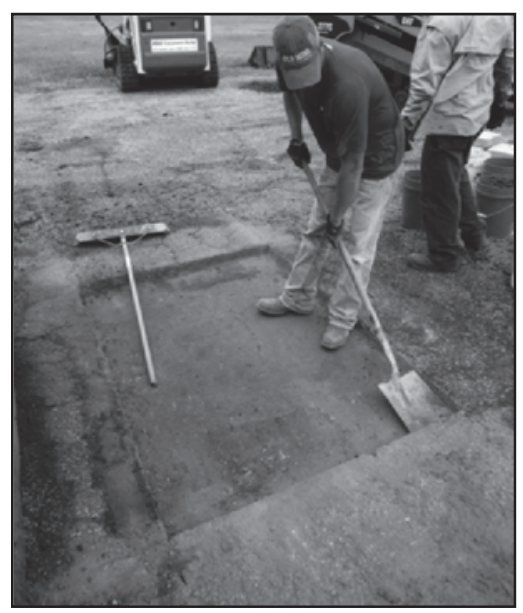

Figure 43. Base compaction (fulldepth).

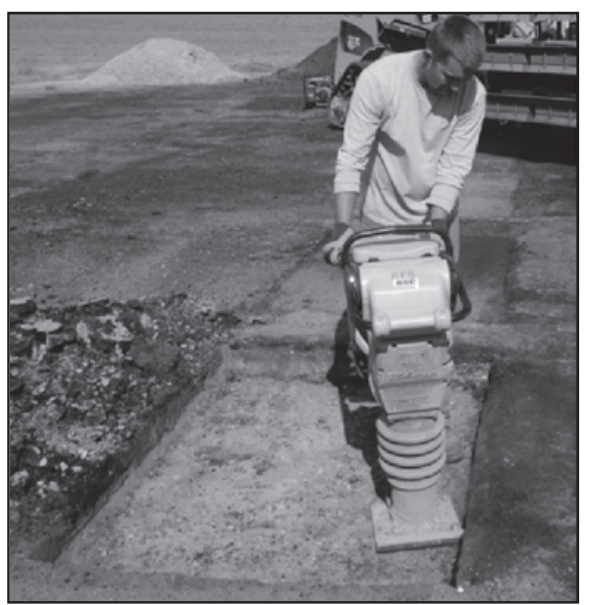


As an added method to ensure the base material did not absorb the rejuvenator from the new material, a light coat of the rejuvenator liquid was sprayed onto the sides and bottom of the repair. This also served as a tack coat for improved bonding between layers. Figure 44 shows the tack coat being applied using a hand-held pneumatic pump and nozzle. Figure 45 shows the repair prior to rejuvenated asphalt placement.

Figure 44. Rejuvenator applied to repair void.

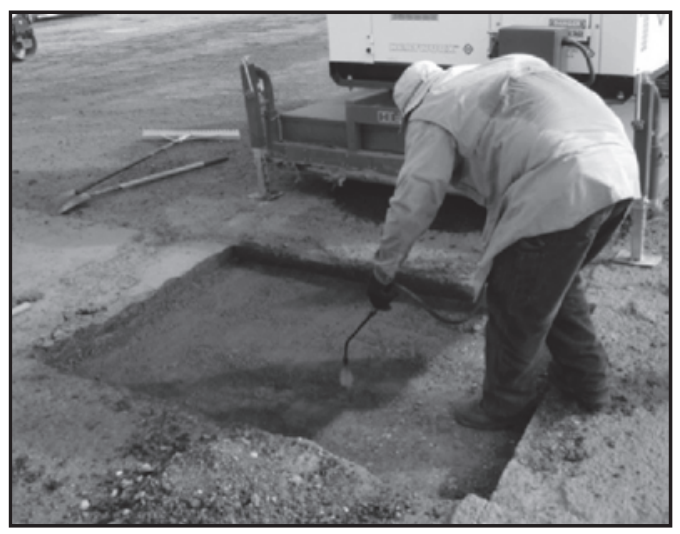

Figure 45. Repair prior to asphalt placement

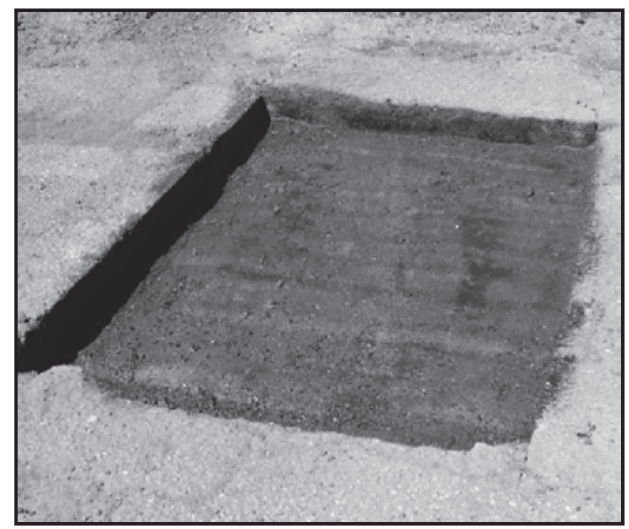

\section{Asphalt rejuvenation}

The rejuvenation process began once the repair preparation had been completed and all materials were staged for use in the mix batch. Due to weight and volume constraints on the skid steer mounted mixing drum, the total volume required for each repair had to be divided into multiple batches.

The removed material was staged in 5-gal buckets for rejuvenation. It was weighed using a digital scale, and mass accuracy of each bucket was measured to the nearest pound. RAP material from the harvest stockpile that had been gathered in 5-gal buckets was individually weighed until the total mass required for replacement had been acquired. All weights were recorded to calculate total mass used per repair.

The buckets of RAP were staged near the skid steer-mounted mixing drum, and the rejuvenator was then weighed based on the percentage required by mass. For cement-based repairs, a total of 0.5 percent (by mass) RejuvaSeal brand rejuvenator was weighed and staged for addition to the mix batch; all other repair batches used 2 percent CRF rejuvenator (by mass). 
Approximately $350 \mathrm{lb}$ was the maximum drum load per mix batch. Buckets of RAP were dumped into the drum until full and mixing was initiated. The retractable burner was locked into place and ignited using a control box within the skid steer cab. The burner was cycled on and off to prevent scorching while the drum slowly rotated. The heating continued until the RAP had reached an average temperature of $350^{\circ} \mathrm{F}$. Depending on ambient temperature and initial RAP temperature when placed into the drum, the duration for this process was typically 15 to $20 \mathrm{~min}$.

The rejuvenator was added once the heating process was complete and the burner retracted. Both rejuvenators had flash points low enough to cause combustion within the drum while the burner was engaged. The mixer was re-engaged for an additional $2 \mathrm{~min}$ to allow full incorporation of the rejuvenator liquid into the RAP mass. The skid steer then dumped the rejuvenated payload on the stockpile staging area adjacent to the repair void. Temperature measurements were taken off the fresh stockpile using both probe and hand-held non-contact thermometers. This temperature was recorded and the rejuvenation process continued until the quantity required to complete the repair was obtained.

\section{Cement stabilization}

Type I Portland cement was used in some of the repairs as recommended from the results of the laboratory evaluation: 1 percent cement by total weight of RAP and 0.5 Rejuvaseal rejuvenator product were added to the RAP material removed from the repair area. The cement was added and mixed for 2 min once the RAP material had been heated and mixed with the rejuvenator in the mixing drum. Figure 46 shows the cement being added to the rejuvenated asphalt in the mixing drum. It must be noted that both rejuvenator and cement were added to the drum only after sufficient heat had been applied.

\section{Rejuvenated stockpile and temperature maintenance}

Due to repair volumes which exceeded the skid steer-mounted drum capacity, it was necessary to rejuvenate the reclaimed asphalt material in several batches. Each rejuvenated drum load was placed into a stockpile adjacent to the repair area and kept hot using one of the asphalt heaters. The target stockpile temp was $350^{\circ} \mathrm{F}$. While the gas pressures and resulting temperatures could be regulated on the HDE propane heater, the Heatwurx electric system did not possess a rheostat, and the output temperature was 
fixed. To compensate, concrete blocks were stacked and used to elevate the heater above the stockpile at a safe distance and prevent material scorching or elevated temperatures, which could potentially reach the rejuvenator flashpoint. Figure 47 illustrates the method used to elevate the heater and maintain stockpile temperature during batch mixing.

Figure 46. Cement being added to rejuvenated batch mixture.

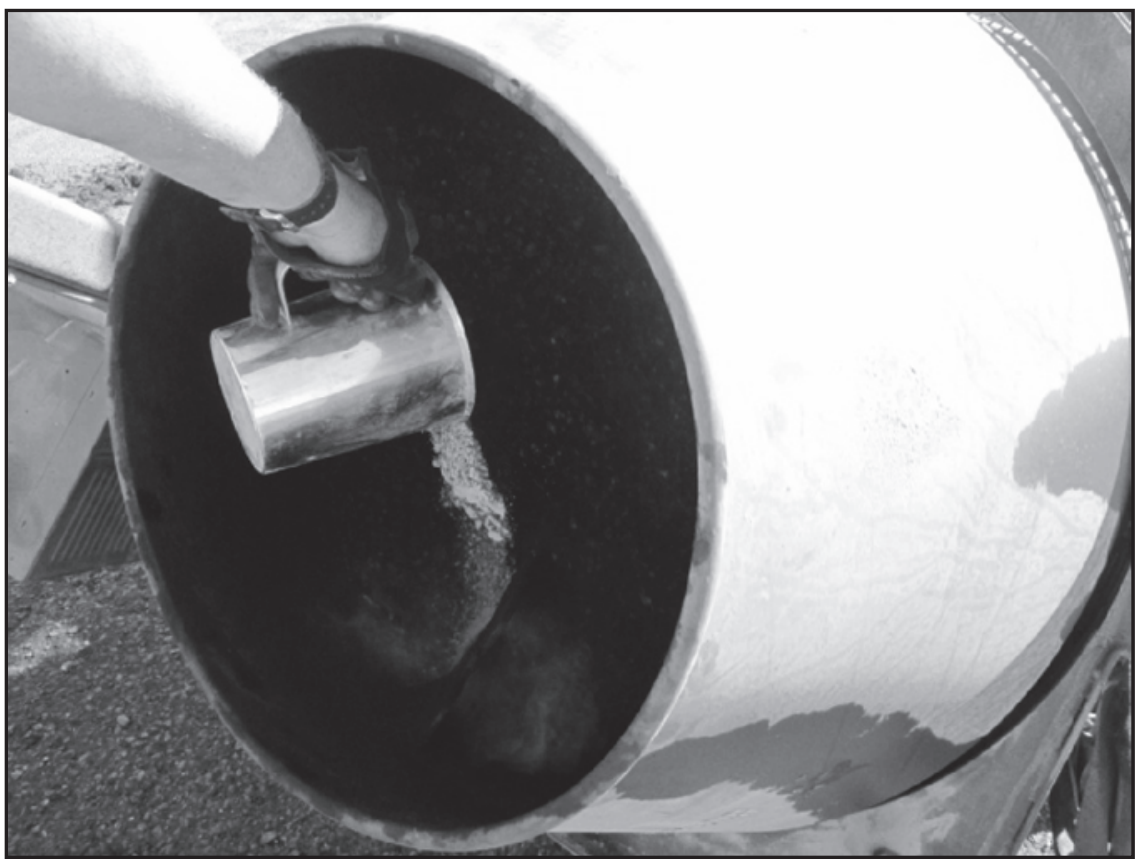

Figure 47. Propane heater keeping rejuvenated stockpile hot.

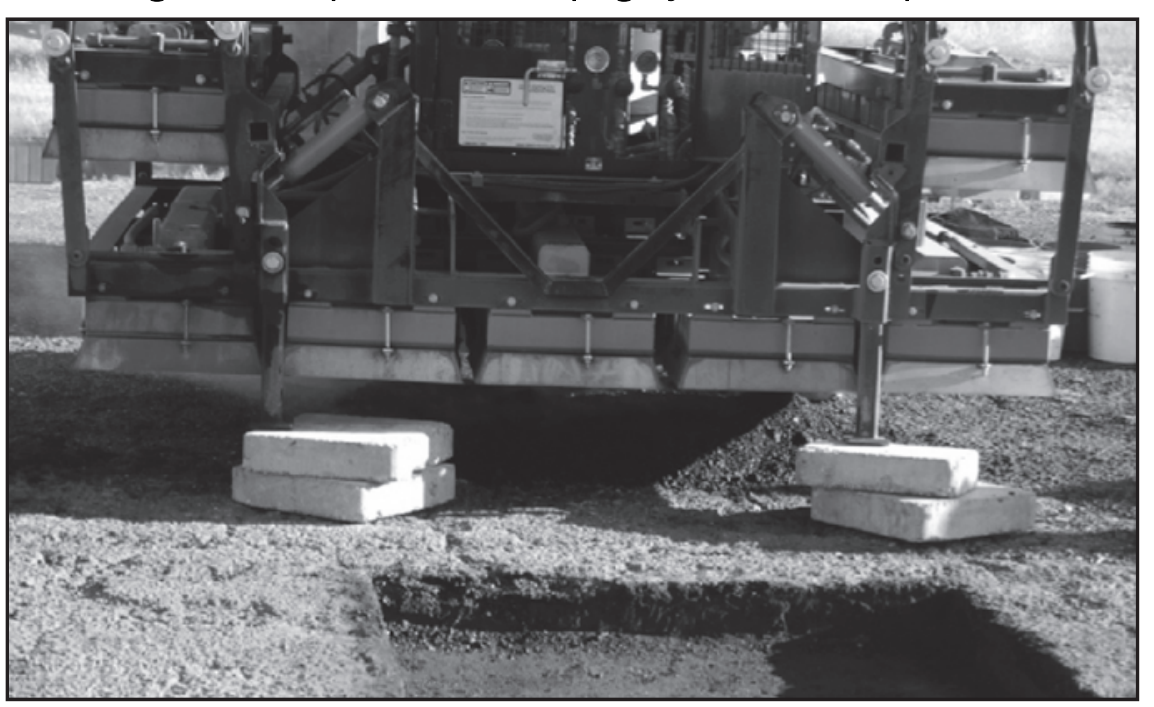

Once the final batch had come to temperature within the mixing drum, the heater was removed from its position above the stockpile, and the asphalt was emptied from the drum as shown in Figure 48. The approximate time 
required for drum loading, temperature gain, rejuvenation, and unloading was 15 to $20 \mathrm{~min}$. The stockpile not exceeding the target temperature of $350^{\circ} \mathrm{F}$ during this time was imperative, because that would cause scorching or material damage. It was also critical to maintain the stockpile at a temperature hot enough to aid compaction. For this reason, internal and external stockpile temperatures were periodically measured using handheld non-contact thermometers and metal thermometers.

Figure 48. Rejuvenated asphalt being stockpiled near repair.

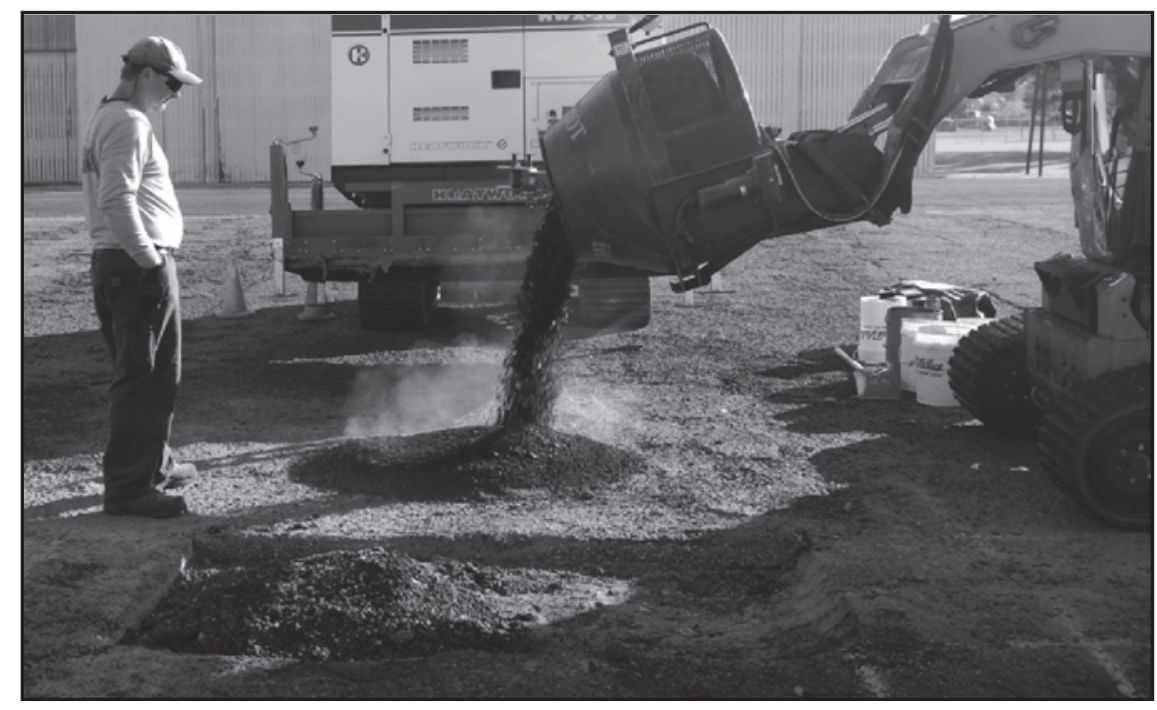

\section{Placement and compaction}

Rejuvenated material placement was performed immediately after the last drum batch was dumped and stockpiled. The surface area around the repair area was cleaned using a hand broom to remove foreign debris prior to placement. The stockpile was then transferred to the repair void using a skid steer mounted bucket as shown in Figure 49.

The heated material was then quickly spread using hand tools and screeded using a lute rake to a target height above the surrounding pavement surface to compensate for compaction and produce a flush repair (Figure 50). The ratio used was $1 / 4$ in. of screeded height for every $1 \mathrm{in}$. of repair depth measured from the pavement surface. Repair edges were pushed tight and beveled at 45 deg to the normal prior to compaction.

The dual-drum wheel vibratory roller was then used to compact the hot material and produce required density. The vibrating feature on the roller was not initially used during the first several passes. The edges were first 
pinched and the first pass series completed before applying dual-drum vibration. The repair in Figure 51 had been edge-pinched and the roller was being used to finish the first pass coverage of compaction.

The compaction effort continued until the first pass series was completed. A coverage was defined as four forward and four backward passes over each one-third of the repair width (left, center, and right). The roller is shown in Figure 52, finishing the first of several coverages.

Figure 49. Rejuvenated stockpile being placed into repair void.

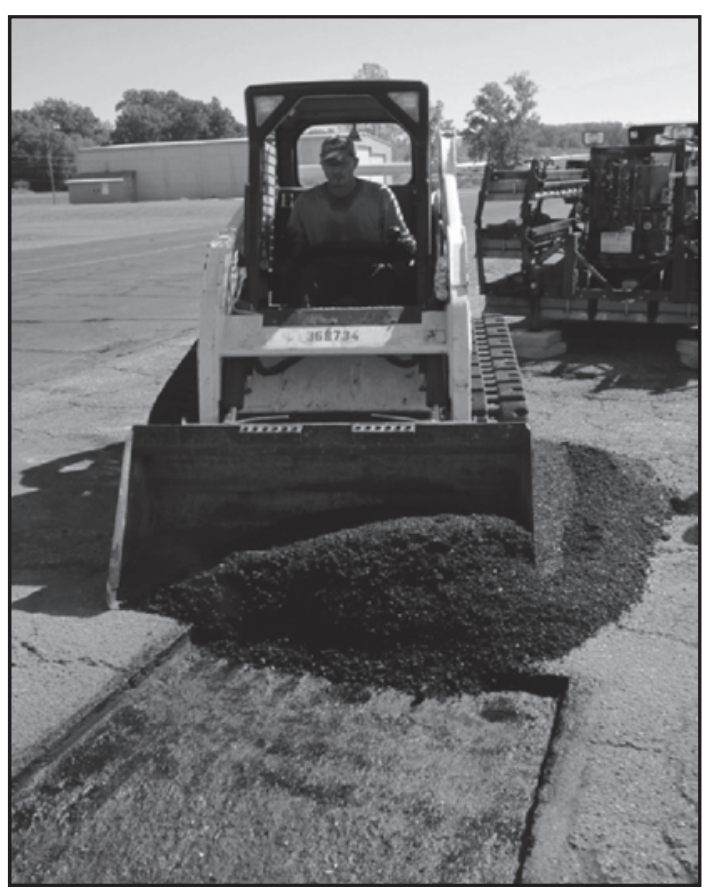

Figure 50. Rejuvenated material being prepared for compaction.

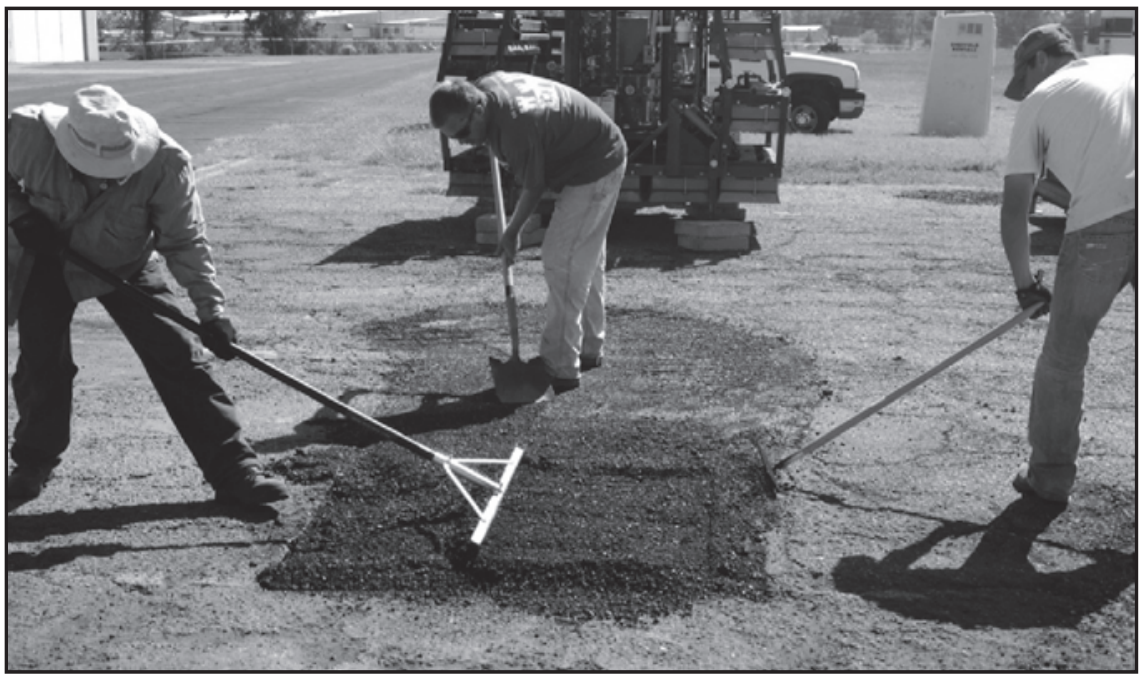


Figure 51. Dual-drum compactor pinching edges of repair.

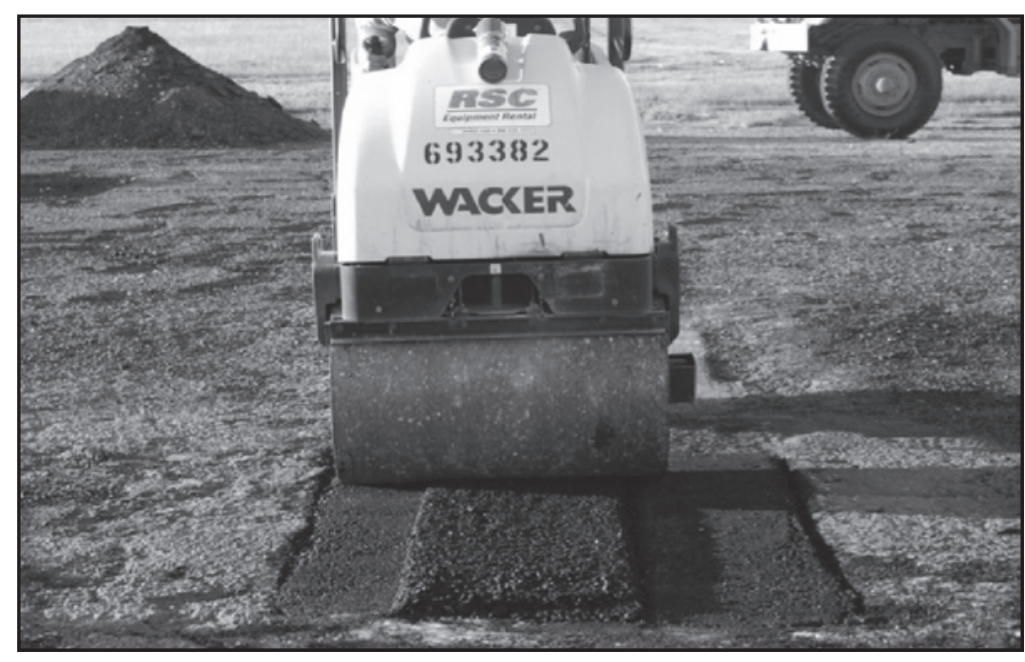

Figure 52. Final compaction effort.

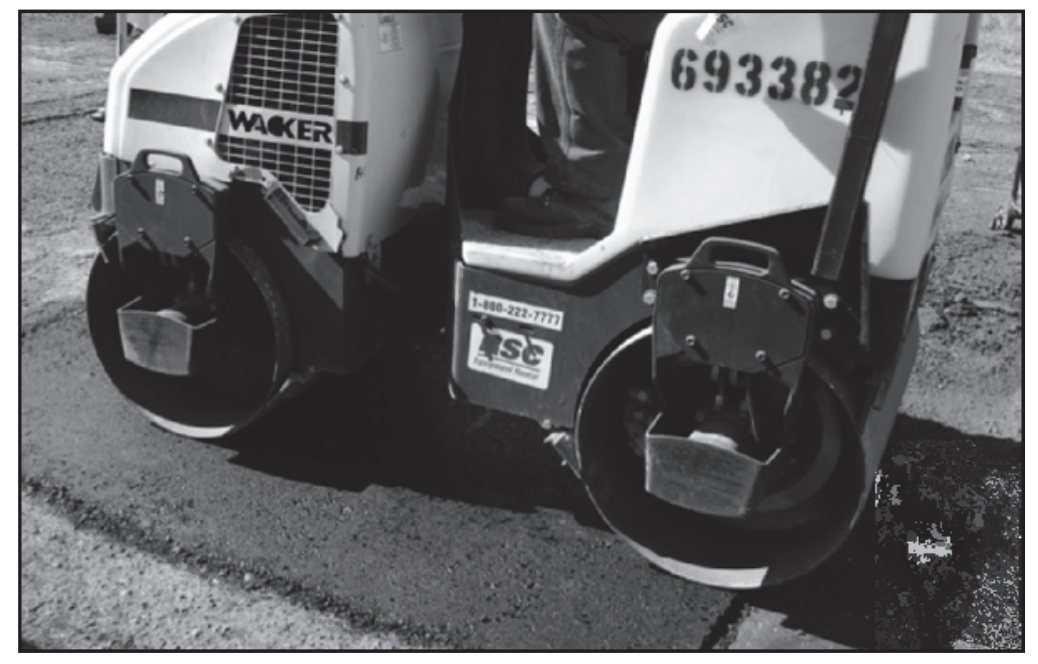

\section{Density measurements}

Repair densities were measured immediately after compaction using a nuclear gauge device as shown in Figure 53. Readings were taken at three locations across the repair center line. The measurement readings were recorded as a single average density for the overall repair and used to evaluate the compaction effort.

To establish a correlation between the nuclear gauge device and actual field densities, two core samples were taken and sent to the laboratory for density determination. Comparative testing revealed that the nuclear gauge results were on average $10 \mathrm{pcf}$ lower than the core densities. Therefore, the compaction effort ceased when nuclear gauge readings were $135 \mathrm{pcf}$ or higher. 
Figure 53. Nuclear density gauge taking measurement.

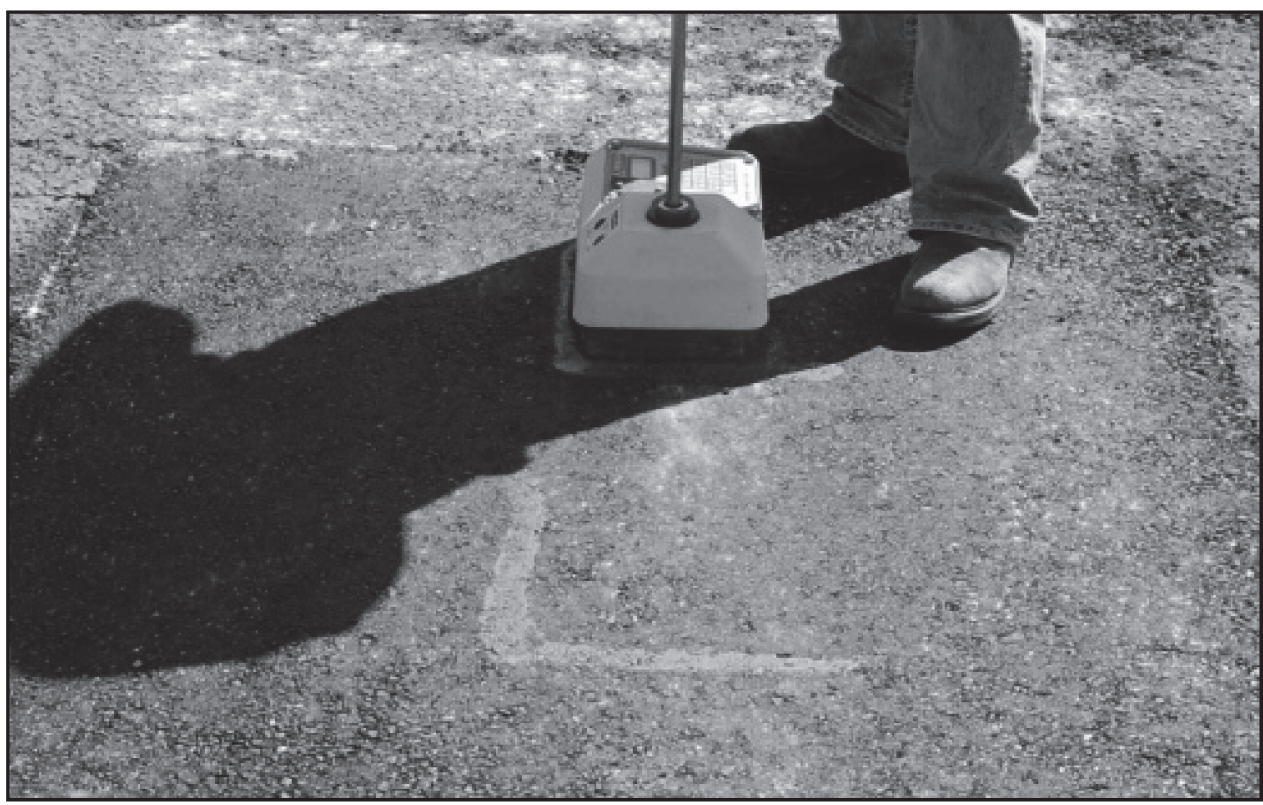

Readings were taken after the completion of one compaction coverage. If the repair density had not met target requirements, an additional coverage was performed. Compaction was continued until density had reached the minimum target.

\section{Individual repair details - Test Site 1}

Table 11 lists the nomenclature associated with each repair and Figure 54 illustrates the repair layout at the Vicksburg Airport test site. Repair specific details are provided in the subsequent sections.

Table 11. Repair nomenclature used for Test Site 1.

\begin{tabular}{|l|l|l|}
\hline Depth & Repair ID & Repair Description \\
\hline \multirow{5}{*}{ Full-depth } & FD-1 & Electric Heater, Airport RAP + 2 percent CRF \\
\cline { 2 - 3 } & FD-1a & Electric Heater, Airport RAP + 2 percent CRF, Repeat \\
\cline { 2 - 3 } & FD-2 & Electric Heater, Airport RAP + 2 percent CRF + Pelletized Asphalt \\
\cline { 2 - 3 } & FD-4 & Electric Heater, Airport RAP + 0.5 percent Rejuvaseal + 1percent Cement \\
\cline { 2 - 3 } & FD-5 & Propane Heater, Airport RAP + 2 percent CRF + Pelletized Asphalt \\
\hline \multirow{3}{*}{$\begin{array}{l}\text { Partial- } \\
\text { depth }\end{array}$} & PD-2 & Electric Heater, Airport RAP + 0.5 percent Rejuvaseal + 1 percent Cement \\
\cline { 2 - 3 } & PD-3 & Propane Heater, Airport RAP + 2 percent CRF \\
\cline { 2 - 3 } & PD-4 & Propane Heater, Airport RAP + 0.5 percent Rejuvaseal + 1 percent Cement \\
\hline
\end{tabular}

Notes: The RAP used in all these repairs was from the Vicksburg Airport.

Repair PD-1 was converted to a full-depth repair (FD-1a). 
Figure 54. Test Site 1 repair layout.

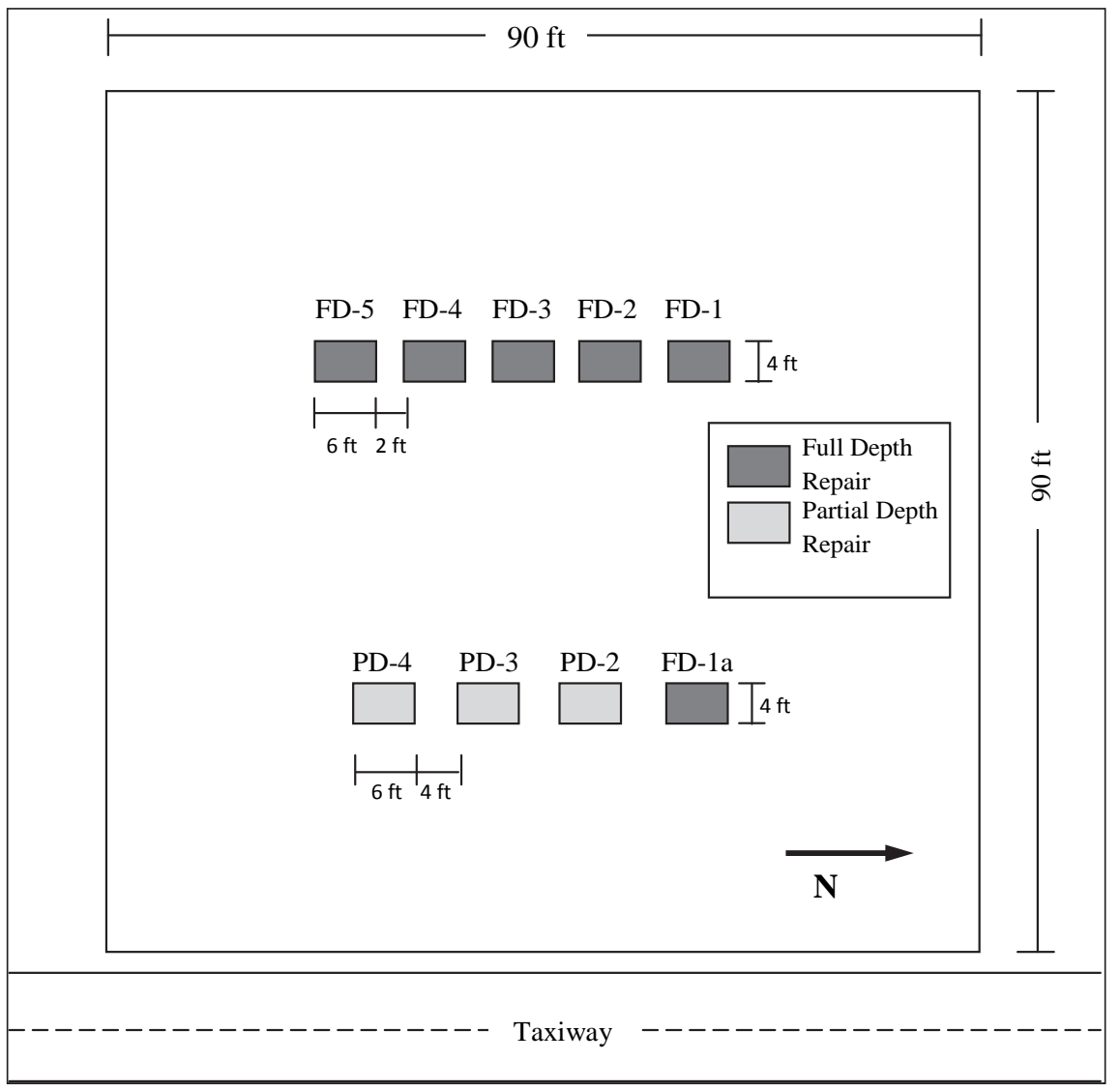

\section{Full-depth repairs}

Among all the full-depth repairs, three had problems during production: FD-1a, FD-2, and FD-4.

FD- $1 \mathrm{~b}$ was intended to be a partial-depth repair (PD-1), and it was excavated to a depth of 4 in. However, when the final material was excavated and removed, the base material was exposed. The excavation revealed that the 6-in.- thick cross section in the partial-depth test area was actually a 4-in.- thick course with a 2-in.- de-bonded asphalt overlay. The overlay was so severely worn and raveled that the broom had removed a majority of its mass, and the result was a partial-depth test zone of varying thickness between 4 and $6 \mathrm{in}$. It was decided to proceed with the repair as a full-depth scenario, and it was considered a repetition of repair FD-1.

After compacting repair FD-2, surface cracking was abundant, and a considerable amount of uncoated aggregates were present. Figure 55 shows a scaled close-up of the final repair surface for FD-2. In an effort to mitigate the cracking and improve surface integrity, $\mathrm{CRF}$ was placed into a pressure 
sprayer and applied lightly to the repair surface (Figure 56). The rejuvenator was allowed to penetrate the surface and become tacky before the roller was used to compact one final time. This effort was completed without vibration to prevent additional cracks from forming. When completed, the repair surface was again inspected visually, and the technique had sealed many of the visible cracks.

Figure 55. Post-compaction surface cracks (FD-2).

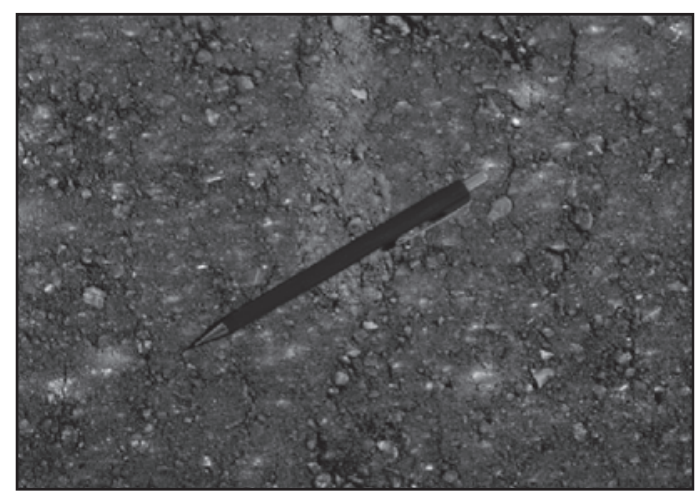

Figure 56. Typical rejuvenator application to mitigate surface cracking.

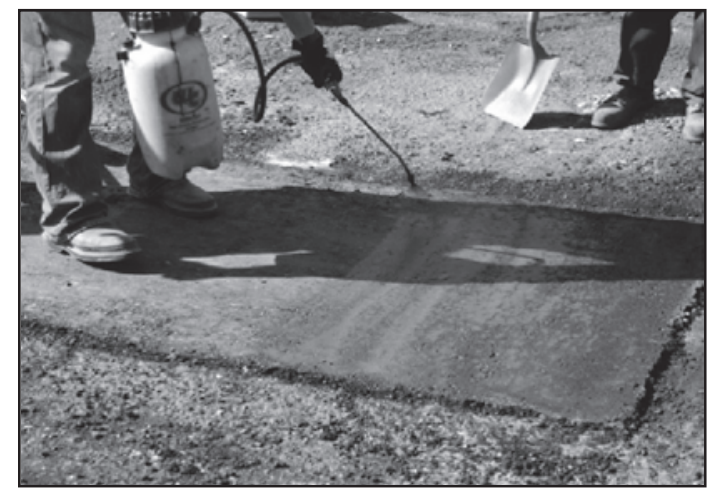

A skid steer-mounted bucket was used for excavation in repair FD-4 instead of the asphalt processor to compare the effectiveness and efficiency of a common bucket attachment during excavation. Removing the overlying asphalt without disturbing the base course was difficult for the operator. Figure 57 shows the disturbed base course mixed in with the RAP and illustrates the ineffectiveness of the bucket excavation method. Table 12 describes the full-depth repairs performed at Test Site 1.

\section{Partial-depth repairs}

Table 13 describes the partial-depth repairs performed at Test Site 1. Repairs PD- 2 and PD- 3 were sprayed with CRF after compaction due to excessive amount of exposed aggregate material in PD-2 (Figure 58) and cracking on the surface of PD-3 (Figure 59). The compaction after spraying $\mathrm{CRF}$ was performed without vibration and seemed to mend the majority of surface cracks, but nuclear density readings indicated low densities.

\section{Individual repair details - Test Site 2}

Figure 60 shows the prepared ERDC Test Site before the repairs commenced. The repair layout in the picture is as follows: (front to back) PHP-1, PHP-2, PHP-3 and PHP-4. Table 14 lists the nomenclature used for the repairs at Test Site 2. 
Figure 57. Disturbed base material mixed with excavated RAP.

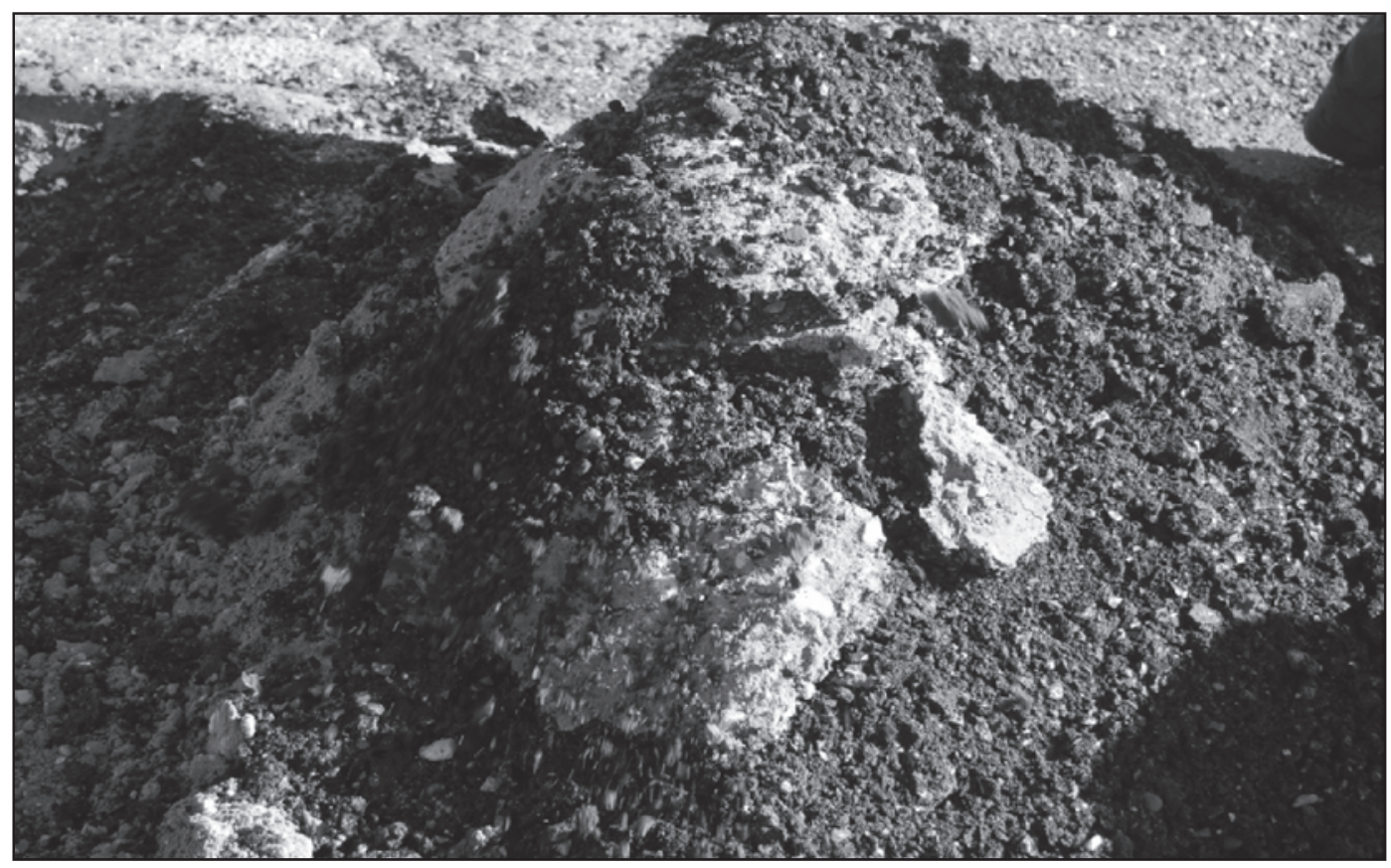

Table 12. Full-depth repairs description.

\begin{tabular}{|c|c|c|c|c|c|c|c|}
\hline \multirow{2}{*}{\multicolumn{2}{|c|}{ Repair Stage }} & \multicolumn{6}{|c|}{ Repair ID } \\
\hline & & \multirow{2}{*}{\begin{tabular}{|l|} 
FD-1 \\
4
\end{tabular}} & \multirow{2}{*}{\begin{tabular}{|l|} 
FD-1a \\
4
\end{tabular}} & \multirow{2}{*}{\begin{tabular}{|l|} 
FD-2 \\
4
\end{tabular}} & \multirow{2}{*}{$\begin{array}{ll}\text { FD-3 } \\
5.5\end{array}$} & \multirow{2}{*}{$\begin{array}{l}\text { FD-4 } \\
4\end{array}$} & \multirow{2}{*}{\begin{tabular}{|l|} 
FD-5 \\
5 \\
\end{tabular}} \\
\hline \multirow{7}{*}{ 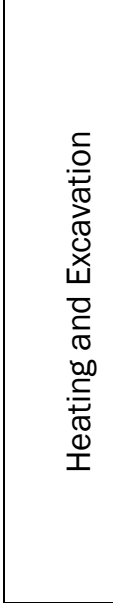 } & Excavation Depth (in.) & & & & & & \\
\hline & $\begin{array}{l}\text { Excavation } \\
\text { Method }\end{array}$ & $\begin{array}{l}\text { Asphalt } \\
\text { Processor }\end{array}$ & $\begin{array}{l}\text { Asphalt } \\
\text { Processor }\end{array}$ & $\begin{array}{l}\text { Asphalt } \\
\text { Processor }\end{array}$ & $\begin{array}{l}\text { Asphalt } \\
\text { Processor }\end{array}$ & Bucket & Bucket \\
\hline & Heater Type & Electric & Electric & Electric & Electric & Propane & Propane \\
\hline & Heating Duration (min) & 40 & 50 & 60 & 60 & 77 & 63 \\
\hline & $\begin{array}{l}\text { Initial Surface } \\
\text { Temperature }\left({ }^{\circ} \mathrm{F}\right)\end{array}$ & 120 & 86 & 61 & 62 & 106 & 75 \\
\hline & $\begin{array}{l}\text { Final Surface } \\
\text { Temperature }\left({ }^{\circ} \mathrm{F}\right)\end{array}$ & 425 & 320 & 495 & 530 & 500 & 450 \\
\hline & $\begin{array}{l}\text { Final Temperature } \\
\text { at Depth }\left({ }^{\circ} \mathrm{F}\right)\end{array}$ & 110 & 120 & 180 & 140 & 140 & 165 \\
\hline \multirow{6}{*}{ 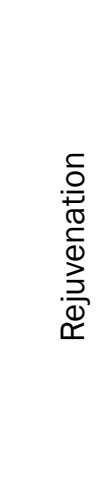 } & Rejuvenator Type & CRF & CRF & CRF & Rejuvaseal & CRF & CRF \\
\hline & $\begin{array}{l}\text { Rejuvenator } \\
\text { Dosage (percent) }\end{array}$ & 2 & 2 & 2 & 0.5 & 2 & 2 \\
\hline & $\begin{array}{l}\text { Type I portland } \\
\text { Cement Dosage (percent) }\end{array}$ & 0 & 0 & 0 & 1 & 0 & 0 \\
\hline & Total Batches & 3 & 6 & 6 & 6 & 6 & 6 \\
\hline & $\begin{array}{l}\text { Total Recycled } \\
\text { Mix Weight (lb) }\end{array}$ & 906 & 1,260 & 944 & 1,646 & 1,254 & 1,881 \\
\hline & Total Mixing Time (min) & 40 & 82 & 68 & 73 & 60 & 52 \\
\hline
\end{tabular}




\begin{tabular}{|c|c|c|c|c|c|c|c|}
\hline \multirow{2}{*}{\multicolumn{2}{|c|}{ Repair Stage }} & \multicolumn{6}{|c|}{ Repair ID } \\
\hline & & \multirow{2}{*}{$\begin{array}{l}\text { FD-1 } \\
490\end{array}$} & \multirow{2}{*}{$\begin{array}{l}\text { FD-1a } \\
607\end{array}$} & \multirow{2}{*}{$\begin{array}{l}\text { FD-2 } \\
156\end{array}$} & \multirow{2}{*}{\begin{tabular}{|l|} 
FD-3 \\
158
\end{tabular}} & \multirow{2}{*}{$\begin{array}{l}\text { FD-4 } \\
77\end{array}$} & \multirow{2}{*}{$\begin{array}{l}\text { FD-5 } \\
127\end{array}$} \\
\hline \multirow{3}{*}{ 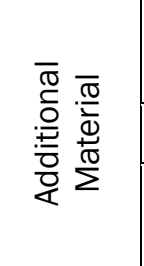 } & $\begin{array}{l}\text { Harvested RAP } \\
\text { Material (Ib) }\end{array}$ & & & & & & \\
\hline & Pelletized Asphalt (Ib) & 250 & 0 & 550 & 0 & 600 & 0 \\
\hline & $\begin{array}{l}\text { Total Repair } \\
\text { Material Weight (Ib) }\end{array}$ & 1,646 & 1,867 & 1,650 & 1,804 & 1,931 & 2,008 \\
\hline \multirow{4}{*}{ 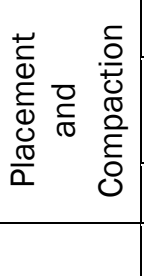 } & No. of Lifts & 2 & 2 & 2 & 2 & 1 & 2 \\
\hline & $\begin{array}{l}\text { Average Compaction } \\
\text { Temperature }\left({ }^{\circ} \mathrm{F}\right)\end{array}$ & 205 & 220 & 228 & 233 & 250 & 238 \\
\hline & Nuclear Density (pcf) & 131.5 & 136.5 & 135.2 & 136.2 & 141.6 & 132.7 \\
\hline & Core Density & 142.2 & 141.2 & 144.0 & 142.0 & 143.7 & 141.8 \\
\hline
\end{tabular}

Table 13. Partial-depth repairs description.

\begin{tabular}{|c|c|c|c|c|}
\hline \multirow{2}{*}{\multicolumn{2}{|c|}{ Repair Stage }} & \multicolumn{3}{|l|}{ Repair ID } \\
\hline & & PD-2 & PD-3 & PD-4 \\
\hline \multirow{7}{*}{ 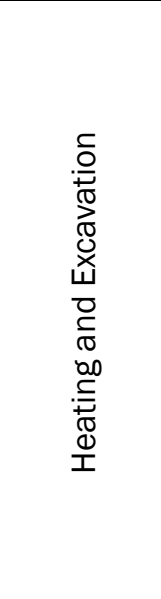 } & Excavation Depth (in.) & 2.5 & 2.5 & 2 \\
\hline & Excavation Method & $\begin{array}{l}\text { Asphalt } \\
\text { Processor }\end{array}$ & $\begin{array}{l}\text { Asphalt } \\
\text { Processor }\end{array}$ & $\begin{array}{l}\text { Asphalt } \\
\text { Processor }\end{array}$ \\
\hline & Heater Type & Electric & Propane & Propane \\
\hline & Heating Duration (min) & 58 & 30 & 37 \\
\hline & $\begin{array}{l}\text { Initial Surface } \\
\text { Temperature }\left({ }^{\circ} \mathrm{F}\right)\end{array}$ & 125 & 108 & 86 \\
\hline & $\begin{array}{l}\text { Final Surface } \\
\text { Temperature }\left({ }^{\circ} \mathrm{F}\right)\end{array}$ & 560 & 450 & 360 \\
\hline & $\begin{array}{l}\text { Final Temperature } \\
\text { at Depth }\left({ }^{\circ} \mathrm{F}\right)\end{array}$ & 145 & 200 & 200 \\
\hline \multirow{6}{*}{ 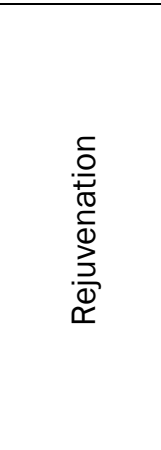 } & Rejuvenator Type & Rejuvaseal & CRF & Rejuvaseal \\
\hline & Rejuvenator Dosage (percent) & 0.5 & 2 & 0.5 \\
\hline & $\begin{array}{l}\text { Type I Portland } \\
\text { Cement Dosage (percent) }\end{array}$ & 1 & 0 & 1 \\
\hline & Total Batches & 2 & 3 & 3 \\
\hline & $\begin{array}{l}\text { Total Recycled } \\
\text { Mix Weight (Ib) }\end{array}$ & 568 & 765 & 840 \\
\hline & Total Mixing Time (min) & 17 & 30 & 30 \\
\hline \multirow{3}{*}{ 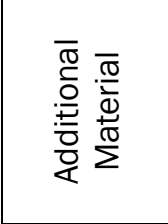 } & Harvested RAP Material (Ib) & 0 & 0 & 0 \\
\hline & Pelletized Asphalt (Ib) & 0 & 0 & 0 \\
\hline & $\begin{array}{l}\text { Total Repair } \\
\text { Material Weight (lb) }\end{array}$ & 568 & 765 & 840 \\
\hline$\pm \frac{1}{\pi} \sigma 0$ & No. of Lifts & 1 & 1 & 1 \\
\hline
\end{tabular}




\begin{tabular}{|c|c|c|c|}
\hline \multirow[b]{2}{*}{ Repair Stage } & \multicolumn{3}{|c|}{ Repair ID } \\
\hline & PD-2 & PD-3 & PD-4 \\
\hline $\begin{array}{l}\text { Average Compaction } \\
\text { Temperature }\left({ }^{\circ} \mathrm{F}\right)\end{array}$ & 185 & 210 & 225 \\
\hline Nuclear Density (pcf) & 123.9 & 126.0 & 134.3 \\
\hline Core Density (pcf) & 135.2 & 141.4 & 143.7 \\
\hline
\end{tabular}

Note: PD-1 was converted to a full-depth repair (FD-1-a).

Figure 58. Post-compaction repair surface (PD-2).

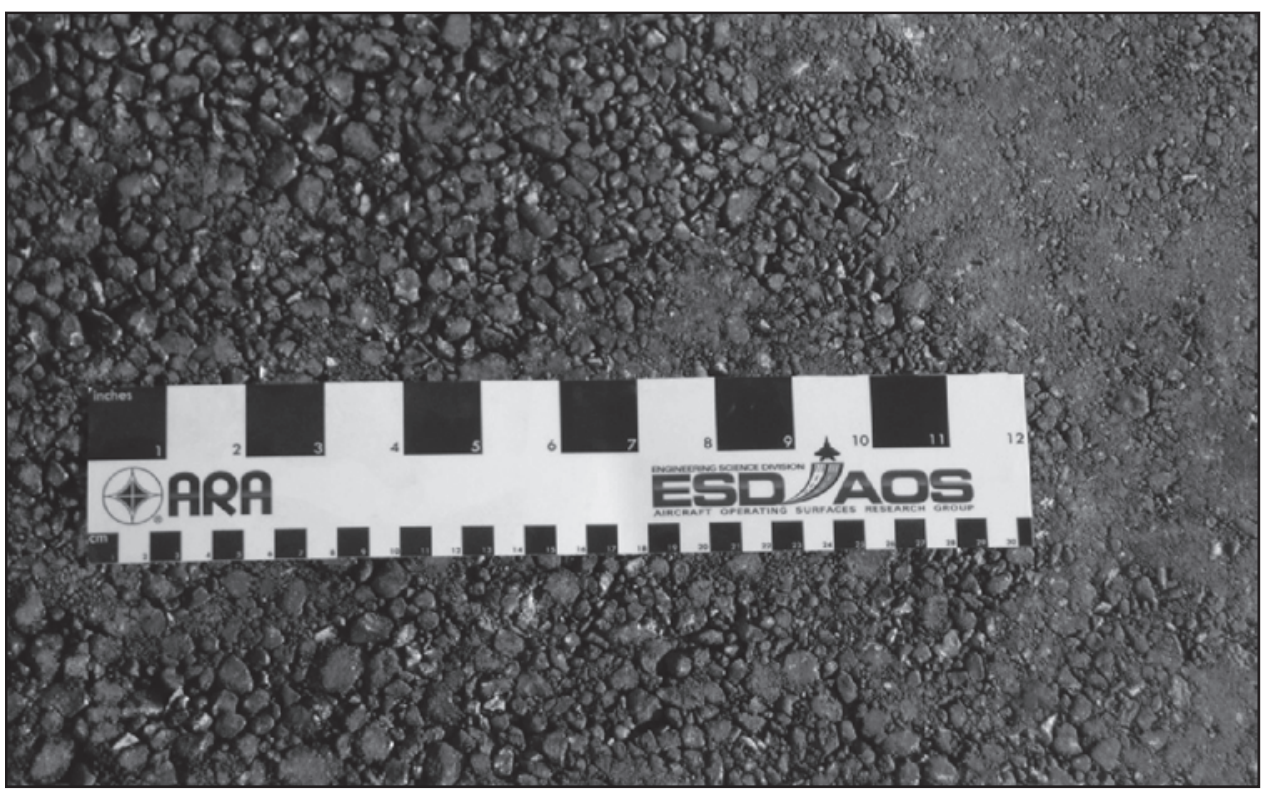

Figure 59. Surface cracking (PD-3).

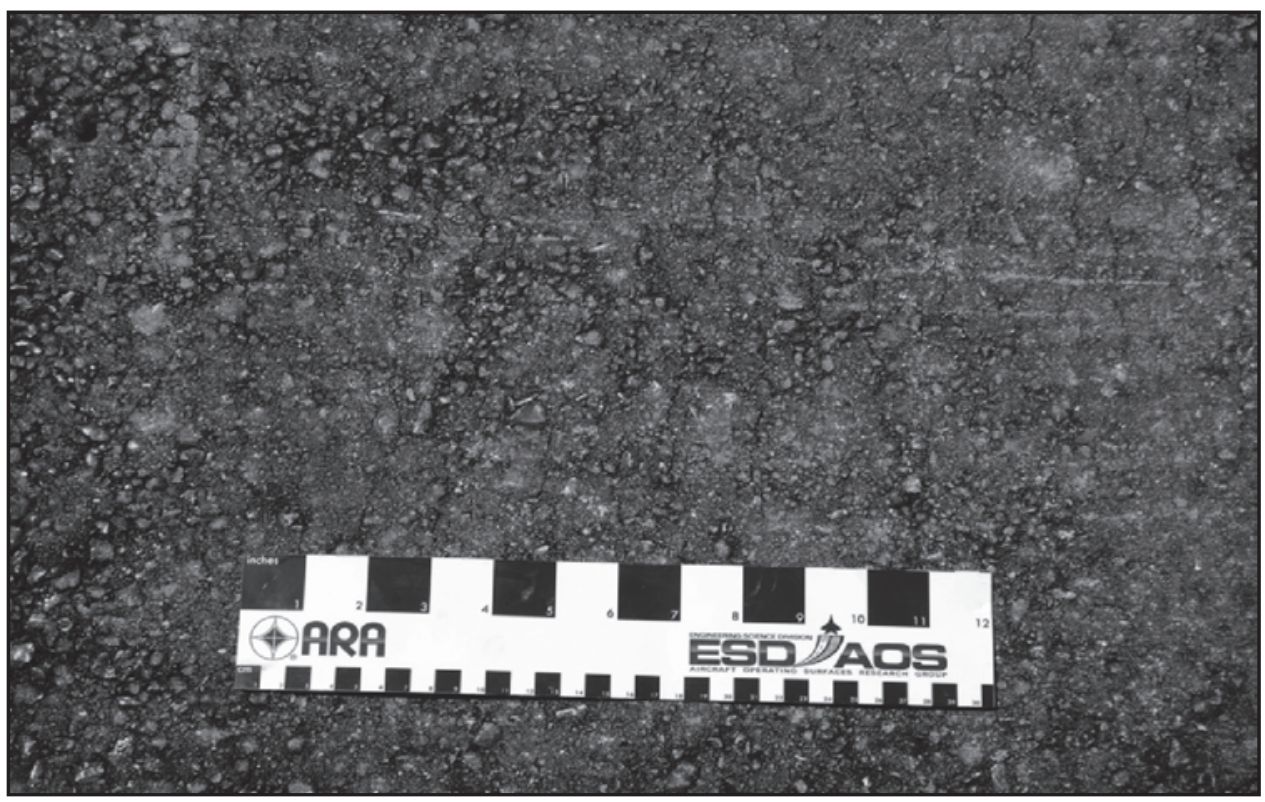


Figure 60. Poorhouse test site repair areas.

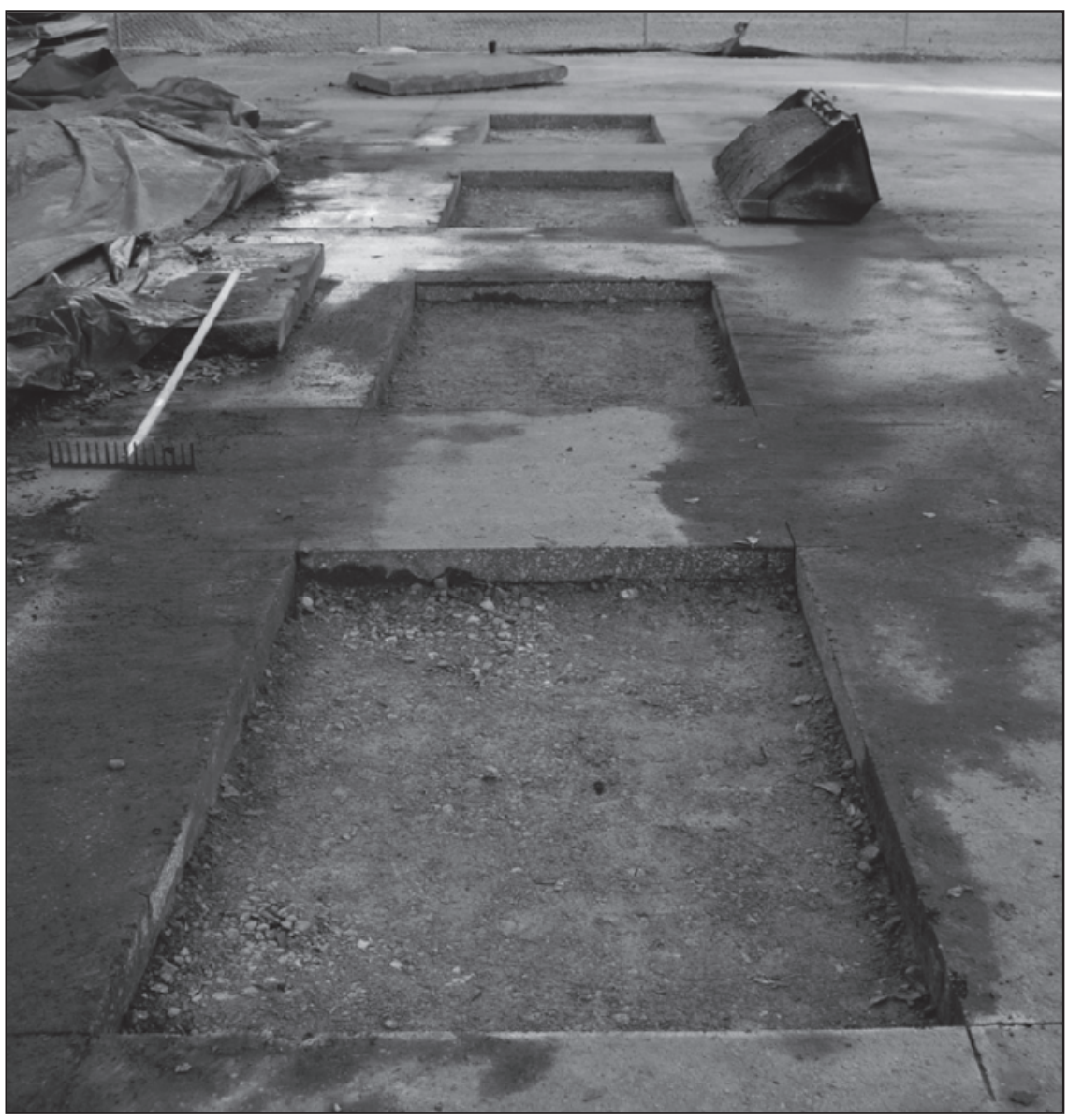

Table 14. Repair nomenclature used for ERDC test site.

\begin{tabular}{|l|l|}
\hline Repair ID & Repair Description \\
\hline PHP-1 & ERDC RAP + 2 percent CRF \\
\hline PHP-2 & ERDC RAP (no rejuvenator) \\
\hline PHP-3 & Vicksburg Airport RAP + 2 percent CRF \\
\hline PHP-4 & Vicksburg Airport RAP + 0.5 percent Rejuvaseal+ 1 percent cement a \\
\hline
\end{tabular}

a Asphalt processor was used for mixing the RAP, rejuvenator, and cement in the repair void.

The PHP-1 repair was performed using RAP material collected from a nearby location (ERDCRAP) and 2 percent CRF rejuvenator. Since laboratory tests had not been performed on this RAP material, it was not known how the rejuvenator and dosage would affect repair performance of RAP derived from relatively new AC. Post-compaction of PHP-1 revealed low nuclear gauge density readings. Two reasons were suspected for the low readings: 1) the added rejuvenator made the mix tender and unstable; and 2) the mat cooled too quickly bringing the mix to a temperature range where the mix moved, shoved, and checked under the applied compactive 
effort. The heater was placed over the compacted repair until a surface temperature of $250^{\circ} \mathrm{F}$ was reached. The mat was recompacted, and the density improved to an acceptable level.

PHP-2 was repaired using only the ERDC RAP; no rejuvenator was added. As a contrast to adding rejuvenator to fairly new asphalt as performed in PHP-1, determining repair characteristics using nothing but the RAP material was of interest. The final repair was visually inspected, and no signs of surface cracking were observed.

PHP-3 was performed using the Vicksburg Airport RAP and 2 percent $\mathrm{CRF}$. The final repair was visually sound and exhibited no signs of surface cracking or bonding issues. However, nuclear gauge density readings were below target values.

PHP- 4 was performed using 0.5 percent Rejuvaseal and 1 percent Type I Portland cement. The repair method specified that the cement and rejuvenator be mixed into the RAP using the mixing drum prior to placement. The first three batches were produced without issue. During the fourth batch, the chain on the skid steer-mounted mixing drum broke and was beyond field repair. The batch remaining in the drum was poured onto the stockpile, and the rejuvenation process was finished in the repair void itself using the propane heater and asphalt processor unit.

The remaining RAP material needed was weighed in 5-gal buckets, emptied on the stockpile cold and pushed into the void using a skid steer and bucket. The heater was then placed over the repair area to slowly bring the cold RAP to temperature. To avoid scorching the surface material, the heater was periodically removed and the processor was used to mix the mass. Once the RAP had reached an average internal temperature of $250^{\circ} \mathrm{F}$, the heater was removed, and the cement and rejuvenator dosages were added as seen in Figure 61 and Figure 62. The cement was added first. The RAP was then processed again to ensure a homogeneous mixture.

The blended RAP was screeded flat, and the surrounding pavement was swept clean before final compaction. The repair was visually inspected for surface cracking and other signs of distress. Surface cracks were observed towards the repair interior and are shown in Figure 63. 
Figure 61. Cement addition to PHP-4.

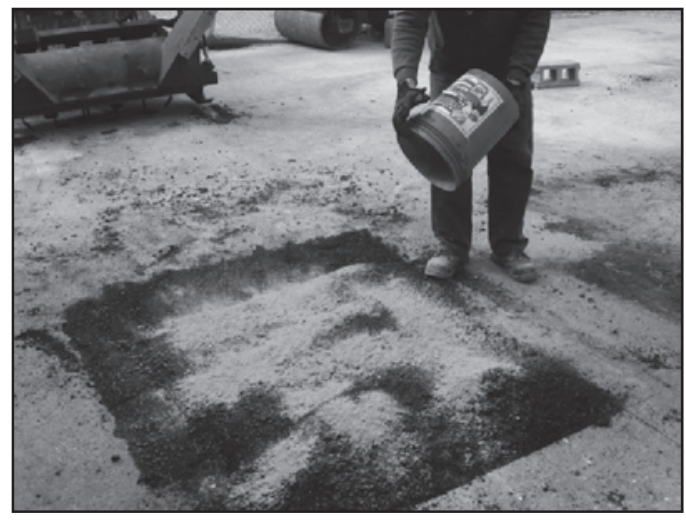

Figure 62. Rejuvenator addition to PHP-4.

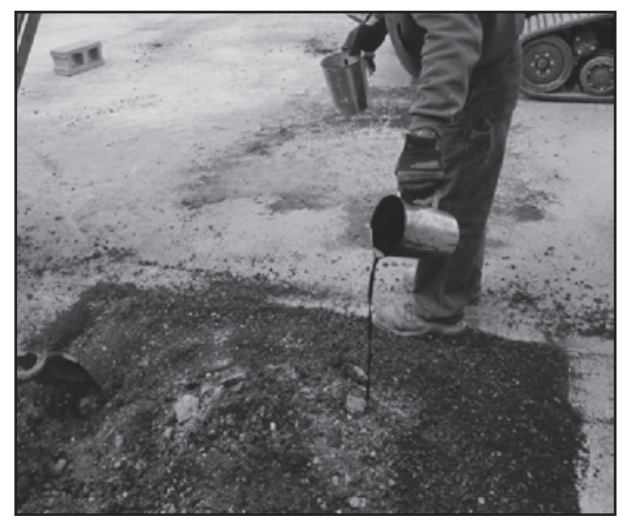

Figure 63. Post-compaction surface cracking (PHP-4).

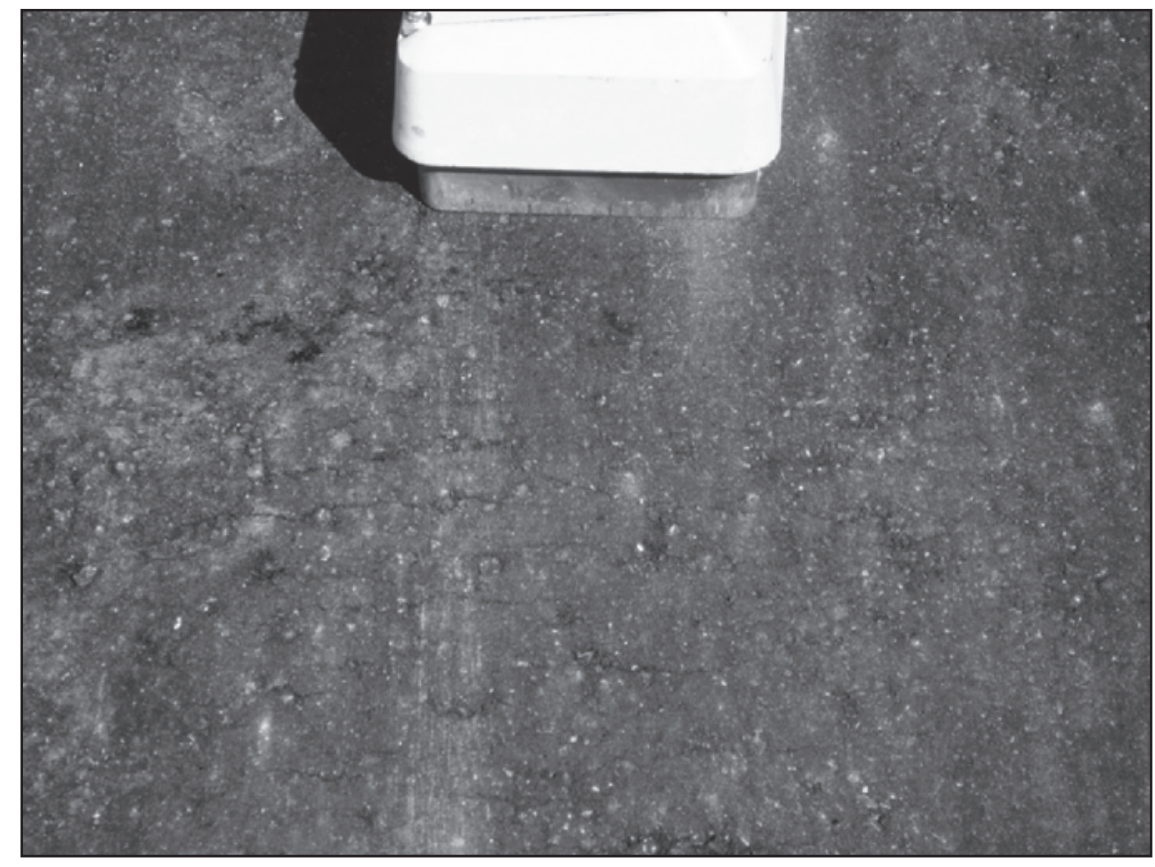

Table summarizes the finished repair compaction data from the repairs at the Test Site 2. 
Table 15. Test Site 2 repairs description.

\begin{tabular}{|c|c|c|c|c|c|}
\hline \multirow{2}{*}{\multicolumn{2}{|c|}{ Repair Stage }} & \multicolumn{4}{|c|}{ Repair ID } \\
\hline & & PHP-1 & PHP-2 & PHP-3 & PHP-4 \\
\hline \multirow{7}{*}{ 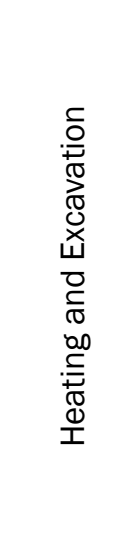 } & Excavation Depth (in.) & 4.5 & 4.5 & 5 & 5 \\
\hline & Excavation Method & Saw Cut & Saw Cut & Saw Cut & Saw Cut \\
\hline & Heater Type & Propane ${ }^{a}$ & Propanea & Propane $^{a}$ & Propane $^{a}$ \\
\hline & Heating Duration (min) & N/A & N/A & N/A & N/A \\
\hline & \begin{tabular}{|l} 
Initial Surface \\
Temperature $\left({ }^{\circ} \mathrm{F}\right)$
\end{tabular} & N/A & N/A & N/A & N/A \\
\hline & $\begin{array}{l}\text { Final Surface } \\
\text { Temperature }\left({ }^{\circ} \mathrm{F}\right)\end{array}$ & N/A & N/A & N/A & N/A \\
\hline & $\begin{array}{l}\text { Final Temperature } \\
\text { at Depth }\left({ }^{\circ} \mathrm{F}\right)\end{array}$ & N/A & N/A & N/A & N/A \\
\hline \multirow{6}{*}{ 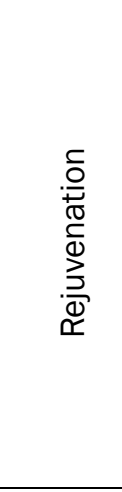 } & Rejuvenator Type & CRF & None & CRF & Rejuvaseal \\
\hline & $\begin{array}{l}\text { Rejuvenator Dosage } \\
\text { (percent) }\end{array}$ & 2 & 0 & 2 & 0.5 \\
\hline & $\begin{array}{l}\text { Type I portland } \\
\text { Cement Dosage (percent) }\end{array}$ & 0 & 0 & 0 & 0 \\
\hline & Total Batches & 6 & 6 & 6 & $3^{b}$ \\
\hline & $\begin{array}{l}\text { Total Recycled } \\
\text { Mix Weight (lb) }\end{array}$ & 1,688 & 1,650 & 1,650 & $841^{c}$ \\
\hline & Total Mixing Time (min) & 63 & 44 & 45 & $24^{d}$ \\
\hline \multirow{3}{*}{ 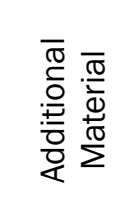 } & Harvested RAP Material & 0 & 0 & 0 & 0 \\
\hline & Pelletized Asphalt & 0 & 0 & 0 & 0 \\
\hline & $\begin{array}{l}\text { Total Repair } \\
\text { Material Weight (Ib) }\end{array}$ & 1,688 & 1,650 & 1,650 & $841^{\circ}$ \\
\hline \multirow{4}{*}{ 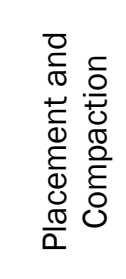 } & No. of Lifts & 1 & 2 & 2 & 2 \\
\hline & $\begin{array}{l}\text { Average Compaction } \\
\text { Temperature }\left({ }^{\circ} \mathrm{F}\right)\end{array}$ & 225 & 248 & 184 & 204 \\
\hline & Nuclear Density (pcf) & 146.9 & 145.2 & 136.0 & 133.9 \\
\hline & Core Density (pcf) & 148.3 & 144.8 & 140.3 & 138.6 \\
\hline
\end{tabular}

a Propane heater was used during the rejuvenation process to keep the rejuvenated RAP material in temperature. It was not used to soften the asphalt pavement for removal.

b Number of batches mixed in the drum mixer.

c Does not include the weight of the material that was mixed in place.

d Does not include the time to mix the material in place. 


\section{Repair Performance Evaluation}

\section{Simulated aircraft traffic operations}

The recycled repairs were evaluated using the ERDC's F-15E load cart shown in Figure 64. This load cart is equipped with a 36-in.-diam., 11-in.wide, 18-ply tire inflated to $325 \mathrm{psi}$ and loaded so that the single test wheel supported 35,235 lb. The load cart was powered by the front half of a US Army 2.5- ton transport truck with an outrigger wheel to prevent overturning.

Figure 64. F15-E load cart.

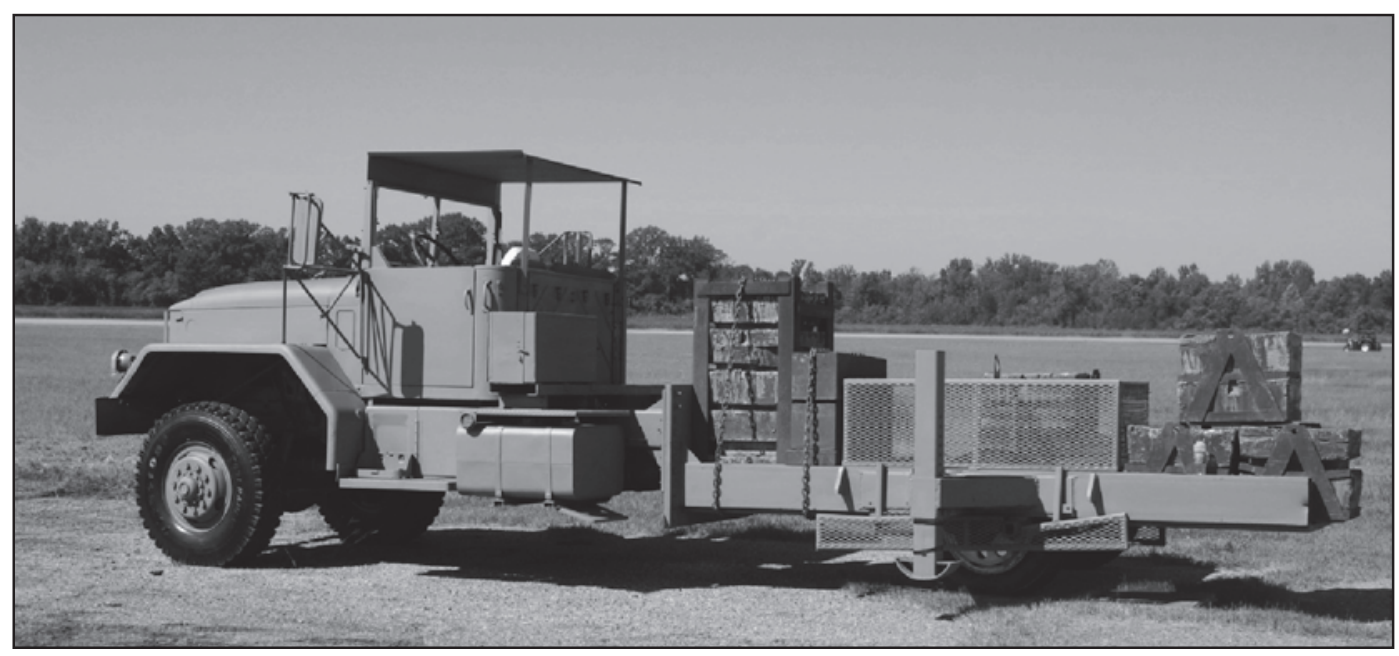

The multiple-lane trafficking pattern illustrated in Figure 65 was used. The normally distributed traffic pattern was simplified for ease-of-use by the load cart operator. Trafficking consisted of driving the load cart forward and then backward over the repairs in the same wheel path, then moving 9 in. laterally to the adjacent path and repeating. The distance between wheel paths was the approximate width of the traffic tire. One traverse of the repair width was defined as one coverage or 16 total passes. Pre-traffic measurements of rut depth were obtained with rod and level as well as straight edge and tape measure as a baseline in three separate cross sections (north, center, and south of each repair). A single series of profile measurements was also obtained along each repair center line. The same measurements were taken after each set of passes (coverage). Failure criterion was considered to be 1-in. rut depth. 
Figure 65. Load cart traffic diagram.

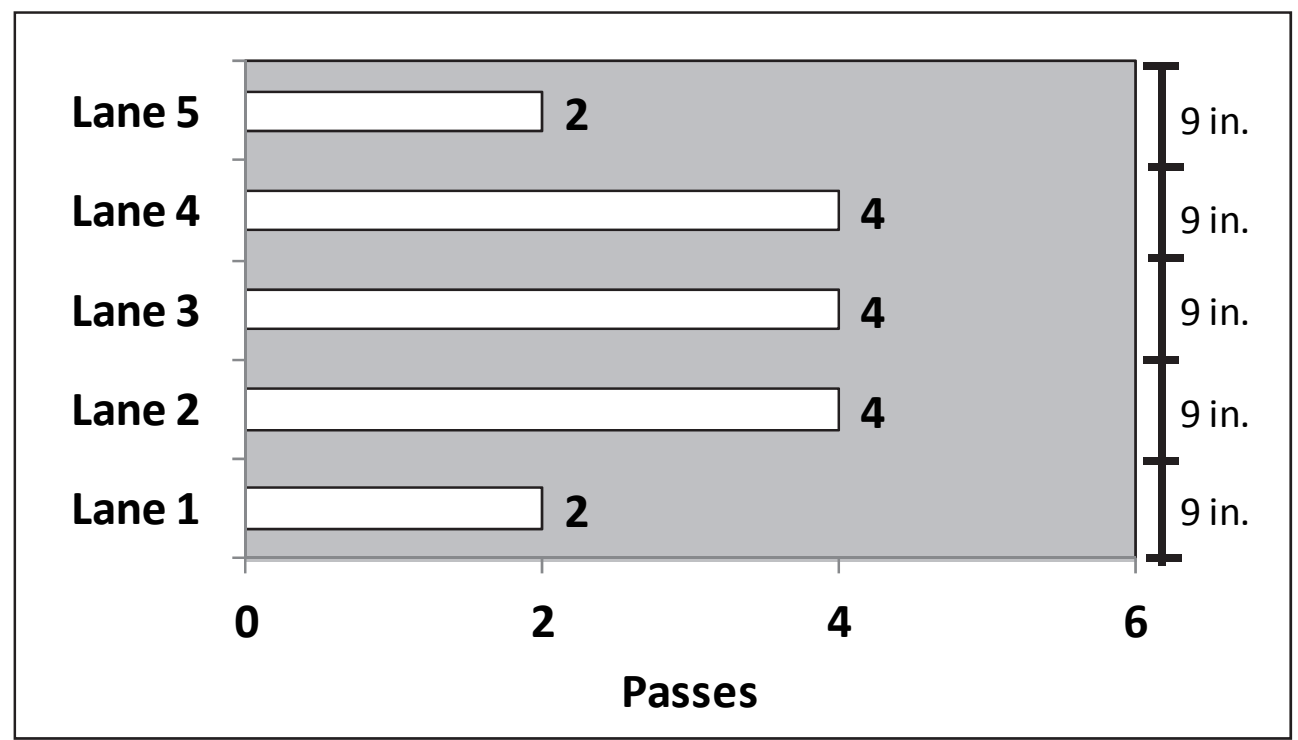

\section{Rutting measurements and forensic analyses}

\section{Test Site 1}

\section{Rutting measurements}

After the third coverage of the F-15 load cart (48 passes total), the measured rut depths in three of the full-depth repairs exceeded 1 in., and the surrounding asphalt rutted excessively. There was excessive loose material, which posed a tire hazard. To protect the load cart tire, traffic was discontinued on the full-depth repair lane. The partial-depth repairs failed after only two coverages of the F-15 load cart (32 passes total) with rut depth measurements exceeding 1 in. (except FD-1a). Figures 66 and 67 show an overview of all post-traffic full- and partial-depth repairs, respectively. No clear sign of tertiary deformation was observed on the surface of each repair. Rutting appeared to be more related to early subgrade failure than to issues within the rejuvenated material, as predicted by the CBR and LEEP design criteria. The traffic data collected at this test site are summarized in Table 16. The rut depth data plots are compiled in Appendix A. The maximum rut depth per number of passes was plotted and is presented in Figure 68 for the full-depth repairs and Figure 69 for the partial-depth repairs. These plots were used to determine the number of passes-to-failure (1-in. rut depth) of each repair. 
Figure 66. Full-depth repairs lane after traffic (front to back: FD-5, FD-4, FD-3, FD-2 and FD-1).

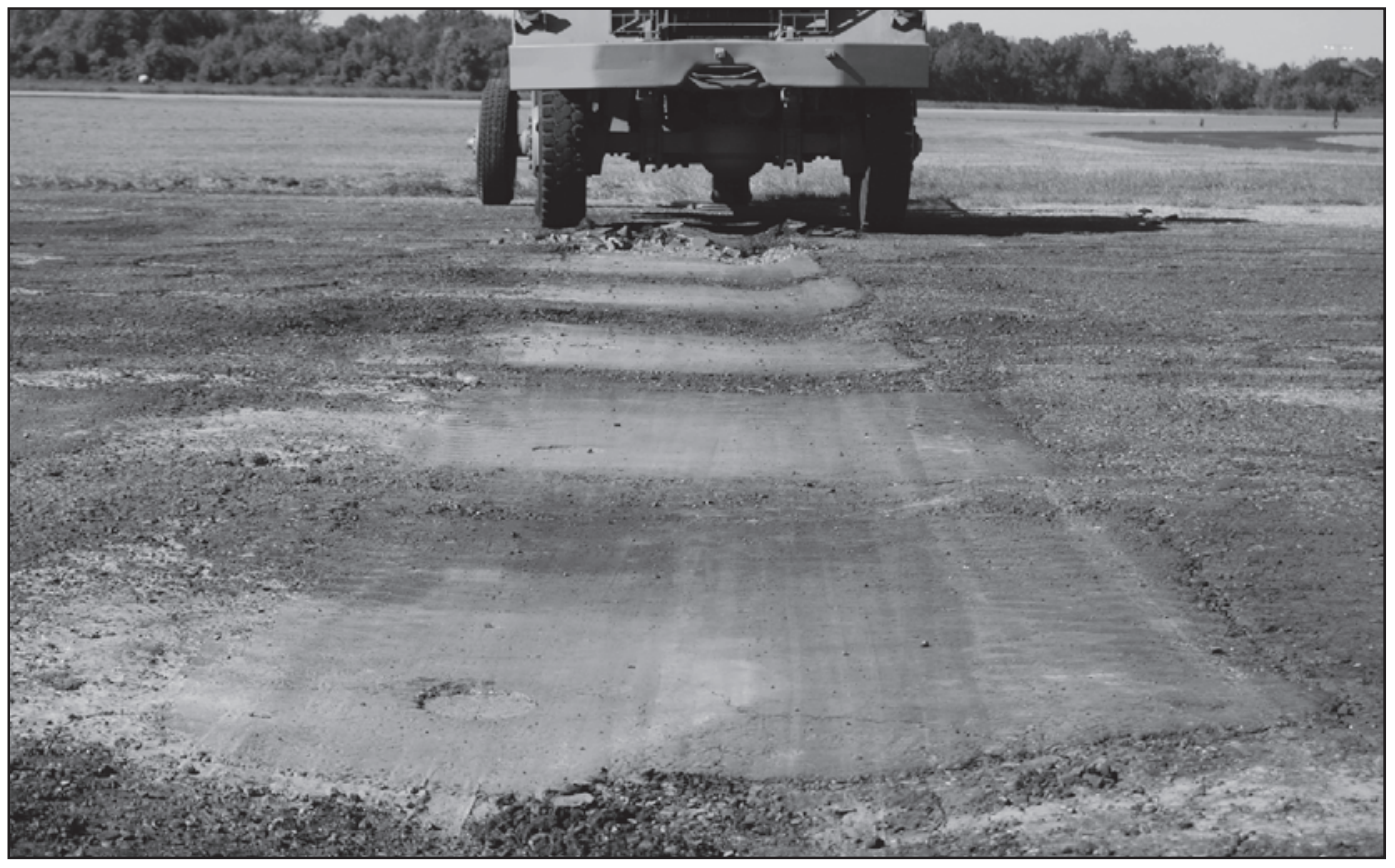

Figure 67. Partial-depth repairs lane after traffic (front to back: PD-4, PD-3, PD-2 and FD-1a).

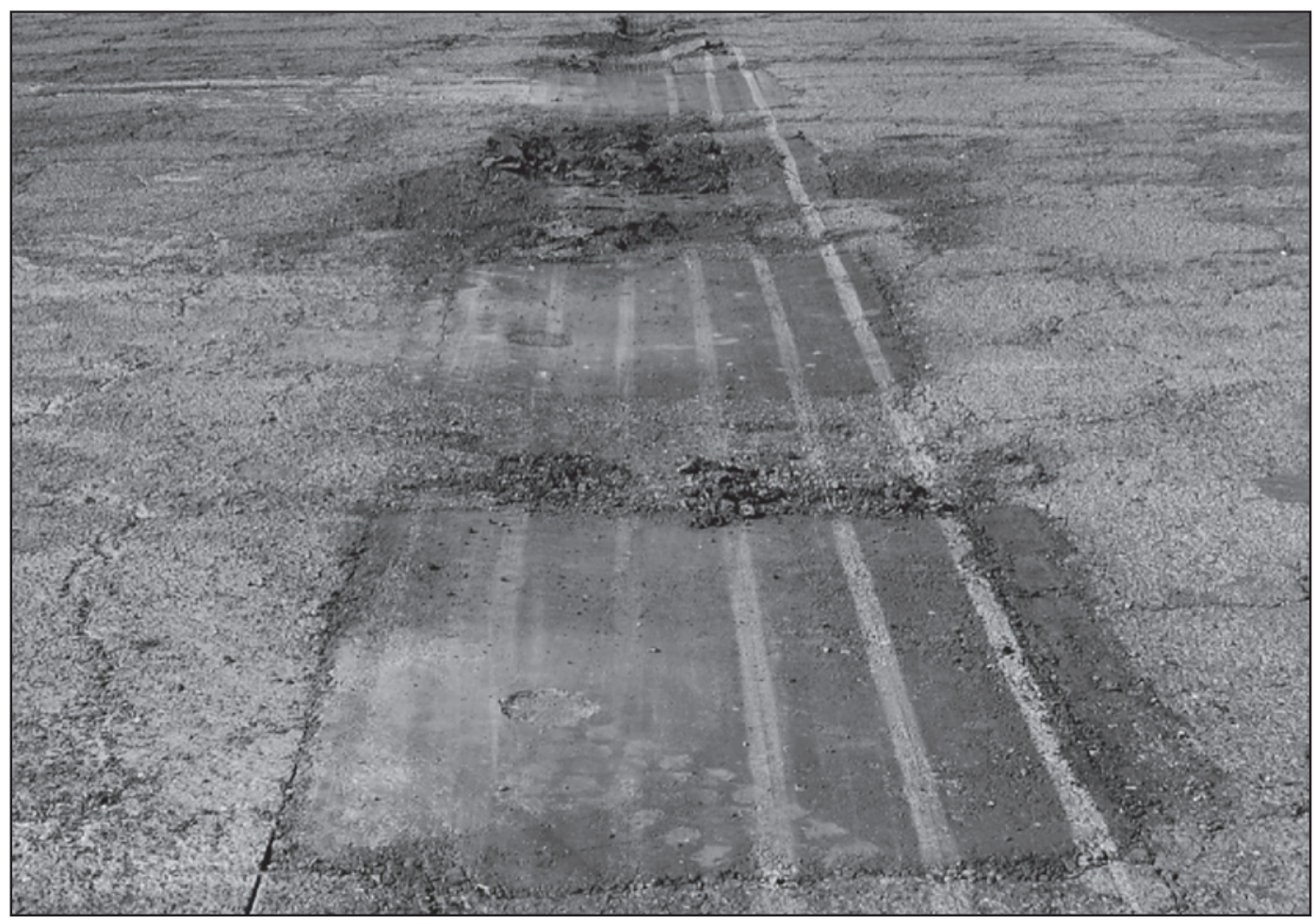


Table 16. Rut depth data from Test Site 1.

\begin{tabular}{|l|l|l|l|l|}
\hline Repair & Description & $\begin{array}{l}\text { In-Place } \\
\text { Density (pcf) }\end{array}$ & $\begin{array}{l}\text { Passes } \\
\text { to Failure }\end{array}$ & $\begin{array}{l}\text { Maximum } \\
\text { Rut Depth (in.) }\end{array}$ \\
\hline FD-1 & Electric Heater, Airport RAP + 2 percent CRF & 142.2 & 26 & 1.5 \\
\hline FD-2 & $\begin{array}{l}\text { Electric Heater, Airport RAP + 2 percent CRF + } \\
\text { Pelletized Asphalt }\end{array}$ & 144.0 & 46 & 1.1 \\
\hline FD-3 & $\begin{array}{l}\text { Electric Heater, Airport RAP + 0.5 percent Rejuvaseal } \\
+1 \text { percent Cement }\end{array}$ & 142.0 & 45 & 1.1 \\
\hline FD-4 & $\begin{array}{l}\text { Propane Heater, Airport RAP + 2 percent CRF + } \\
\text { Pelletized Asphalt }\end{array}$ & 143.7 & $48^{a}$ & 0.4 \\
\hline FD-5 & Propane Heater, Airport RAP + 2 percent CRF & 141.8 & $48^{a}$ & 0.9 \\
\hline FD-1ab & Electric Heater, Airport RAP + 2 percent CRF, Repeat & 141.2 & $32^{a}$ & 0.7 \\
\hline PD-2 & $\begin{array}{l}\text { Electric Heater, Airport RAP + 0.5 percent Rejuvaseal } \\
+1 \text { percent Cement }\end{array}$ & 135.5 & 20 & 1.7 \\
\hline PD-3 & Propane Heater, Airport RAP + 2 percent CRF & 141.4 & 18 & 1.6 \\
\hline PD-4 & $\begin{array}{l}\text { Propane Heater, Airport RAP + 0.5 percent } \\
\text { Rejuvaseal + 1 percent Cement }\end{array}$ & 143.7 & 32 & 1.0 \\
\hline
\end{tabular}

a Repairs did not fail at the maximum pass level applied.

b FD-1a was trafficked with partial-depth repairs to a maximum of 32 passes.

Figure 68. Rut depth measurements on full-depth repairs.

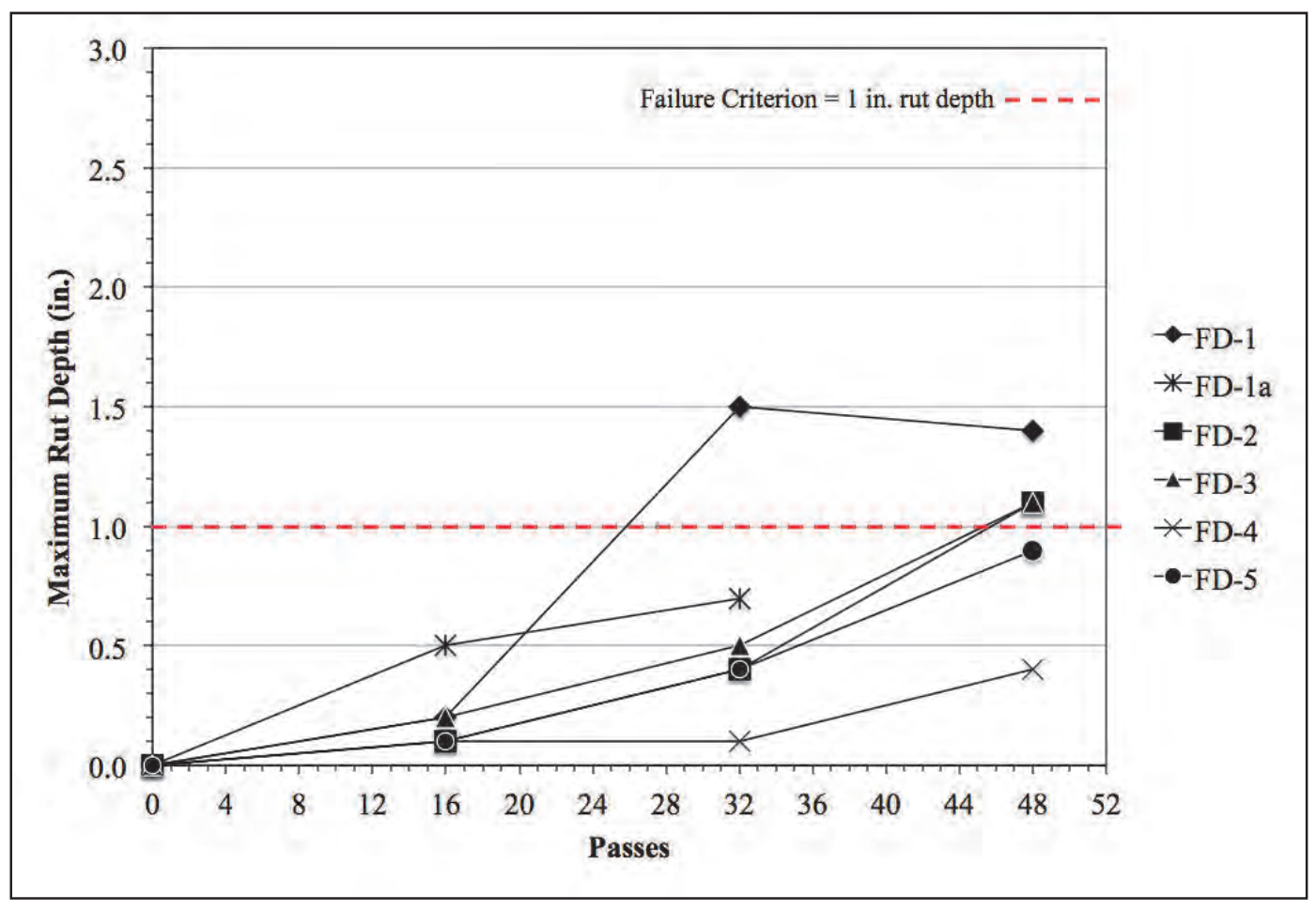


Figure 69. Rut depth measurements on partial-depth repairs.

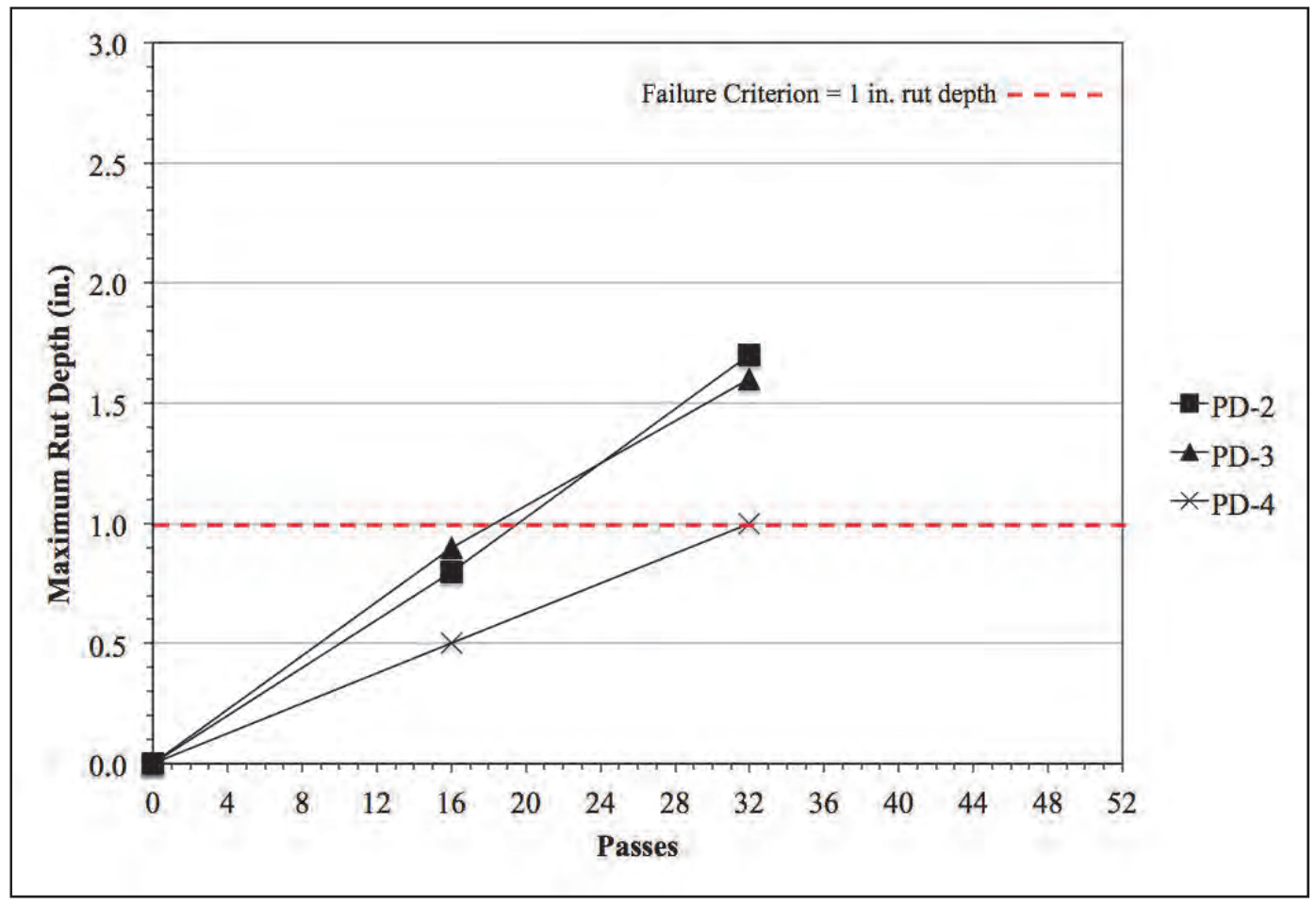

The number of passes that produced a 1-in. rut depth was determined from Figures 68 and 69. Although, the repairs at this test site did not meet the traffic requirements for sustainment operations ( $>3,500$ passes of F- 15 load cart) due to early failure of the subgrade, general observations may be used to compare performance between the different types of repair.

Based upon the rutting failure results obtained, the full-depth repairs performed better than the partial-depth repairs. The full-depth repairs where the propane heater was used (FD-4 and FD-5) performed better than most repairs using the electric heater (FD-1, FD-2, and FD-3). Some of the full-depth repairs where pelletized asphalt was used (FD-2 and FD4) yielded equivalent or better results than where only rejuvenated RAP material was used (FD-1a, FD-3 and FD-5). However, repair FD-1 failed before FD-1a. One difference between these two repairs was that FD-1 had a small amount of pelletized asphalt, and seemingly the pelletized asphalt performed better than the RAP material. The better performance could also be attributed to the fact that FD-1 was compacted at a lower temperature, which caused a lower final density than that of FD-1a.

The partial-depth repair with the highest rut depth was PD-2. Figure 70 shows PD-2 after failure. Excessive loose material with high foreign object 
damage (FOD) potential was observed after traffic. Because this repair had the highest air voids after compaction as shown in Table 15, failure could have been attributed to poor compaction.

Figure 70. Repair PD-2 after traffic.

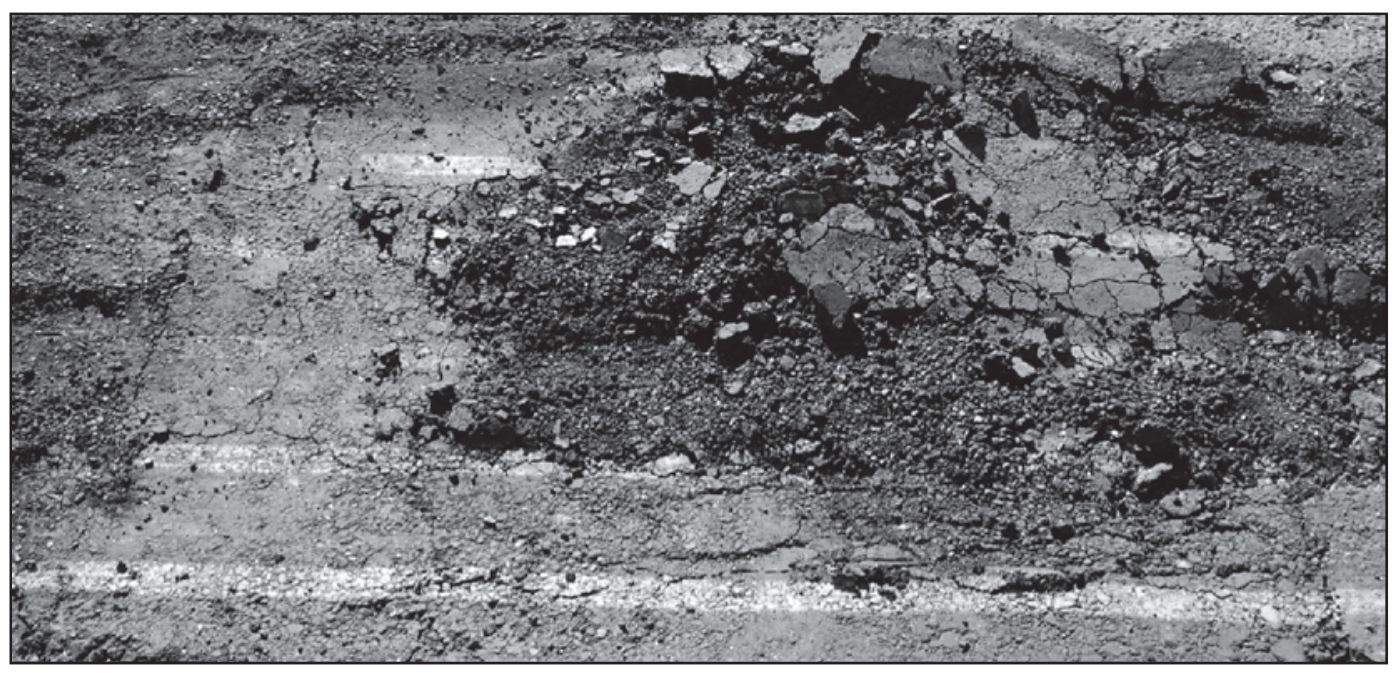

Repair entrance and exit areas relative to traffic direction showed cracking near the edges as shown in Figure 71. This was attributed to deformation of the surrounding asphalt material during traffic. The existing pavement did not provide enough confinement to prevent cracking and failure of the recycled asphalt material in these areas. A factor of failure in the Vicksburg Airport tests site was early subgrade failure and poor surrounding asphalt conditions.

Figure 71. Cracking on repair FD-1 caused by surrounding material failure.

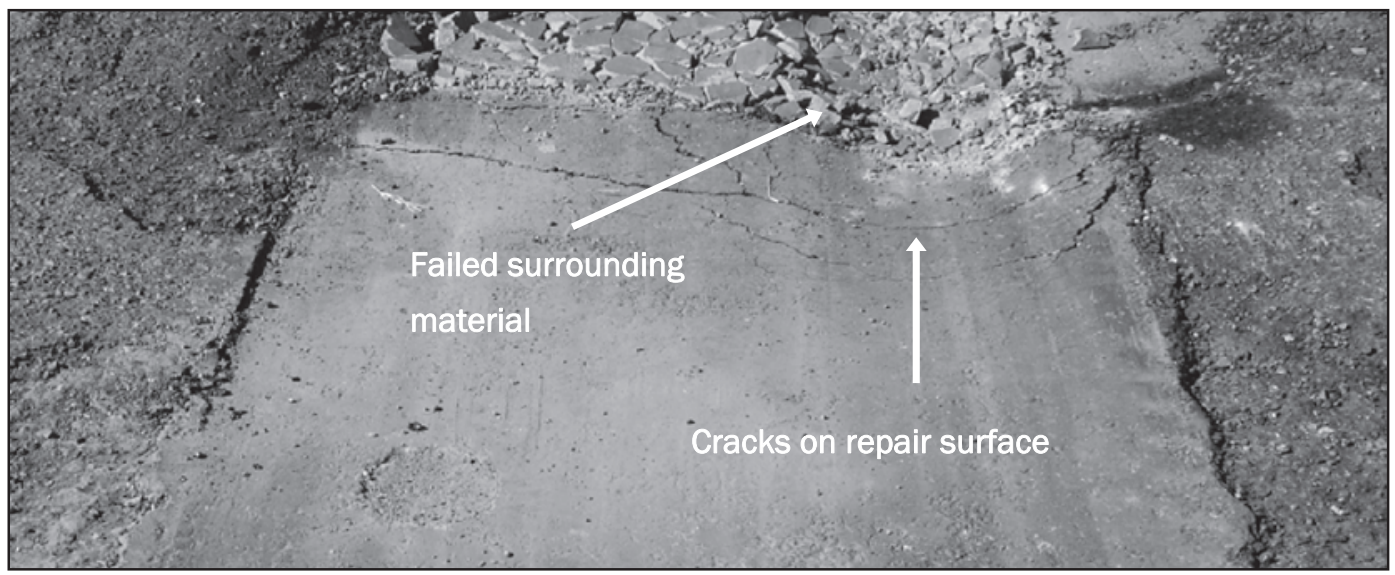

Additional testing was conducted at an alternative test location (Test Site 2), which was constructed to military specifications. This provided a sharp 
contrast to the weaker conditions encountered at the airport site. The stronger pavement structure in Test Site 2 supported traffic operations more effectively and helped isolate the analysis of failure to only the repair materials. The results from this evaluation are discussed in the next section.

\section{Forensic analysis}

Tertiary flow was not evident on any of the recycled asphalt repairs. The poor subgrade conditions at Test Site 1 caused the early failure of all the repairs under the heavy traffic load. For this reason, only two repairs were trenched for forensic analysis. Figures 72 and 73 show the post-failure cross-section trenches of repairs FD-2 and FD-5, respectively. The white lines shown delineate the boundaries between layers. From the trenches, the deformation of the asphalt layer was projected to the base material, as observed and the deformation was attributed to the poor subgrade conditions of this test site. This concurs with the failure predictions presented in Chapter 3, where failure was estimated to occur between 24-156 passes of the F-15 load cart subgrade layer.

Figure 72. Repair FD-2 trenched cross-section view after failure.

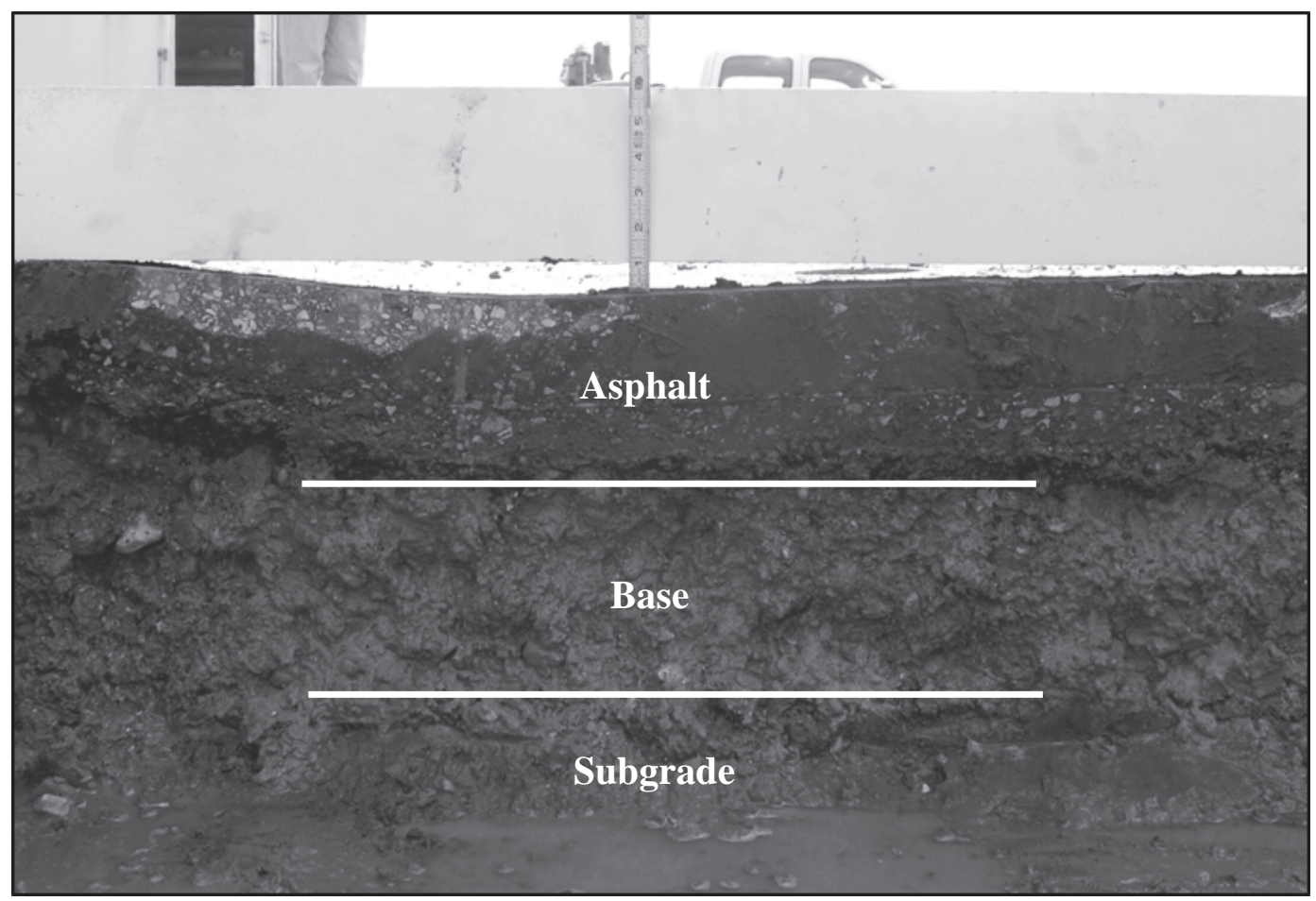


Figure 73. Repair FD-5 trenched cross-section view after failure.

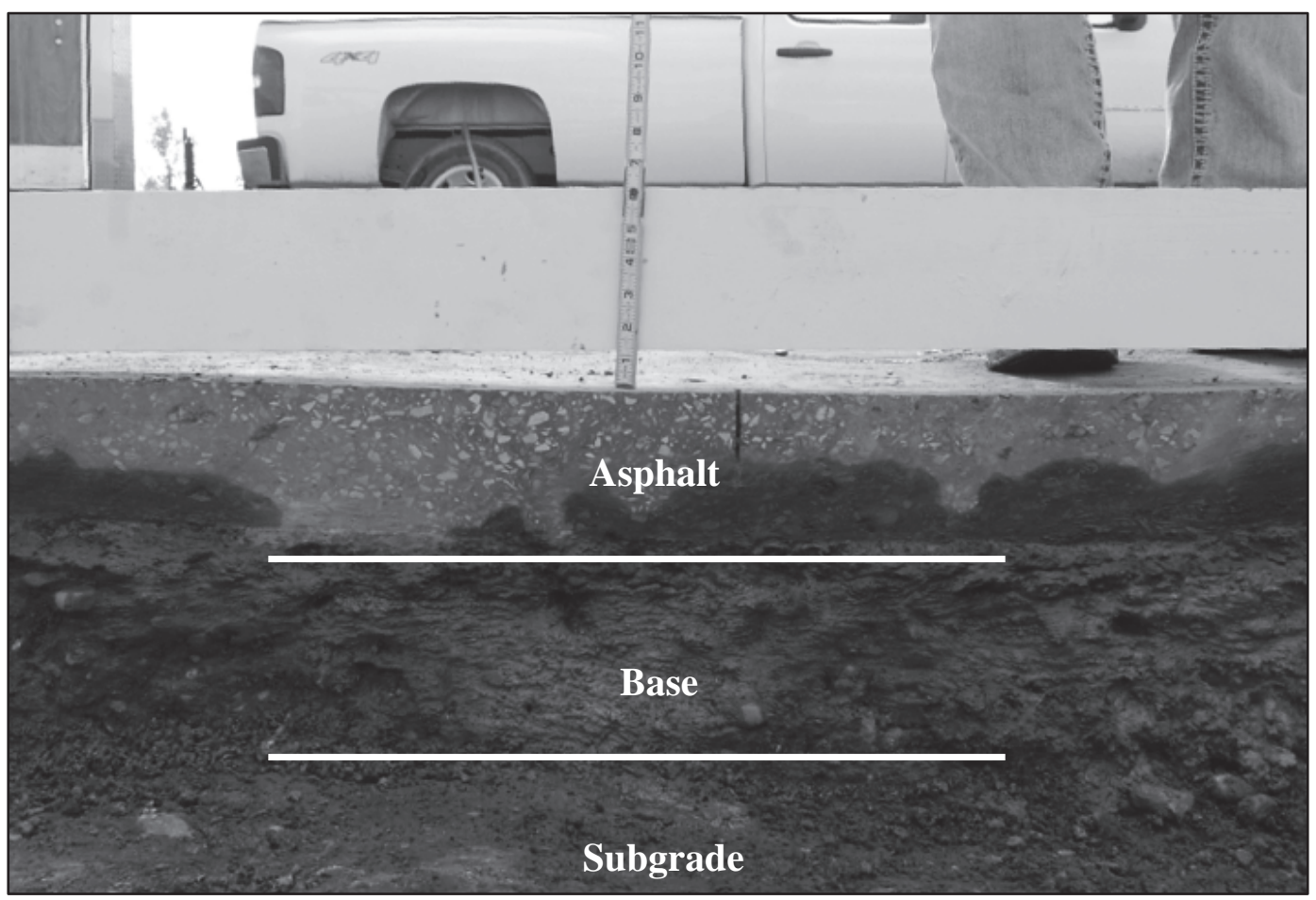

\section{Test Site 2}

\section{Rutting measurements}

The traffic data were collected at different intervals to capture the rutting behavior of the repairs as trafficking progressed. The F-15 load cart was trafficked over the repairs to a maximum of 255 coverages (4,080 passes), and none of the repairs experienced rut depth failure of $1 \mathrm{in}$. or greater. Traffic data collected at this test site are summarized in Table 17 and presented in Figure 74.

Table 17. Rut depth data from ERDC test site.

\begin{tabular}{|l|l|l|l|l|}
\hline Repair & Repair Description & $\begin{array}{l}\text { In-Place } \\
\text { Density (pcf) }\end{array}$ & $\begin{array}{l}\text { Passes } \\
\text { to Failure }\end{array}$ & $\begin{array}{l}\text { Maximum } \\
\text { Rut Depth (in.) }\end{array}$ \\
\hline PHP-1 & ERDC RAP + 2 percent CRF & 148.3 & $4086^{a}$ & 0.3 \\
\hline PHP-2 & ERDC RAP (no rejuvenator) & 144.8 & $4086^{a}$ & 0.4 \\
\hline PHP-3 & Vicksburg Airport RAP + 2 percent CRF & 140.3 & $4086^{a}$ & 0.6 \\
\hline PHP-4 & $\begin{array}{l}\text { Vicksburg Airport RAP + 0.5 percent } \\
\text { Rejuvaseal+ 1 percent cement a }\end{array}$ & 138.6 & $4086^{a}$ & 0.9 \\
\hline
\end{tabular}

a Repair did not fail at the maximum pass level applied. 
Figure 74. Rut depth measurements on repairs at Test Site 2.

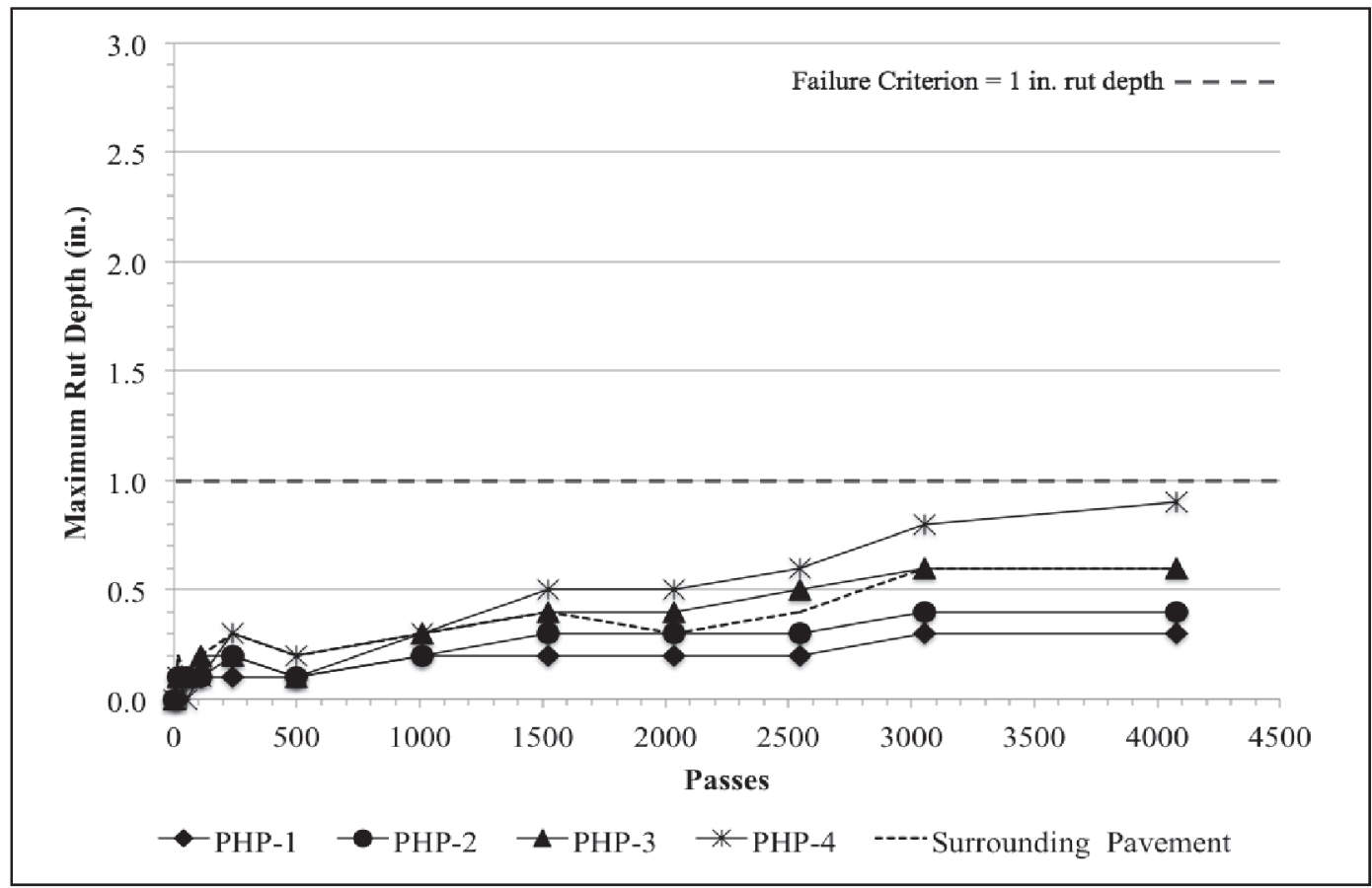

The fact that all the repairs installed and tested at Test Site 2 passed the sustainment repair criteria showed that repairs completed using the protocol set forth during these experiments meet the requirements for sustainment airfield pavement repair. Furthermore, the successful loading of repairs PHP- 1 and PHP- 2 suggests that the criteria may also be met when using an untested RAP material. PHP- 2 did not receive rejuvenation, and PHP-1 received 2.0 percent CRF, and both repairs passed. Repairs PHP-3 and PHP-4 showed that the rejuvenation and cement stabilization methods evaluated could produce repairs, which meet sustainment repair requirements for airfield pavements. As a result, cement stabilization could be a suitable option for early strength gain for sustainment repair operations.

\section{Forensic analysis}

Figures 75 to 76 show the trenched cross-section view of repairs at the ERDC test site after failure. The white lines delineate the boundary between the asphalt and base layers. Shear deformation was not evident in the asphalt pavement, and no deformation was observed at the bottom of the asphalt layer. Therefore, the small amount of deformation observed at the surface of the asphalt layer was attributed to compaction of the asphalt mix. The surrounding asphalt pavement rutted equal to or greater than all the repairs (except for PHP-4) as shown in Figure 78. 
Figure 75. Repair PHP-1 trenched cross-section view post traffic.

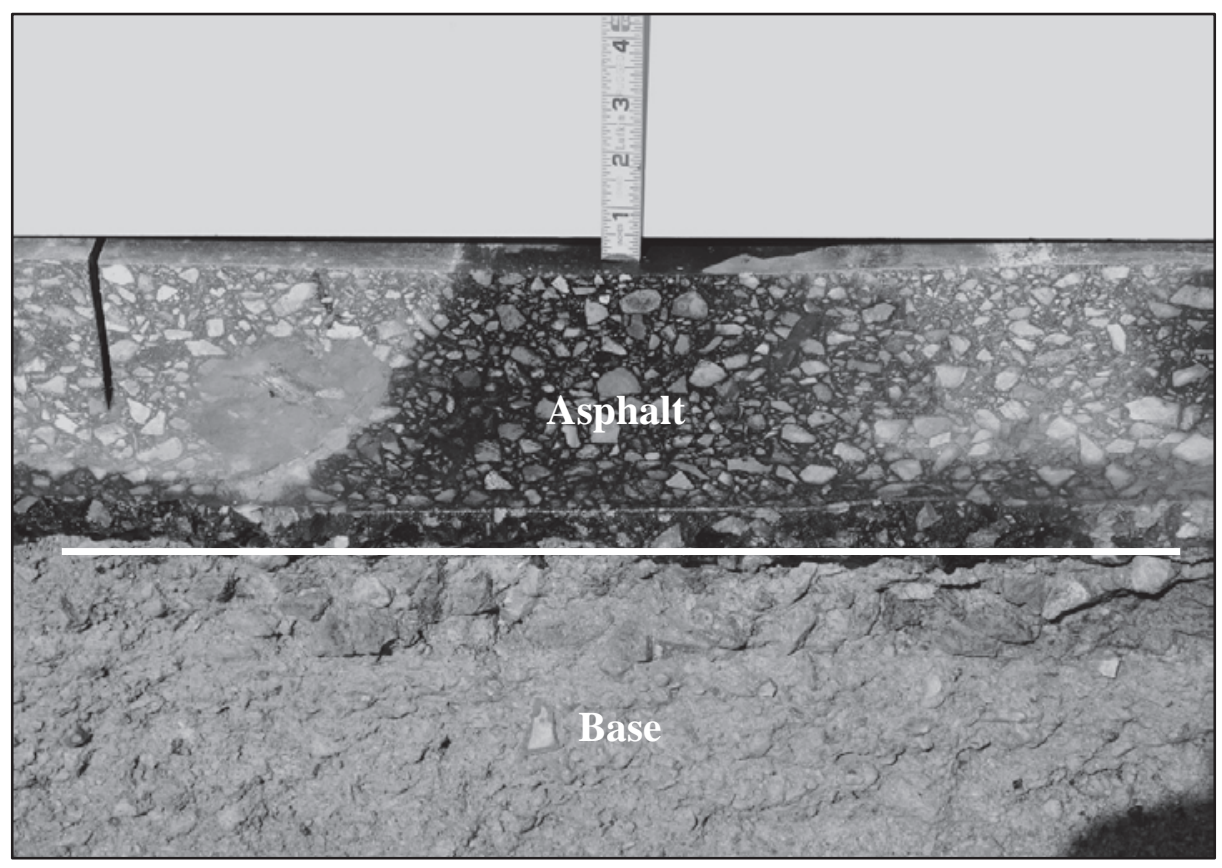

Figure 76. Repair PHP-2 trenched cross-section view post traffic.

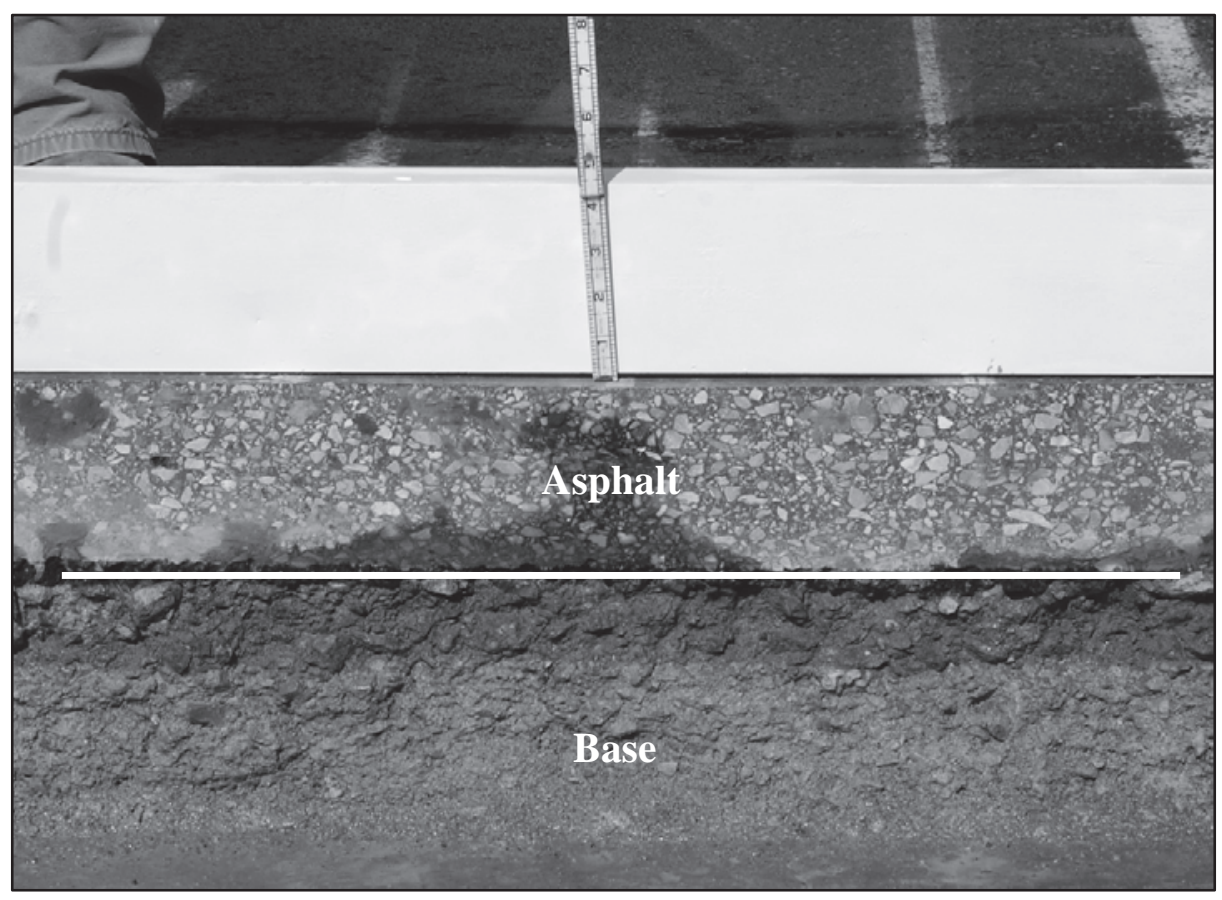


Figure 77. Repair PHP-3 trenched cross-section view post traffic.

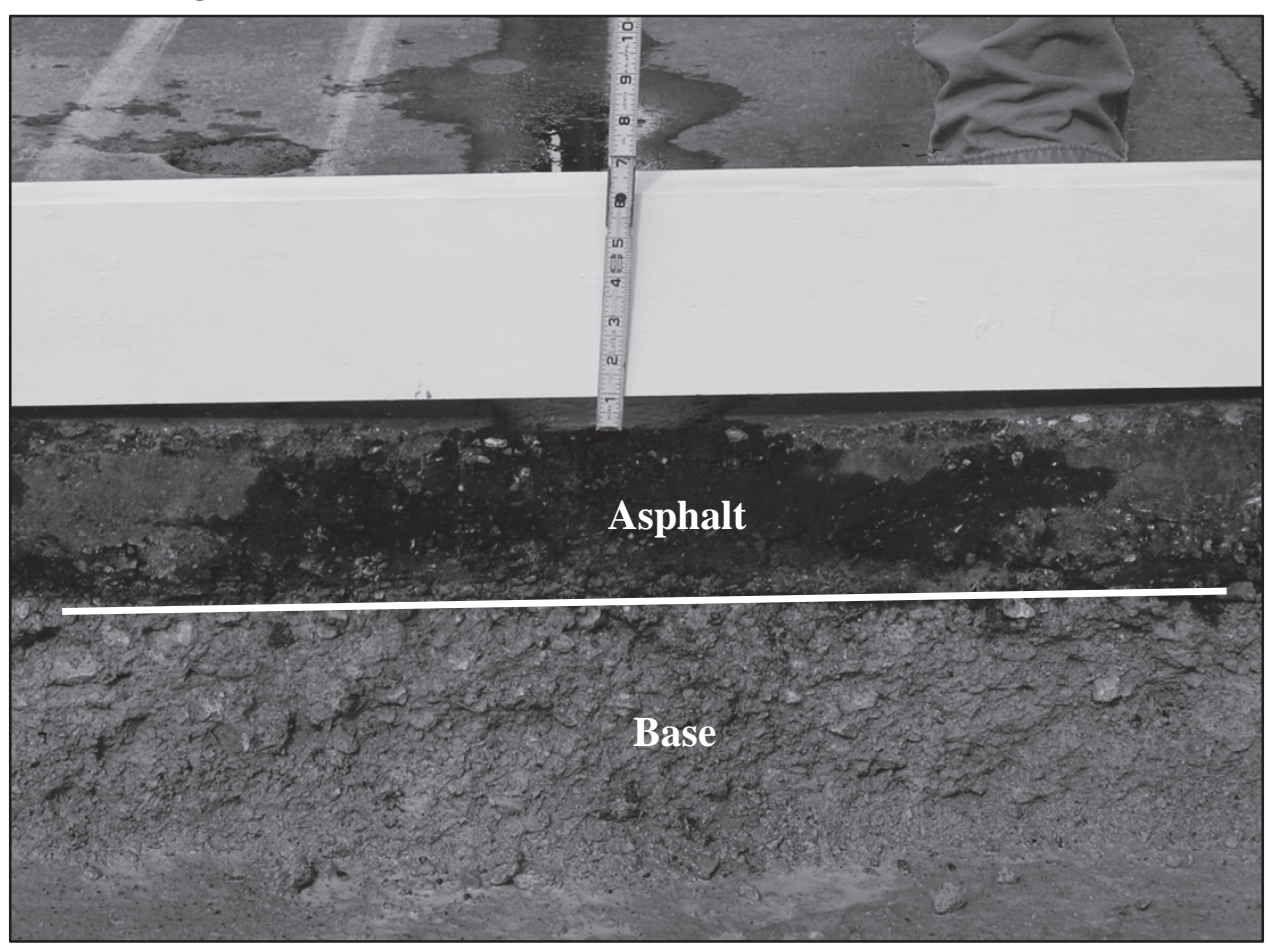

Figure 78. Repair PHP-4 trenched cross-section view post traffic.

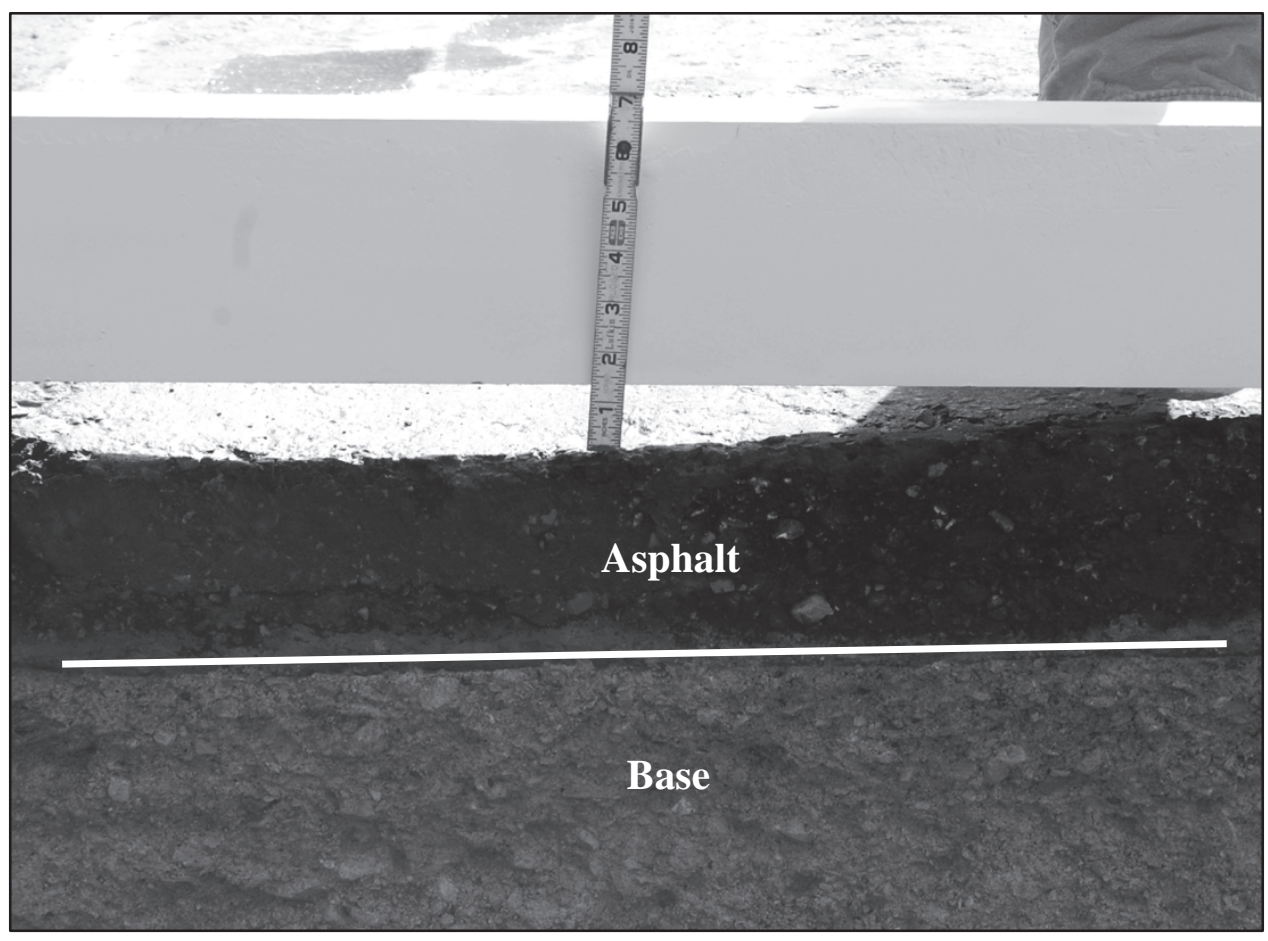

PHP-4 exhibited the greatest rut depth of all four repairs conducted at Test Site 2. Trenching revealed loose material close to one edge (which could be expected for repair edges), but uncoated aggregate was also observed as 
shown in Figure 80. PHP-4 had the highest in-place air voids of all four repairs as shown in Table 15, and it was hypothesized the uncoated aggregate could have been to blame. As mentioned in Chapter 3, the drum mixer malfunctioned during the repair process in PHP-4. Mixing was subsequently completed inside the repair void using the asphalt processor and the heater to maintain the RAP temperature. This mixing method may have caused inadequate mixing and resulted in poor performance. However, this repair did meet the sustainment repair criteria. Repair success could be attributed to the fact that cement was used as a stabilizing agent. This scenario suggests that in-hole mixing of all constituents can produce sustainment asphalt repairs, which meet and exceed military airfield requirements.

Figure 79. Trenched cross-section view of original asphalt pavement between repairs PHP-1 and PHP-2 post traffic.

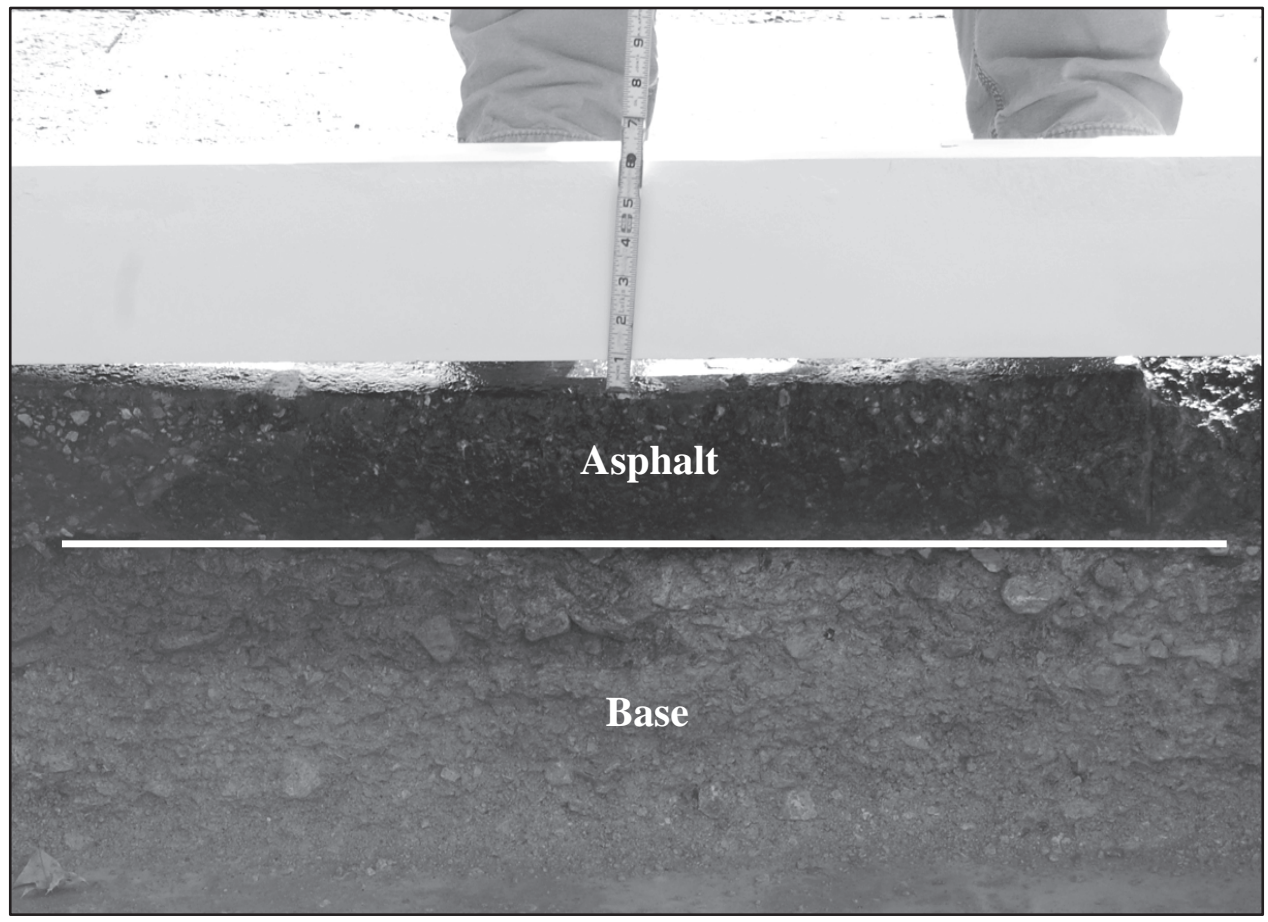


Figure 80. Loose recycled asphalt material after repair PHP-4 was trenched. (Note the uncoated aggregates).

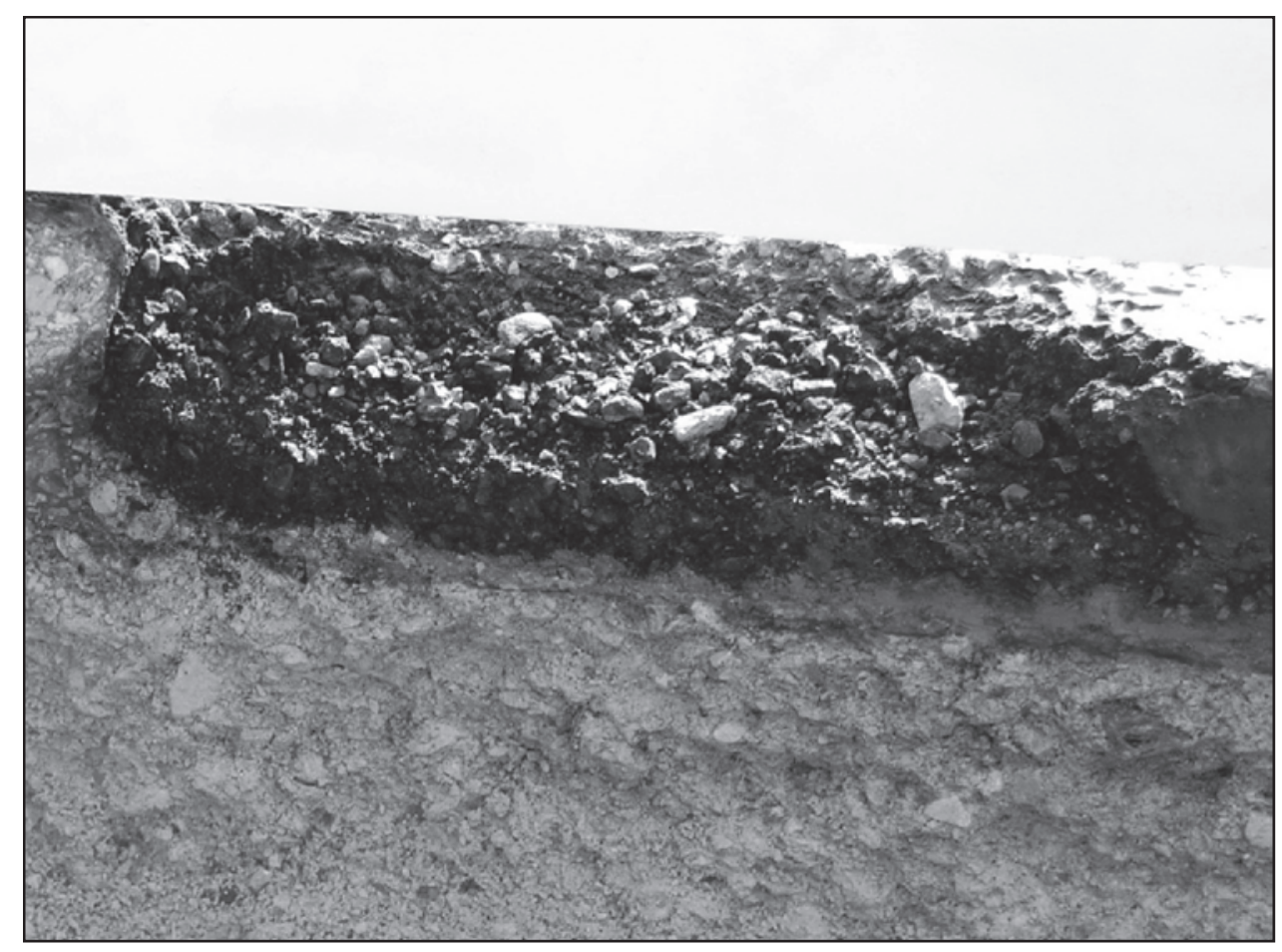




\section{Recycling Effects on Asphalt Properties}

\section{Oxidation test}

\section{Description}

Testing was performed at the ERDC site described previously to determine the feasibility of prematurely oxidizing a newer pavement using an infrared heater in onder to gain additional stiffness. Each heater was placed over the pavement for $5 \mathrm{hr}$, and samples of the pavement were obtained at several intervals. Sampling of loose material was conducted after 3, 4, and $5 \mathrm{hr}$ of heating for the propane heater (HD 3, HDE 4, and HDE 5), and after 4 and $5 \mathrm{hr}$ for the electric heater (HW 4 and HW 5). Since the pavement was very hot at the time of sampling, core samples could not be obtained. The asphalt was loose enough to be sampled by simply shoveling loose material from the surface of the pavement. Attempting to obtain a core sample prevented any material from being obtained after $3 \mathrm{hr}$ of heating with the electric heater. During sampling, it was noted that the top $1 / 2$ inch of the pavement had stiffened considerably as evidenced by the small piece of material shown in Figure 81. However, the pavement below the stiffened portion was much looser and appeared similar to newer hot mix asphalt. The stiffness of the extracted and recovered binder from each sample was determined using the Dynamic Shear Rheometer (DSR). Also, binder specimens were aged in the Pressure Aging Vessel (PAV), and then subjected to DSR testing to determine the long-term impact of premature oxidation.

\section{PG grade results}

Superpave performance grade binder specifications were used to analyze the DSR data (1.0 kPa minimum for original binder and 5,000 kPa max for PAV aged binder). The failure temperatures from each sample for the original binder and the PAV aged binder are shown in Figure 82, respectively. Higher failure temperatures indicate stiffer binder. As shown, the original binder from the ERDC Test Site and the HW 4-hr specimen failed at similar temperatures, while the HW 5-hr specimen failed at a much higher temperature than the PHP original binder. The failure temperature of the HDE-3-hr specimen was higher than the HDE 4-hr specimen, and both were higher than the original PHP binder. The HDE 5-hr specimen had a noticeably higher failure temperature than the original binder. Since 
the HDE 4-hr specimen was aged for a longer period of time, the failure temperature of the HDE 4-hr specimen was expected to be higher than that of the HDE 3-hr specimen. The sampling procedure used is believed to have caused this result, since some of the softer material under the hardened asphalt surface may have been inadvertently obtained during sampling.

Figure 81. Asphalt material from oxidation test.

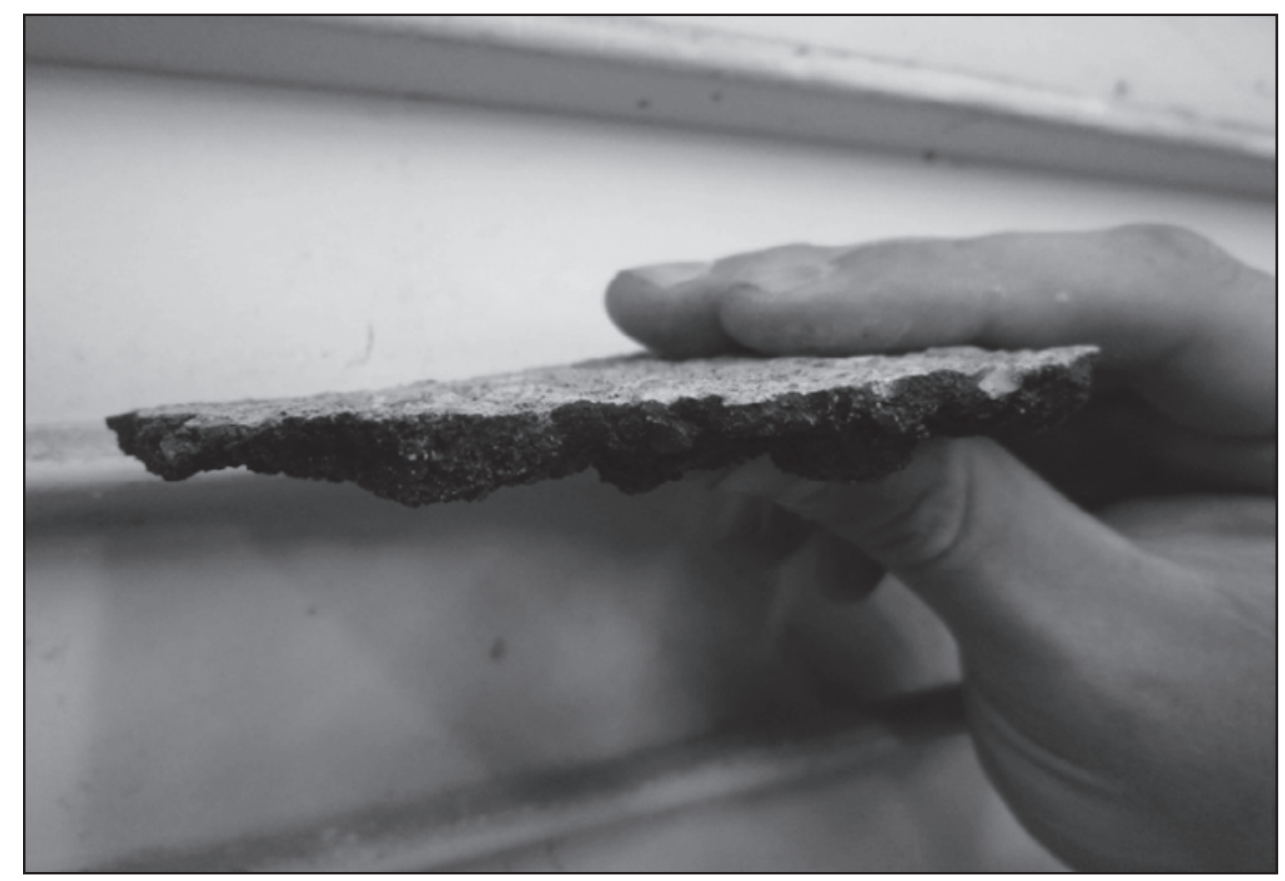

Figure 82. Oxidation test binder failure temperatures.

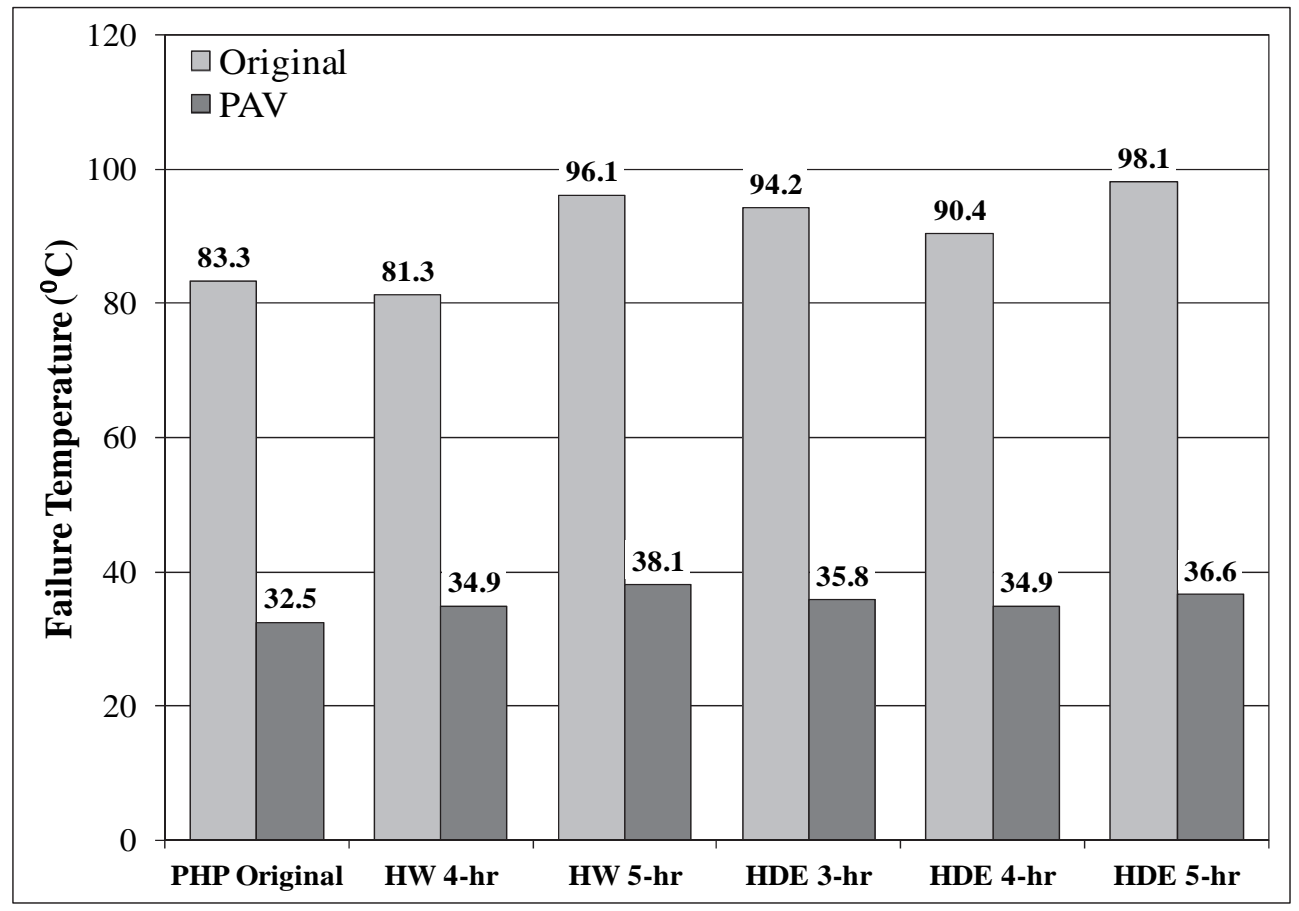


Specimens were then subjected to aging in the Pressure Aging Vessel (PAV), which simulates long-term aging of asphalt binder specimens. As shown, the failure temperatures of the HW 4-hr and HW 5-hr specimens were greater than the PHP specimen. The HDE 3-hr, 4-hr, and 5-hr specimens had similar failure temperatures that were all slightly higher than the PHP binder. The higher failure temperatures values exhibited by the prematurely oxidized specimens indicate a possible decrease in the long-term performance of the repairs. Additionally, using this method to prematurely oxidize a pavement section appears to only stiffen the top $1 / 2$ to $1 \mathrm{in}$. of the pavement as discussed previously.

\section{Post-repair binder elastic properties}

\section{Effects of the recycling process}

In order to ascertain the effects of the recycling processes described in Chapter 3 on the elastic properties of the asphalt, core samples were obtained from select repairs after trafficking so that the asphalt binder could be extracted, recovered, and subjected to DSR testing. The original binder was tested along with the binder aged in the PAV as described in the previous section of this chapter. The repairs selected for testing were FD-1, FD-2, FD-3, FD-5, PHP-3, and PHP-4. These repairs were selected so that the effects on binder elastic properties could be compared for the two rejuvenator products (CRF and Rejuvaseal with cement) and the two filler materials used (RAP and pelletized asphalt). Two control repairs were also selected in order to assess the variability associated with the extraction and testing of the binder. DSR data from the original binder and PAV aged binder are displayed in Figure 83. Binder extracted from core samples taken from the original pavement (Original) and loose asphalt that was heated and excavated from the existing pavement, but not rejuvenated or subjected to any additional heating (No Rejuv.) was also subjected to the same testing as a means of comparison.

As shown in Figure 83, the binder extracted from the material that was heated but not rejuvenated had a higher failure temperature than the binder extracted from the original pavement. The stiffening of the binder indicated that a considerable amount of oxidation occurred during the heating of the original pavement before removal and rejuvenation. The PAV data suggest that if the removed material is not rejuvenated before compaction, the resulting repair could be more susceptible to performance problems. 
Figure 83. Repair binder failure temperatures.

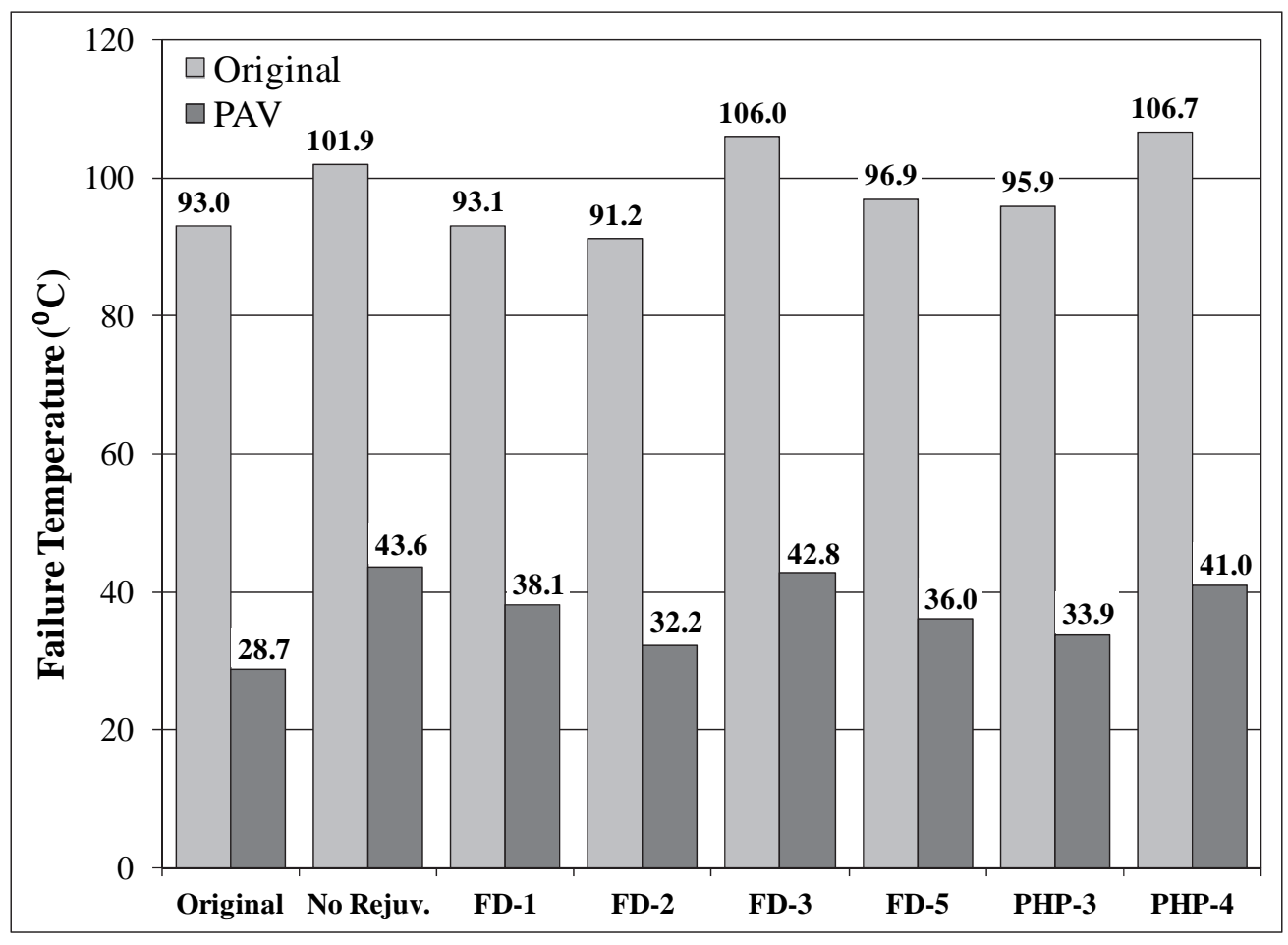

As shown in Figure 83, all original binder specimens extracted from the various repairs exhibited a lower failure temperature than the material that was not rejuvenated, except for FD-3 and PHP-4. Although nearly all of the original binder specimens had a lower failure temperature than the material that was not rejuvenated, only FD-2 and FD-3 showed lower stiffness values than the original pavement binder. However, binder extracted from the 2 -in. overlay at the test location was extremely stiff, to the point that no DSR testing could be performed. Although no data could be collected, it is clear that any of the rejuvenated repairs would be an improvement compared to the existing, highly oxidized overlay at the test location. All of the PAV-aged binders had failure temperatures that were higher than the original pavement. The PAV data suggest that the expected long-term performance could be slightly reduced due to the recycling process when compared to the existing asphalt binder's elastic properties. However, as mentioned previously, the recycling process does appear to provide binder flexibility compared to the existing, highly oxidized overlay.

\section{Comparison of repair properties}

Figure 83 was used to compare the elastic properties of the recovered binder from each repair. FD-1 and PHP-3 were both control repairs as described in Chapter 3. As shown, both repairs exhibited slightly different 
failure temperatures for the original binder and PAV aged binder, indicating that there was some variability in terms of the elastic properties of the extracted binder samples, as expected. The use of pelletized asphalt to replace lost material during removal appeared to soften the overall repair binder, as FD-2 exhibited a slightly lower failure temperature than that of FD-1, for both the original and PAV-aged binder. The repairs where Rejuvaseal and cement were used also appeared to stiffen the extracted binder. PHP-4 and FD-3 showed considerably higher failure temperatures than repairs FD-1, FD-2 and PHP-3 for original and PAV aged binder. The increased stiffness of the binder could adversely affect the long-term performance of the repair. 


\section{Conclusions and Recommendations}

ERDC was tasked by the AFCEC to evaluate and determine the most expedient methods, materials, and equipment for performing sustainment repairs in damaged airfield asphalt pavements. Infrared asphalt heaters and rejuvenator technologies were evaluated to develop a repair process that will give military engineers the capability for in-place asphalt recycling.

Relevant conclusions from laboratory and field testing are noted in this chapter. Recommendations for the use of in-place asphalt recycling for airfield pavement repair are also provided.

\section{Conclusions}

The following conclusions were derived from the evaluation of in-place asphalt recycling technologies:

- There are several commercially available asphalt heating technologies that work well with tracked skid steer equipment. The infrared heaters evaluated in this study demonstrated the efficiency of this type of heating technology in providing enough heat to soften the asphalt pavement for easy removal within a reasonable time frame. These heaters can also be used to maintain stockpile temperatures when multiple batches of repair material are required.

- The residual heat from the in-situ heating process was not sufficient to maintain proper temperatures during rejuvenation, placement, and final compaction.

- An additional heating source was required to elevate and maintain RAP temperatures to approximately $300^{\circ} \mathrm{F}$ within the mixing drum during the rejuvenation phase.

o The heaters were needed to maintain stockpile temperatures when multiple batches were required. A minimum stockpile temperature of $225^{\circ} \mathrm{F}$ was required during placement to achieve target density measurements of 7 percent air voids.

- A variety of rejuvenator products are commercially available. The rutting performance of a recycled mix depends on the type of rejuvenator and the dosage rate used. The dosage rate will vary for 
different types of RAP material. CRF proved to be the best product of the rejuvenators tested and 2 percent proved to be its optimum dosage for the RAP material used in this study.

- Addition of Type I Portland cement along with a rejuvenator product produced mixed results in terms of rutting resistance. Therefore, no conclusion could be drawn regarding its potential to improve rutting performance. Cement addition also noticeably increased binder stiffness indicating a possible decrease in long-term performance of the repairs.

- The use of pelletized asphalt to replace material lost during the removal process appeared to soften the overall asphalt binder of the repair material, but it did not affect the field rutting performance.

- The in-place asphalt recycling technology including the use of rejuvenator and asphalt infrared heater proved to be effective in terms of repair times and repair quality. With appropriate materials and equipment, repairs that met the in-place density requirements could be completed in less than $3 \mathrm{hr}$.

- In terms of rutting performance, when the repairs were tested at Test Site 2 , which had a higher quality pavement structure, the recycled asphalt pavement repairs met the requirements for sustainment repairs on airfields.

- Premature oxidation of a newer asphalt pavement appeared to be impracticable with infrared heaters and could cause a reduction in the pavement's long-term performance.

- Using infrared heaters to facilitate removal of asphalt material causes some level of oxidation. Rejuvenation of the material is necessary before placement and compaction to provide the highest performance possible. The rejuvenation process appeared to greatly increase the flexibility of the binder compared to the existing, highly oxidized overlay in Test Site 1.

\section{Recommendations}

Based on the laboratory and field-testing completed, the following general recommendations are provided:

- In-place asphalt pavement recycling using rejuvenation and infrared heating technology is recommended for sustainment repairs on airfields.

- It is recommended to investigate the properties of the existing pavement material beforehand, and if possible to study at least the 
compaction behavior of the rejuvenated RAP, which would give a better idea of the optimum rejuvenator dosage rate to be used.

- The rejuvenator product recommended for in-place asphalt recycling is CRF. A 2 percent dosage rate is recommended for materials with similar characteristics to the ones used in this evaluation. However, it is recommended that the optimum dosage rate should be determined for individual RAP materials.

- The infrared heating unit should be used not only to heat and soften the asphalt pavement for removal, but also to maintain stockpile temperatures when multiple batches are required. The electric heater unit is recommended for the augmentation kit, since it is commercially available and it meets the Air Force's transportation requirements. The propane-fueled unit does not meet the Air Force's requirements since propane cannot be transported on aircrafts.

- The asphalt processor attachment is recommended for use since it proved to be effective for pavement removal and, also, its screed attachment was efficient for preparing the recycled material after it was placed back in the repair void for compaction.

- Pelletized asphalt can be used effectively for any additional material needed to compensate for volume loss.

- Premature oxidation of a newer asphalt pavement with infrared heaters is not recommended, since it could cause a reduction in the pavement's long-term performance.

Specific recommendations of details on the in-place asphalt recycling equipment, materials, and process will be subsequently published in an Air Force Engineering Technical Letter (ETL). 


\section{References}

American Association of State Highway and Transportation Officials (AASHTO). 2009a. Determining rutting susceptibility of hot-mix asphalt (HMA) using the asphalt pavement analyzer (APA). Designation: TP-63.

. 2009b. Performance-graded asphalt binder. Designation: M320

. 2009c. Mechanical analysis of extracted aggregate. Designation: T 30

. 2009d. Specific gravity and absorption of fine aggregate. Designation: T 84

. 2009e. Specific gravity and absorption of coarse aggregate. Designation: T 85

. 2009f. Quantitative extraction of asphalt binder from hot-mix asphalt (HMA). Designation: T 164

. 2009g. Effect of heat and air on a moving film of asphalt binder (Rolling ThinFilm Oven Test). Designation: T 240

. 2009h. Determining the rheological properties of asphalt binder using a dynamic shear rheometer (DSR). Designation: T 315

. 2009i. Quantitative extraction and recovery of asphalt binder from asphalt mixtures. Designation: T 319

American Society for Testing and Materials (ASTM). 2011a. Standard specification for road tar. Designation: D 490.

. 2011b. Standard test method for theoretical maximum specific gravity and density of bituminous paving mixtures. Designation: D 2041.

. 2011c. Standard test method for bulk specific gravity and density of nonabsorptive compacted bituminous mixtures. Designation: D 2726.

. 2011d. Standard test method for percent air voids in compacted dense and open bituminous paving mixtures. Designation: D 3203.

Headquarters, Department of the Army, the Navy, and the Air Force. 2001. Pavement design for airfields. Unified Facilities Criteria (UFC) 3-260-02. Washington, DC. 


\section{Appendix A: Recommended Equipment, Materials, and Process for Repair of Airfield Asphalt Pavements Using In-Place Asphalt Recycling Technology}

This appendix presents the recommended equipment, materials and procedures for in-place asphalt recycling for sustainment airfield pavement repair. Further details will be provided in an Engineering Technical Letter (ETL) to be published after this report.

\section{Equipment}

The following equipment is recommended for in-place asphalt recycling:

- Caterpillar Model 277C High Flow Skid Steer Loader (or equivalent)

- Heatwurx Model HWX-30 Electric Infrared Heater (or equivalent)

- Heatwurx Model HWX-AP40 Asphalt Processor (or equivalent)

- Caterpillar Dual Wheel Vibratory Roller Compactor, Model CB14 (or equivalent)

- Skid steer-mounted bucket attachment

- Skid-steer-mounted mixer with burner attachment

- Skid-steer mounted collection broom

- J umping jack tamper

- Non-contact infrared digital thermometer gun

- Metal probe thermometer

- Portable electric generator

- 100-ft electrical extension cord

- Metal straightedge (approx. $6 \mathrm{ft} \mathrm{long)}$

- Metal tape measure

- Digital scale with 200-lb capacity

- Hand-held concrete saw and spare blades

- 5-gal fuel can, filled

- One dozen empty 5-gal buckets (preferably plastic)

- Flat edge shovels, pick axe, pry bar, utility broom, lute rakes

- Hand pump sprayer

- Spray paint

- Density Measurement Device (nuclear densometer or equivalent) 


\section{Materials}

Based on the findings of this study, the materials recommended for inplace asphalt recycling are the rejuvenator product called CRF, used for improving the properties of the oxidized asphalt binder, and pelletized asphalt to be used to compensate any mass lost during repairs. The Material Safety Data Sheets (MSDS) for these materials are provided in Appendix B.

\section{Detailed procedure}

The flowchart in Figure A1 summarizes the recommended asphalt sustainment repair process using in-place asphalt recycling technology. The following sections describe the step-by-step process in more detail.

Figure A1. In-place asphalt recycling repair process.

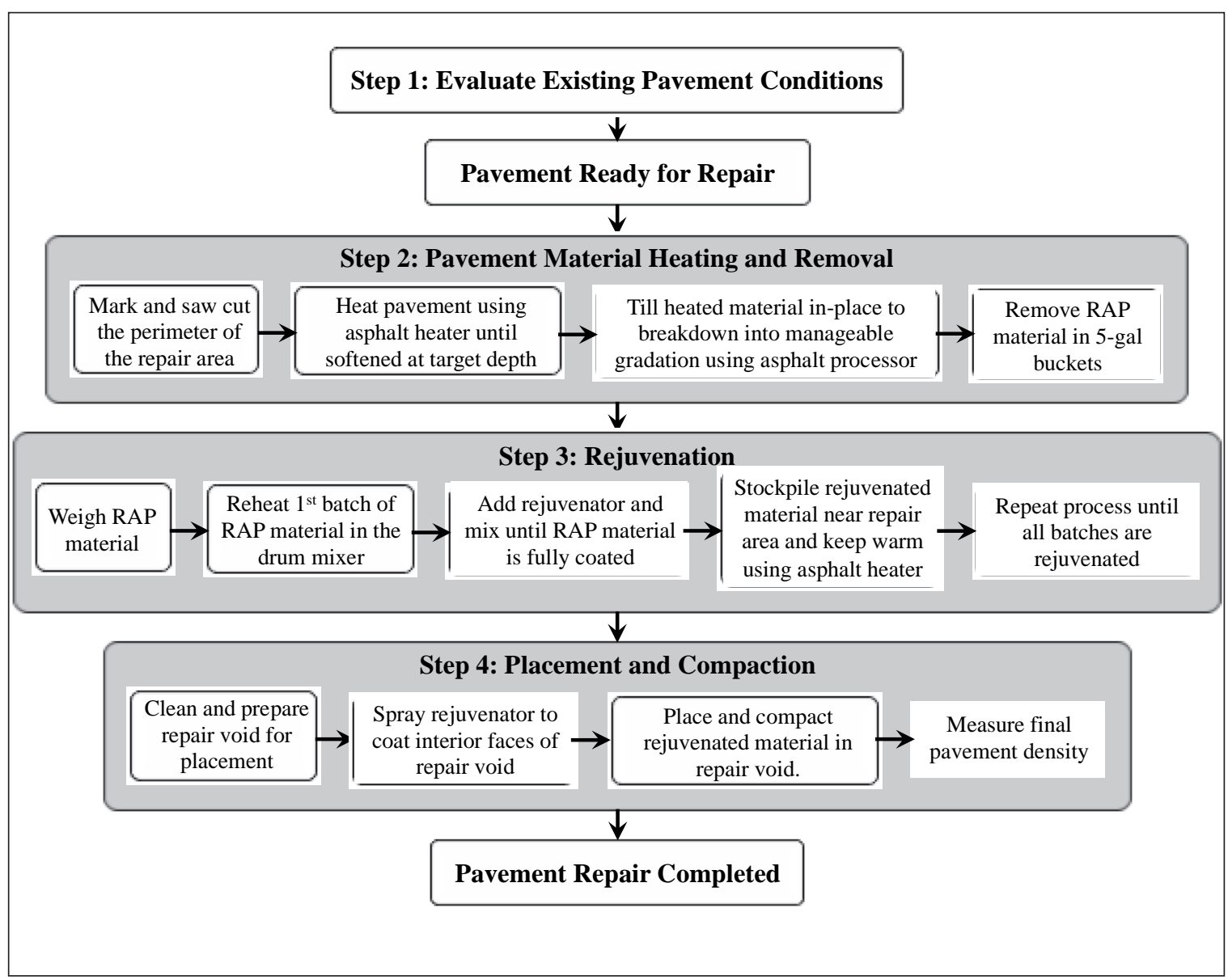




\section{Step 1: Evaluate the existing pavement conditions}

Evaluate in situ pavement conditions by visually inspecting the pavement surface to determine if there are any pavement distresses. Collect core samples for laboratory determination of asphalt binder and aggregate properties. When possible, evaluate mix compaction properties to determine optimum rejuvenator dosage required.

\section{Step 2: Pavement material heating and removal}

- 2.1. Mobilize the heater unit, CTL w/ asphalt processor attachment, bucket attachment, front-end loader and bucket, and hand shovels to the selected repair area.

- 2.2. Pre-heat the asphalt heater 30 min prior to placement on pavement surface. (Follow the manufacturer's recommended startup procedure.)

- 2.3. While the heater is coming to operational temperature, use a CTL mounted collection broom (or kick broom if available) to remove loose debris from the general repair area. If the repair area is small, then a hand broom will suffice.

- 2.4. Mark outer edge of the repair area using spray paint.

o 2.4.1. The repair area should be square or rectangular in shape. The dimensions of the rectangle should be equal to the measured dimensions of the heating unit footprint.

o 2.4.2. Repairs wider or longer than the heating unit dimension shall be performed in adjacent separate repairs until the desired area is achieved.

- 2.5. Using a hand-held concrete saw, proceed to cut along the marked repair perimeter to define clean repair edges. Remove all dust and debris from area after cutting with hand broom and/ or shop vacuum.

- 2.6. When the heater has achieved operating temperature, use the CTL to place the heating unit directly over the marked repair area as shown in Figure A2. Periodically lift heater and use shovel or metal probe to check the depth to which the asphalt has been softened; cease heating at target depth. 
Figure A2. Heater being placed over repair area.

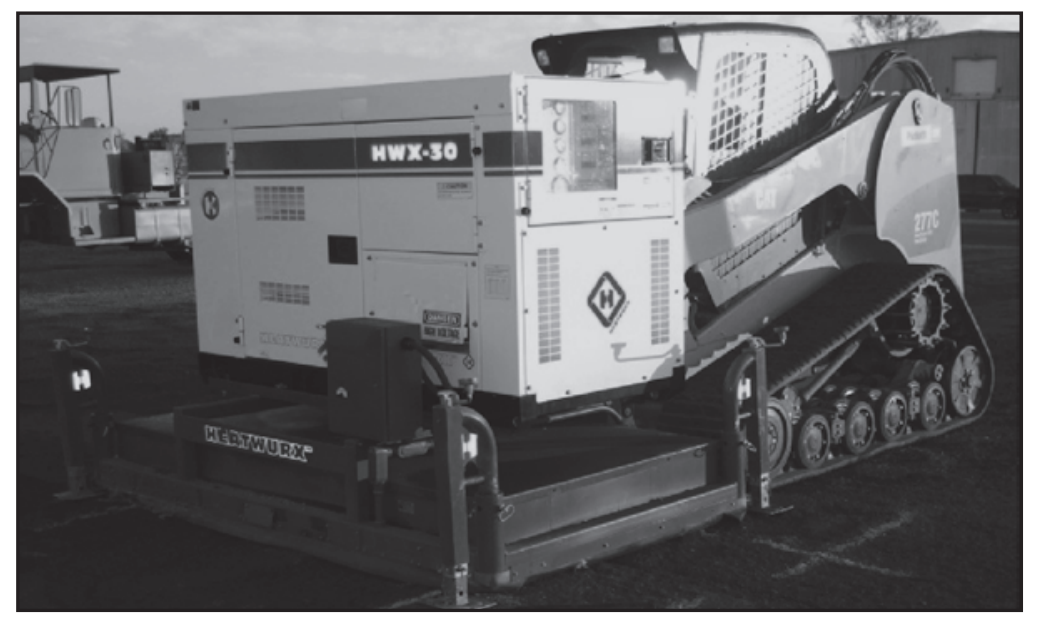

- 2.7. Remove heater unit and align CTL w/ processor attachment (Figure A3) to begin excavation of softened asphalt pavement material. Prepare the asphalt processor by manually adjusting the skids on each side to achieve the desired cutting depth. Figure A4 shows the process for adjustment.

Figure A3.CTL-mounted asphalt processor.

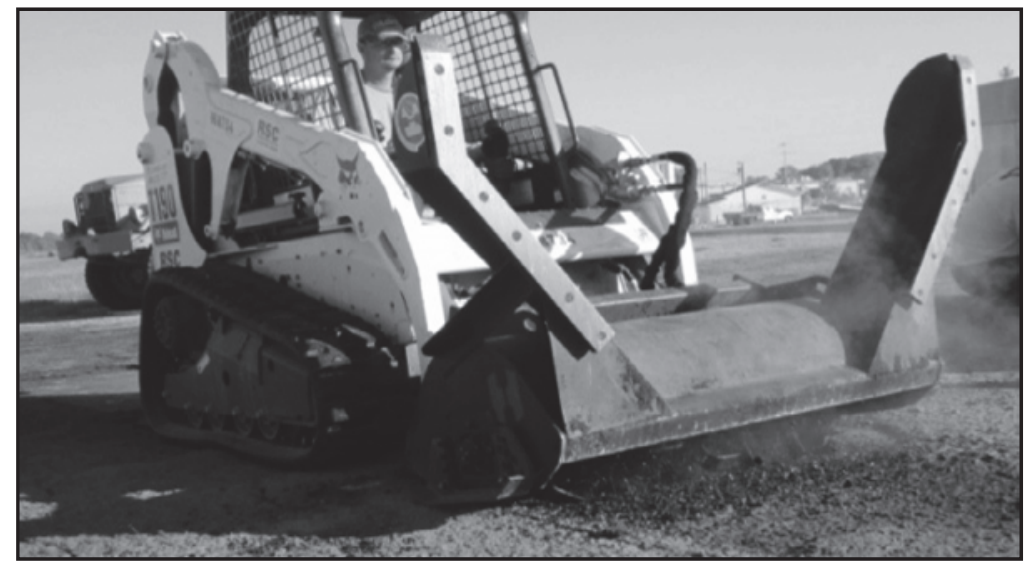

Figure A4. Manually adjusting processor cut depth.

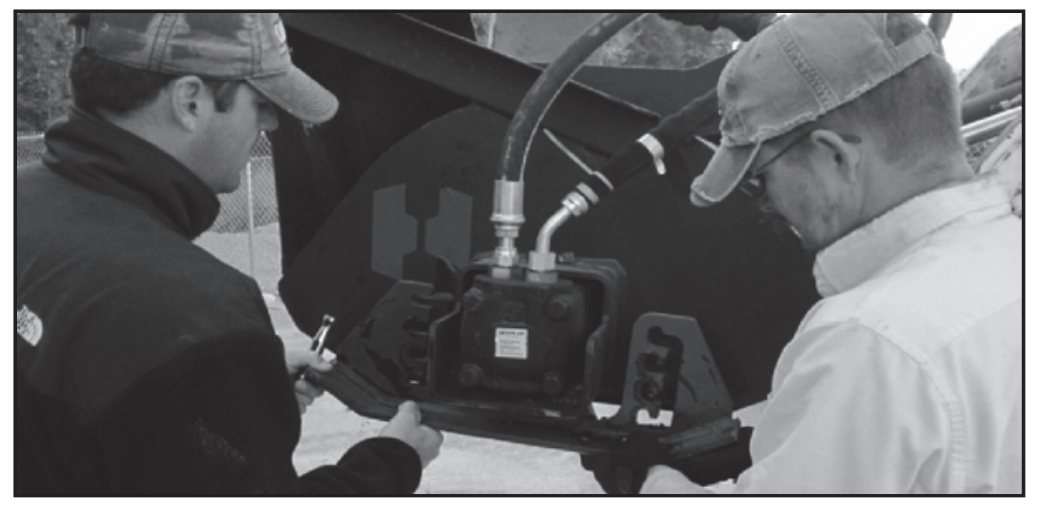


- 2.8. Use processor attachment to till the heated material in-place and to break it down into a manageable gradation. Ensure that the outer processor tines are within the boundaries of the saw cut lines to prevent damage to the adjacent pavement. Slowly lower the processor until it rests on the depth guides. Traverse up and back the length of repair until all asphalt pavement material has been loosened and effectively broken down into a manageable gradation.

Note: If processor is not available, a CTL-mounted bucket attachment (Figure A5) may be used for heated pavement material excavation. This is not the preferred method due to the increased potential for base disruption and mixture into the pavement material. Exercise caution if/ when the bucket is used and segregate any pavement material contaminated with base soil material.

Figure A5. CTL-mounted bucket attachment.

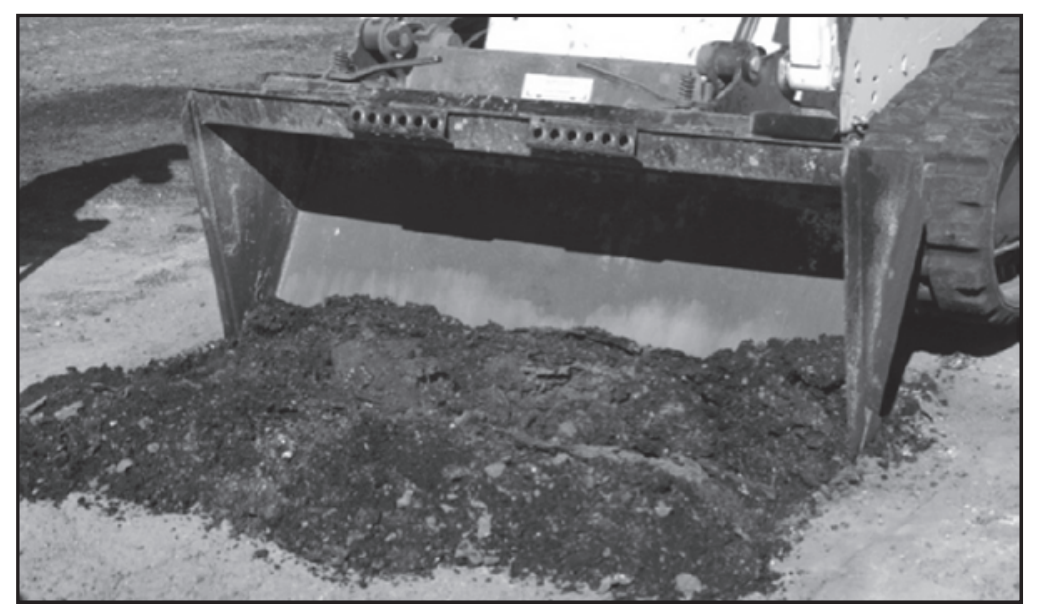

- 2.9. Once the tilling is complete, remove the processor and begin to shovel the loosened reclaimed asphalt pavement (RAP) material into 5-gal buckets for transport to the scale.

o 2.9.1. Be sure to avoid any RAP material which has been mixed with excessive base soil material.

o 2.9.2. Omit any larger pieces that have not been broken down to approximately the size of the largest aggregates. These larger pieces will not break down in the rejuvenation mix cycle and will impede proper compaction.

- 2.10. Use hand tools to remove the larger pieces left between the processor path and the saw cut edge. Do not dispose of these pieces 
until they have been weighed and masses recorded. Place the pieces in 5-gal buckets.

\section{Step 3: Rejuvenation}

- 3.1. Weigh all the buckets with the material removed from the repair void, including the large piece buckets.

o 3.1.1. The total measured weight of all large pieces should be replaced with pelletized asphalt (Figure A6).

Figure A6. Pelletized asphalt.

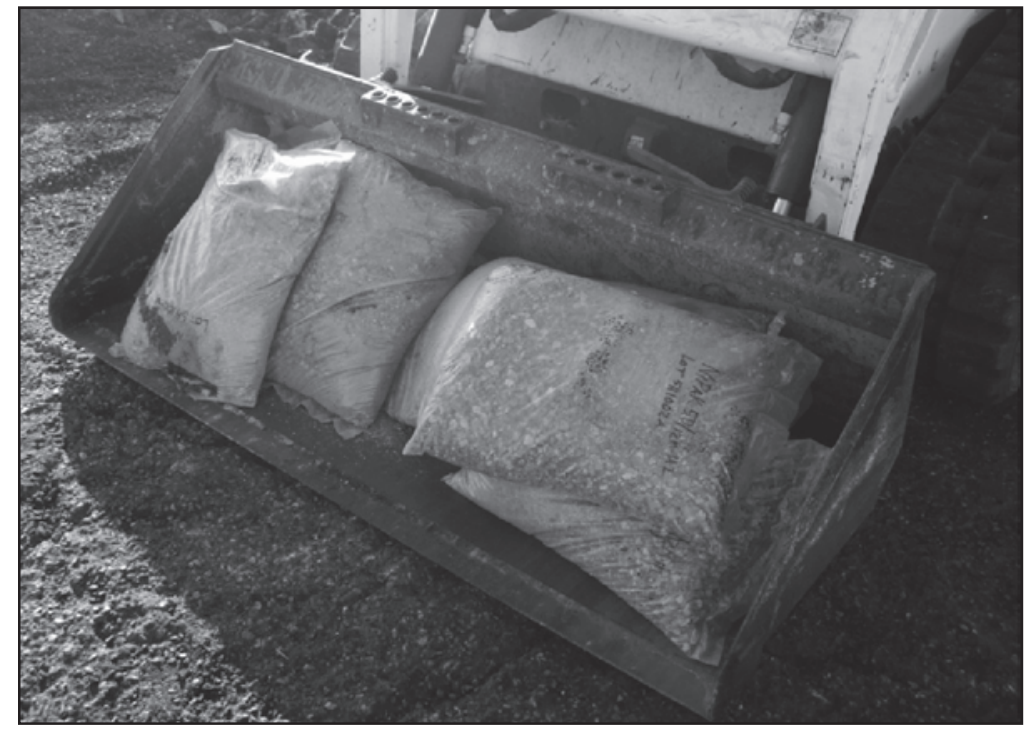

Note: In the absence of pelletized asphalt, additional RAP material should be harvested from nearby pavement areas (using the same procedure in steps 2.7 - 2.10) and used as replacement.

o 3.1.2. Pelletized asphalt (or replacement RAP) will only be used as needed in the final mix batches to achieve the required total mass for the repair. The initial batches will be 100 percent RAP from the repair void. Once that material has been exhausted and fully rejuvenated, the pelletized asphalt (or replacement RAP) will be used to compensate the loss of the large pieces and to complete the repair.

- 3.2. Use the scale to measure the required mass of rejuvenator for the first batch and set aside. Be sure to compensate for any additional water mass required for dilution. 
- 3.3. Position the CTL with mixer attachment near the repair area.

- 3.4. Begin to load the mixing drum to maximum capacity with repair void RAP. Be sure to record the total mass added.

- 3.5. Rotate the burner into position and begin drum rotation.

- 3.6. Initiate the burner cycles and continue until the RAP material has reached an average temperature of $325^{\circ} \mathrm{F}\left(162.8^{\circ} \mathrm{C}\right)$ within the drum. The burner is shown operational in Figure A7.

Figure A7. Additional heat being applied to rap material.

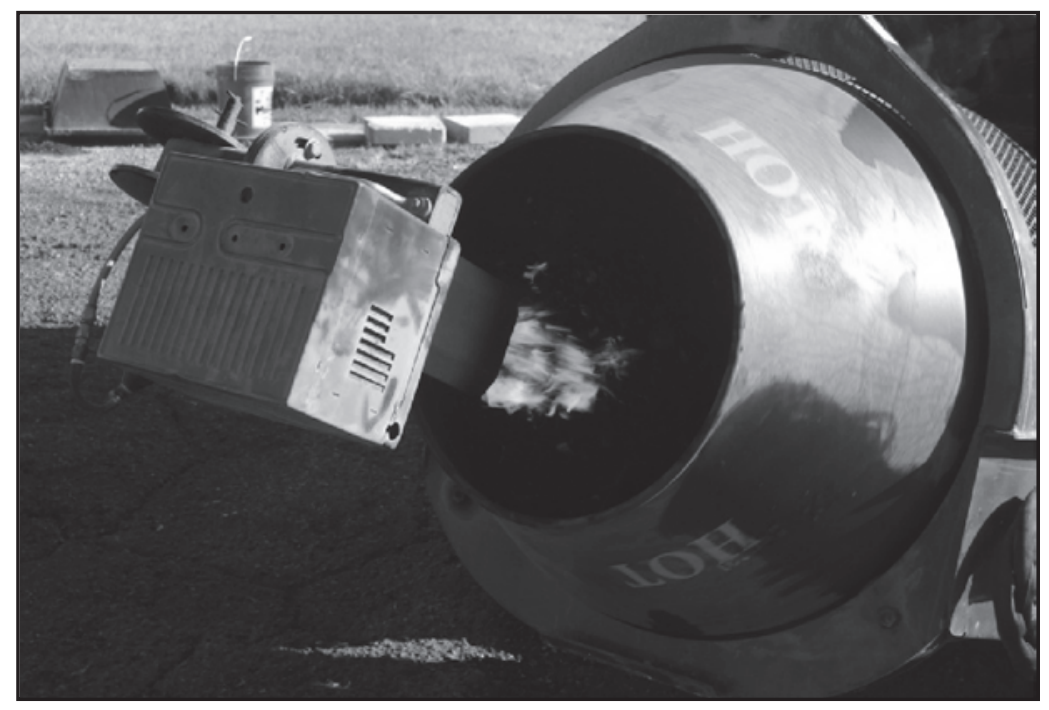

- 3.7. Cease drum rotation, rotate the burner to the stationary position and carefully add the required volume of rejuvenator to the heated RAP.

- 3.8. Immediately begin drum rotation once again and continue for 5 min (or until the RAP has been sufficiently coated).

Warning: DO NOT re-apply the open flame burner to the rejuvenated RAP. The flash point of these materials would likely be exceeded and the volatiles could be ignited.

- 3.9. While the drum is still rotating, dump the rejuvenated material on the swept pavement surface adjacent to the repair void and return the CTL to the staging area to begin the next mix batch. Figure A8 shows an initial mix batch being stockpiled. 
Figure A8. Rejuvenated asphalt being stockpiled near repair.

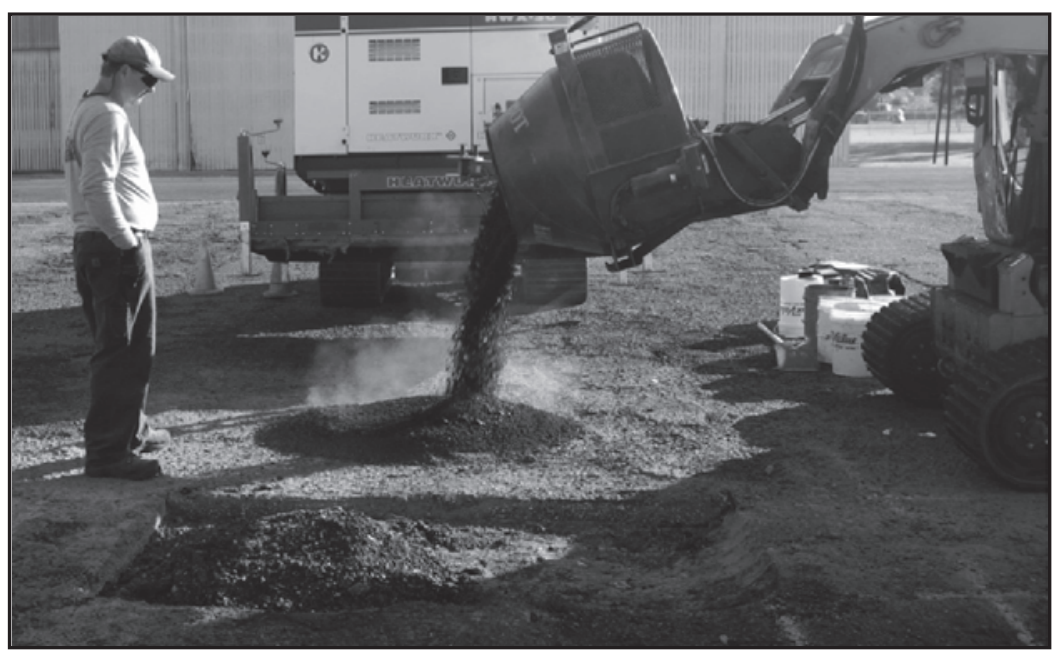

- 3.10. Immediately place the heater unit directly over the rejuvenated stockpile to maintain its temperature during the remaining mix batches

o 3.10.1. Use concrete blocks to elevate the heater to a distance away from the stockpile surface. This allows for temperature maintenance, yet prevents scorching over time. There is no specific distance; it will be dependent on variables such as wind speed and ambient temperature. Figure A9 illustrates the general positioning of the heater.

Figure A9. Heater placed over the rejuvenated stockpile.

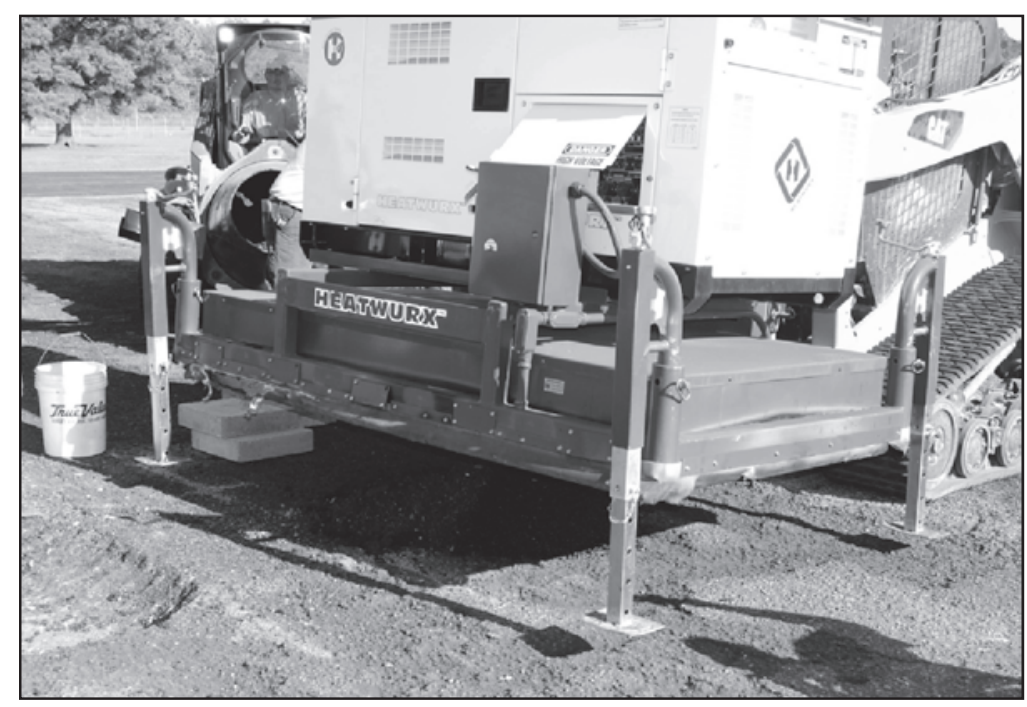


- 3.11. Repeat steps 3.1 through 3.10 until all repair void RAP has been rejuvenated and stockpiled under the heater.

- 3.12. Once all original repair void RAP has been rejuvenated and stockpiled, calculate the difference between what is required for repair and the stockpile mass.

- 3.13. Add an equivalent mass of pelletized asphalt bags to the drum. Place bags in the drum mixer and lock the flame burner in place to provide enough heat to melt the plastic bags while the mix is broken down into a homogenous granular mixture. Once heated and mixed, dump the pelletized asphalt in the rejuvenated RAP stockpile.

Note: If replacement RAP is used, add the required mass to the drum and mix with a proportional amount of rejuvenator and continue the standard mix protocol.

- 3.14. Dump the final mix batch onto the stockpile and use both laser gun and metal probe thermometer to check the stockpile temperature.

o 3.14.1. If the measured temperature is below $250^{\circ} \mathrm{F}\left(121.1^{\circ} \mathrm{C}\right)$, replace the heater above the stockpile until this temperature is reached. Otherwise, immediately begin placement.

\section{Step 4: Placement and compaction}

- 4.1. If the repair is partial-depth, prepare the repair void for placement by removing any foreign objects, fines and any remaining asphalt with a utility broom and hand shovel as shown in Figure A10. If the repair is full-depth (to the base layer), use a jumping jack tamper to compact and strengthen the underlying base layer as shown in Figure A11.

- 4.2. Regardless of repair type, use a hand pump sprayer to apply a light coat of rejuvenator to all interior faces of the repair void as shown in Figure A12.

Note: By the time the last mix batch is being loaded, the repair void should be ready for placement.

- 4.3. Use the CTL-mounted bucket attachment to push approximately one half of the stockpile into the adjacent repair void. This process is illustrated in Figure A13. 
Figure A10. Final repair void preparation for partial-depth repair.

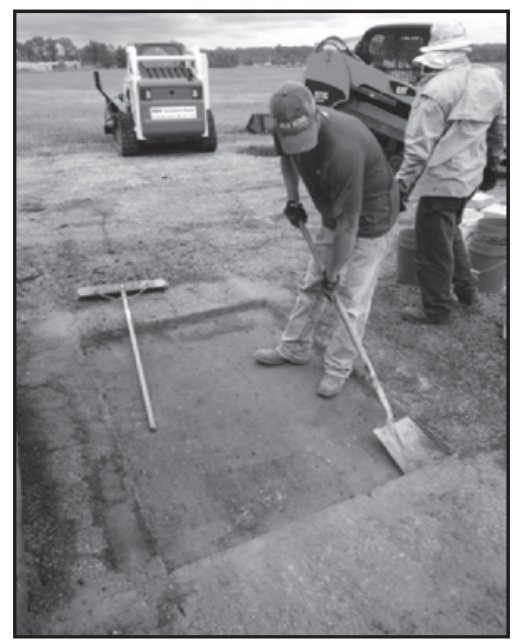

Figure A11. Base compaction for fulldepth repair.

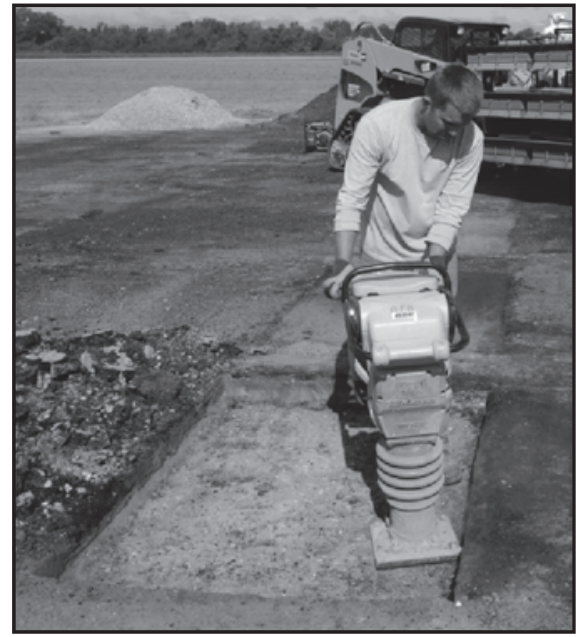

Figure A12. Rejuvenator applied to repair void.

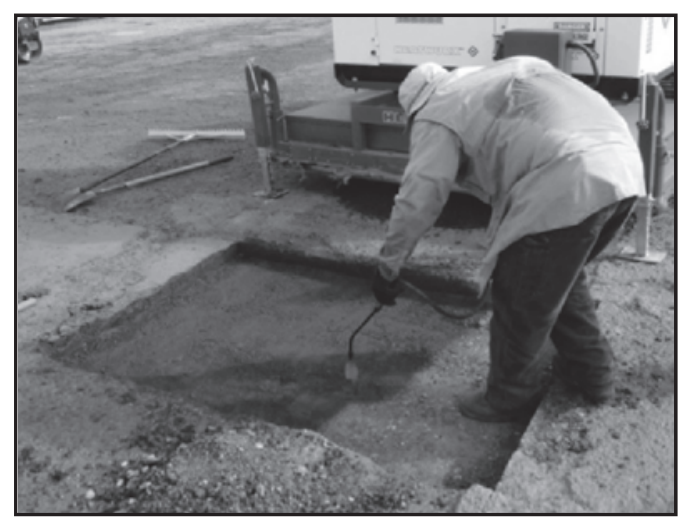

Figure A13. CTL placing rejuvenated material into repair void.

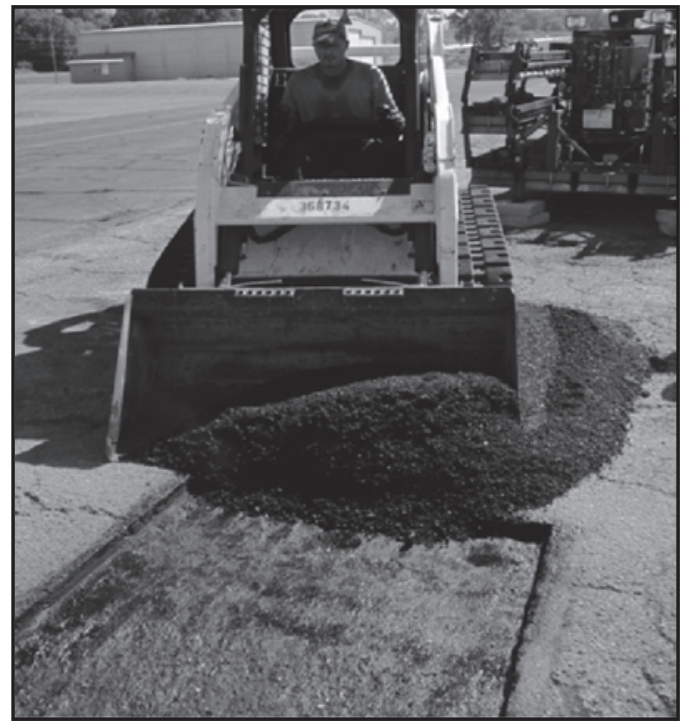


- 4.4. Immediately begin using lute rakes and shovels to level the lift surface and prepare for compaction as shown in Figure A14.

Figure A14. Preparing final lift for compaction.

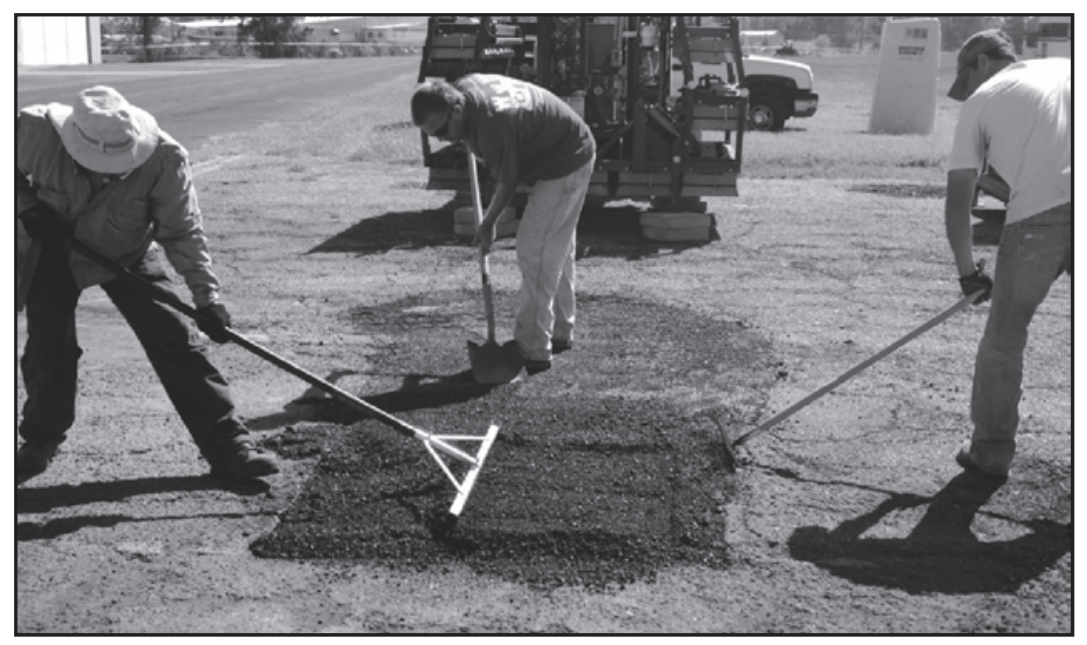

- 4.5. When performing full-depth repairs, place and compact material in a minimum of two lifts. Build small asphalt ramps within the void at each end of the first lift for compactor ingress and egress to avoid edge damage. Begin compaction on the first lift using the dual wheel vibratory roller.

o 4.5.1. Compact the outer edges with vibration and then the center, working inward. Be sure to pinch edges first and then work inward as shown in Figure A15. Then, repeat the same traverse protocol, but now without vibration. Repeat this process until reaching the desired density.

Figure A15. Compaction of final lift.

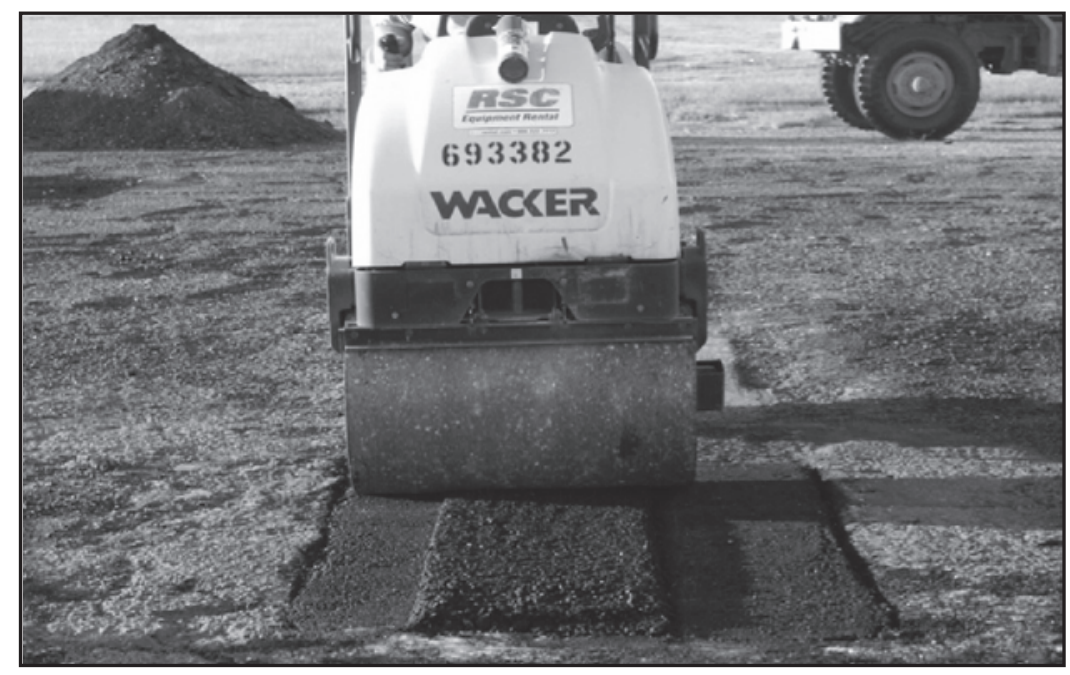


o 4.5.2. Use the CTL-mounted bucket attachment to push the remaining material into the void and repeat Step 4.5.1 on the second lift.

- 4.6. When performing partial-depth repairs, place and compact the material in one lift. Use Step 4.5.1 for compaction.

- 4.7. Use the laser gun to monitor and record the compacted lift surface temperature.

- 4.8. Place a calibrated nuclear gauge density machine at various locations across the repair to measure the average final repair density.

- 4.9. Allow repair to cool to a temperature of $70^{\circ} \mathrm{F}\left(21^{\circ} \mathrm{C}\right)$ before applying traffic.

- 4.10. Once this temperature is attained, the repair is considered complete. A final repair is shown in Figure A16.

Figure A16. Final repair.

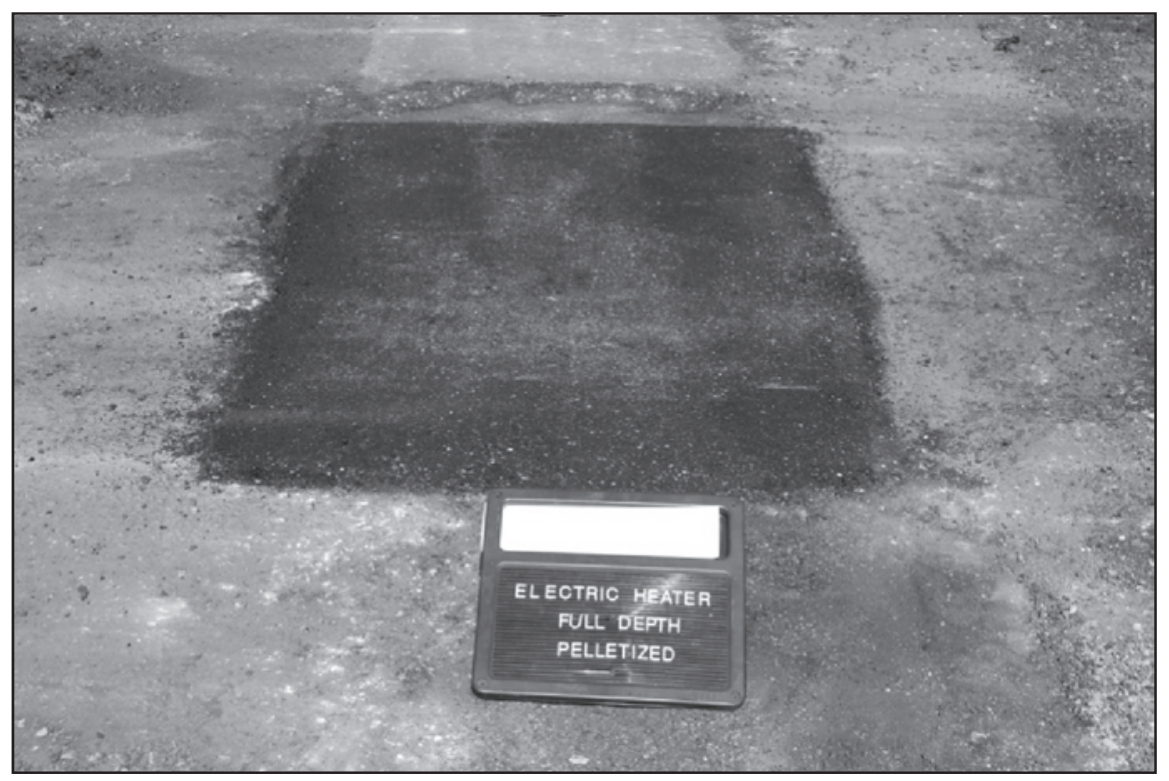




\title{
Appendix B: Material Fact Sheets
}

\author{
1. Name: NiPak 59 FG-NDGB Pelletized Asphalt
}

2. Manufacturer:

NiTech Corporation

P. O. Box 235,

South Pomfret, VT 05067

Telephone: (802)-457-4571

Fax: (802)-457-3844

www.nitechcorp.com

\section{Description:}

NiPak pelletized asphalt is a premade asphalt mix that was specifically designed for onsite production to facilitate expedient pavement repair of military airfields, roadway, parking lots, and driveways. The technology was designed for the US Air Force (USAF) and is currently being deployed by the USAF at airfields around the world. The asphalt binder comes in pellets that are coated with a patented two-step process utilizing a polymer emulsion followed by a fine powder, usually a clay. This prevents the asphalt pellets from sticking together. The coating comprises approximately 13 percent of the pellets by weight.

The aggregate type is granite and is sourced from a Martin Marietta NCDOT approved quarry in North Carolina (hickory Quarry \#44308).

\section{Manufacturer's provided information:}

\begin{tabular}{|l|l|}
\hline \multicolumn{2}{|c|}{ Aggregate Properties } \\
\hline Sieve Size & $\begin{array}{l}\text { Aggregate Gradation } \\
\text { (Percent Passing) }\end{array}$ \\
\hline 3/4-in. & 100 \\
\hline 1/2-in. & 94 \\
\hline $3 / 8$-in. & 88 \\
\hline No. 4 & 61 \\
\hline No. 8 & 44 \\
\hline No. 16 & 35 \\
\hline No. 30 & 26 \\
\hline No. 50 & 16 \\
\hline No. 100 & 9 \\
\hline No. 200 & 3.5 \\
\hline
\end{tabular}




\begin{tabular}{|l|l|}
\hline Specific Gravity of coarse aggregate & 2.709 \\
\hline Specific Gravity of coarse aggregate & 2.730 \\
\hline Coarse aggregate absorption, percent & 0.46 \\
\hline Fine aggregate absorption, percent & 0.12 \\
\hline LA Abrasion, percent loss & 45 \\
\hline Flat and Elongated & $0.2 / 7.3$ \\
\hline Fine Aggregate Angularity & -- \\
\hline Sand Equivalent & 76 \\
\hline Sulfate Soundness Loss & 5.9 \\
\hline
\end{tabular}

\begin{tabular}{|l|l|}
\hline \multicolumn{2}{|c|}{ Mix Properties (75-blow Marshall compaction) } \\
\hline Optimum Binder Content (percent) & $\begin{array}{l}6.4 \text { percent of pellets (5.6 percent asphalt } \\
\text { binder) }\end{array}$ \\
\hline Binder PG Grade & $76-22$ \\
\hline$V_{a}$ & 4.0 \\
\hline$P_{\text {be }}$ & 5.9 \\
\hline D/B & 0.59 \\
\hline VMA & 17.9 \\
\hline VFA & 77.7 \\
\hline$P_{b a}$ & 0.5 \\
\hline Gmm & 96 \\
\hline Gmb & 2.436 \\
\hline Stability (Ib) & 4750 \\
\hline Flow (0.01 in.) & 14.5 \\
\hline $\begin{array}{l}\text { APA Rutting (mm @ 8,000 cylces) } \\
\text { (240 lb, 120 psi) }\end{array}$ & 2.0 \\
\hline
\end{tabular}

\section{Mixing conditions:}

This technology was designed to be heated in a skid steer-mounted mixer (NiCAT 10A) to produce DOT spec asphalt mix in a matter of minutes. A typical batch of 2 pails $(100 \mathrm{lb})$ is mixed in the drum for about $5 \mathrm{~min}$ at a target temperature of $320^{\circ} \mathrm{F}$.

\section{Physiographic factors:}

The standard packaging of the patch material is in 5-gal pails. The pails may be stored outdoors in extreme temperatures, but should be covered for longterm storage. 
The material should be allowed to heat up and mix. The shelf life in sealed containers is several years at ambient temperatures up to $130^{\circ} \mathrm{F}$. Longer periods are possible when they are stored at moderate levels of temperature and humidity. 
1. Name: $\underline{\mathrm{CRF}}$

2. Manufacturer:

Martin Asphalt Company

Three Riverway, Suite 400

Houston, TX 77056

Telephone: (713)-350-6800

Fax: (713)-350-6801

www.martinasphalt.com

\section{Description:}

$\mathrm{CRF} \circledast$ water-based cationic emulsion is formulated with a petroleum oil engineered to restore and seal deteriorating asphalt pavements. CRF emulsion can be used for three purposes: as a cold-pour crack filler, a restorative seal and a reclaimed asphalt pavement (RAP) rejuvenator. Its chemistry restores aged, cracked and raveled asphalt, prolonging pavement life. As a rejuvenator, it can be added to cold RAP material but it is recommended to mix it with hot RAP for better results.

\section{Manufacturer's provided information:}

\section{Physical properties:}

Boiling point $(\mathrm{F}): 212^{\circ} \mathrm{F}$

Specific gravity $(\mathrm{H} 2 \mathrm{O}=1): 1$

Percent volatile: 0

Solubility in water: Soluble

Appearance and odor: Brown liquid, faint petroleum odor

Flammability: Non-flammable in water-based state

\section{Application conditions:}

Seal: CRF can be applied at almost any temperature with all types of equipment, or simply poured into the crack. After an application of a light coat of sand, the pavement is ready for traffic, which kneads the sand into the CRF filler.

There are several methods of application:

- Restorative seal: The CRF emulsion is applied by a distributor truck at a predetermined spread rate, allowed to cure, then covered with sand.

- Broom seal/ Scrub seal: The above restorative seal, followed by brooming to work the emulsion and sand into cracks.

- Squeegee seal: The CRF emulsion is applied by a distributor, followed by a rubber blade to work the product into surface distresses. A second application can be made, if required, after the first has cured. The surface is then sanded and rolled with a rubber-tired roller. This is low cost pavement preservation, repairing cracks and sealing the surface. 
Rejuvenator: CRF can be mixed with hot reclaimed asphalt pavement (RAP) material either by using a portable mixer with a burner or by spraying it to the RAP in the repair void and mixing it in-place.

\section{Specifications}

\begin{tabular}{|c|c|c|c|}
\hline Property & Test procedure & Min & Max \\
\hline Viscosity, Saybolt Furol, $77^{\circ} \mathrm{F}\left(25^{\circ} \mathrm{C}\right)$, ssf & T 72 & 25 & 150 \\
\hline Sieve Test, percent & T $59(\bmod )$ a & --- & 0.1 \\
\hline Particle Change Test & T 59 & \multicolumn{2}{|c|}{ Positive } \\
\hline Cement Mixing & ASTM D 244 & & 2.0 \\
\hline Pumping Stability & $\mathrm{b}$ & \multicolumn{2}{|l|}{ Pass } \\
\hline 5-day Settlement Test, percent weight & ASTM D 244 & & 5.0 \\
\hline Residue, percent weight & T59 (mod) ${ }^{c}$ & 64 & \\
\hline \multicolumn{4}{|l|}{ Tests on residue from distillation: } \\
\hline Viscosity, $140^{\circ} \mathrm{F}\left(60^{\circ} \mathrm{C}\right)$, cSt & D 445 & 1,000 & 4,000 \\
\hline Asphaltenes, percent weight & D 2006-70 & & 11.0 \\
\hline Maltene Distribution Ratio $\left(P C+A_{1}\right) /\left(S+A_{2}\right) d$ & D 2006-70 & 0.7 & 1.1 \\
\hline PC/S Ratio d & D 2006-70 & 0.5 & \\
\hline \multicolumn{4}{|c|}{$\begin{array}{l}\text { a Test procedure identical with ASTM D-244 / AASHTO T } 59 \text { except that distilled water shall be used in place } \\
\text { of } 2 \text { percent sodium oleate solution. }\end{array}$} \\
\hline \multicolumn{4}{|c|}{$\begin{array}{l}\text { b Pumping stability is determined by charging } 450 \mathrm{ml} \text { of emulsion into } 1 \text {-liter beaker and circulating the } \\
\text { emulsion through a gear pump (Roper } 29 . \mathrm{B} 22621 \text { ) having } 1 / 4 \text { " inlet and outlet. The emulsion passes if there } \\
\text { is no significant oil separation after circulating ten min. }\end{array}$} \\
\hline \multicolumn{4}{|c|}{$\begin{array}{l}{ }^{\circ} \text { ASTM D-244/ AASHTO T59 modified by heating } 50 \text {-gram sample to } 149^{\circ} \mathrm{C}\left(300^{\circ} \mathrm{F}\right) \text { until foaming ceases, } \\
\text { then immediate cooling and reweighing. }\end{array}$} \\
\hline \multicolumn{4}{|l|}{ d Chemical composition by ASTM Method D-2006-70: } \\
\hline \multicolumn{4}{|l|}{$\mathrm{PC}=$ Polar Compounds, $\mathrm{A} 1=$ First Acidaffins.} \\
\hline \multicolumn{4}{|l|}{ A2 = Second Acidaffins, S = Saturated Hydrocarbons. } \\
\hline \multicolumn{4}{|c|}{$\begin{array}{l}\text { Product shall be freeze stabilized; if freezing has occurred, the thawed material should be thoroughly mixed } \\
\text { until homogeneous }\end{array}$} \\
\hline
\end{tabular}

\section{Physiographic factors:}

CRF emulsion is diluted 2:1 (2 parts product to 1 part water) or 1:1.The CRF emulsion is diluted 2:1 (2 parts product to 1 part water) or 1:1. Typical cure time is $20 \mathrm{~min}$ to $1 \mathrm{hr}$ with minimum ambient temperature of $50^{\circ} \mathrm{F}\left(10^{\circ} \mathrm{C}\right)$ and rising.

The emulsion is a chemically stabilized system, so care should be taken not to upset the chemical balance with contamination by chemicals, overexposure to air, or adverse mechanical or thermal conditions. Before being 
filled, tanks and trucks should be examined for possible contaminants. The crack filler may be applied over a wide range of temperatures, but the surface seal should be applied at temperatures greater than $50^{\circ} \mathrm{C}$ and rising. 


\section{Appendix C: Field Raw Data}

This appendix compiles all the rut depth data collected during the traffic operations at both test sites. These data were used to determine the maximum rut depth experienced by each repair under the F-15 load cart traffic and the permanent deformation. The following figure shows the layout used to collect measurements from each repair.

Figure C1. Layout of rut depth measurements on each repair.

\begin{tabular}{|c|c|c|c|c|}
\hline & North & Center & South & \\
\hline $\begin{array}{l}T \\
T \\
4 \mathrm{ft}\end{array}$ & $\begin{array}{r}1 \\
1 \\
1 \\
1 \\
1 \\
1 \\
1 \\
1 \\
1 \\
1 \\
1 \\
1 \\
1 \\
1 \\
-1 \\
1 \\
1 \\
1 \\
1 \\
1 \\
1 \\
1 \\
1 \\
1 \\
1 \\
1 \\
1\end{array}$ & $\begin{array}{r}1 \\
1 \\
1 \\
1 \\
1 \\
1 \\
1 \\
1 \\
1 \\
1 \\
-7 \\
-1 \\
1 \\
1 \\
1 \\
1 \\
1 \\
1 \\
1 \\
1 \\
1\end{array}$ & $\begin{array}{r}1 \\
1 \\
1 \\
1 \\
1 \\
1 \\
1 \\
1 \\
1 \\
1 \\
1 \\
1 \\
1 \\
- \\
-1 \\
1 \\
1 \\
1 \\
1 \\
1 \\
1 \\
1 \\
1 \\
1 \\
1 \\
1 \\
1 \\
1 \\
1\end{array}$ & C.enterline \\
\hline & 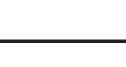 & $6 \mathrm{ft}$ & 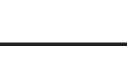 & $t$ \\
\hline
\end{tabular}




\section{Test Site 1 Repairs}

Figure C2. Rut depth measurements on north cross-section of FD-1.

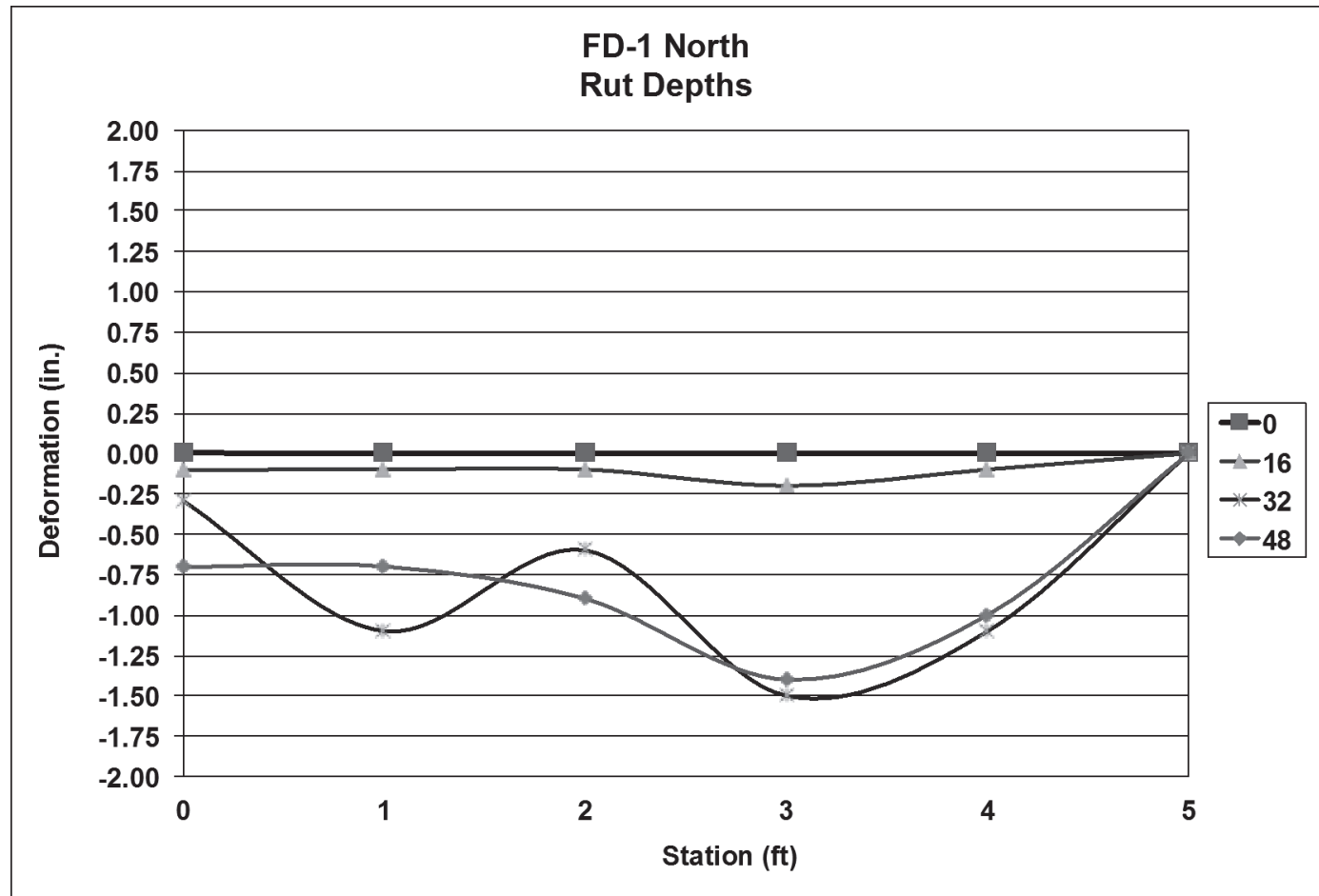

Figure C3. Rut depth measurements on center cross-section of FD-1.

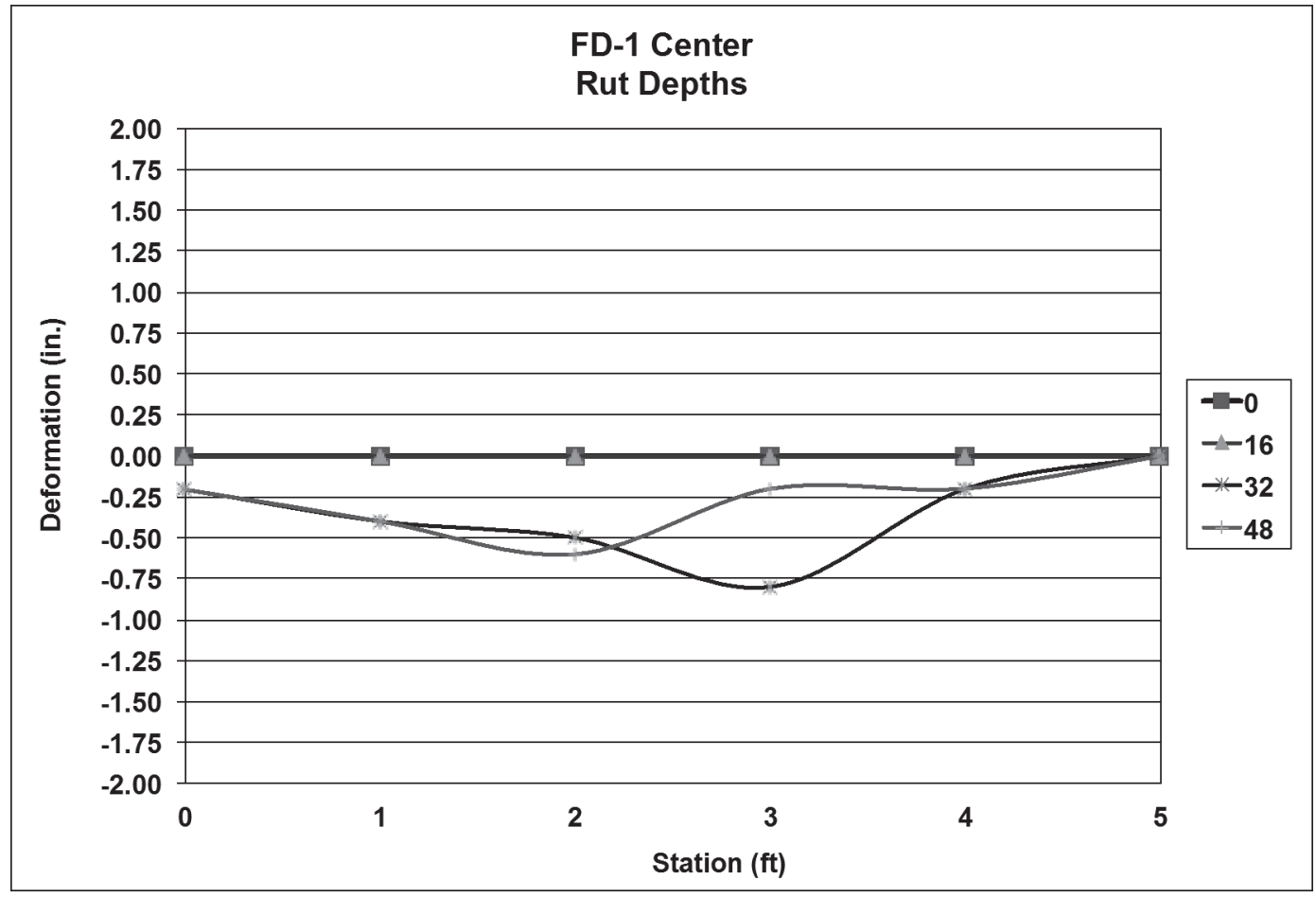


Figure C4. Rut depth measurements on south cross-section of FD-1.

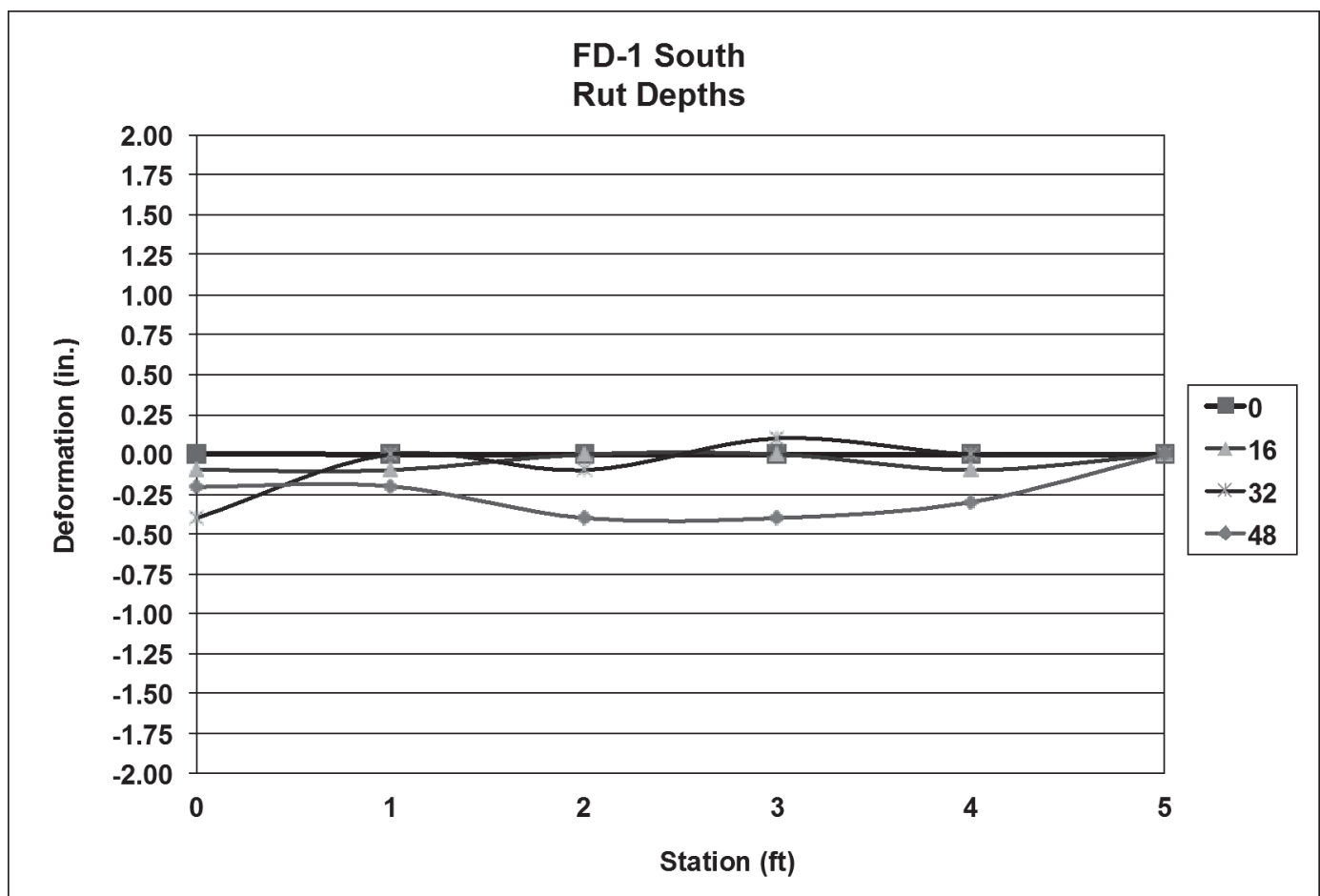

Figure $\mathrm{C5}$. Rut depth measurements on cross-section at midpoint between repairs FD-1 and FD-2 (existing asphalt pavement).

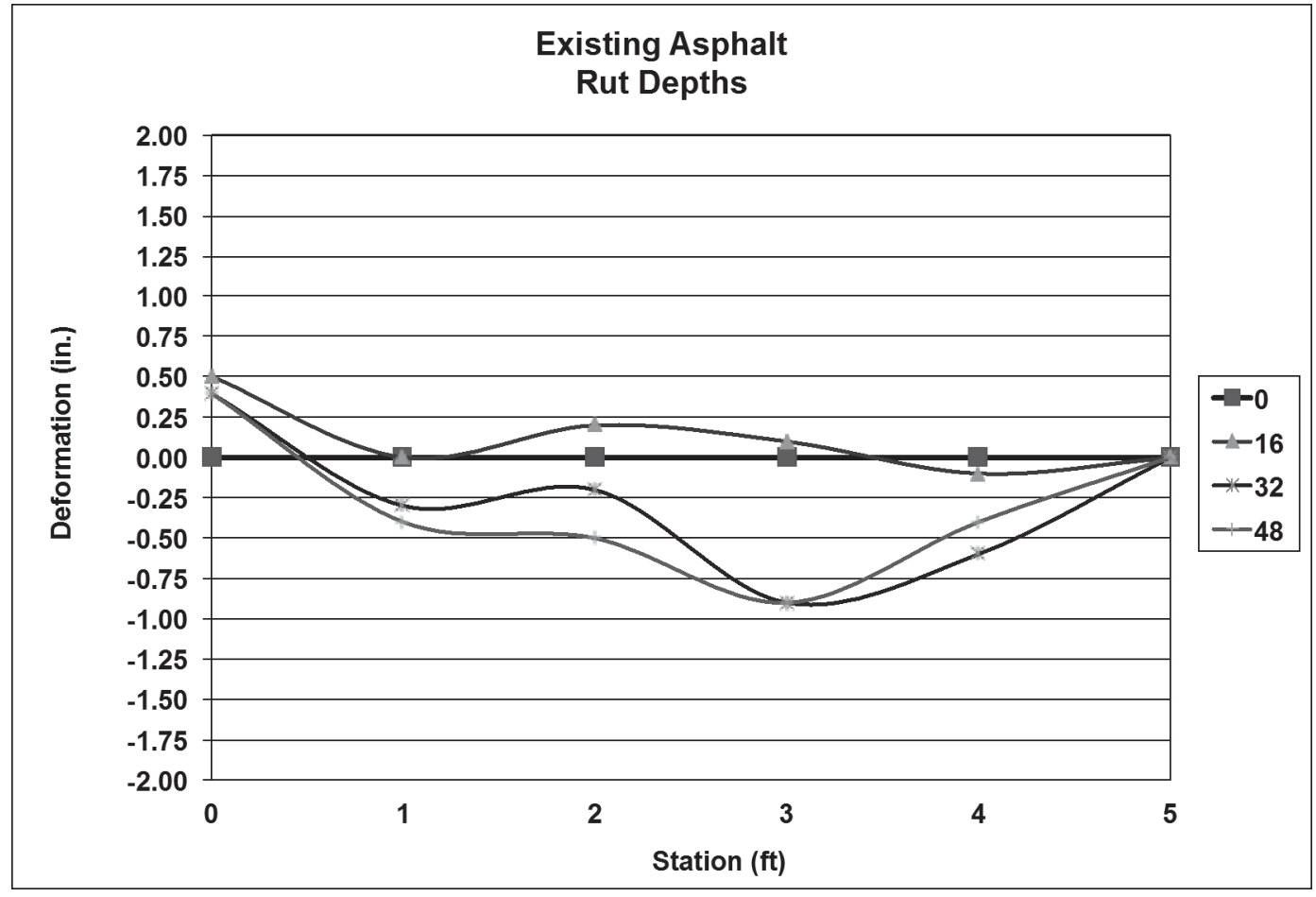


Figure C6. Rut depth measurements on north cross-section of FD-2.

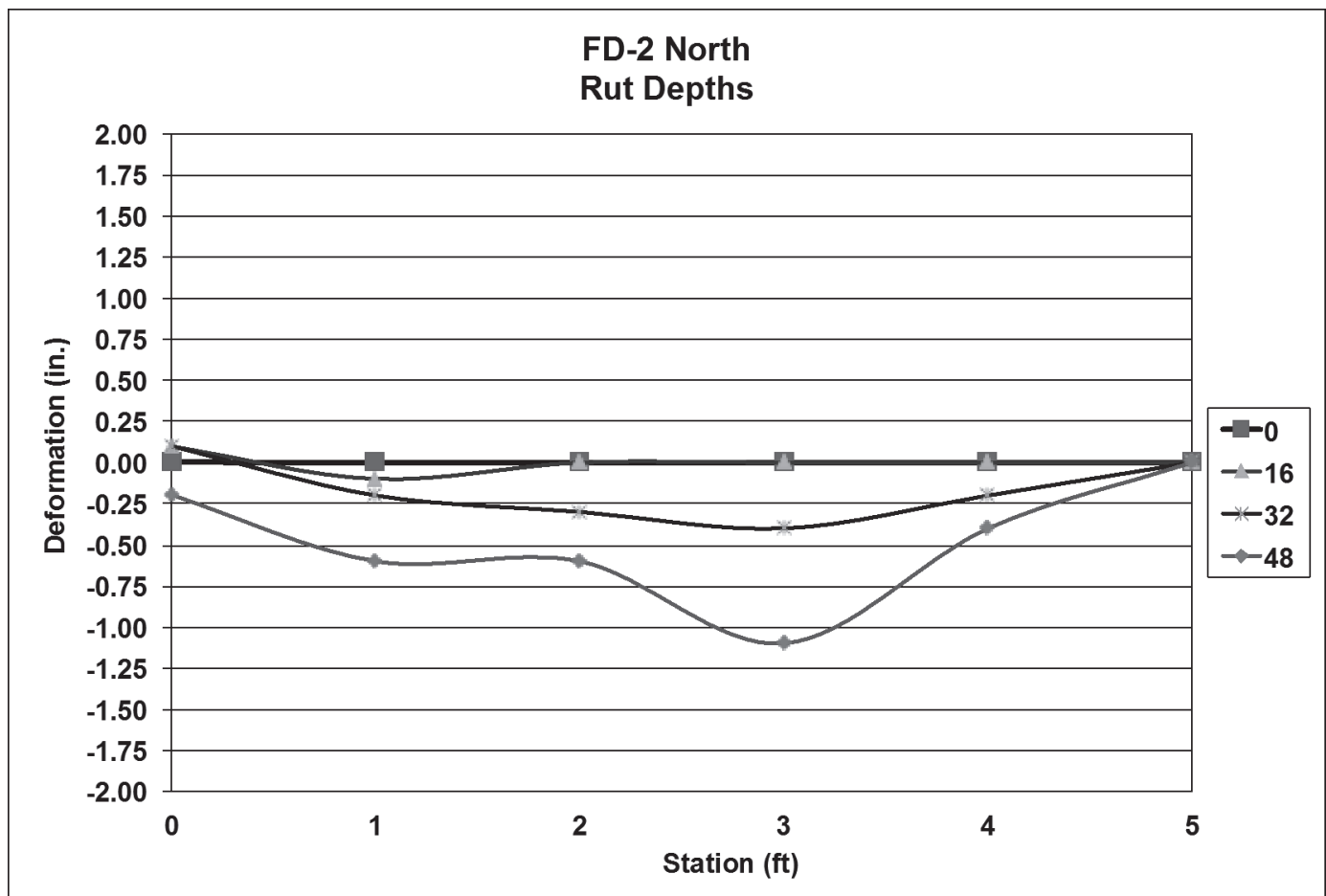

Figure $\mathrm{C7}$. Rut depth measurements on center cross-section of FD-2.

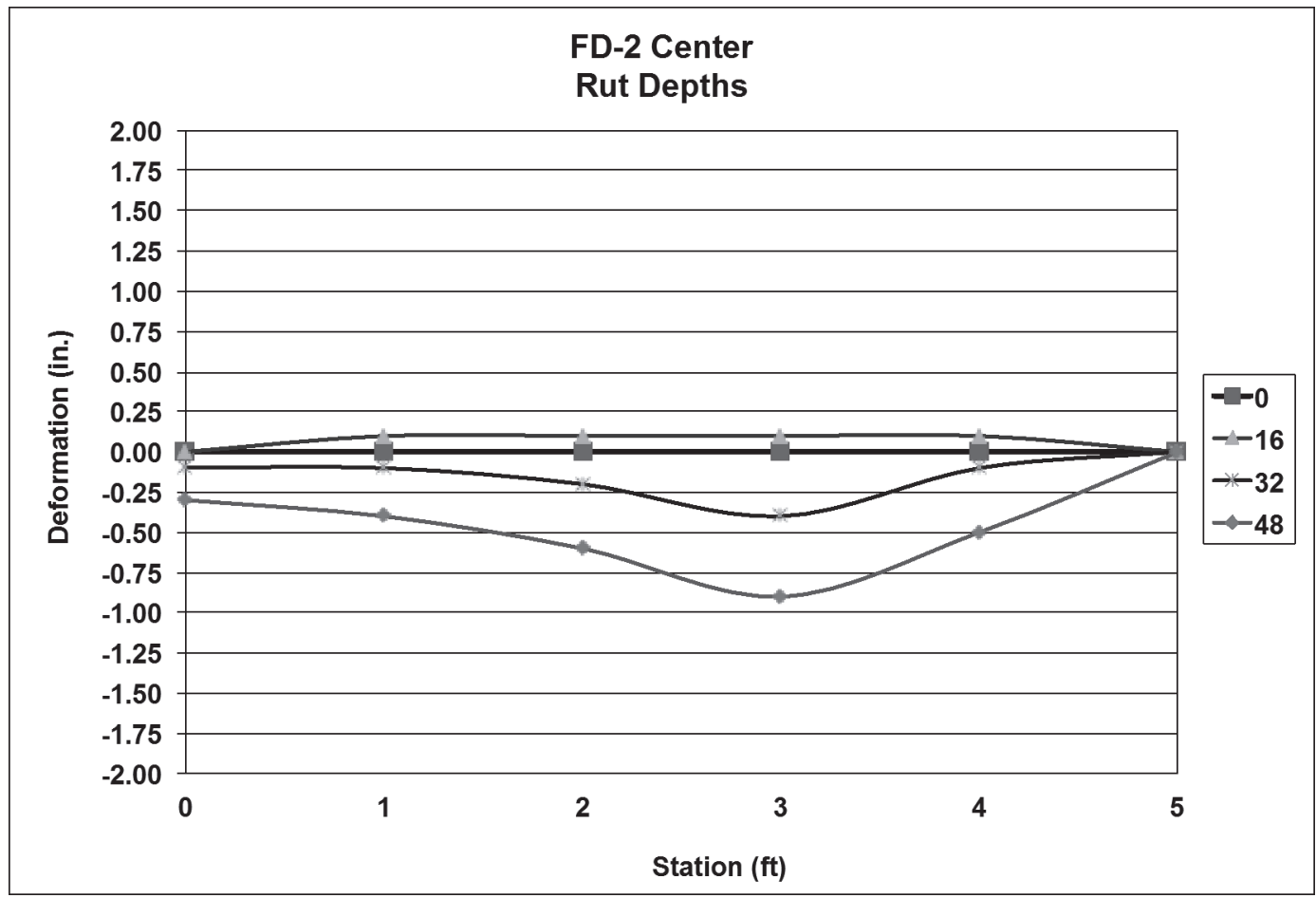


Figure C8. Rut depth measurements on south cross-section of FD-2.

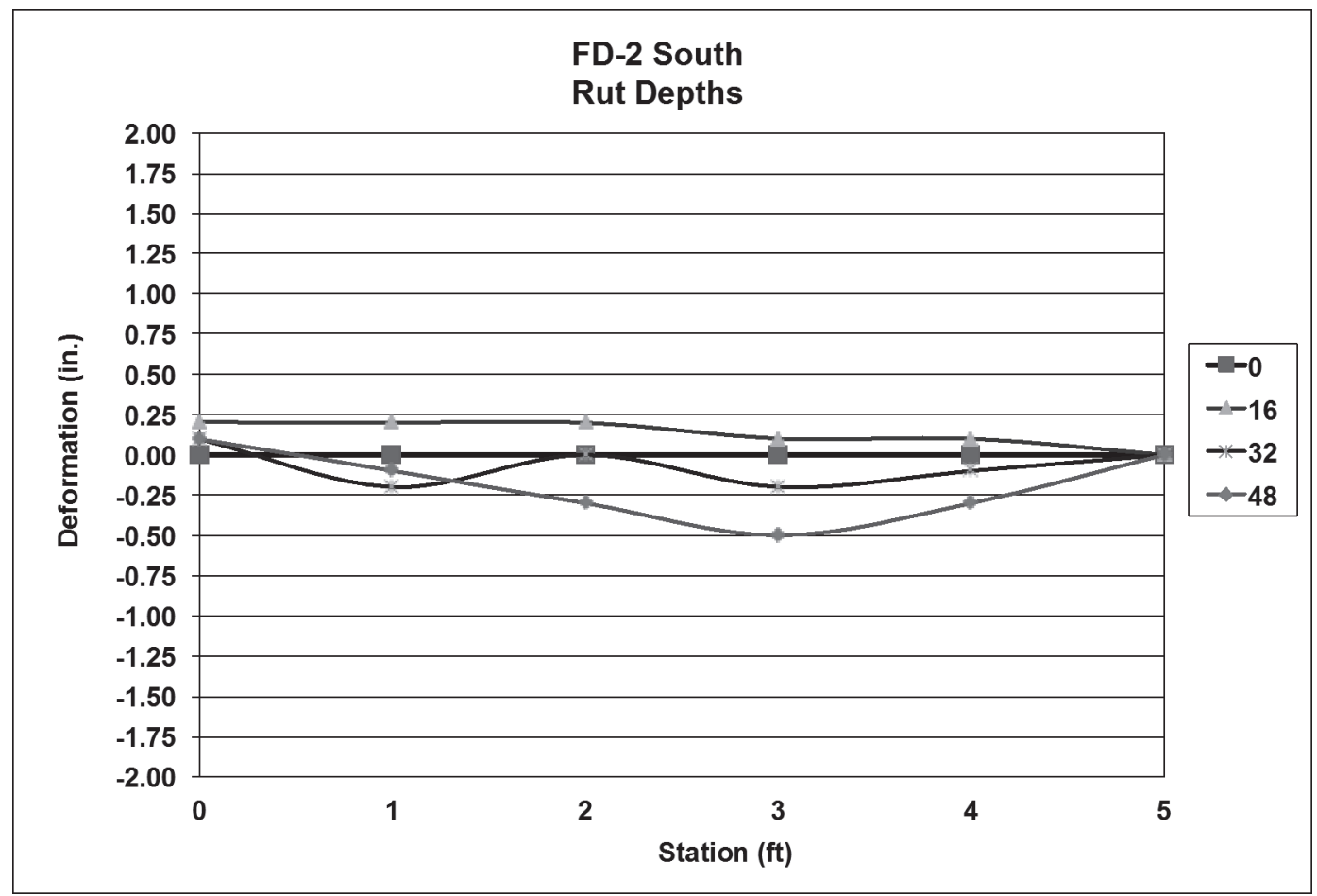

Figure C9. Rut depth measurements on cross-section at midpoint between repairs FD-2 and FD-3 (existing asphalt pavement).

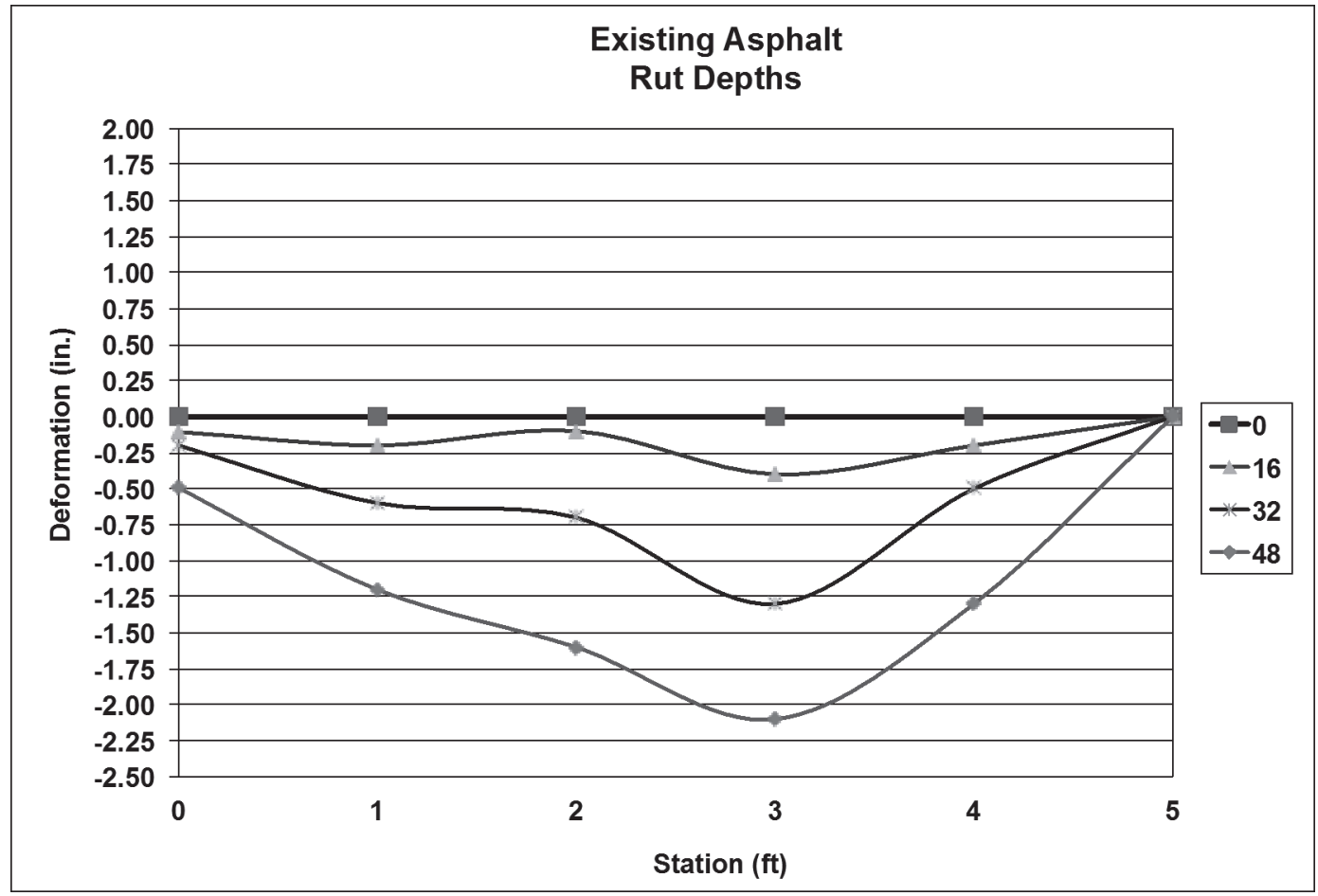


Figure C10. Rut depth measurements on north cross-section of FD-3.

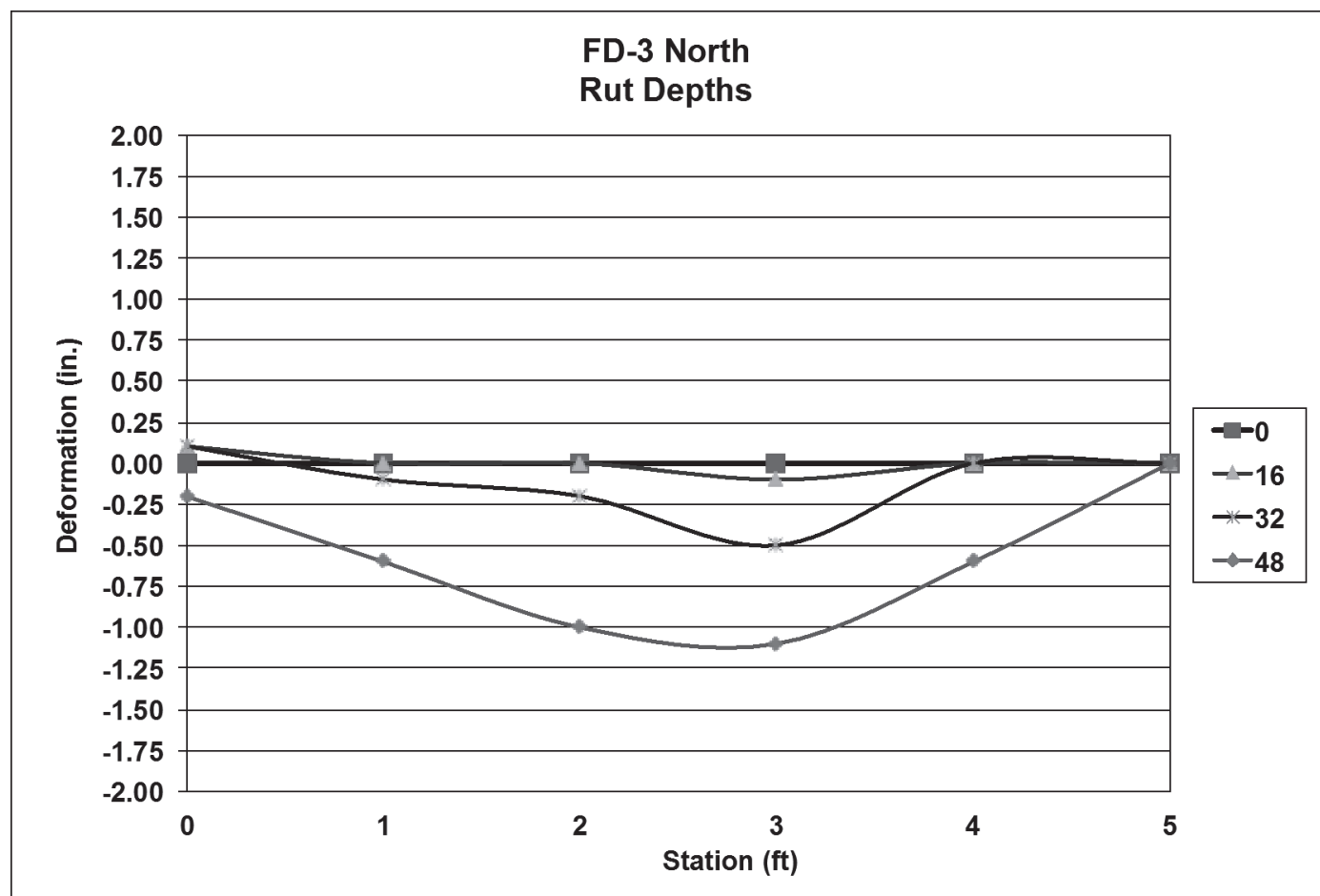

Figure C11. Rut depth measurements on center cross-section of FD-3.

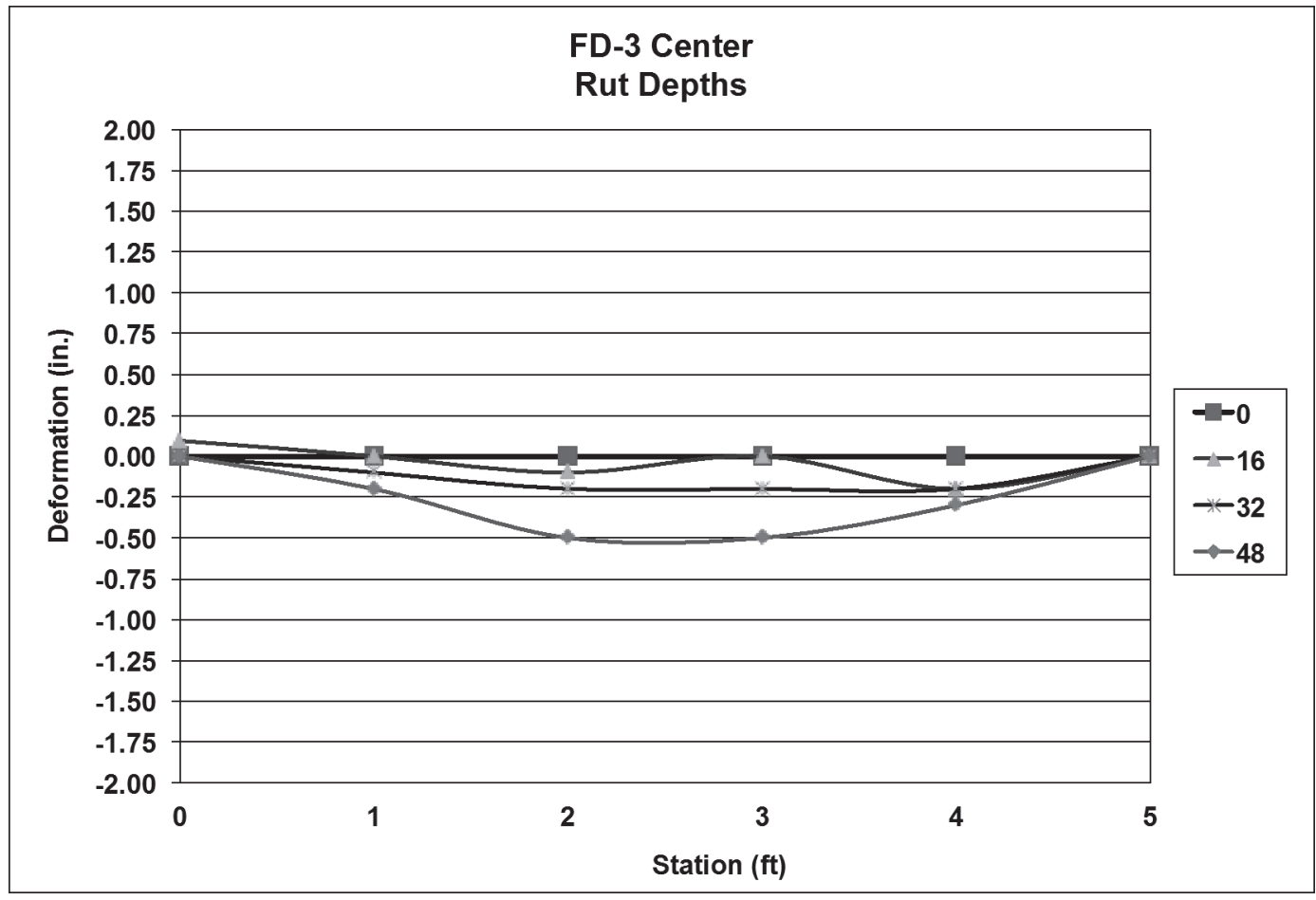


Figure C12. Rut depth measurements on south cross-section of FD-3.

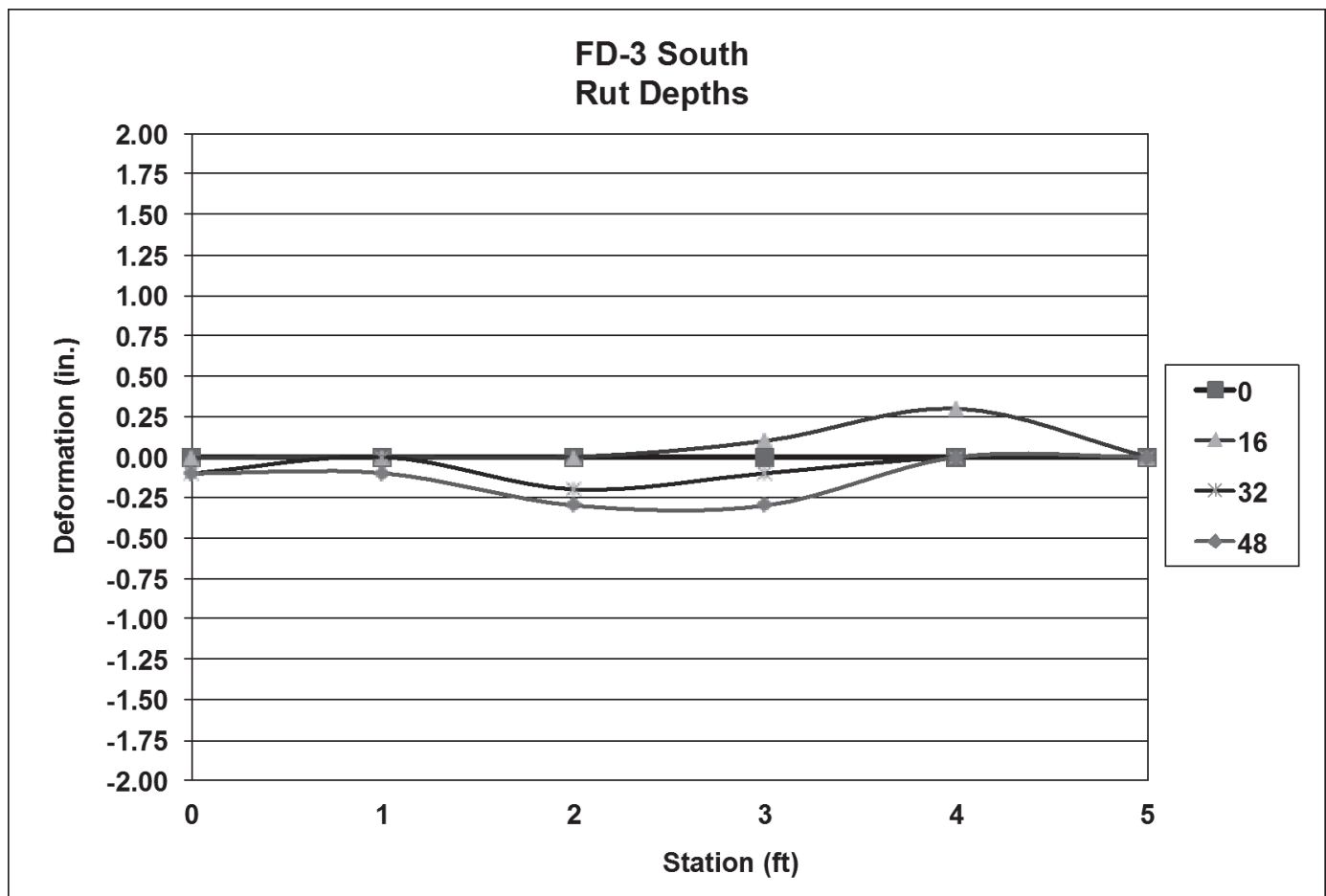

Figure 13. Rut depth measurements on cross-section at midpoint between repairs FD-3 and FD-4 (existing asphalt pavement).

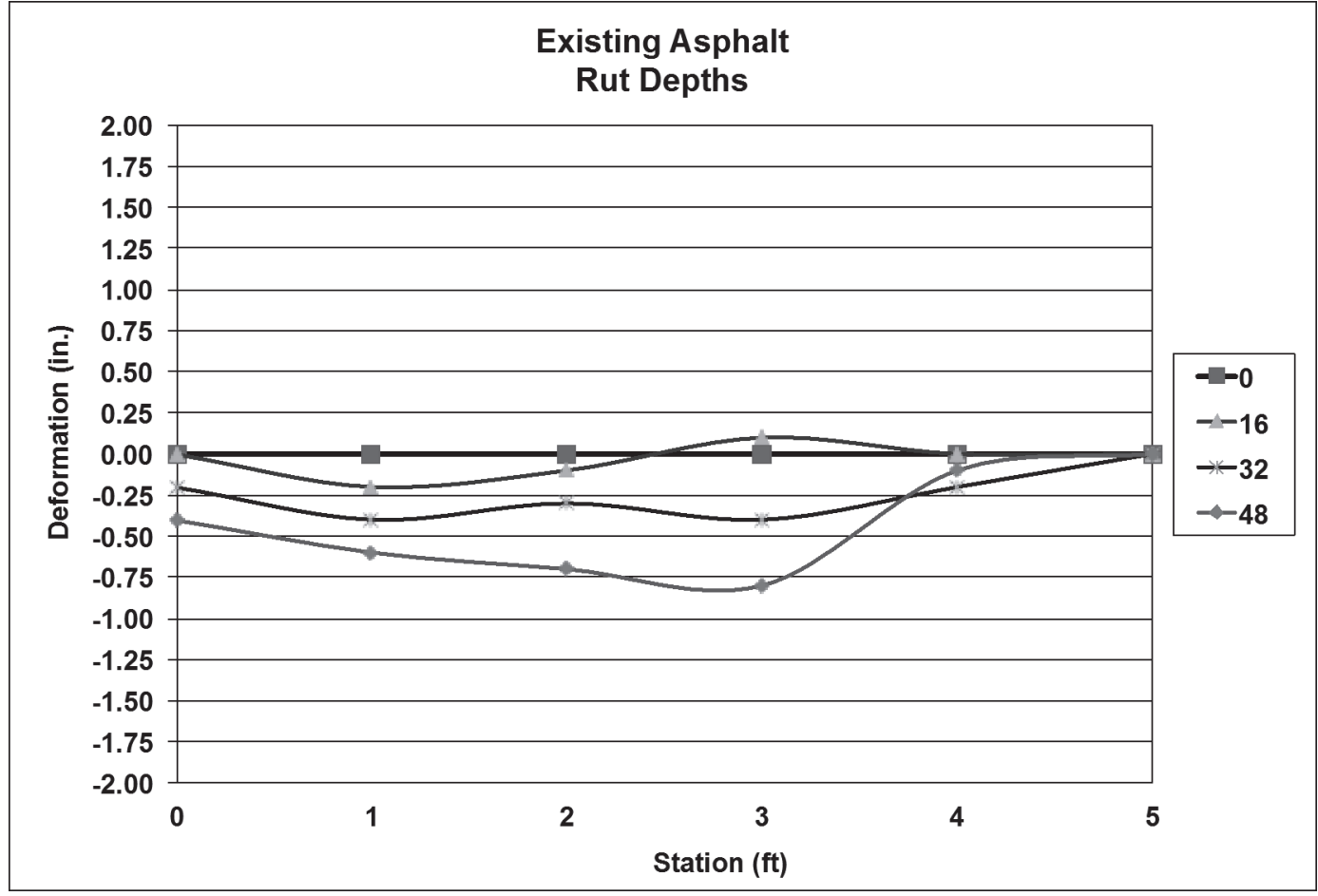


Figure C14. Rut depth measurements on north cross-section of FD-4.

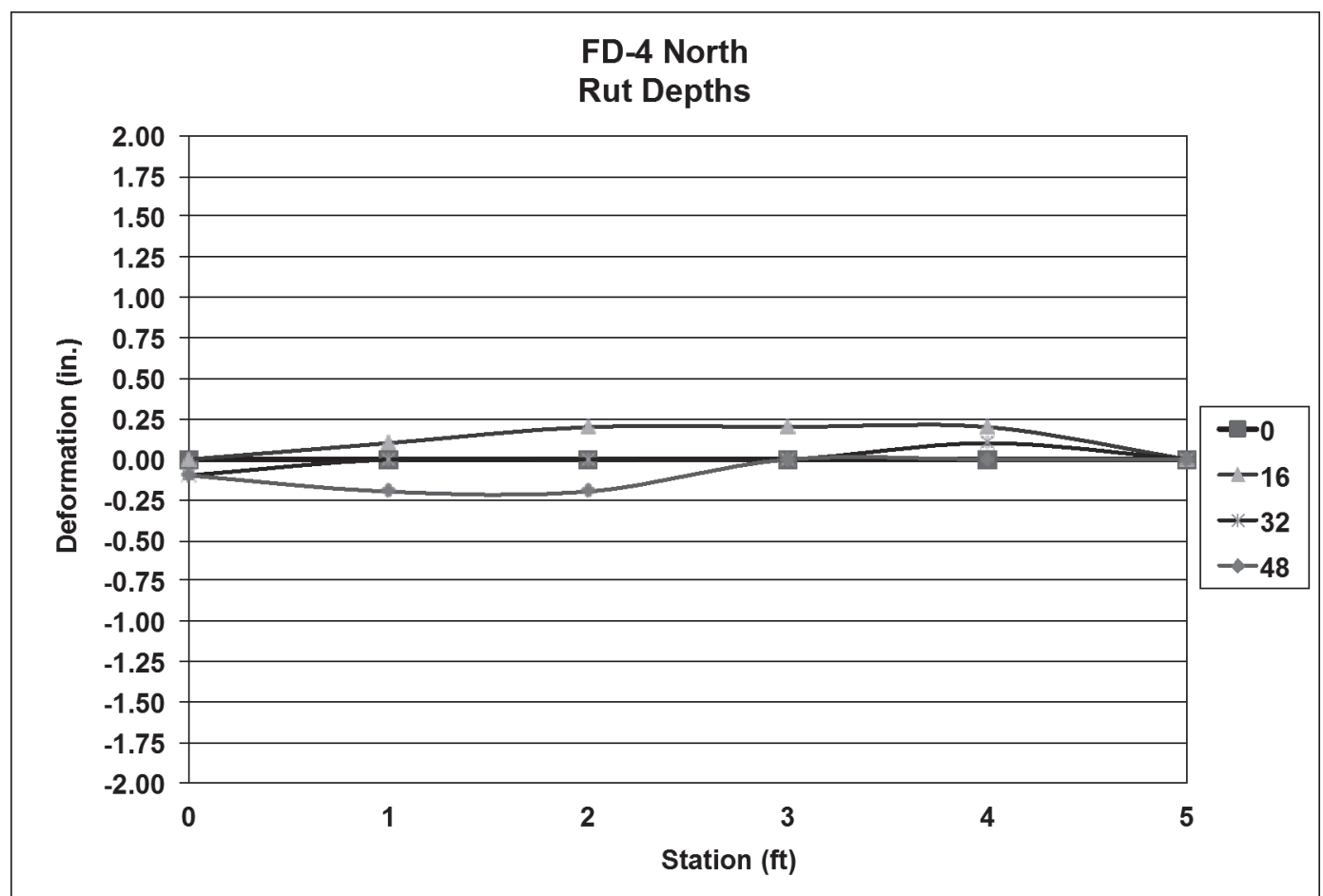

Figure $\mathrm{C} 15$. Rut depth measurements on center cross-section of FD-4.

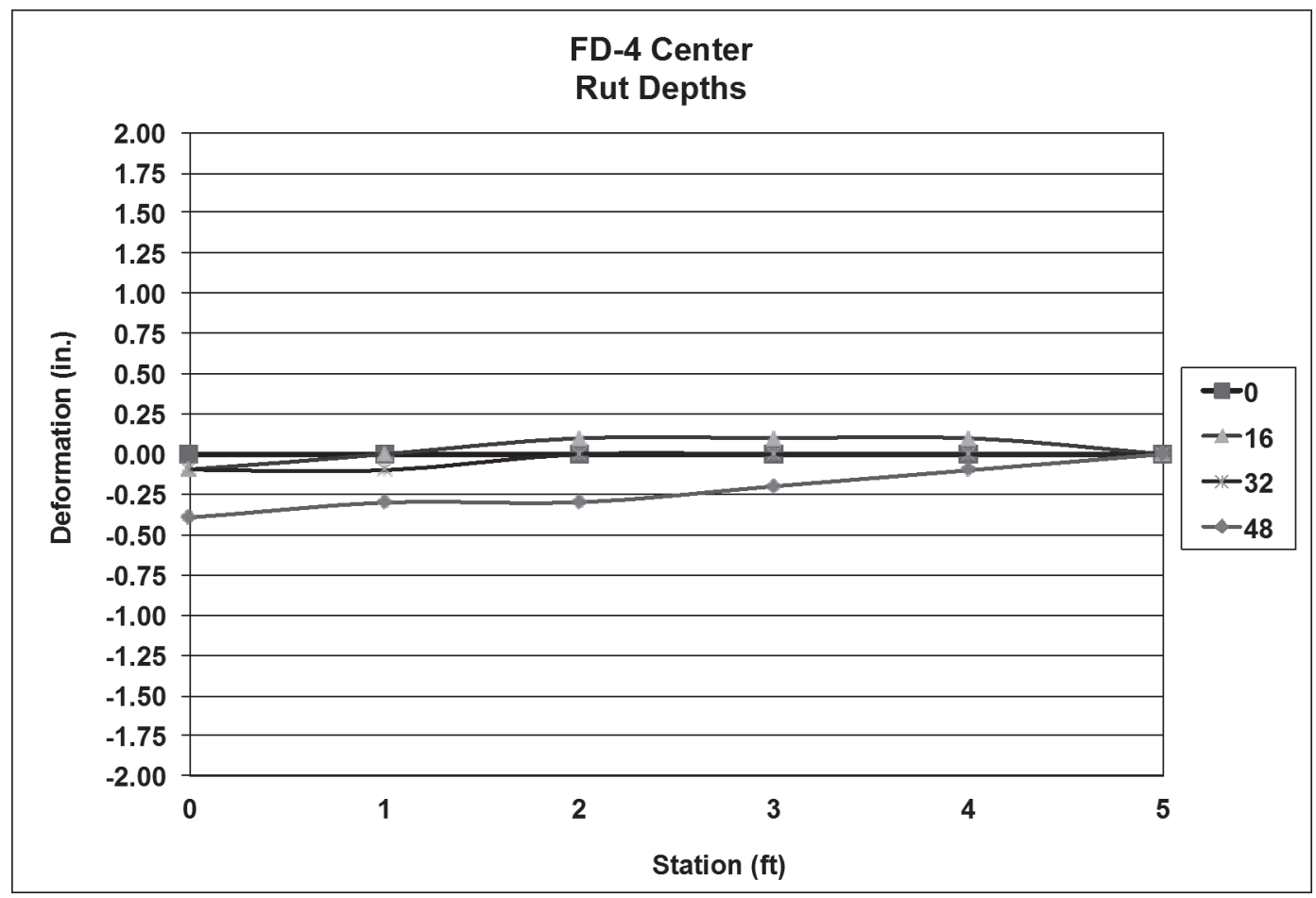


Figure C16. Rut depth measurements on south cross-section of FD-4.

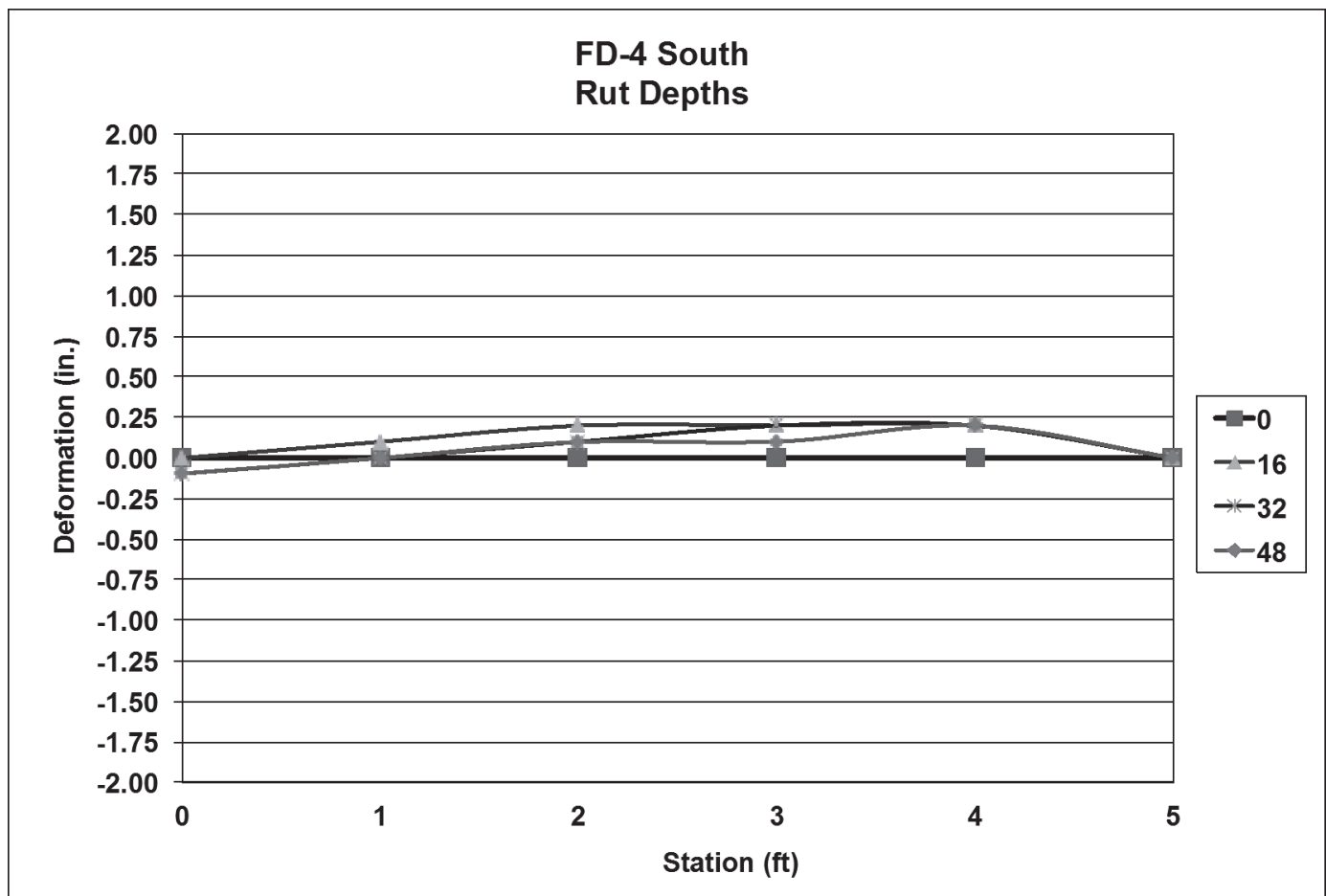

Figure $\mathrm{C} 17$. Rut depth measurements on cross-section at midpoint between repairs FD-4 and FD-5 (existing asphalt pavement).

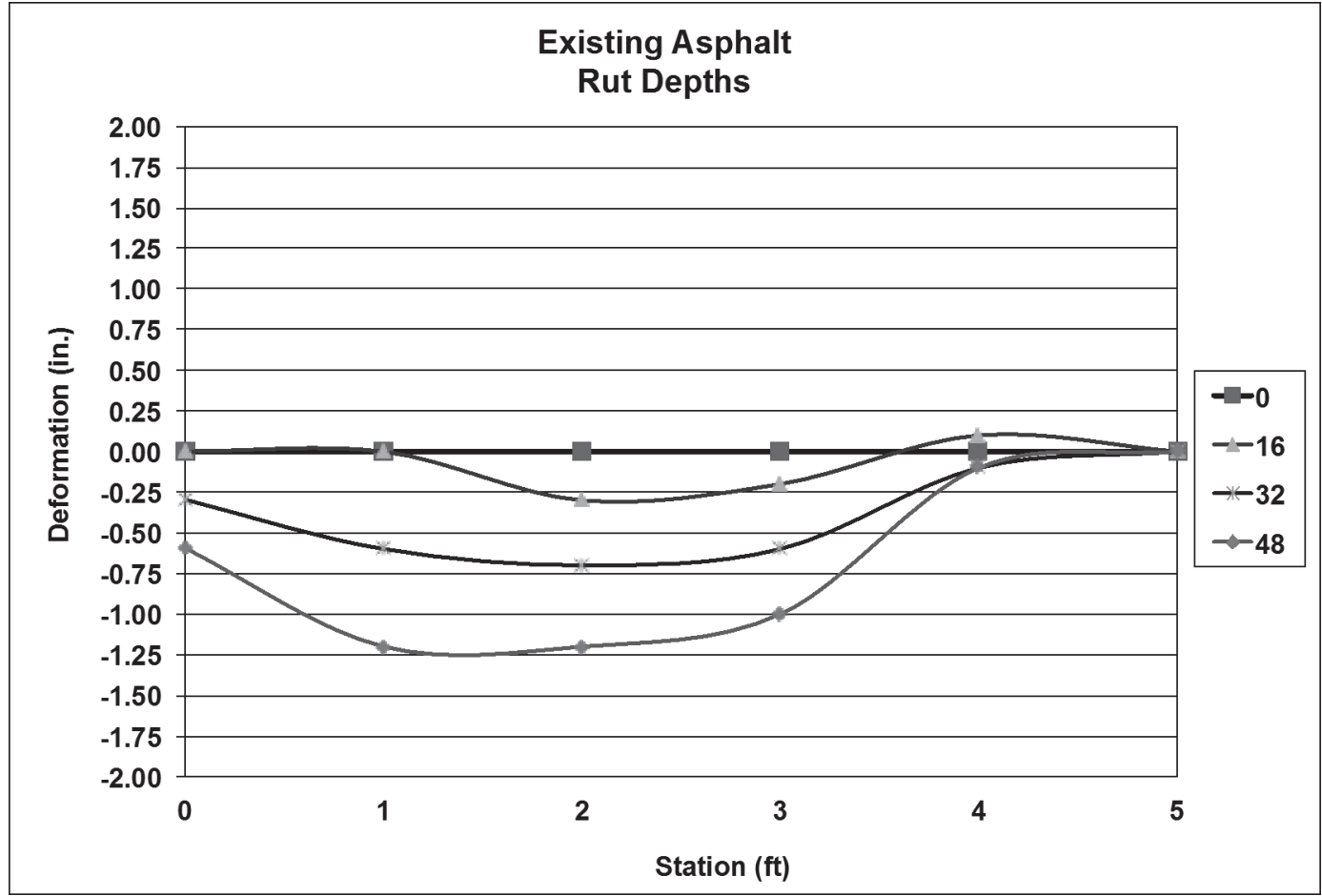


Figure C18. Rut depth measurements on north cross-section of FD-5.

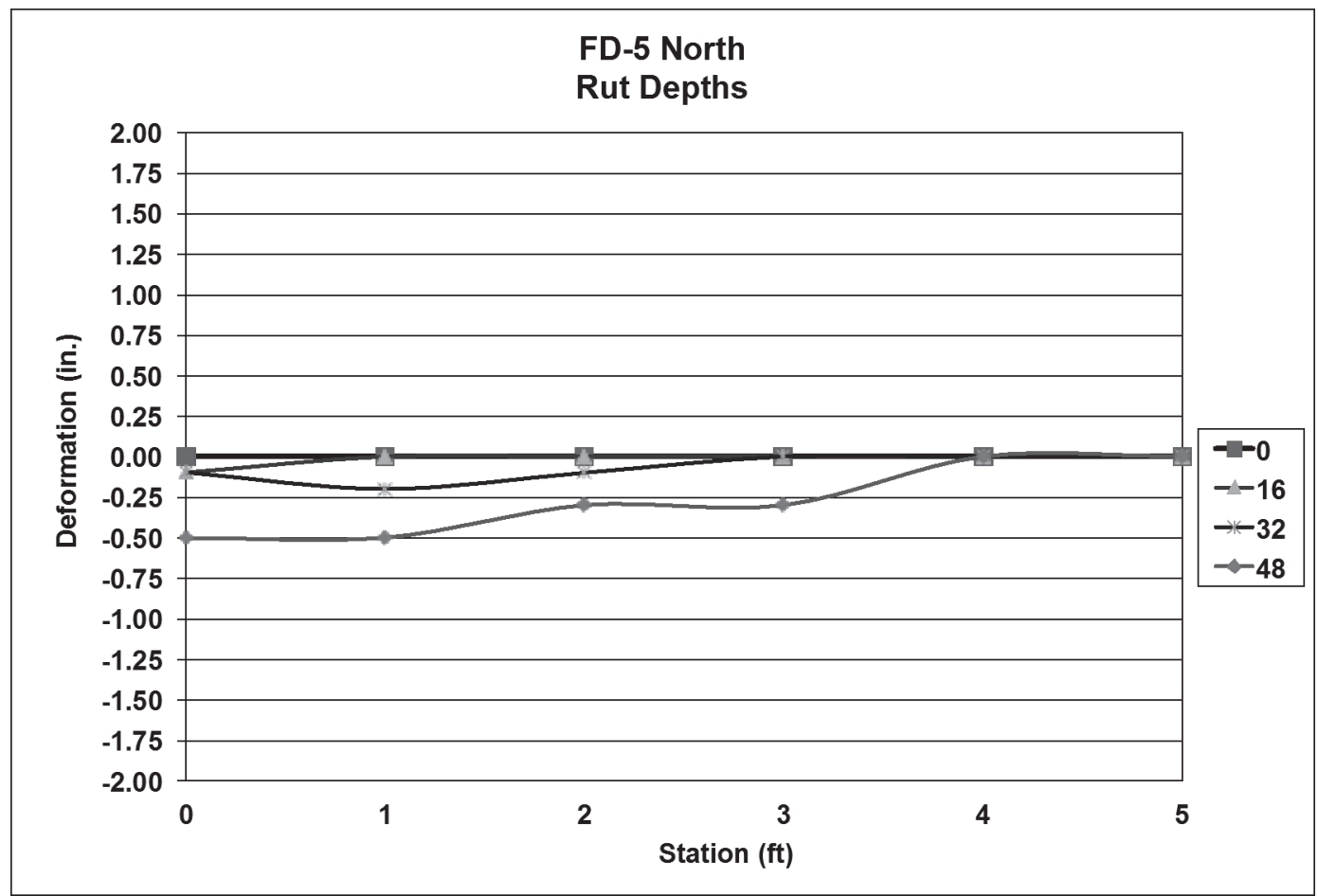

Figure C19. Rut depth measurements on center cross-section of FD-5.

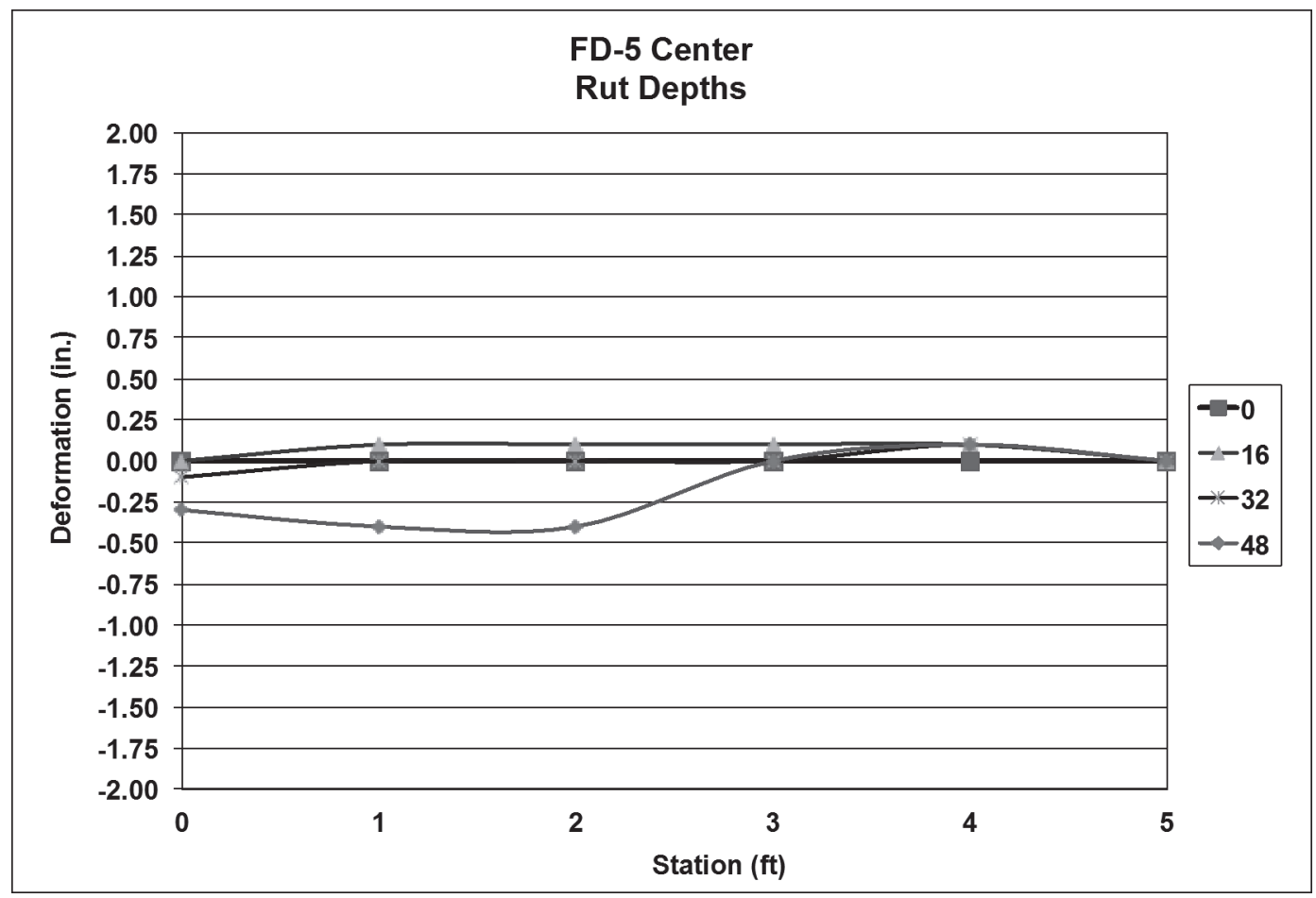


Figure C20. Rut depth measurements on south cross-section of FD-5.

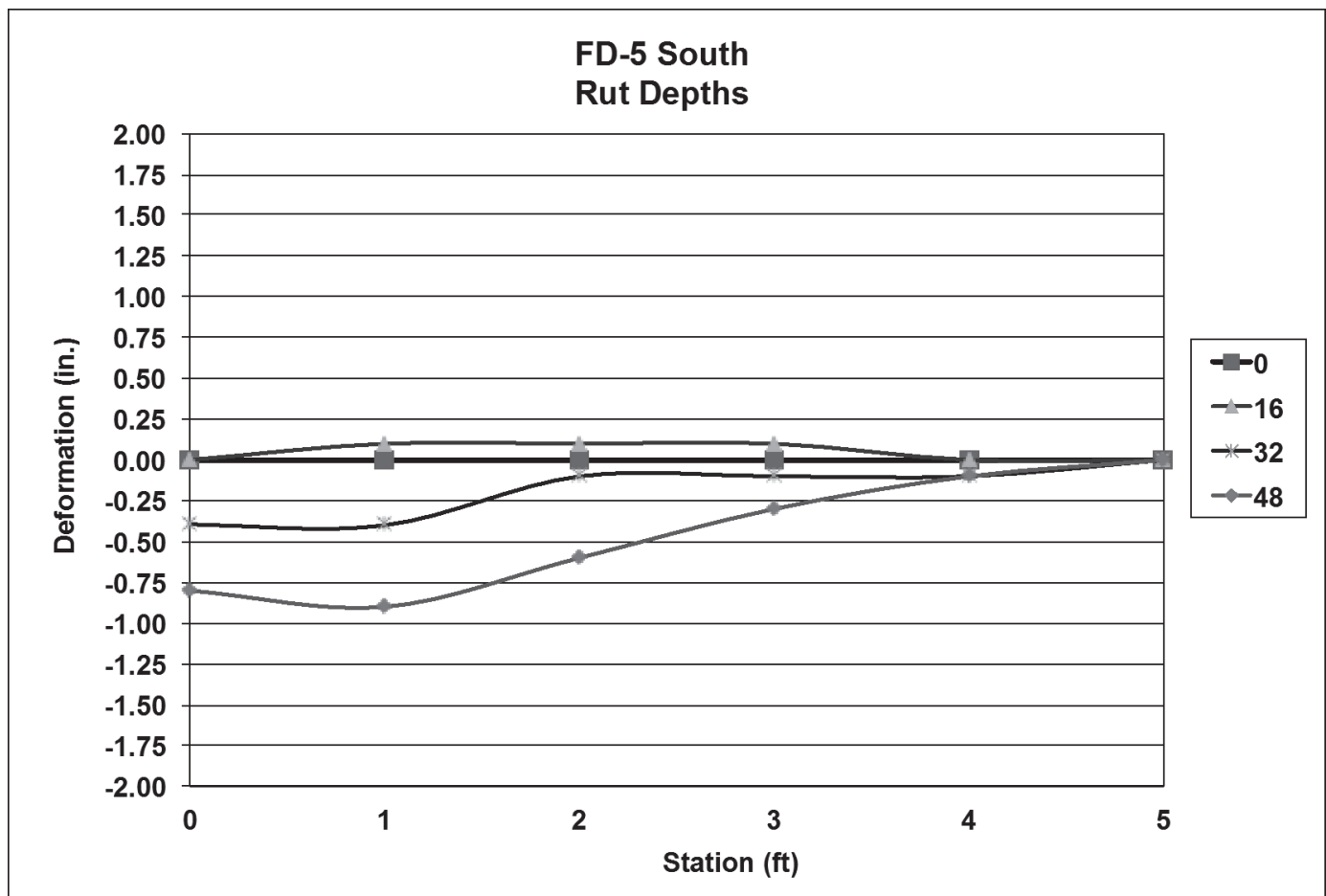

Figure C21. Rut depth measurements on cross-section $2 \mathrm{ft}$ after repair FD-5 (existing asphalt pavement).

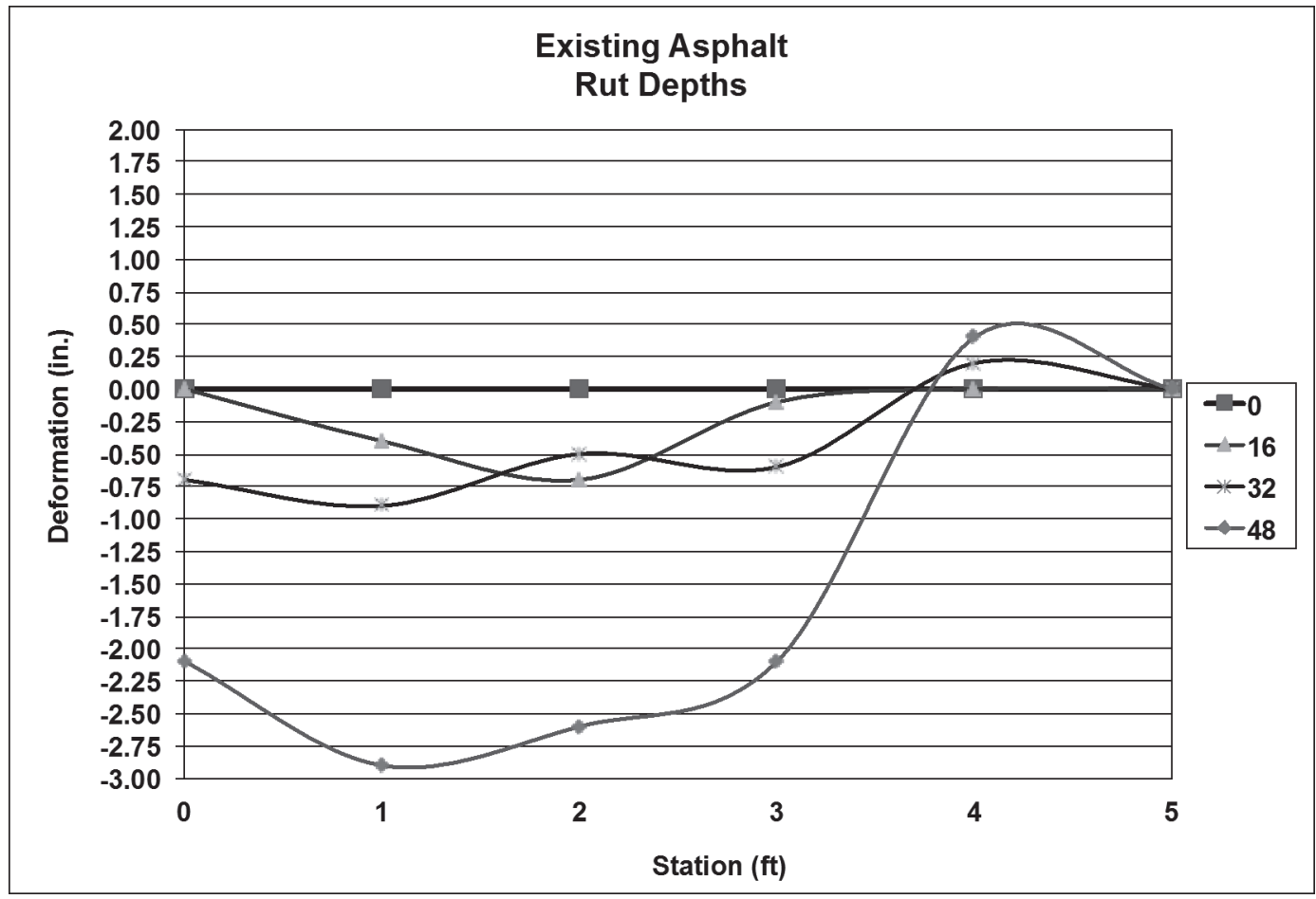


Figure C22. Rut depth measurements on north cross-section of FD-1a.

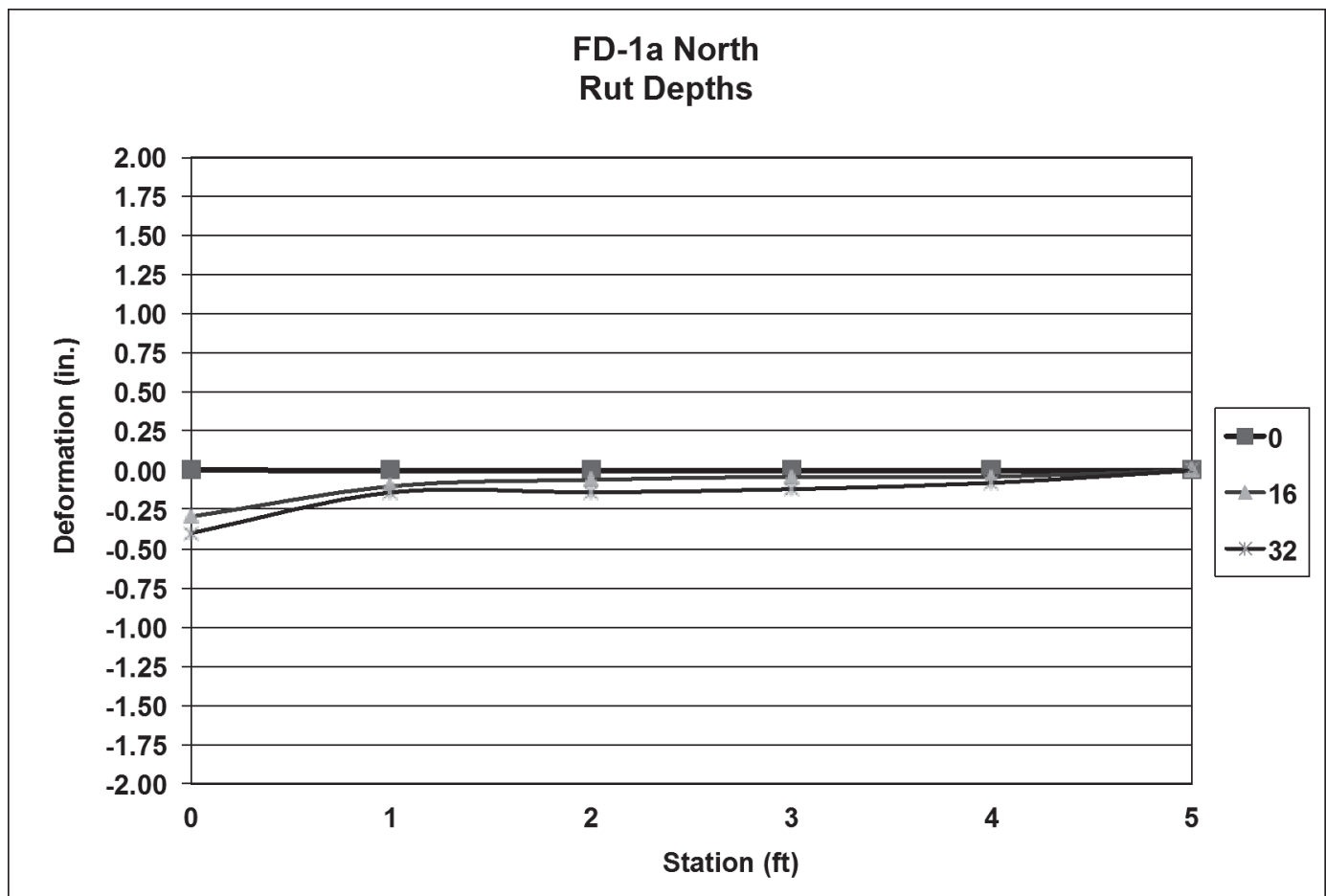

Figure C23. Rut depth measurements on center cross-section of FD-1a.

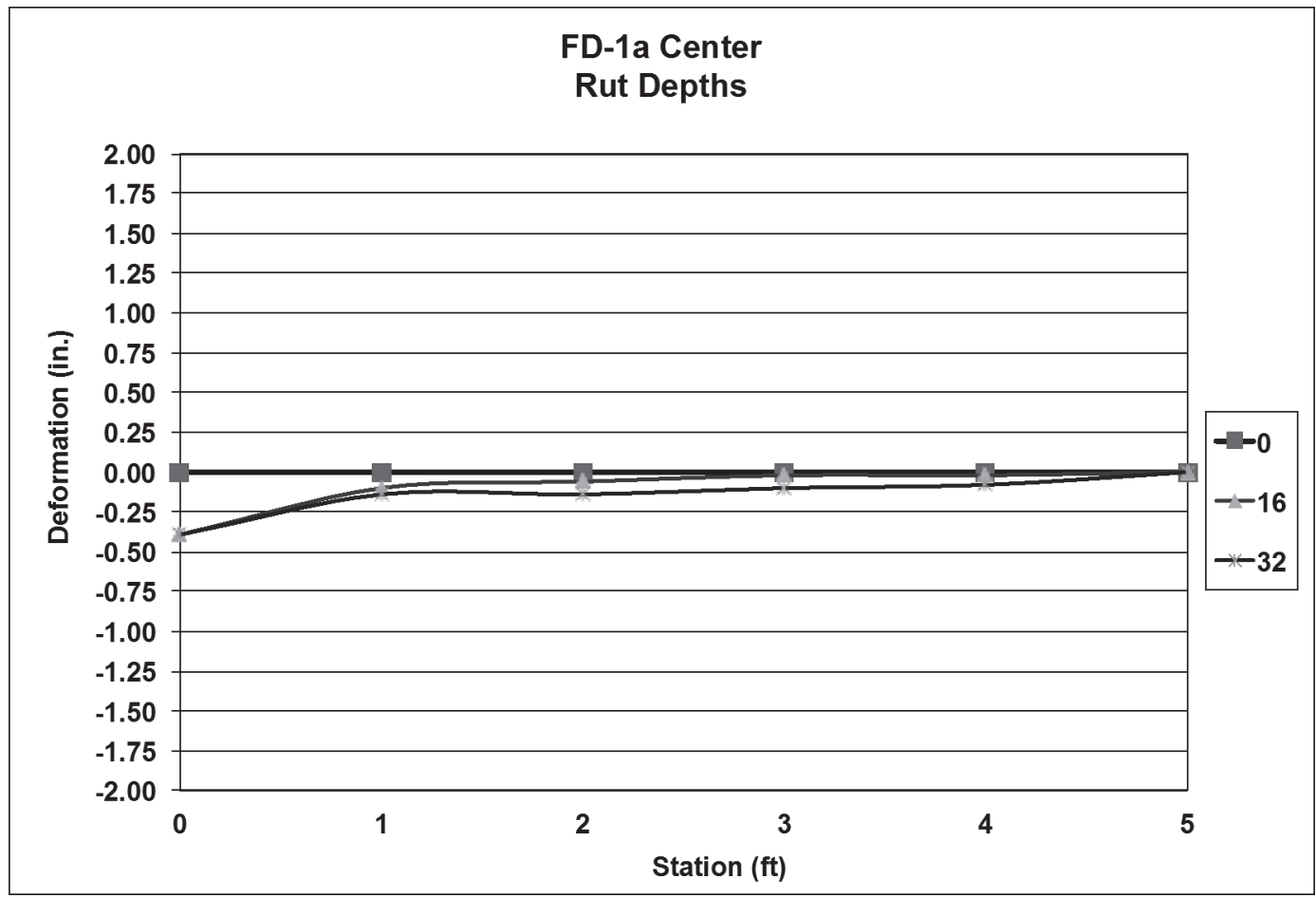


Figure C24. Rut depth measurements on south cross-section of FD-1a.

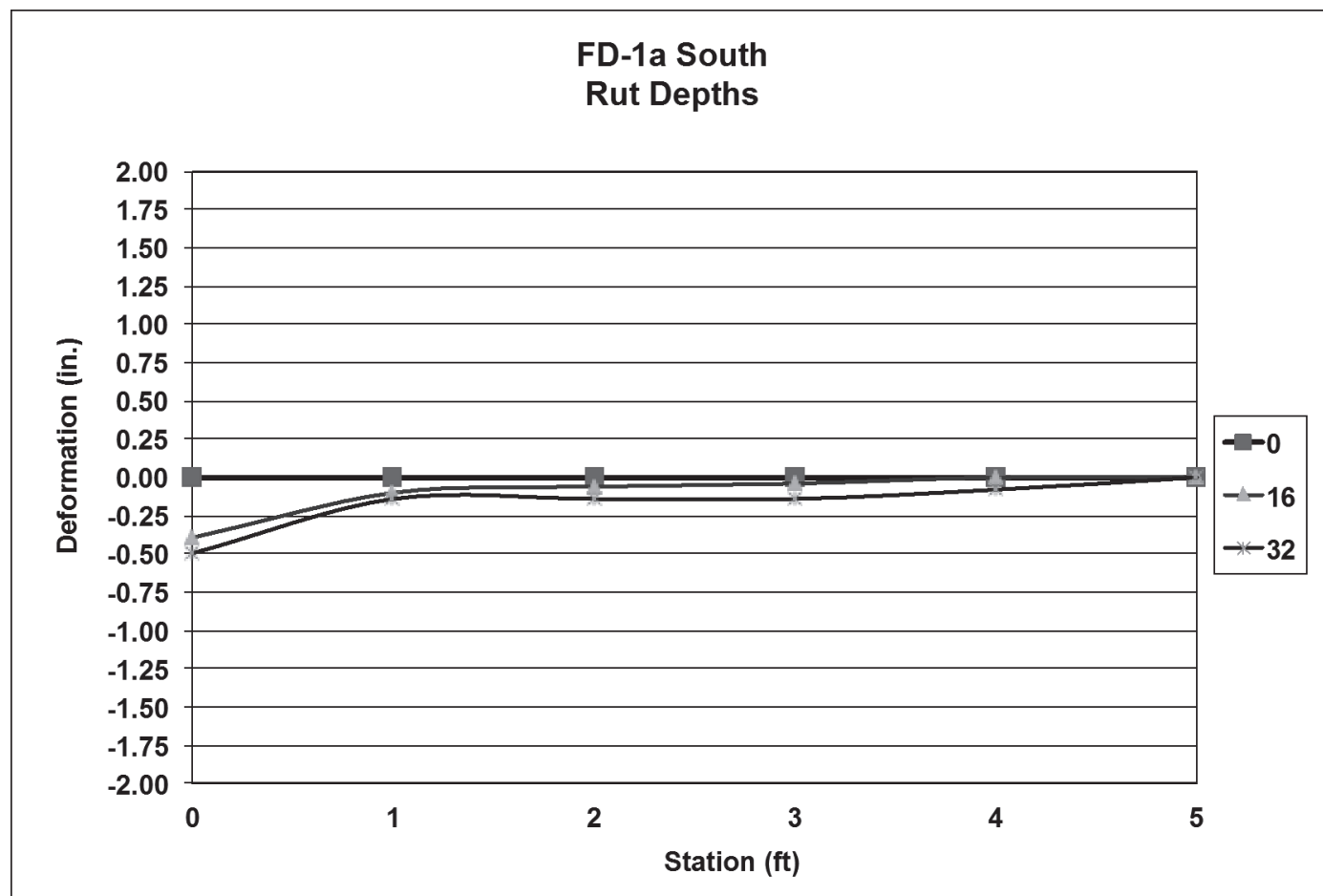

Figure C25. Rut depth measurements on cross-section at mid-point between repairs FD-1a and PD-2 (existing asphalt pavement).

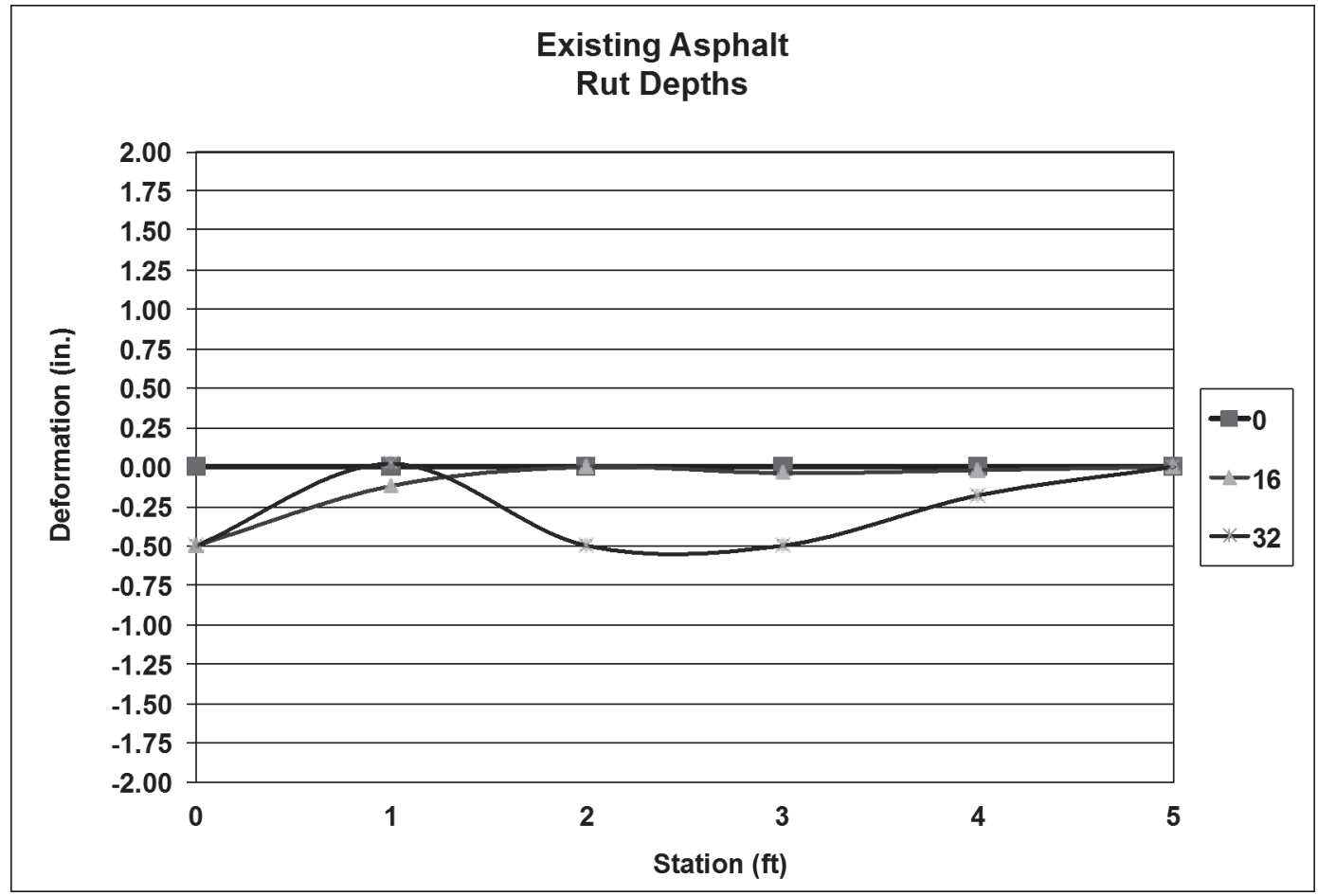


Figure C26. Rut depth measurements on north cross-section of PD-2.

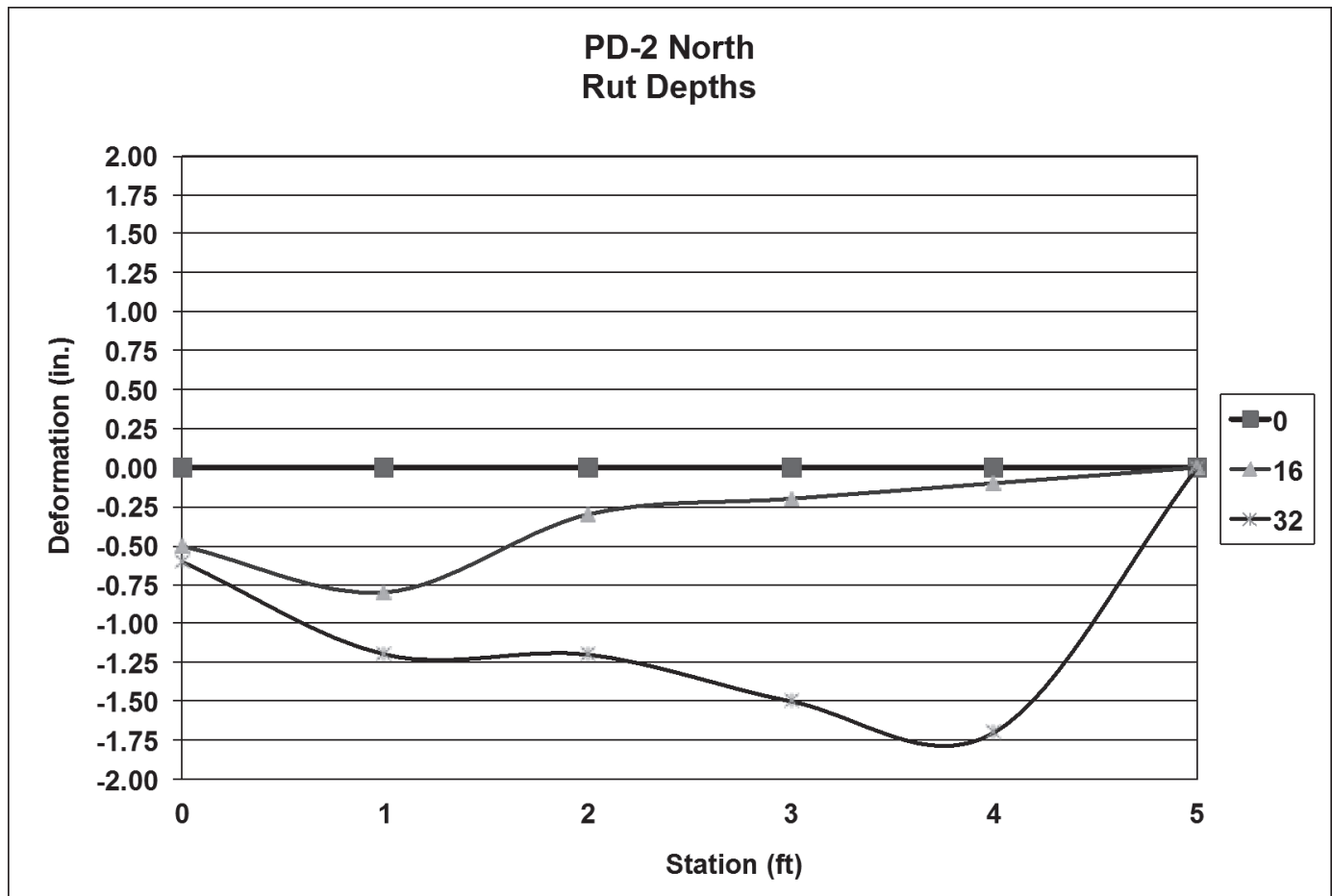

Figure C27. Rut depth measurements on center cross-section of PD-2.

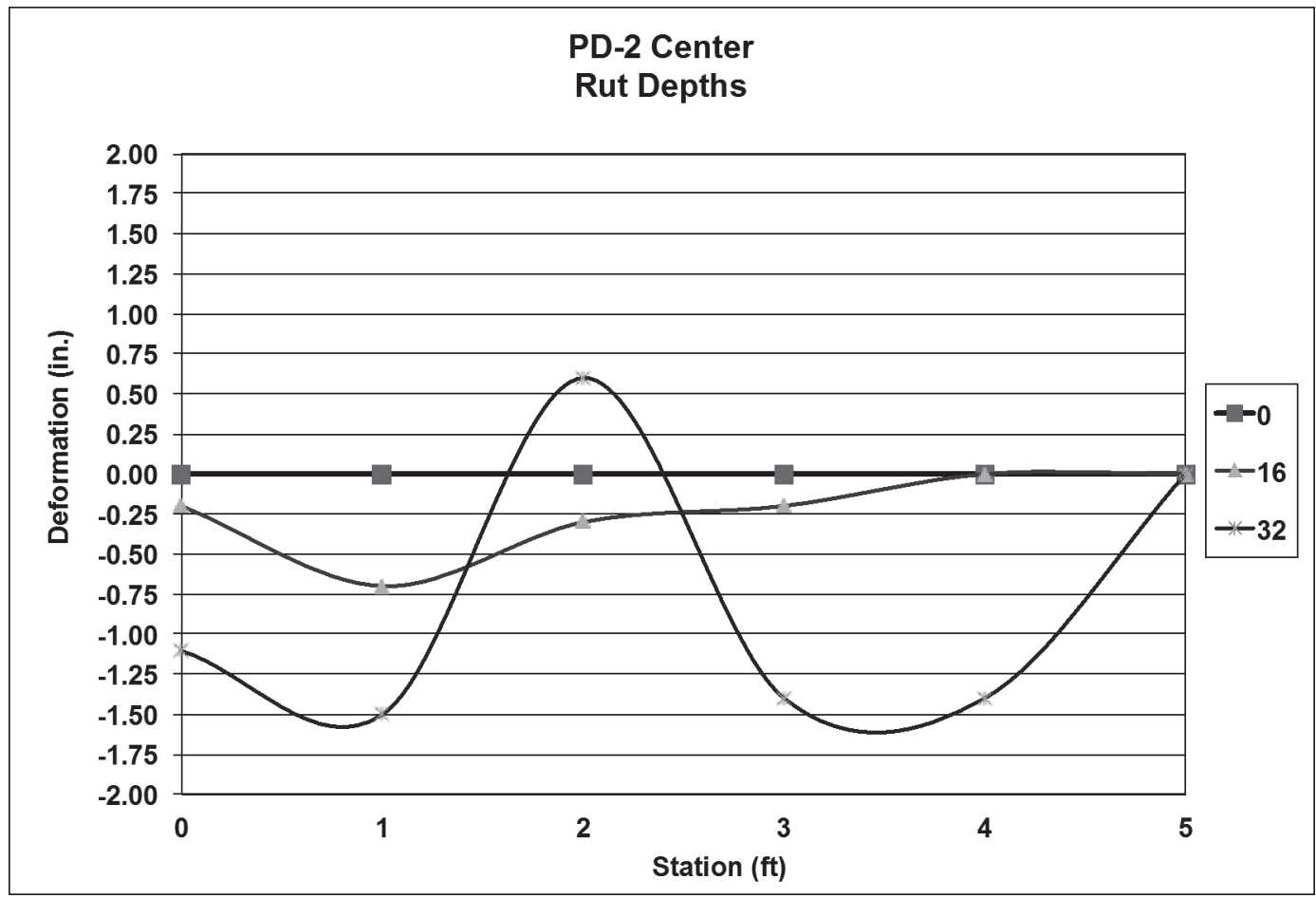


Figure C28. Rut depth measurements on south cross-section of PD-2.

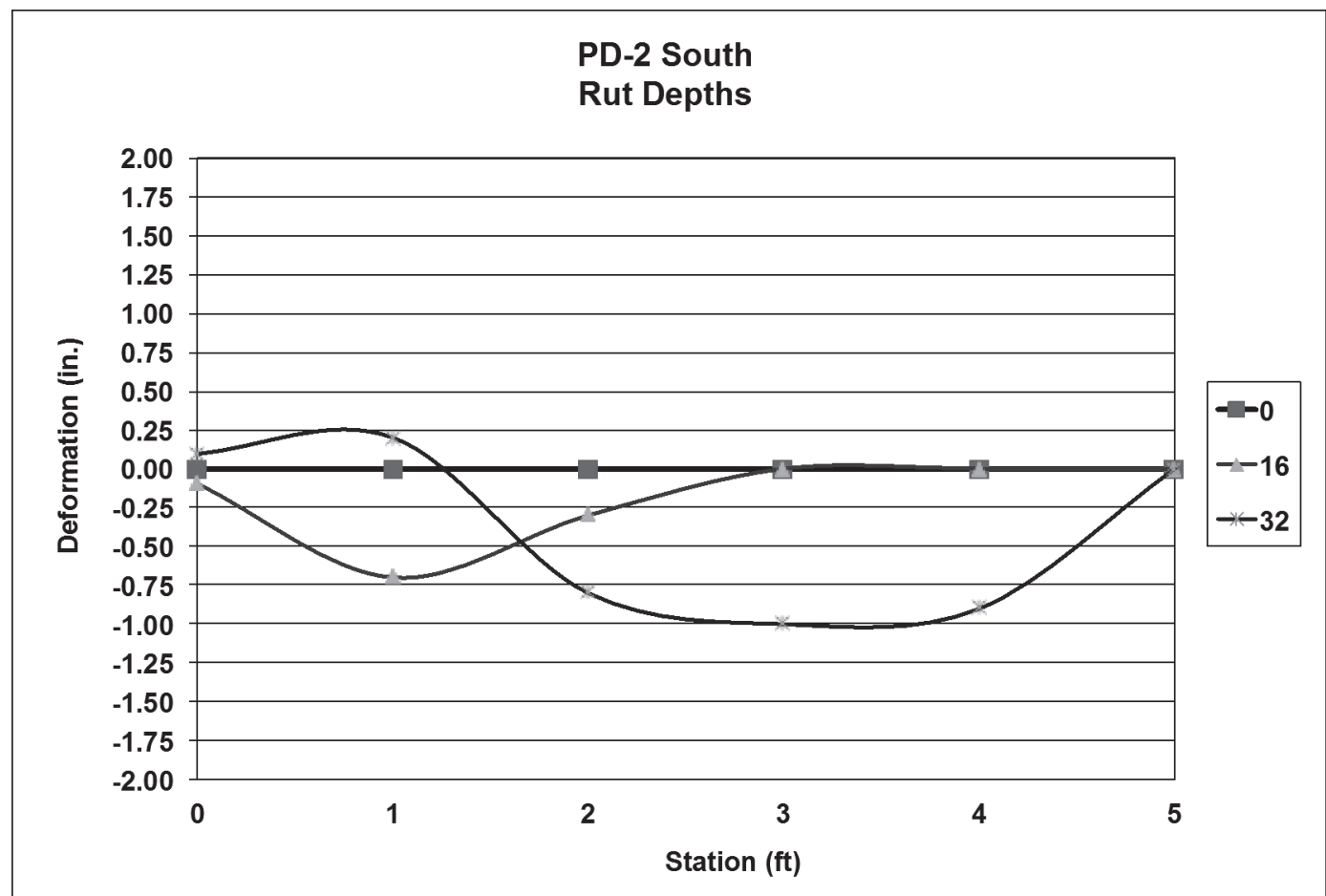

Figure C29. Rut depth measurements on cross-section at midpoint between repairs PD-2 and PD-3 (existing asphalt pavement).

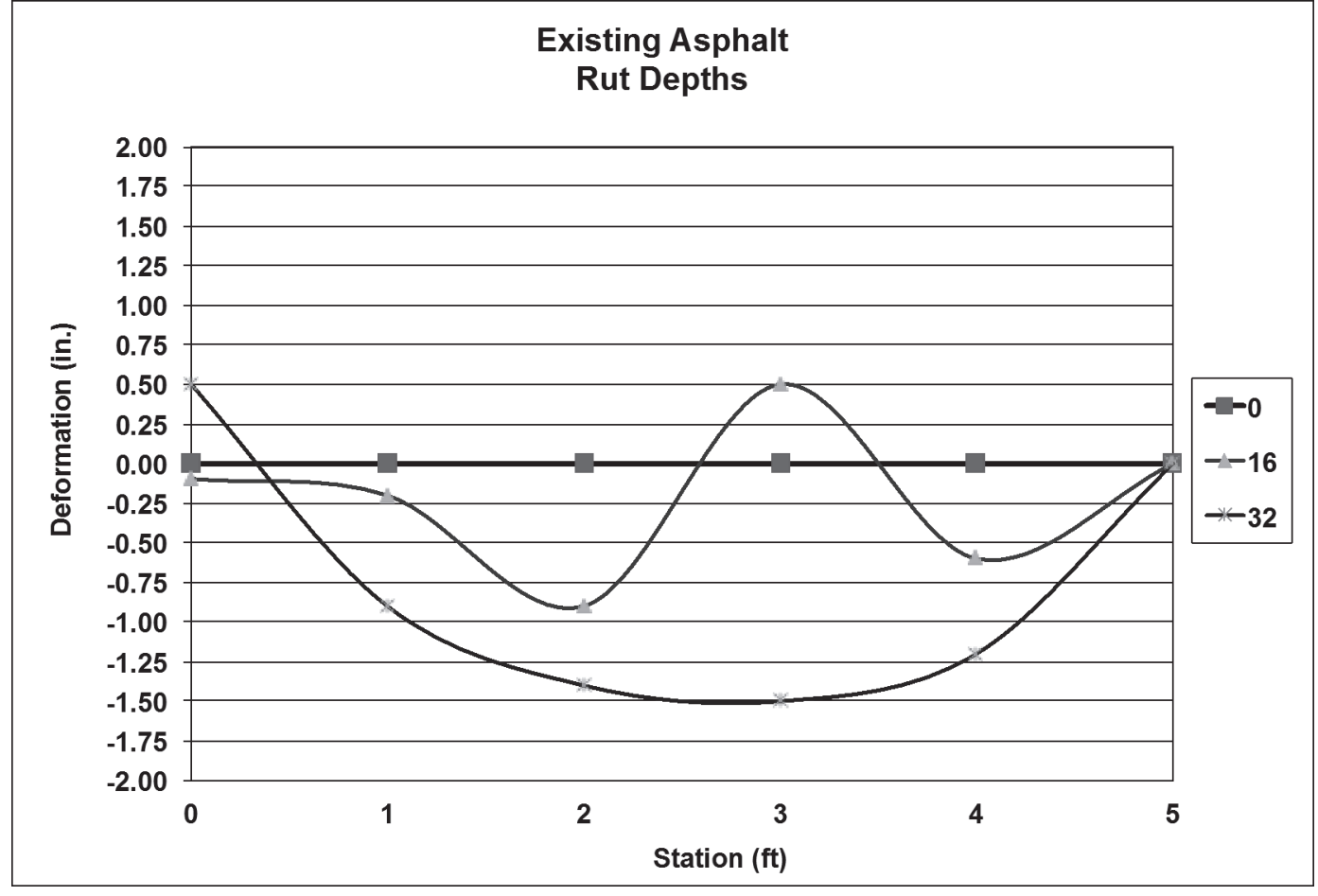


Figure C30. Rut depth measurements on north cross-section of PD-3.

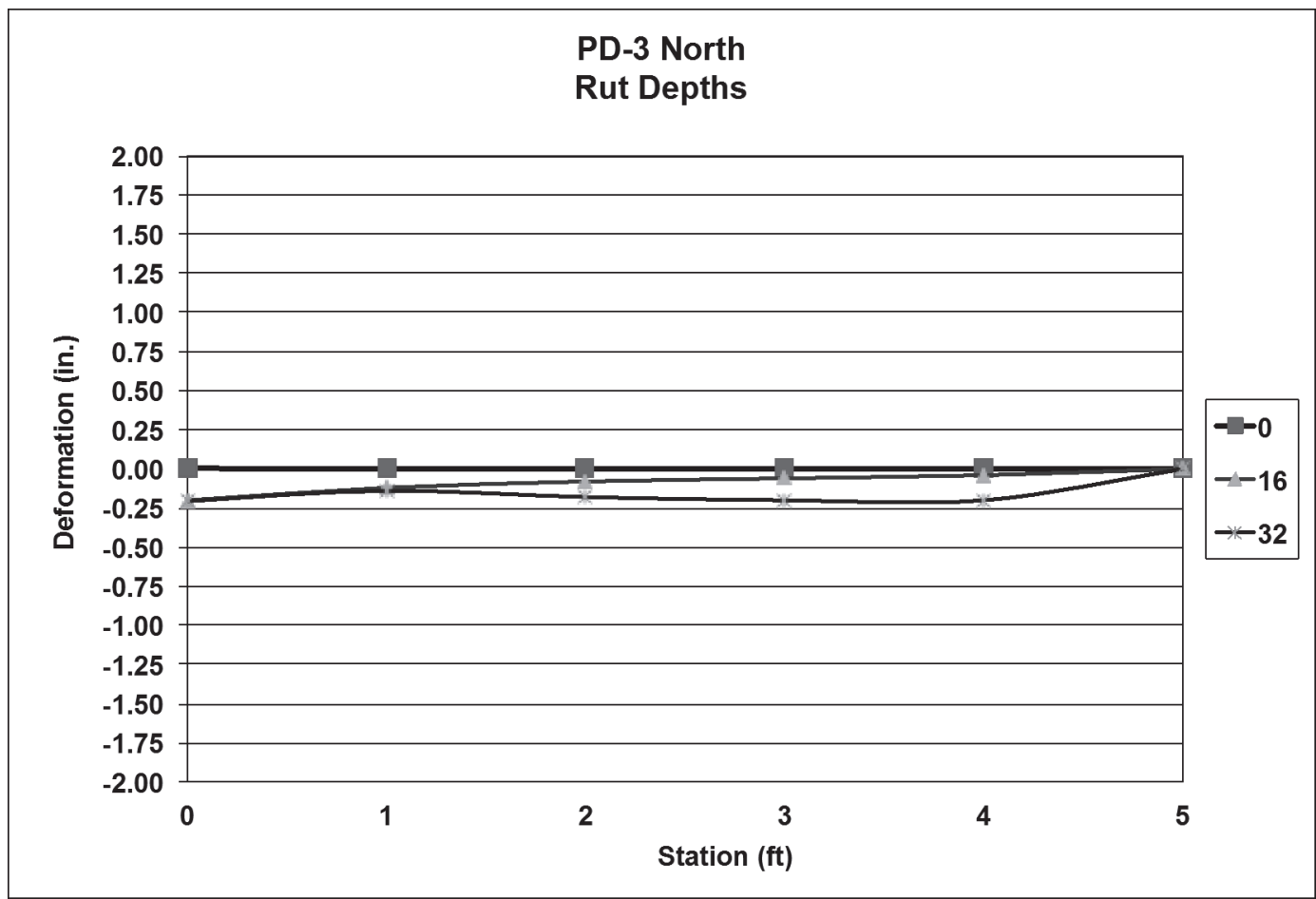

Figure C31. Rut depth measurements on center cross-section of PD-3.

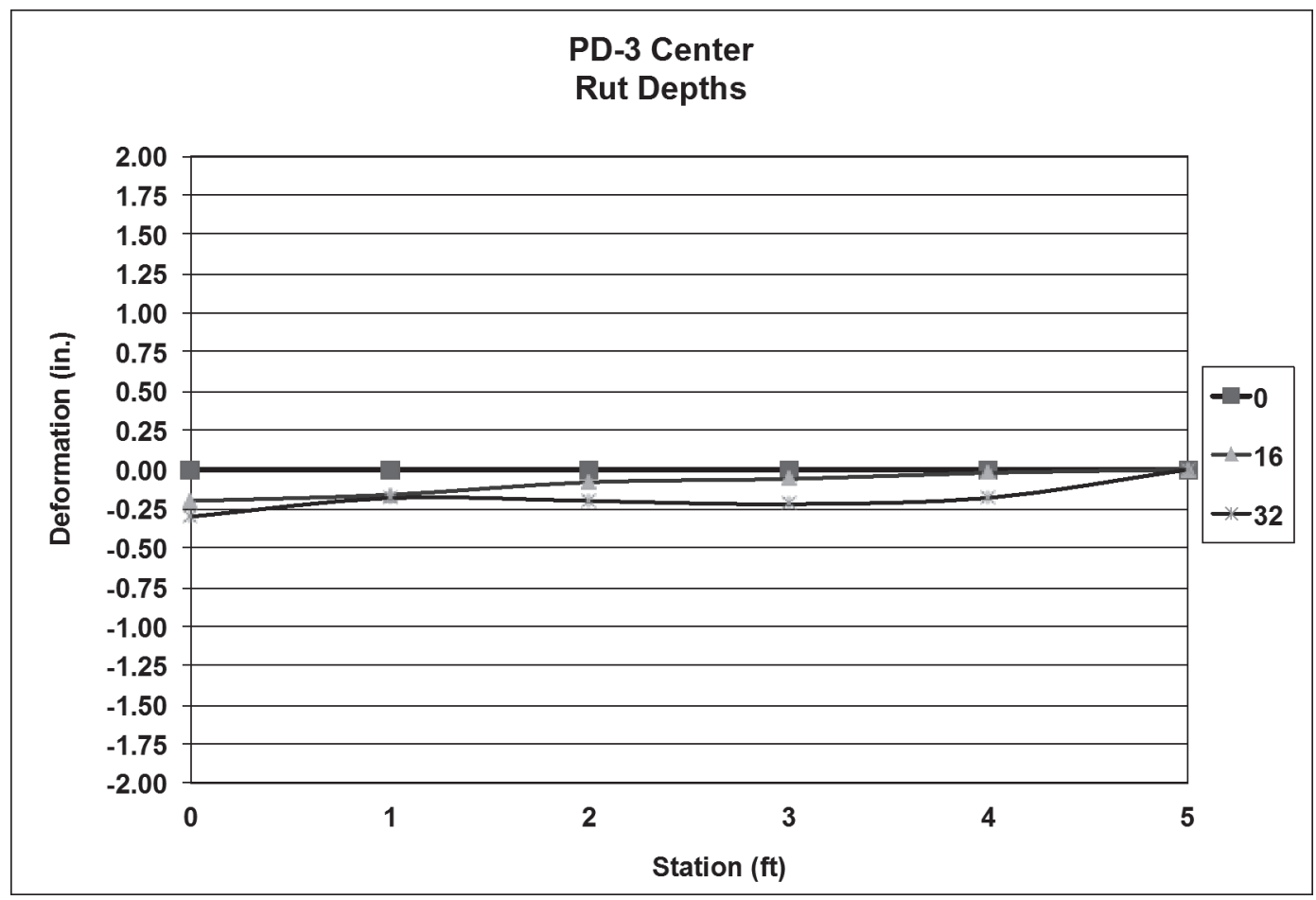


Figure C32. Rut depth measurements on south cross-section of PD-3.

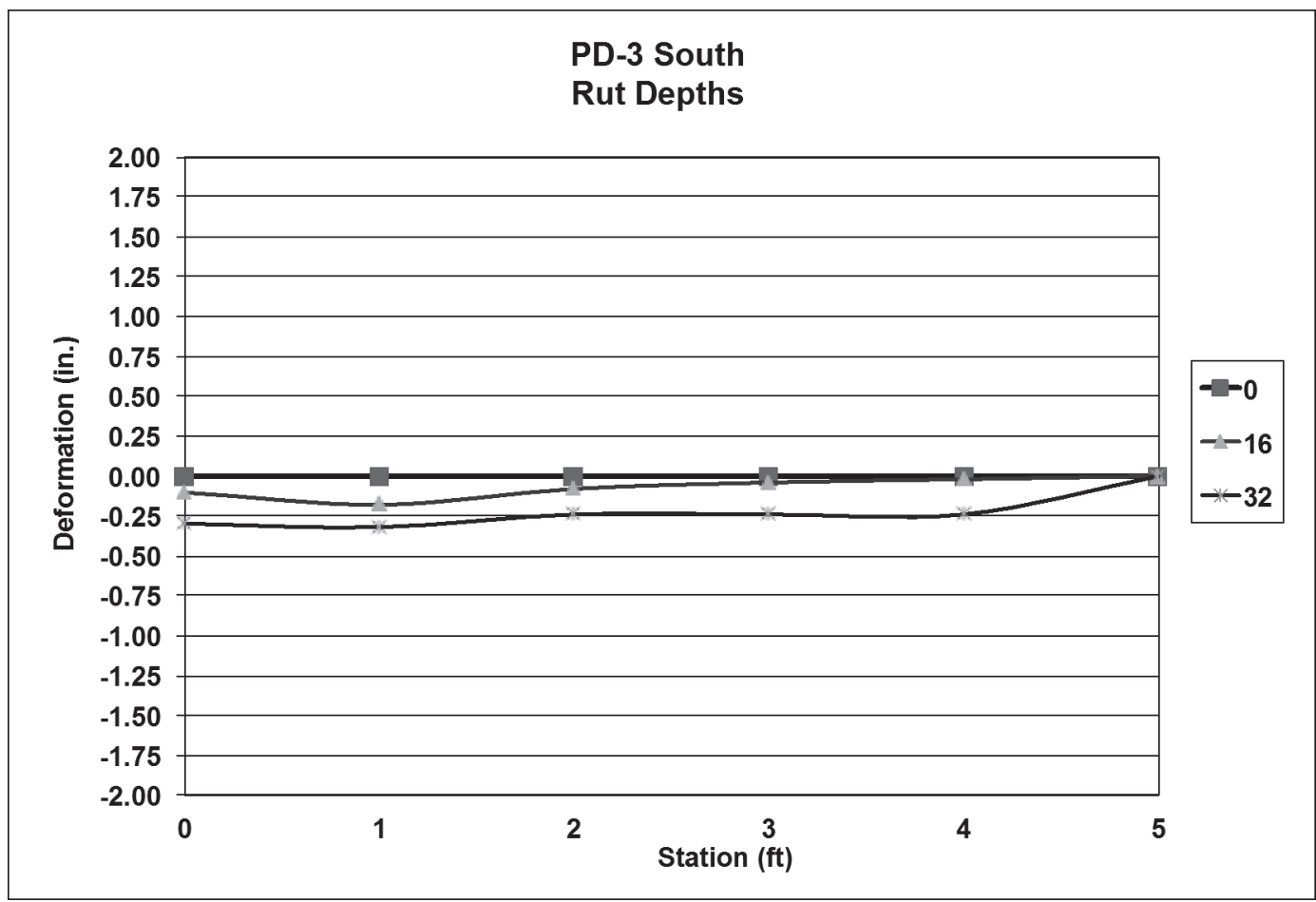

Figure C33. Rut depth measurements on cross-section at midpoint between repairs PD-3 and PD-4 (existing asphalt pavement).

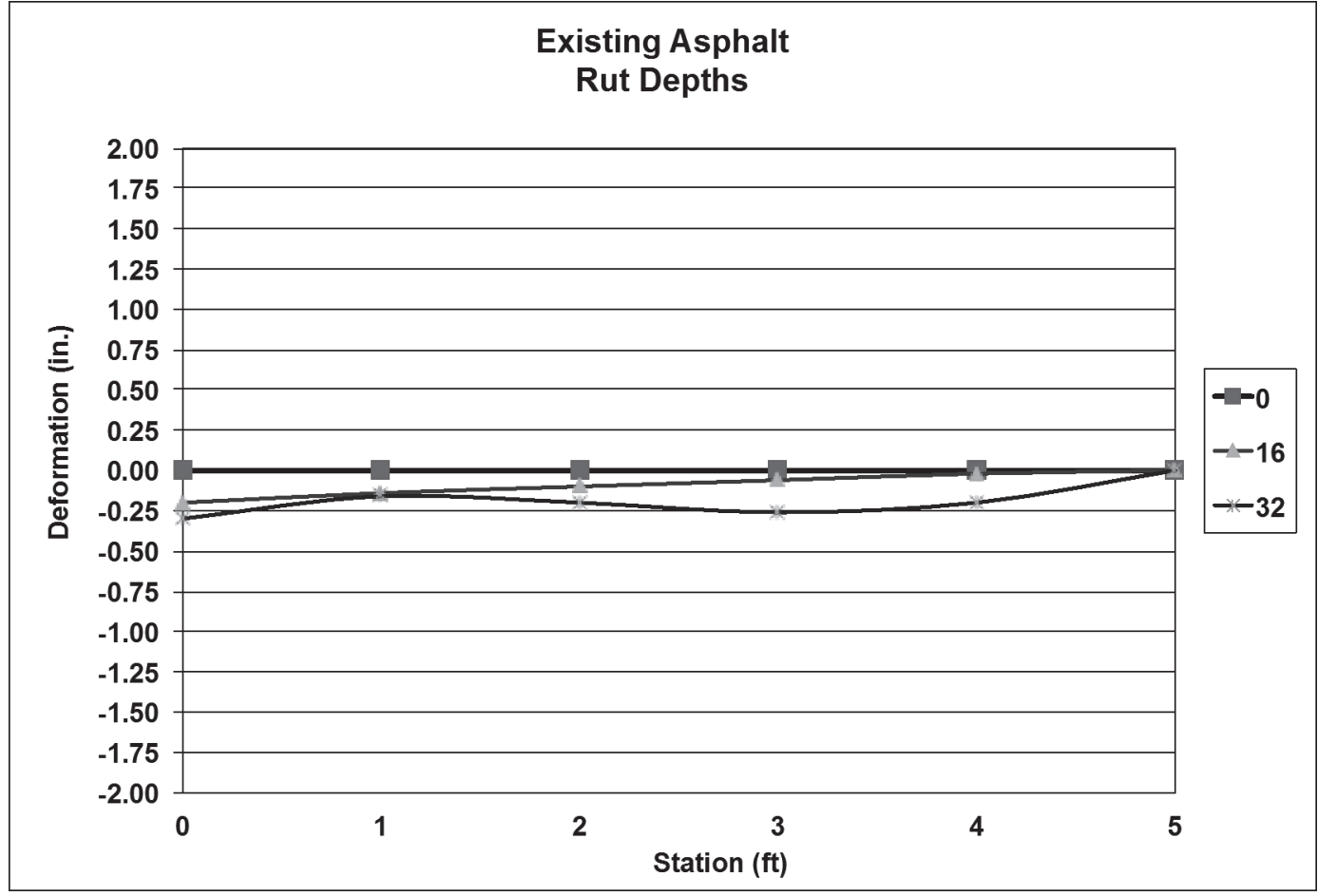


Figure C34. Rut depth measurements on north cross-section of PD-4.

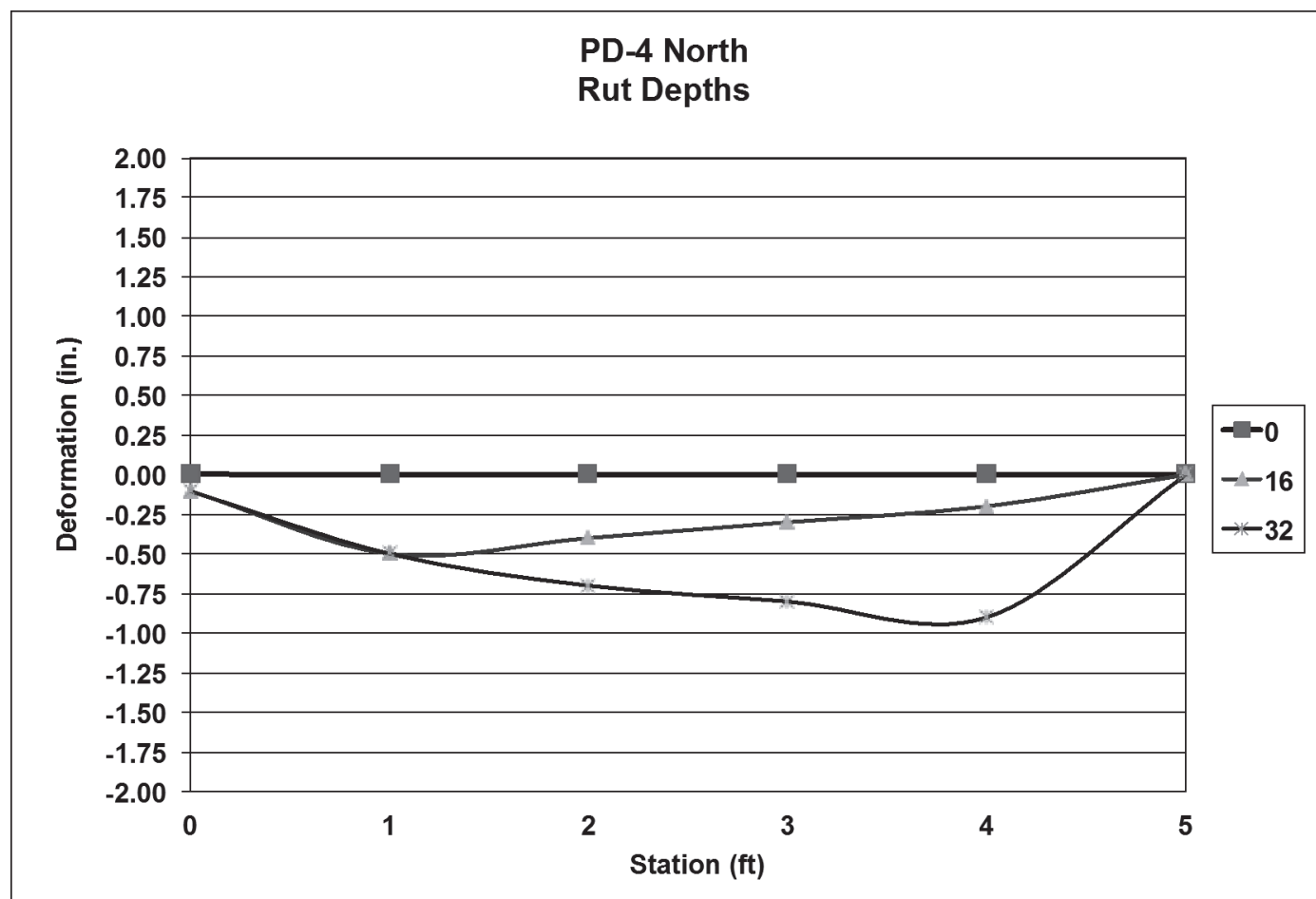

Figure C35. Rut depth measurements on center cross-section of PD-4.

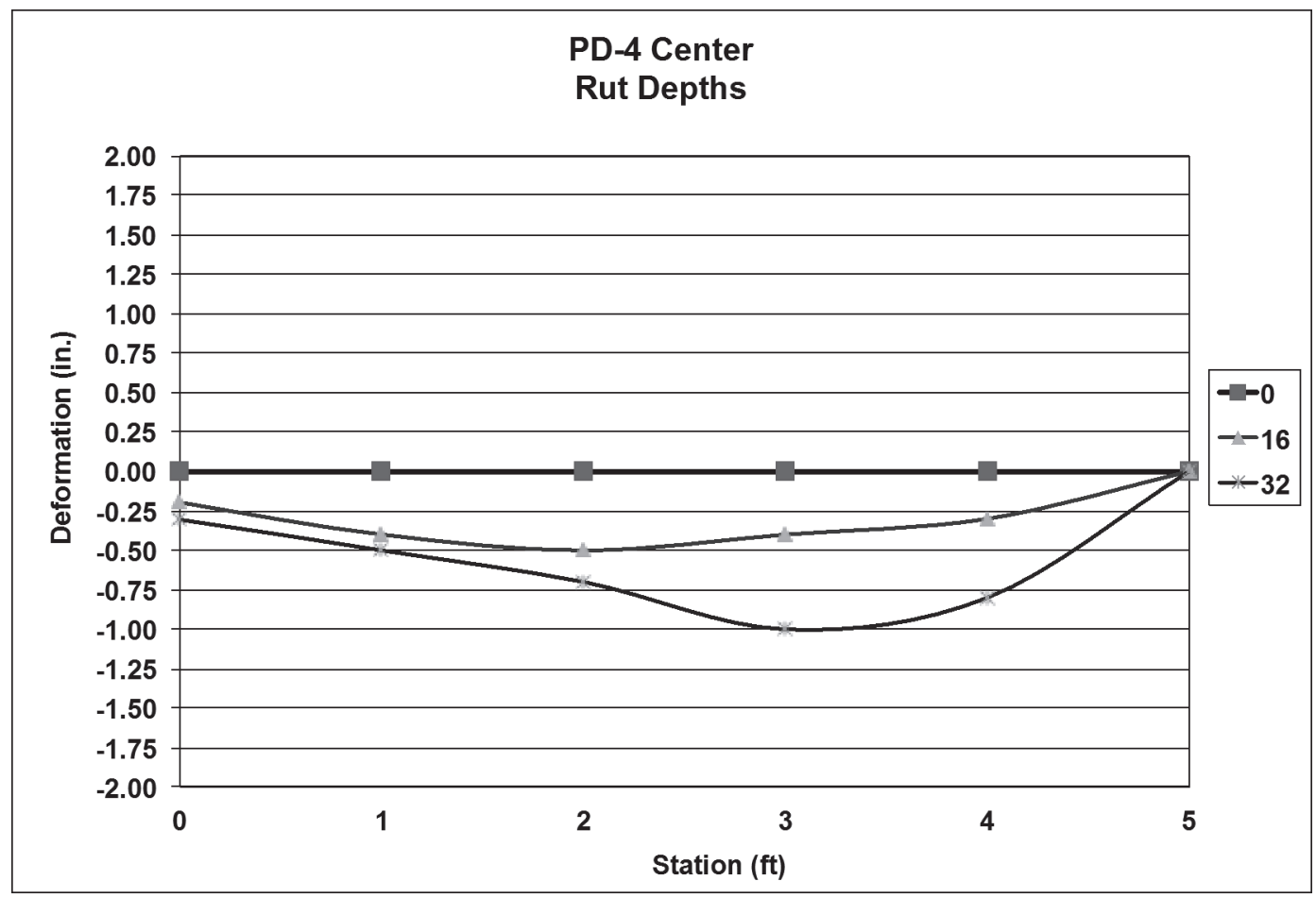


Figure C36. Rut depth measurements on south cross-section of PD-4.

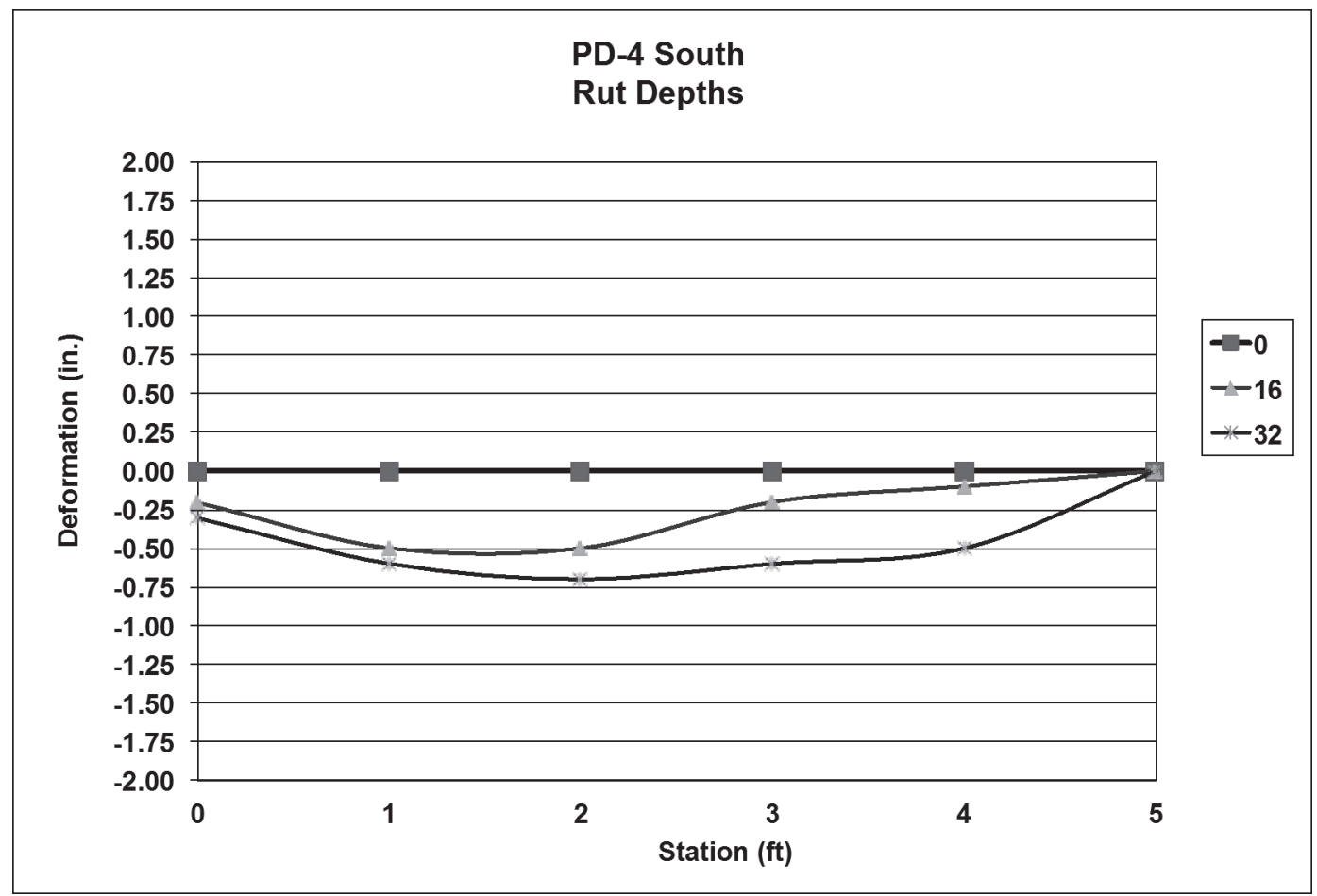

Figure C37. Rut depth measurements on cross-section at midpoint between repairs PD-4 and PD-5 (existing asphalt pavement).

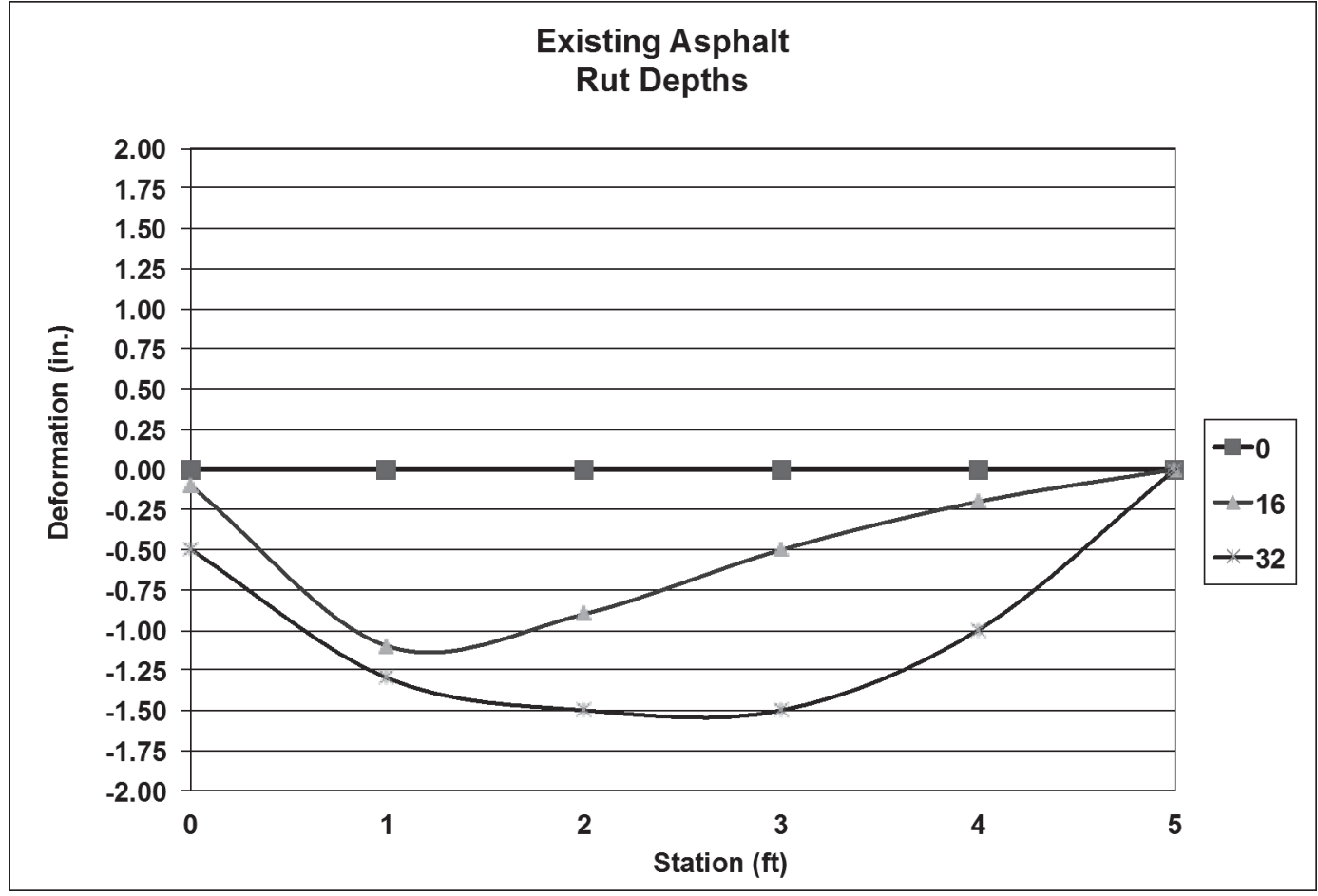




\section{Test Site 2 Repairs}

Figure C38. Rut depth measurements on north cross-section of PHP-1.

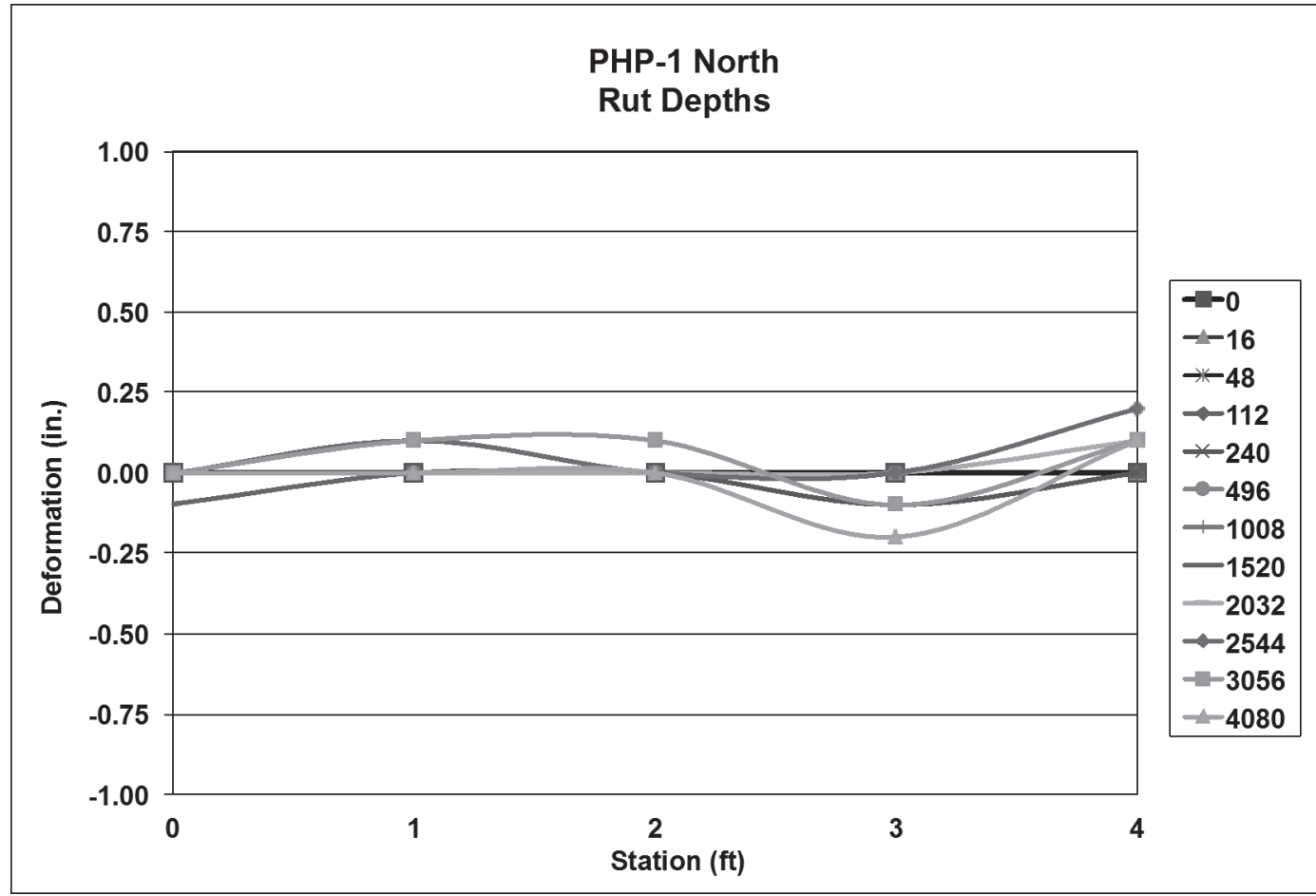

Figure C39. Rut depth measurements on center cross-section of PHP-1.

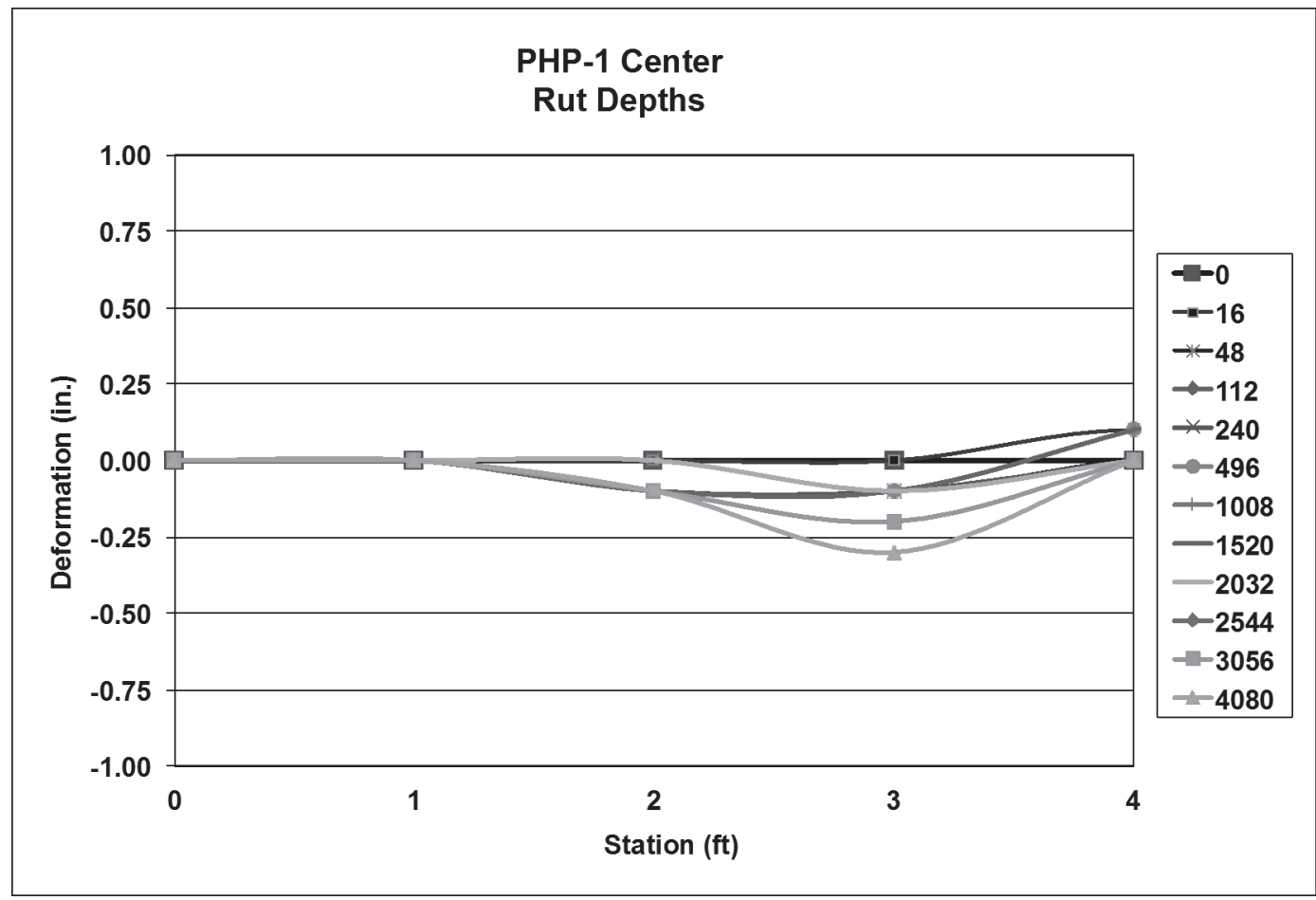


Figure C40. Rut depth measurements on south cross-section of PHP-1.

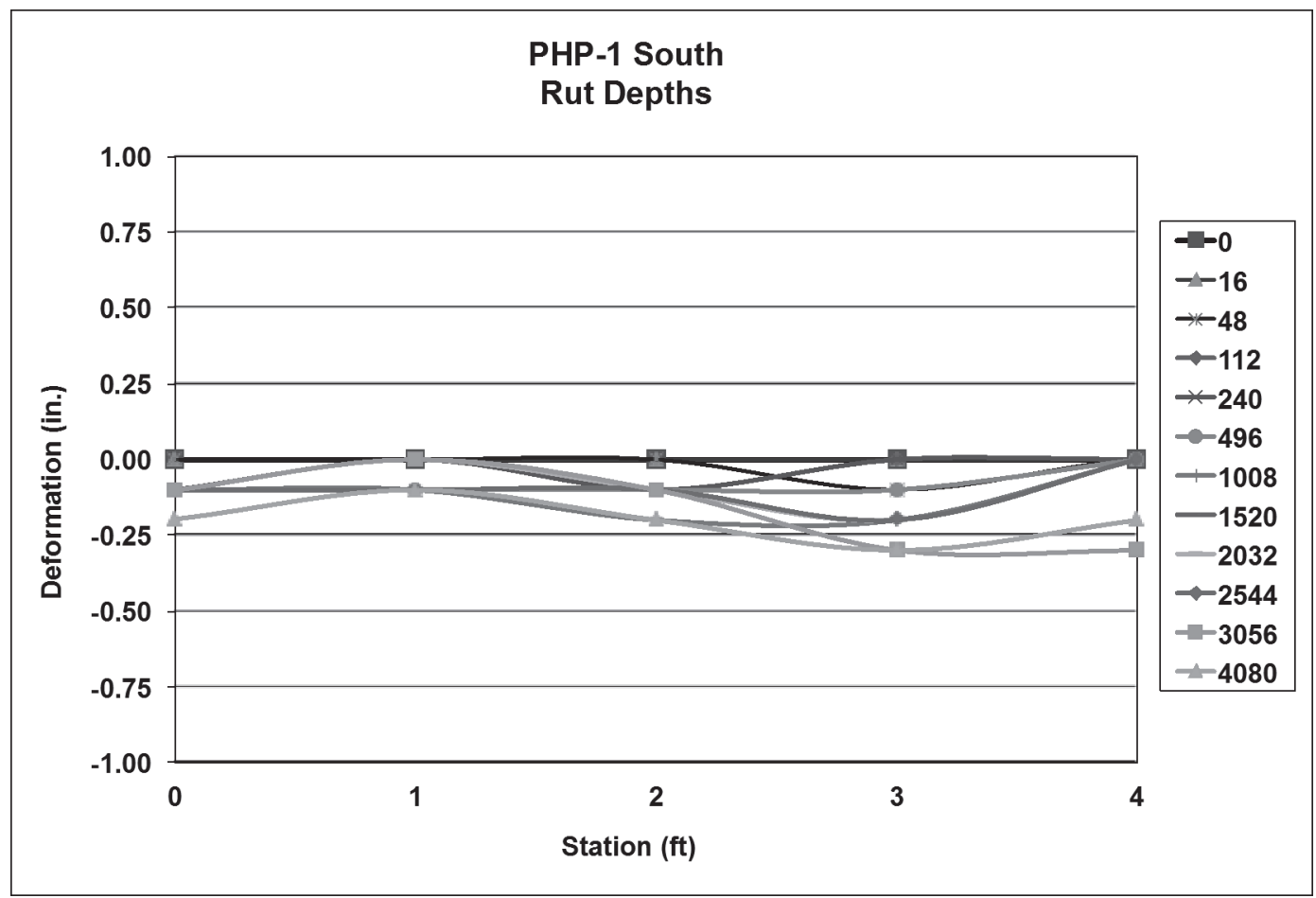

Figure C41. Rut depth measurements on cross-section at midpoint between repairs PHP-1 and PHP-2 (existing asphalt pavement).

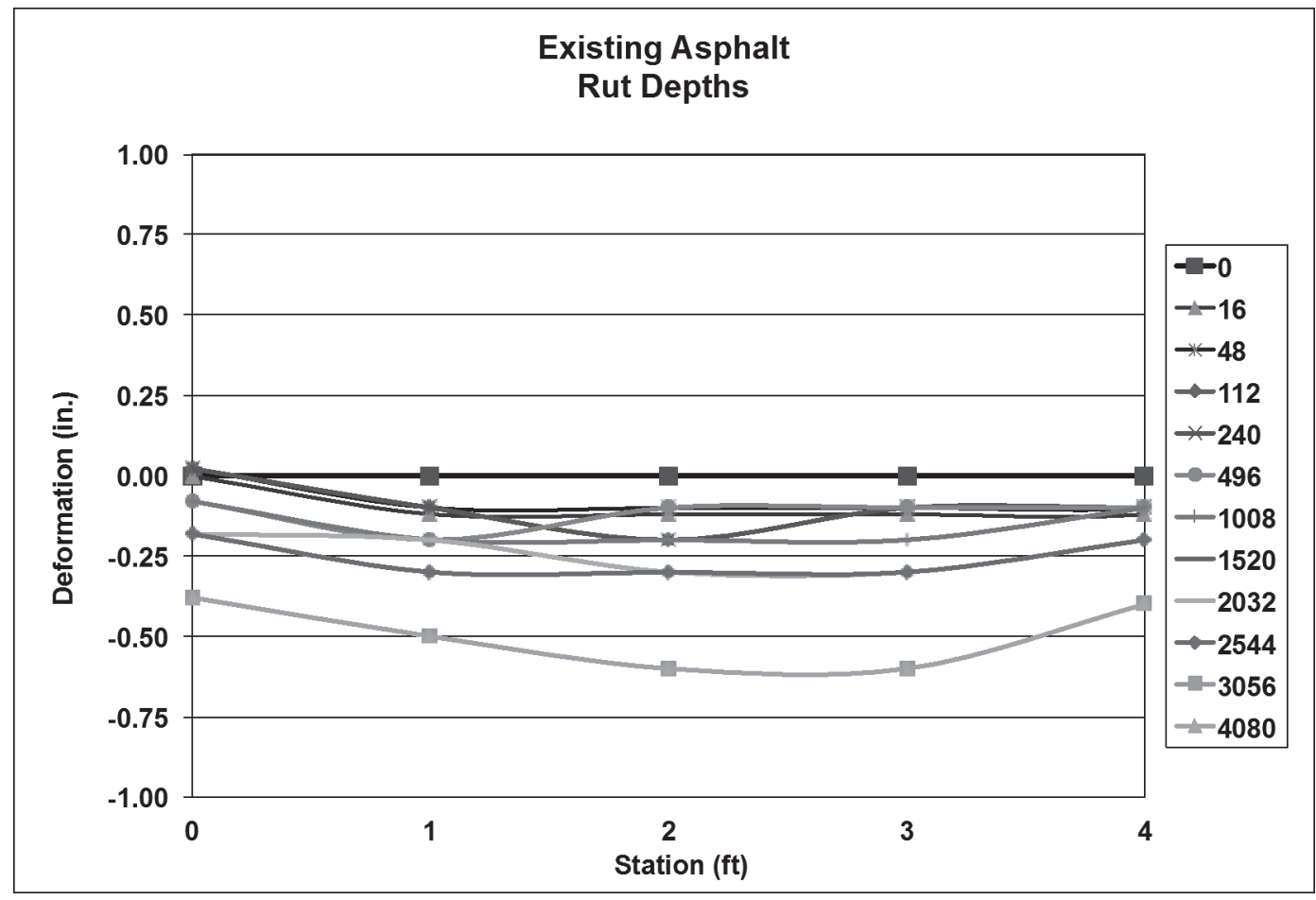


Figure C42. Rut depth measurements on north cross-section of PHP-2.

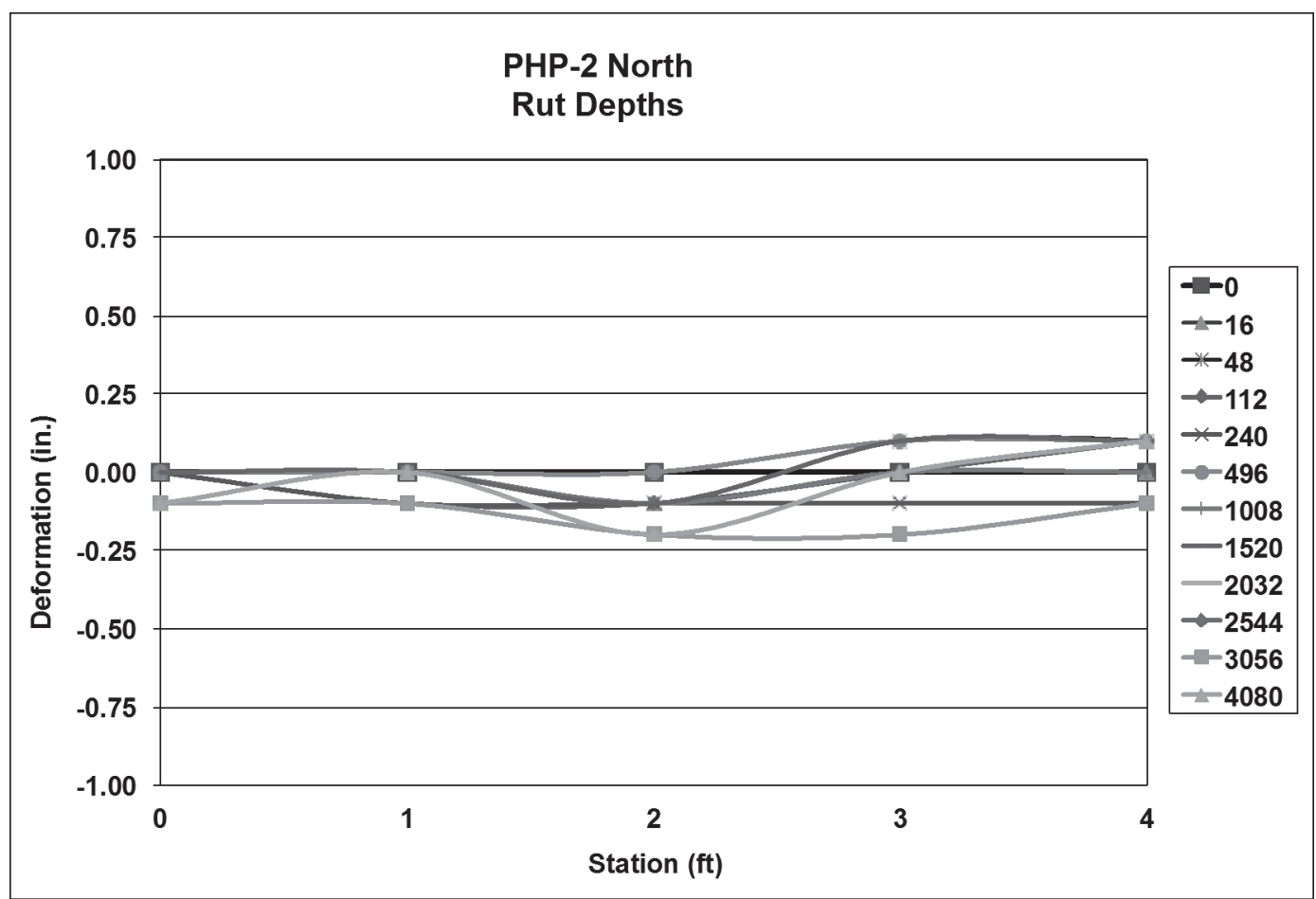

Figure C43. Rut depth measurements on center cross-section of PHP-2.

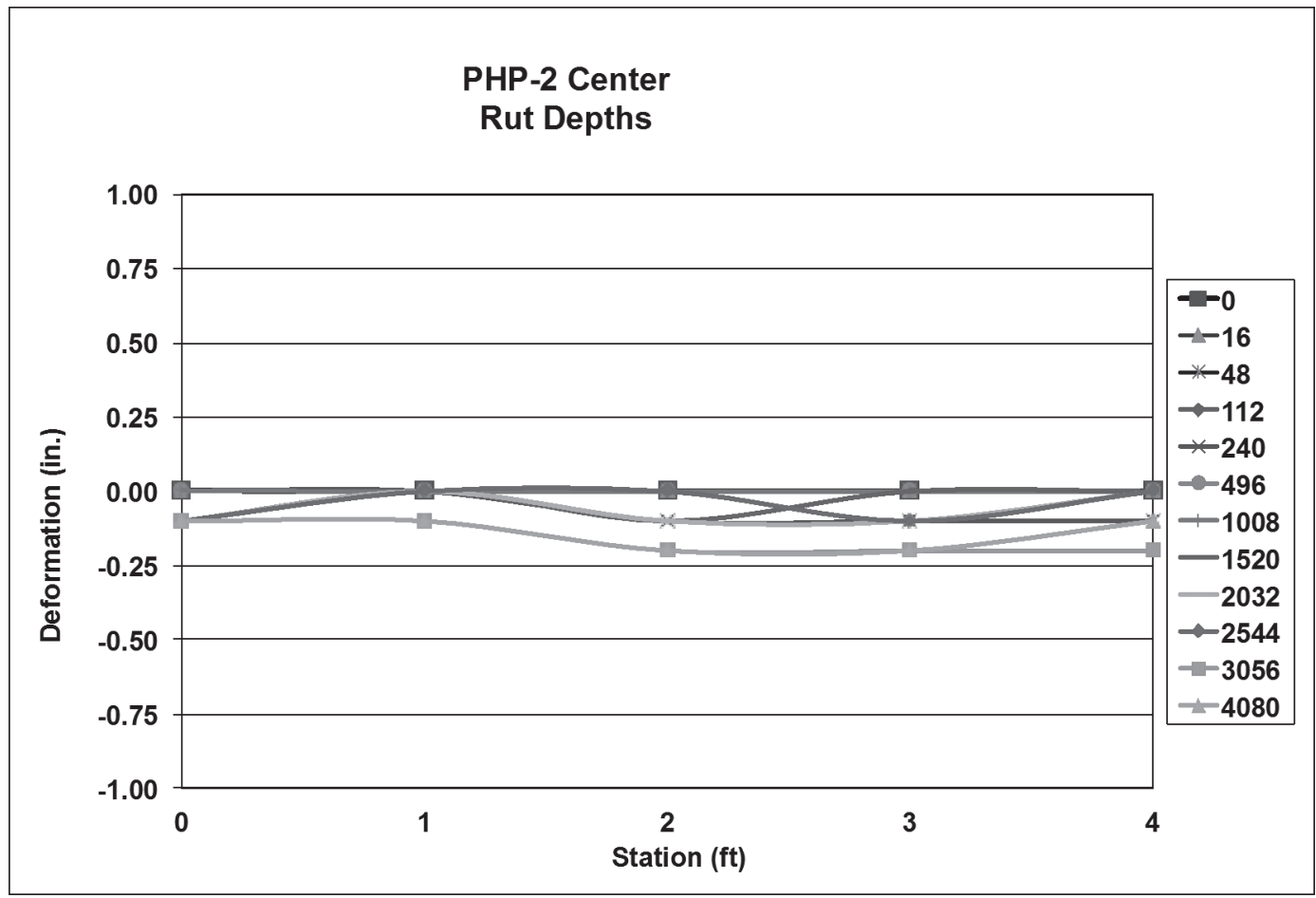


Figure C44. Rut depth measurements on south cross-section of PHP-2.

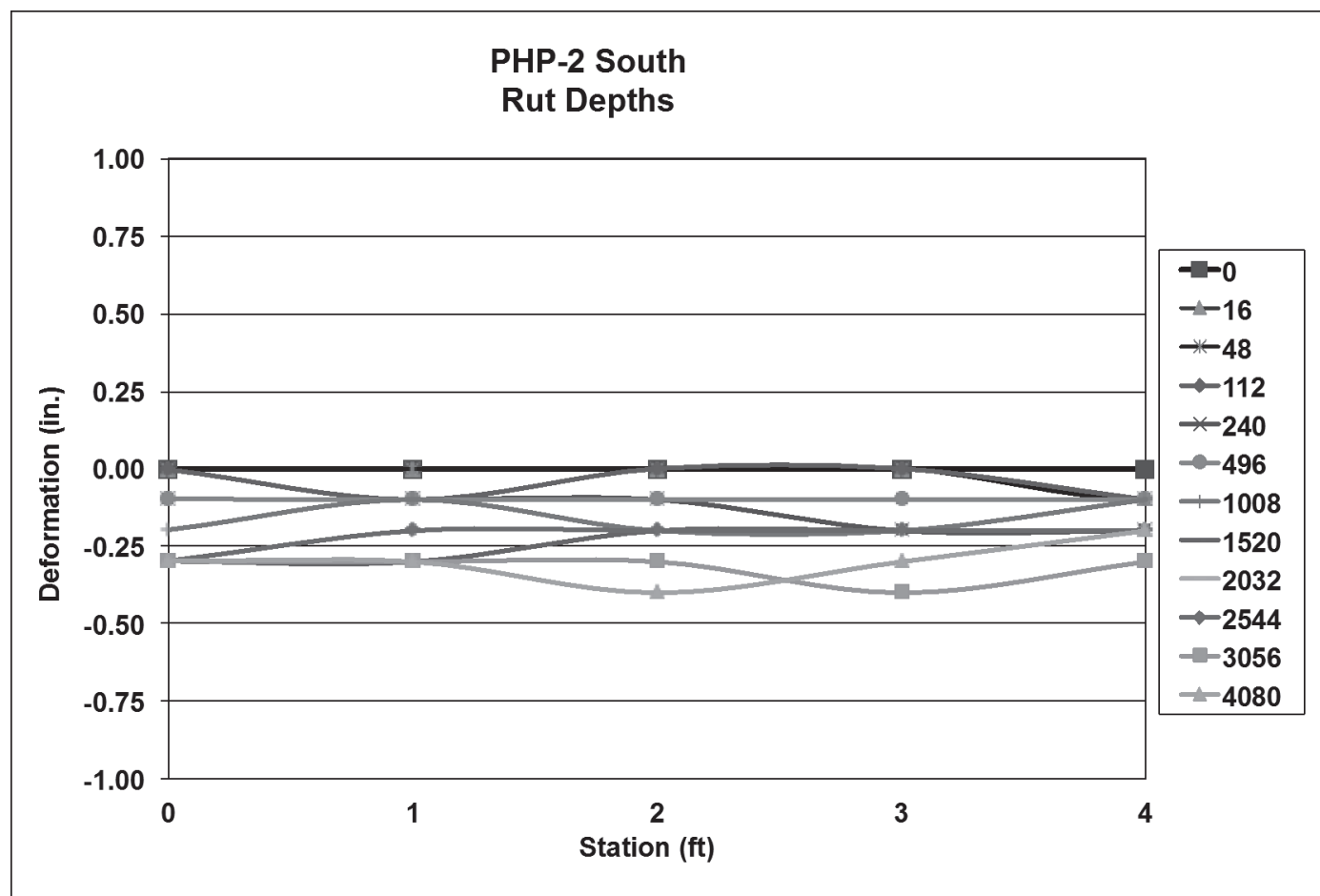

Figure C45. Rut depth measurements on cross-section at midpoint between repairs PHP-2 and PHP-3 (existing asphalt pavement).

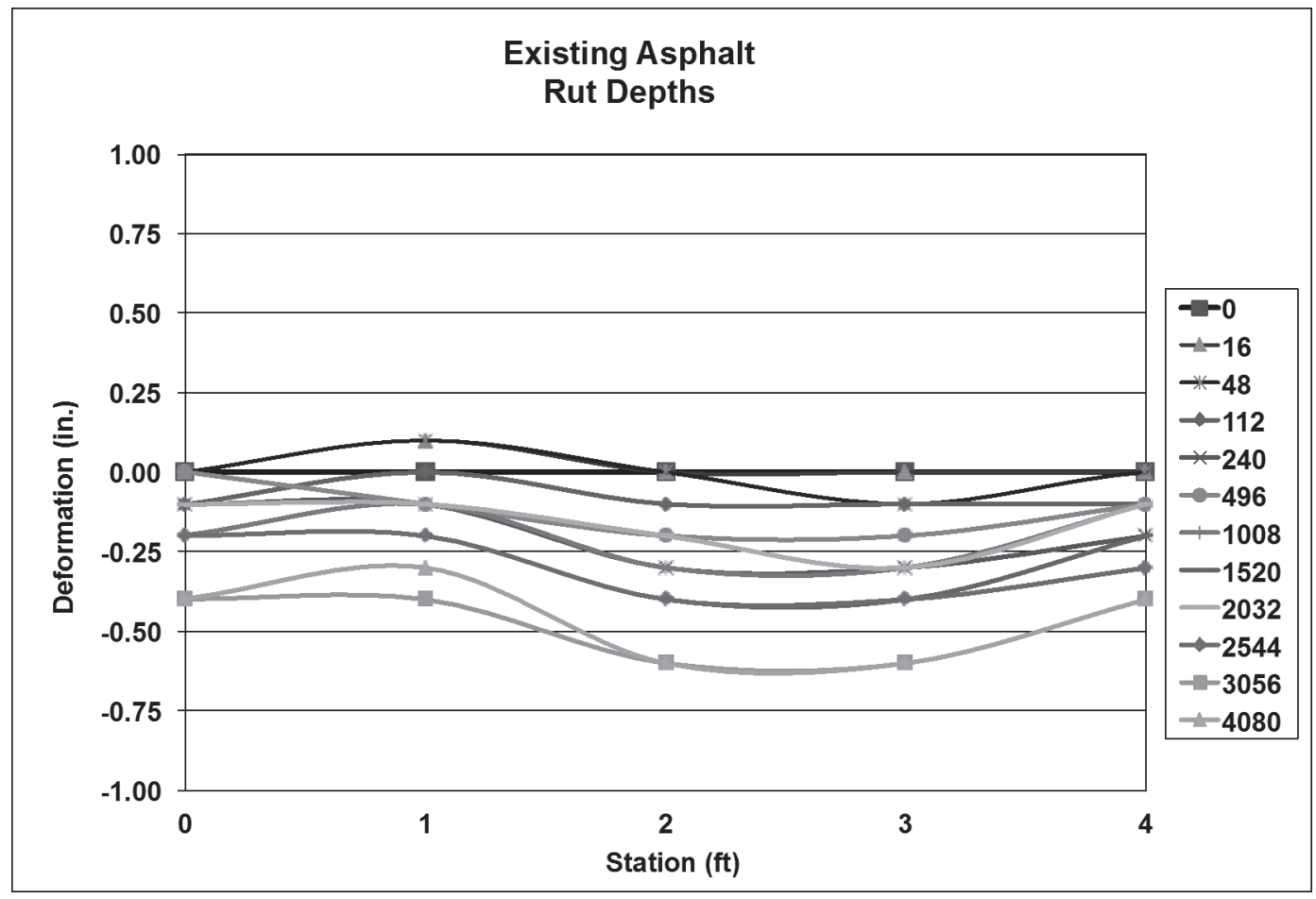


Figure C46. Rut depth measurements on north cross-section of PHP-3.

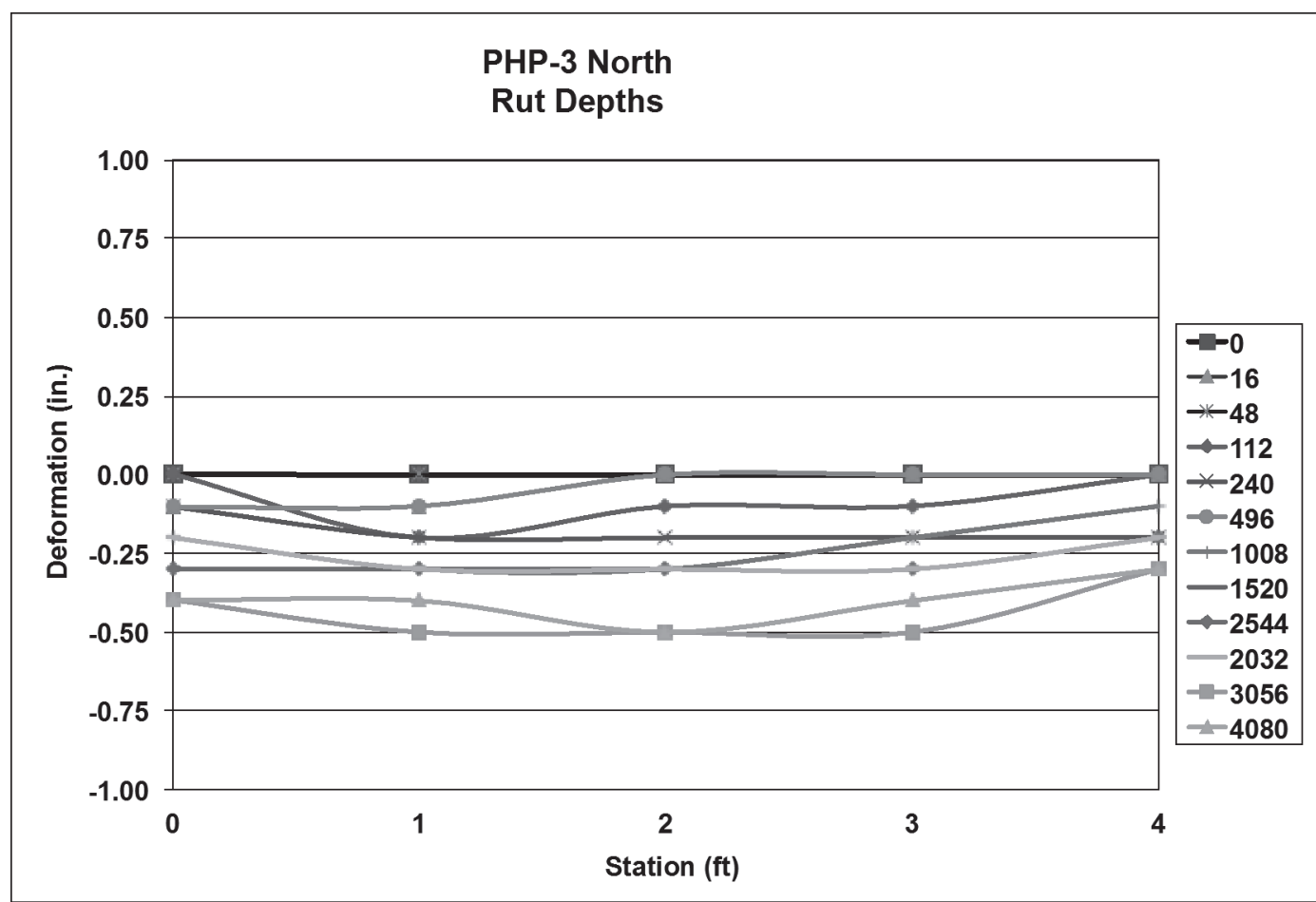

Figure C47. Rut depth measurements on center cross-section of PHP-3.

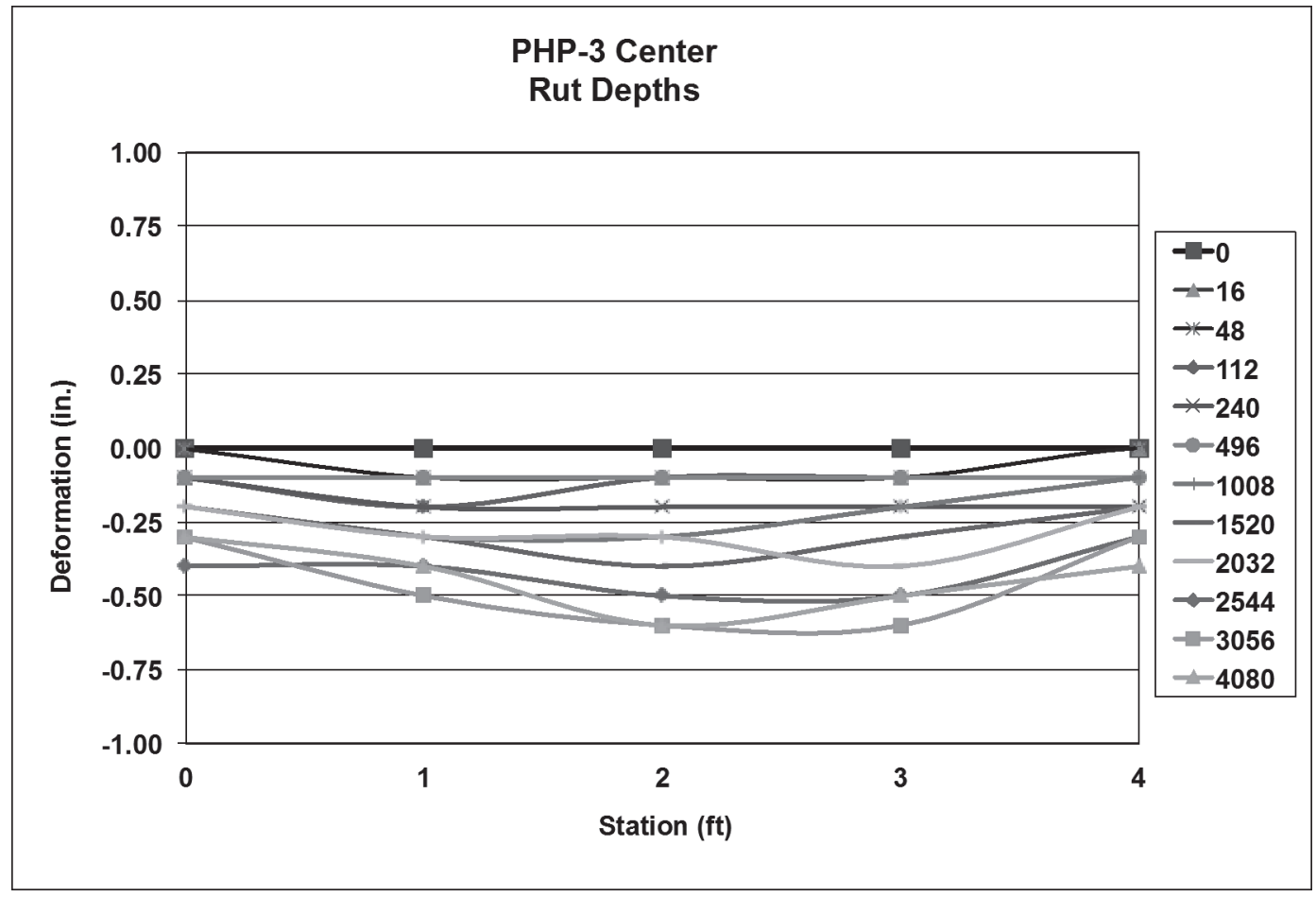


Figure C48. Rut depth measurements on south cross-section of PHP-3.

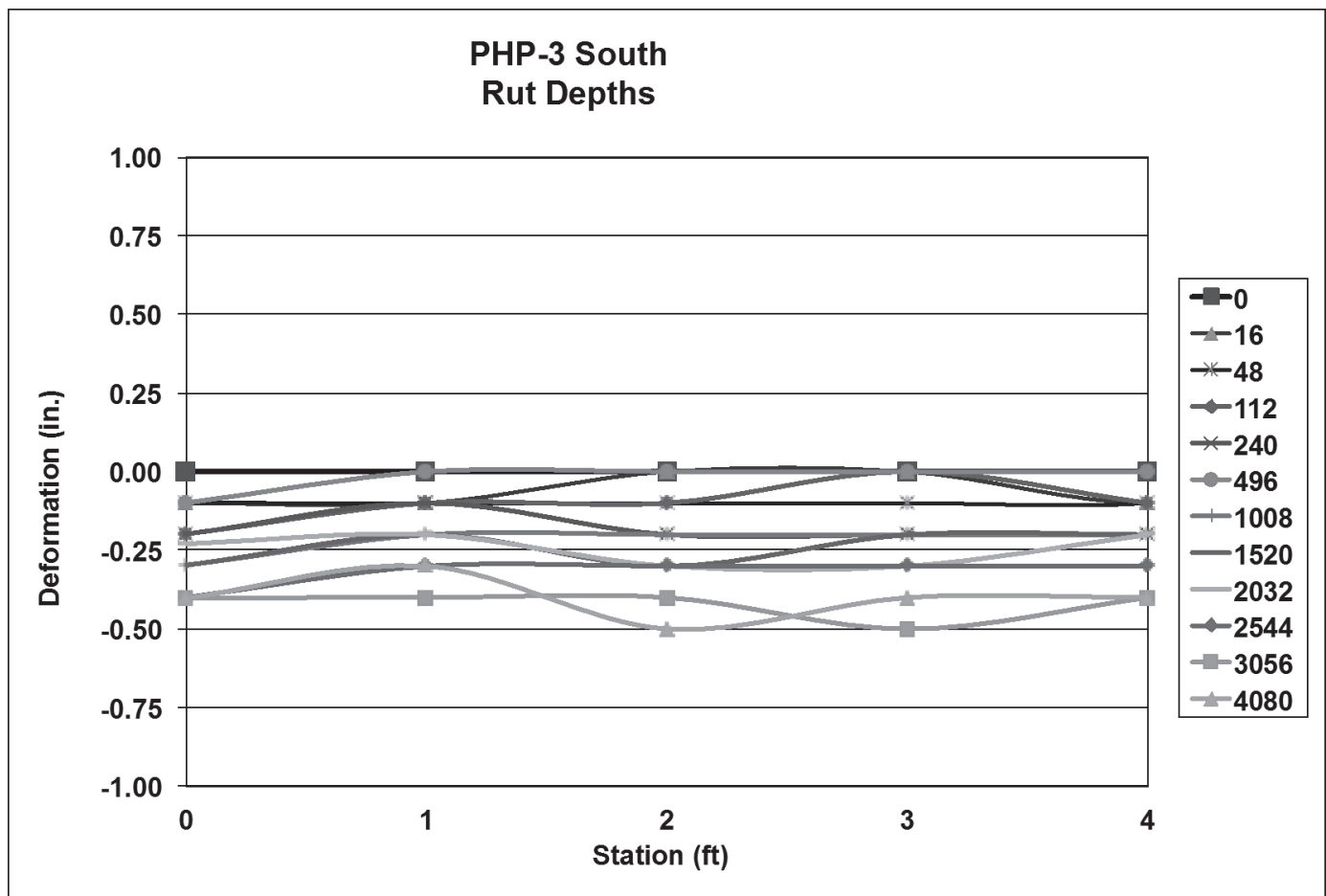

Figure C49. Rut depth measurements on cross-section at midpoint between repairs PHP-3 and PHP-4 (existing asphalt pavement).

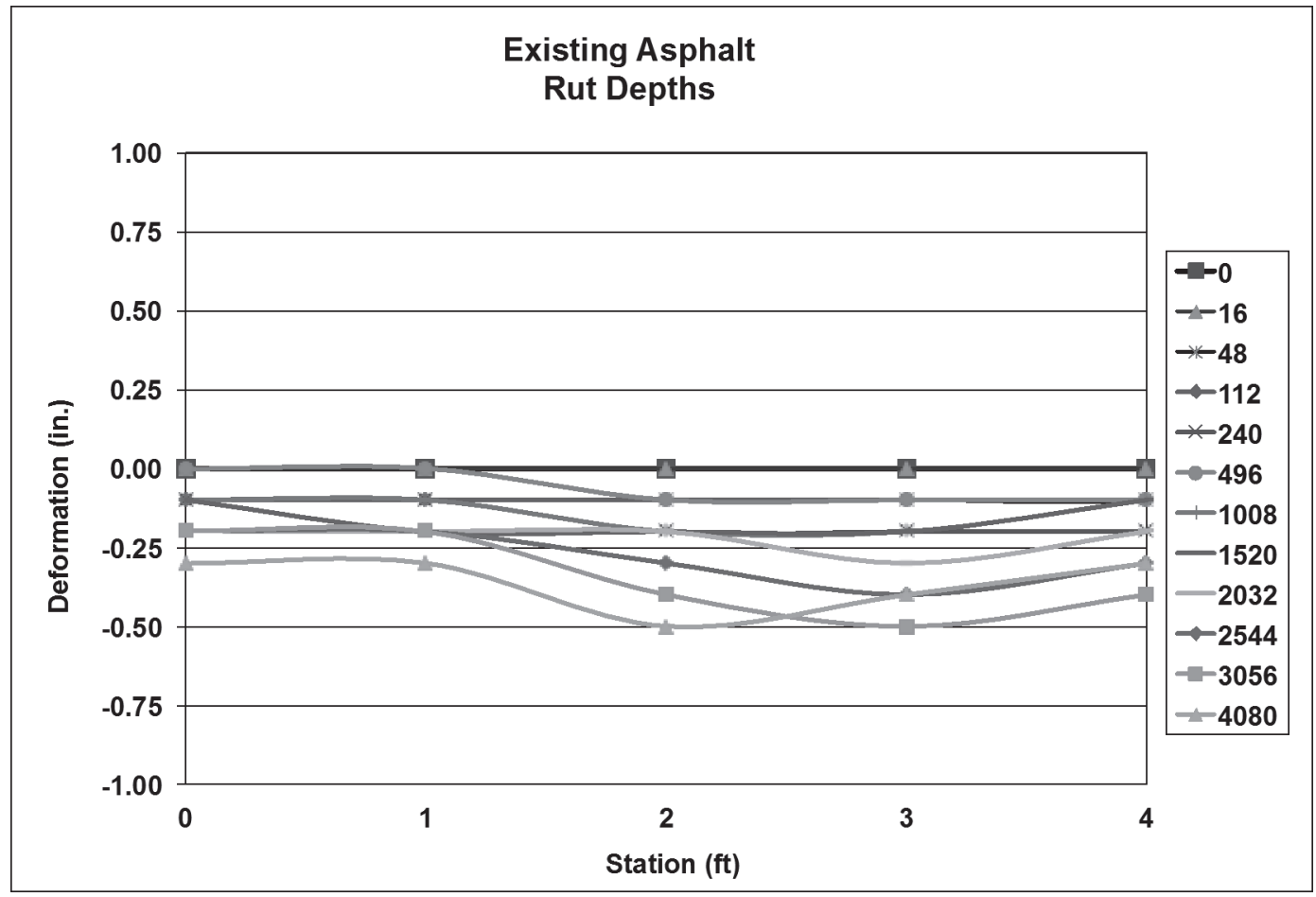


Figure C50. Rut depth measurements on north cross-section of PHP-4.

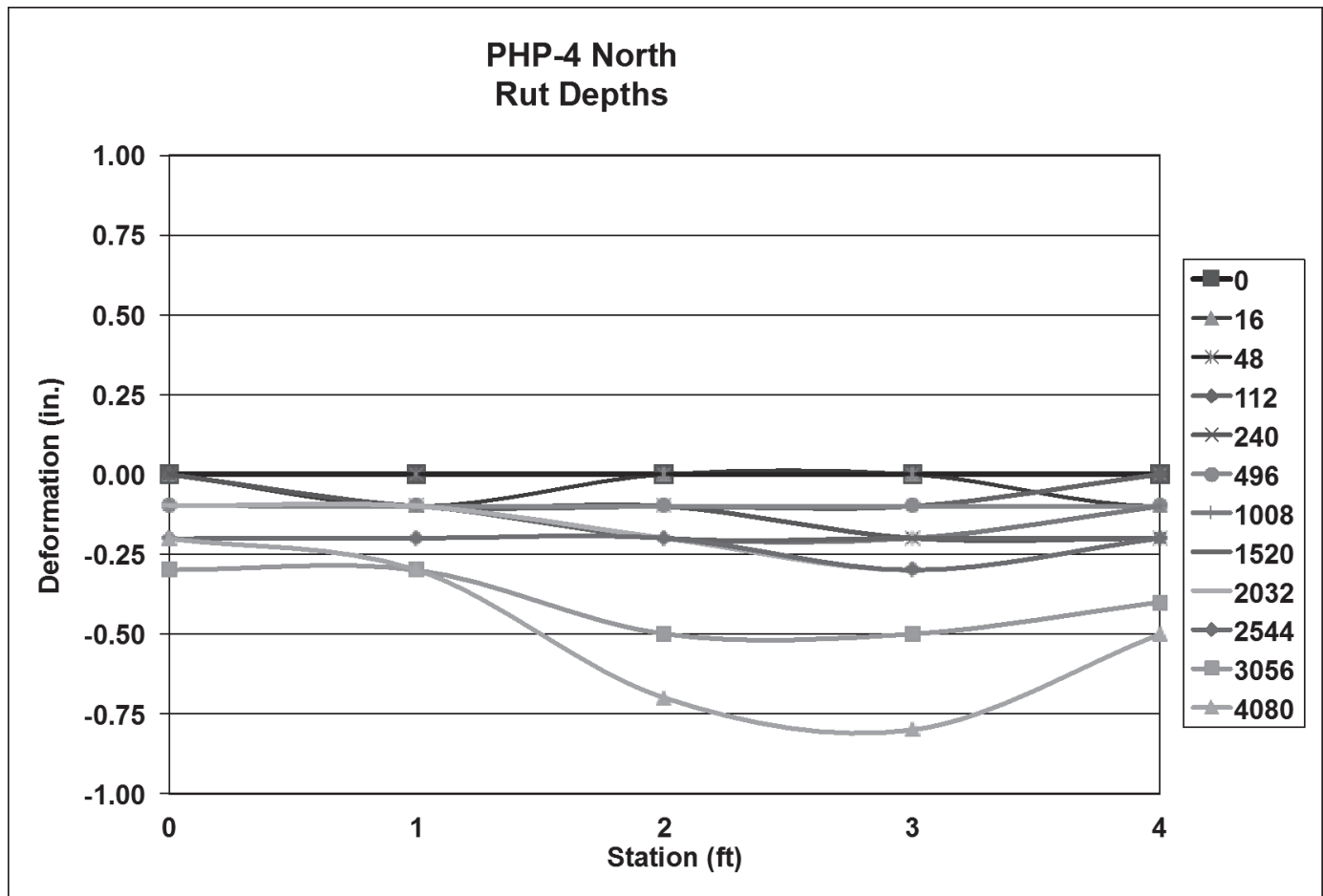

Figure C51. Rut depth measurements on center cross-section of PHP-4.

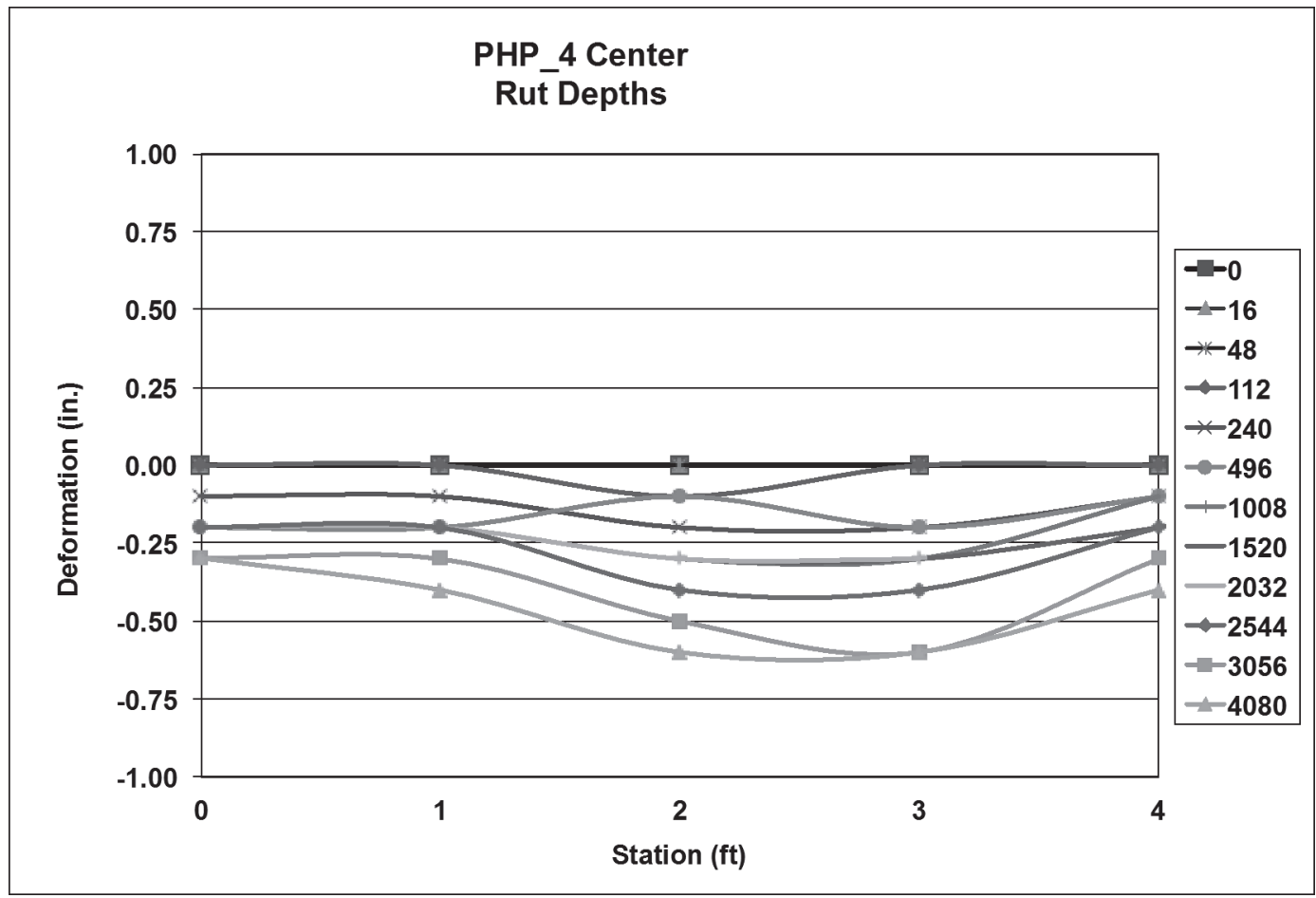


Figure C52. Rut depth measurements on south cross-section of PHP-4.

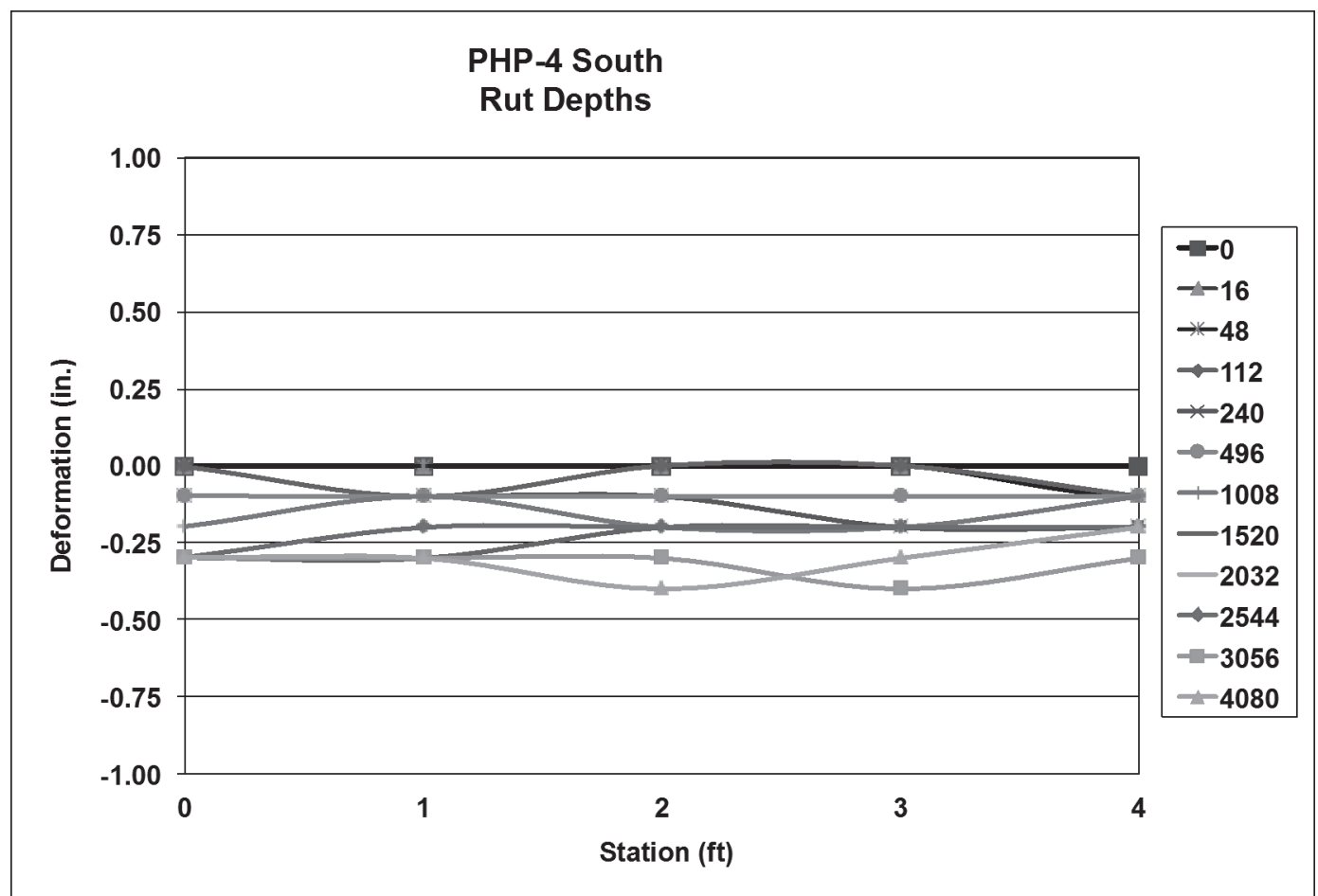

Figure C53. Rut depth measurements on cross-section $2 \mathrm{ft}$ after repair PHP-4 (existing asphalt pavement).

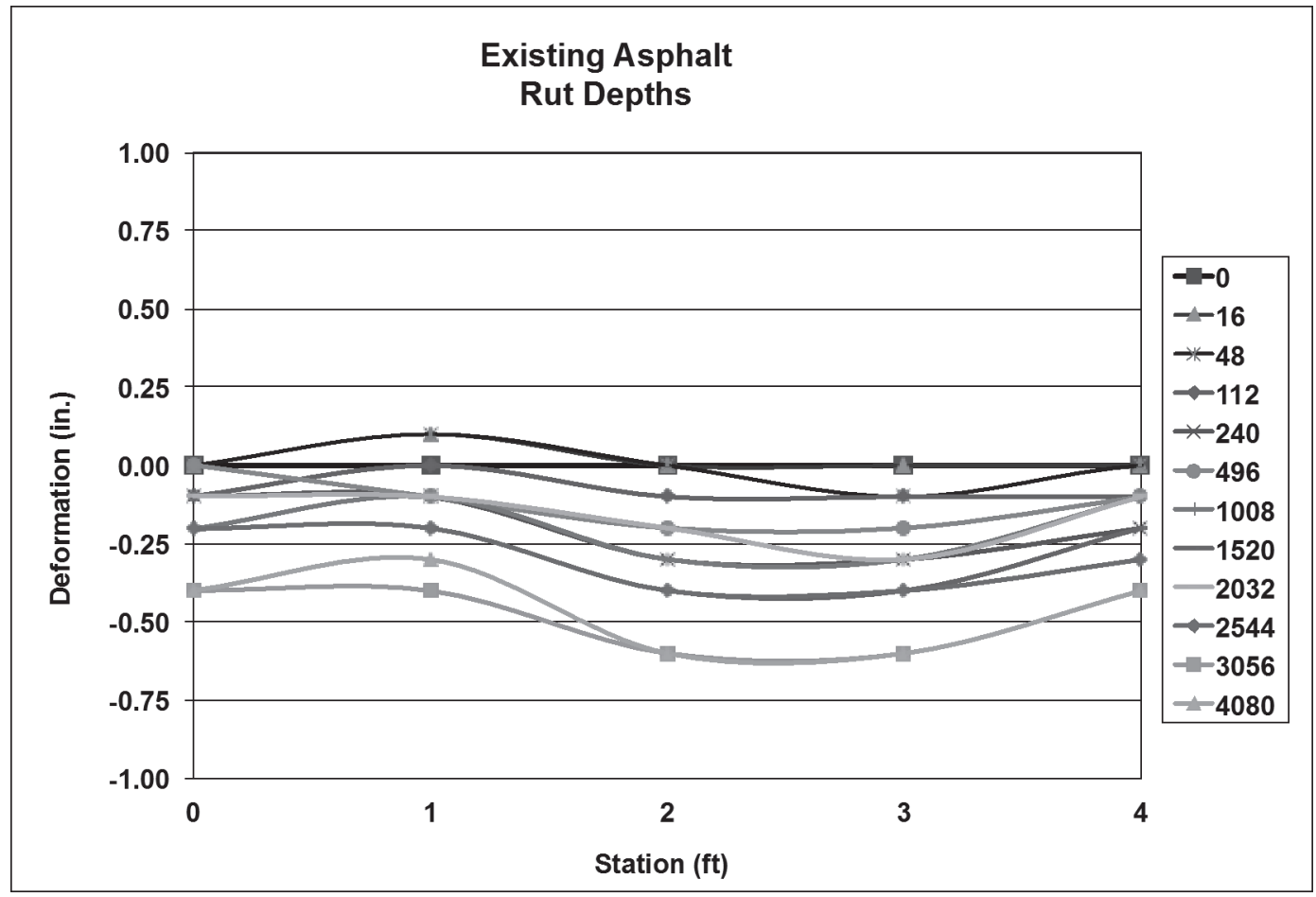




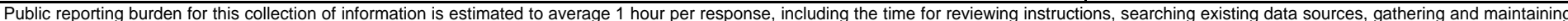

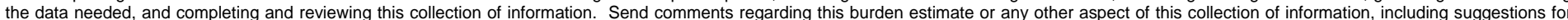

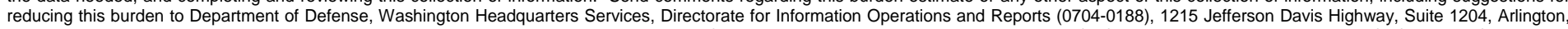

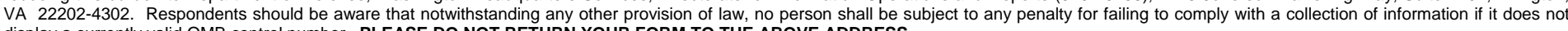
display a currently valid OMB control number. PLEASE DO NOT RETURN YOUR FORM TO THE ABOVE ADDRESS.

\begin{tabular}{l|c}
$\begin{array}{l}\text { 1. REPORT DATE (DD-MM-YYYY) } \\
\text { June } 2013\end{array}$ & $\begin{array}{c}\text { 2. REPORT TYPE } \\
\text { Final report }\end{array}$ \\
\hline
\end{tabular}

\section{TITLE AND SUBTITLE}

Laboratory and Field Evaluation of In-Place Asphalt Recycling Technologies for Small Airfield Repair

3. DATES COVERED (From - To)

5a. CONTRACT NUMBER

5b. GRANT NUMBER

\section{AUTHOR(S)}

5c. PROGRAM ELEMENT NUMBER

Mariely Mejias-Santiago, William D. Carruth, Jeffery C. Petermann, and Dean H. Hitzelberger

5d. PROJECT NUMBER

5e. TASK NUMBER

5f. WORK UNIT NUMBER

\section{PERFORMING ORGANIZATION NAME(S) AND ADDRESS(ES)}

8. PERFORMING ORGANIZATION REPORT NUMBER

US Army Engineer Research and Development Center

Geotechnical and Structures Laboratory

ERDC/GSL TR-13-23

3909 Halls Ferry Road

Vicksburg, MS 39180-6199;

Applied Research Associates, Inc., 421 Oak Ave., Panama City, FL 32401

9. SPONSORING I MONITORING AGENCY NAME(S) AND ADDRESS(ES)

Headquarters, US Army Corps of Engineers

Washington DC 20314-5000

10. SPONSOR/MONITOR'S ACRONYM(S)

11. SPONSOR/MONITOR'S REPORT NUMBER(S)

\section{DISTRIBUTION I AVAILABILITY STATEMENT}

Approved for public release; distribution is unlimited.

\section{SUPPLEMENTARY NOTES}

\section{ABSTRACT}

This report describes development of an augmentation kit that will give users of the sustainment pavement repair (SuPR) kit the capability for in-place asphalt recycling. This type of repair has the potential for reducing not only logistics associated with airfield pavement repair, but also the airfield downtime during the repairs. The specific technologies evaluated were infrared heaters, rejuvenator products, and cement stabilization. Different variations of these technologies were combined and evaluated in the laboratory to study the best combination that would produce quality sustainment repairs in asphalt concrete pavement yielding good performance with limited construction periods. The researchers also performed a series of pavement repairs to evaluate the equipment, materials and procedures required for in-place asphalt recycling in terms of the efficiency of the components to reduce repair logistics, equipment footprint, and airfield downtime during repairs. The performance of the repairs was evaluated under simulated F-15 aircraft traffic. Data collected from this study were used to develop guidance for the use of in-place asphalt recycling for sustainment repairs on military airfield pavements.

\section{SUBJECT TERMS}

In-place asphalt recycling
Infrared heaters

Rejuvenators

\section{SECURITY CLASSIFICATION OF:}

a. REPORT

UNCLASSIFIED

b. ABSTRACT
UNCLASSIFIED

c. THIS PAGE

UNCLASSIFIED
17. LIMITATION OF ABSTRACT

\section{NUMBER} OF PAGES

135 19a. NAME OF RESPONSIBLE PERSON

19b. TELEPHONE NUMBER (include area code) 